Center for Open Access in Science

\title{
$6^{\text {th }}$ International e-Conference on Studies in Humanities and Social Sciences
}

24 December 2020

\section{Conference Proceedings}

ISBN 978-86-81294-06-2

https://doi.org/10.32591/coas.e-conf.o6 
$6^{\text {th }}$ International e-Conference on Studies in Humanities and Social Sciences (6IeCSHSS)

24 December 2020 • Conference Proceedings • ISBN 978-86-81294-06-2

https://www.centerprode.com/conferences/6IeCSHSS.html

e-conference@centerprode.com

\section{Organizer and Publisher:}

Center for Open Access in Science (COAS), Belgrade - SERBIA

https://www.centerprode.com

office@centerprode.com

\section{Partner Institutions:}

South-West University "Neofit Rilski", Faculty of Philosophy, Blagoevgrad, BULGARIA

University of Ruse "Angel Kanchev", Faculty of Business and Management, Ruse, BULGARIA

Albanian University, Tirana, ALBANIA

\section{Editors:}

Tatyana Vasileva Petkova (PhD)

South-West University "Neofit Rilski”, Faculty of Philosophy, Blagoevgrad, BULGARIA

Vladimir Stefanov Chukov (PhD)

University of Ruse "Angel Kanchev", Faculty of Business and Management, Ruse, BULGARIA

\section{Scientific Committee:}

Christiane Wagner (PhD), UNICAMP, Sao Paulo, BRAZIL

Fernando Barragán Medero (PhD), University of La Laguna, SPAIN

Christiana Constantopoulou (PhD), Panteion University of Social and Political Sciences, Athens, GREECE

Tatyana Vasileva Petkova (PhD), South-West University "Neofit Rilski", Blagoevgrad, BULGARIA

Vladimir Stefanov Chukov (PhD), University of Ruse "Angel Kanchev", Ruse, BULGARIA

Stylianos Koukoumialos (PhD), Technological Educational Institute of Thessaly, Larissa, GREECE

Jolanta Maćkowicz (PhD), Pedagogical University of Cracow, POLAND

Mirela-Luminita Murgescu (PhD), University of Bucharest, ROMANIA

Konstadin Rabadjiev (PhD), Sofia University "St. Kliment Ohridski”, BULGARIA

Teuta Danuza (PhD), University of Pristina, KOSOVO

Valbona Habili Sauku (PhD), University of Tirana, ALBANIA

Silva Ibrahimi (PhD), Albanian University, Tirana, ALBANIA

Silvia Nikolaeva Gaftandzhieva (PhD), University of Plovdiv "Paisii Hilendarski", BULGARIA

Meri Zornija (PhD), University of Zadar, CROATIA

Iva Slivar (PhD), Juraj Dobrila University, Pula, CROATIA

Tamara Floričić (PhD), Juraj Dobrila University, Pula, CROATIA

Boryana Nikolaeva Miteva (PhD), Sofia University “St. Kliment Ohridski”, BULGARIA 


\section{CONTENTS}

\section{Preface}

1 L2 teaching to PR undergraduates through theatre techniques elements Elizaveta Vishnyakova, Olga Vishnyakova, Alla Minyar-Beloroucheva \& Polina Sergienko

15 Adaptation studies in Europe

Colleen Kennedy-Karpat

29 Family life satisfaction - Perception of the youth and their parents

Jasminka Zloković, Zlatka Gregorović Belaić \& Nadja Čekolj

41 Situational map: A strategy to develop critical thinking in the teaching of scientific research

Cecilia Alejandra Marambio Carrasco \& Carla Lobos Stevens

55 Application of problematic situational tasks method at Russian as a foreign language classes in technical high school

Elena Shtekhman, Yulia Melnik \& Anastasia Zhurova

73 Hava Nagila

Tatyana Vasileva Petkova \& Daniel Galily

85 Kurdish migration waves to Rojava (Northern Syria)

Vladimir Stefanov Chukov

95 The problem of intersubjectivity in Western philosophy: Boundaries of the communicative approach

Oksana Somova \& Pavel Vladimirov 
103 Polish music press in the face of systemic change in 1989 as an example of cultural transformation in post-communist countries

Konrad Tyszka \& Michat Jagosz

121 Word formative structure of words with the root lěp- in Old Russian written records

\section{Tatiana Galochkina}

129 Cognitive approach to the theory of abbreviation

Tatyana Bychkova

139 Russian and English metaphorics: Comparative analysis of biathlon discourse

Liudmila Osinovskaia \& Yuliya Shekhovskaya

153 The studying of Russian phraseological units and paroemias in English speaking audience

Anna Baskakova

163 Word-image interaction in the treatise "Voyage en Siberie"

Elizaveta Panova

173 Particularities of defense in judicial rhetoric

Ekaterina Korobova

183 Feminization of emigration

Petya Pachkova

201 Behavioral disorders in children

Nikolaos Georgoulas

207 Kandinsky-Clérambault syndrome: Narration and psychosis

Petar Dimkov

219 Psychotherapy of psychosomatic anxiety responses

Lubomira Dimitrova 
$6^{\text {th }}$ International e-Conference on Studies in Humanities and Social Sciences (6IeCSHSS) 24 December $2020 \bullet$ Conference Proceedings • ISBN 978-86-81294-06-2

223 Experimenting with factors enhancing reading comprehension of media texts in university students majoring in IR studies

Elena Korotkova

225 Nietzsche and the search of new values

Valeri Valchev

231 E-Conference Discussion

245 Upcoming e-Conference 
$6^{\text {th }}$ International e-Conference on Studies in Humanities and Social Sciences (6IeCSHSS) 24 December $2020 \bullet$ Conference Proceedings • ISBN 978-86-81294-06-2 


\section{Preface}

The aim of the $\boldsymbol{6}^{\text {th }}$ International e-Conference on Studies in Humanities and Social Sciences (6IeCSHSS) was to bring together scholars, administrators and students from different countries, and to discuss theoretical and practical issues in different areas of Humanities and Social Sciences. The e-Conference was organized as a kind of a multi-disciplinary forum which provided the appropriate opportunities for inter-disciplinary communications.

The areas of study covered by the e-Conference were the following: Philosophy, Anthropology, Psychology, Science of Education, History, Linguistics, Arts, Sociology, Political Science, Law, and Economics.

The e-Conference was organized in cooperation with the COAS Partner Institutions: South-West University "Neofit Rilski”, Faculty of Philosophy, Blagoevgrad, BULGARIA, University of Ruse "Angel Kanchev", Faculty of Business and Management, Ruse, BULGARIA, and Albanian University, Tirana, ALBANIA.

The e-Conference was organized exclusively as an online conference, and the English was the only language of the conference.

Two phases of the e-Conference realization was applied.

The first phase was realized as the e-Pre-Conference Discussion (from 20 to 23 December 2020), and this phase was followed by the posting at the COAS website different textual forms sent by the e-Conference participants, such as discussions, analyses, critics, comments, suggestions, proposals, etc., regarding exposed abstracts.

The second phase was the e-Conference Discussion, and it was realized at the e-Conference day (24 December 2020), from oo to 24 (GMT+01:00). This discussion was realized in the same way as the e-Pre-Conference discussion, regarding the full texts exposed at the COAS website.

All submitted abstracts/full texts went through two reviewing processes: (1) double-blind (at least two reviewers), and (2) non-blind (two members of the Scientific Committee). Thus, final decision for the presenting and publishing depended of these two kinds of reviews, in order to be accepted for presentation at the conference and to be published in the e-Conference Proceedings.

The Conference Proceedings will be submitted for indexing in different international databases.

Finally, we would like to thanks to all participants of the e-Conference, as well as to all reviewers and editors, for their efforts, which enable that the e-Conference was productive experience.

We are looking forward to the $7^{\text {th }}$ International e-Conference on Studies in Humanities and Social Sciences (7IeCSHSS) that will be held on 28 June 2021, using the same online model. We hope that it will be an interesting and enjoying at least as the previous e-Conference. 
$6^{\text {th }}$ International e-Conference on Studies in Humanities and Social Sciences (6IeCSHSS) 24 December $2020 \bullet$ Conference Proceedings • ISBN 978-86-81294-06-2 


\title{
L2 Teaching to PR Undergraduates through Theatre Techniques Elements
}

\author{
Elizaveta Vishnyakova \\ Tula State Lev Tolstoy Pedagogical University, RUSSIAN FEDERATION \\ Faculty of Foreign Languages
}

Olga Vishnyakova

Lomonosov Moscow State University, Philological Faculty, RUSSIAN FEDERATION

\author{
Alla Minyar-Beloroucheva \\ Lomonosov Moscow State University, Faculty of History, RUSSIAN FEDERATION \\ Polina Sergienko \\ Lomonosov Moscow State University, RUSSIAN FEDERATION \\ Faculty of Foreign Languages and Area Studies
}

Received: 1 September 2020 - Accepted: 26 November 2020 • Published Online: 25 December 2020

\section{Abstract}

\begin{abstract}
Modern methods of L2 teaching aimed at improving its efficiency to overcome language barriers require the construction of the learning climate for undergraduates to develop professional skills and competencies essential for their academic communication with ease and pleasure. The purpose of this article is to demonstrate one of the ways of achieving educational goals by creating positive emotions that PR undergraduates experience during L2 classwork through the introduction of the elements of theatrical techniques, which can help educators perform the tasks required to instill creativity. Effective L2 acquisition by PR undergraduates is allegedly best achieved through neutral emotions. Expressive and emotional actions in class create a theatre-like atmosphere that disseminates positive emotions fostering education. The research has demonstrated the necessity to introduce theatre techniques elements into L2 teaching to PR undergraduates.
\end{abstract}

Keywords: theatre techniques elements, L2 teaching, PR undergraduates.

\section{Introduction}

Theatre pedagogy is gaining momentum at present (O’Neill, 2015). We have all the evidence to state that theatre and teaching have a lot in common: both of them are interactive means. Both theatre and teaching are aimed at educating people to transform their mentality and make them experience deep empathy and compassion. Both actors and students perform their roles, the former do it on stage, while the latter do it in class. In addition, everyone is focused on the director of the performance and the teacher in class. It is soundly argued that theatre

(C) Authors. Terms and conditions of Creative Commons Attribution 4.0 International (CC BY 4.0) apply.

Correspondence: Polina Sergienko (PhD), Lomonosov Moscow State University, Faculty of Foreign Languages and Area Studies, Moscow, RUSSIAN FEDERATION. E-mail: sergienkopauline@gmail.com. 
techniques used in L2 classes encourage effective language learning despite different final results (O’Toole, 1992), which is a performance for a theatre director, and a lesson for a teacher.

The idea of bringing theatre to a classroom is not novel (Vygotsky, 1978; Bolton, 1986; McGuinn, 2014). Plays or their fragments have always been staged in class to motivate students to learn foreign languages (Bolton, 1999). The total response aimed at L2 teaching through action leaves no chances to be passive. This method that makes the foreign language learning process an active one is based on games (Swale, 2009) and exercises (Wagner, 1999) dealing with facial expressions and gestures. Both theater performance and class activities are ephemeral and stop to exist with the last sound of a cue and the first sound of a bell unless they are recorded.

- L2 teaching in PR classes resembles theatre performances in terms of participants.

- Educator artistry is manifested in the role of the theatre director.

- Creativity, intuition, spontaneous reaction are necessary for successful L2 teaching.

- Negative emotions hinder L2 acquisition, positive ones foster it.

The study has revealed two approaches to application of theatre techniques during L2 teaching. The first is when a theatrical performance is a kind of revision of a module or a unit studied in the course of the curriculum. The second approach is to include theatrical elements into every class. In this case undergraduates are fostered to take an active action every time when the class is conducted.

Activities, imitating reality, optimize L2 teaching. Action-event-situation participants of communication (the undergraduates) are linked by a common learning situation scene. Action and reaction, activity and counteraction, create a unity of dramatic action. Game and theatre are interconnected and characterized by effective expression: actions form a chain that defines a person's life (Stanislavsky, 1988).

Theatrical techniques used in L2 teaching affect the undergraduates with words and actions, which they use themselves. Being participants and spectators at the same time, they can feel they can regulate and change the situation scenes during L2 classwork. Unlike theatre performance, during L2 classwork the undergraduates are not passive spectators, but are able to influence the actions in the performance they participate in.

Special literature that discusses a variety of methodological trends and approaches dealing with L2 teaching indicates that they should be effective and enjoyable at the same time (Vygotsky, 1978). Western educational theory and practice have paid special attention to the emotional appeal of learning. "Learner based or Learner centered teaching" was the name of the approach with the focus on the undergraduates' needs, interests and concerns. This approach combined emotional L2 learning and a high level of cognition. To achieve this the educators and theorists tried to correlate the educational topic, educational material with the life experience of undergraduates.

\section{Literature review}

At present during L2 teaching much attention is paid to the undergraduates' development of creative competences. By creative competences we mean the ability of the undergraduates to improvise during the classes, be them online or face-to-face on the basis of the tasks proposed by the educator. The classes resemble theatrical performances, as there is also a director and actors. We cannot leave aside the spectators, because actors during L2 teaching classes perform two roles simultaneously as the actors and the spectators. The role of the educator is akin to the one of the director in a theatre - to draw the attention of the participants to a certain issue, help them concentrate and get involved in the educational process, as foreseen by the 
traditional educational theory (Sweet, 1899), including translation (Sergienko, 2019), learning LSP vocabulary (Vishnyakova, 2019; Minyar-Beloroucheva, 2019) and new approaches (Vishnyakova et al., 2020; Zhang et al., 2020).

A special interest has been paid to teaching methods through theatre techniques elements since the advent of the new type of theatre, directed by K. S. Stanislavsky, who invented a true-to-life performing experience (Stanislavsky, 1988), when the actors were supposed to show true-to-life feelings and emotions during the performance. In the vision of the authors of the current research the foundations of Stanislavsky's approach can be applied to L2 teaching to university undergraduates.

Any gifted person is inclined to play a certain role during any social interaction, including L2 classes. It should be noted that educational games during L2 classes can be treated with humor, both on the side of the educator and the undergraduates. Humor brings about artistic license, which is known for its open- mindedness, easy-goingness and numerous associations. As early as the late $19^{\text {th }}$ century Francis Galton introduced the notion of hereditary genius (Galton, 1892) speaking about the natural power of intellect. The scholar draws a distinction between the natural ability, which he defined as "qualities of intellect and disposition, which urge and qualify a man to perform acts that lead to reputation" (Galton, 1892: 67), zeal and capacity, which he commented in the following way: "I do not mean capacity without zeal, nor zeal without capacity, nor even a combination of both of them, without an adequate power of doing a great deal of very laborious work." To produce different performances in class it is necessary to develop creativity (Minyar-Beloroucheva, 2015; Minyar-Beloroucheva, 2016b) of the educators basing on natural ability and zeal.

The present article claims that these competences can be developed by means of training and hard work. Any educator is gifted by nature and he/she is able to insert a spark of one's talent and creativity in his/her undergraduates. Educational process as "an expression of the internal independent actions of the person" (Kapterev, 1914) develops the creative abilities of undergraduates. However, some researchers indicate that in the field of education, issues dealing with the development and shaping undergraduates' personality generally are studied without consideration of the educational system that can develop their creative ability to a full extent (Friedman, 1997). To follow E. Stone who asserts that actual teaching practice is the most consistent and essential way to test different theories (Stone, 1984) we can state that theatricality should be inserted in L2 teaching practice as its one of the fundamental principles. Theatricality of educator should be a particular trait of character of every professional who helps reveal the talents of his students, achieve better academic results and professional development. It is manifested in a number of educational means, the tempo and a variety of pedagogical activities as well as the positive climate in the class.

\section{Hypothesis}

We assume the hypothesis that it is possible for all kinds of undergraduates, including Philology, PR, History and Political Science students, to facilitate the process of L2 acquisition by means of introduction of the elements of theatre techniques into the education process. If the undergraduates experience positive emotions, they respond to the techniques better and acquire L2 learning material faster. Negative emotions hinder the process of L2 acquisitions, as they do not accept the theatrical technologies used in L2 class. The undergraduates' type of personality plays the crucial role in the readiness to accept the novelty. 
4. Study methods and procedures

4.1 Methods and methodology

We have chosen some elements of theatrical techniques based on Stanislavsky's "Method of Physical Action" that inspire undergraduates of all years, especially of the $1^{\text {st }}$ year to learn L2 more eagerly and effectively. The study has revealed that the undergraduates of the above-mentioned Departments at Lomonosov Moscow State University are more responsive to participate in situation scenes based on their professionally oriented learning material.

The given research involved the following methods: analysis, generalization and systematization of the research data, working out the content and procedure of the diagnostic methodology for studying the activity, observation, description, comparison, analogy and interpretation.

\subsection{Procedures}

To carry out the procedures of trying out the suggested theatre techniques the authors introduced situation scenes to act out in L2 classrooms among the undergraduates of Lomonosov Moscow State University of 1-2 years of study. Each L2 situation scene was directed by the educator and staged by the undergraduates, leaving no space for passive spectators. For the educational purposes, L2 situational scenes lasted from 5 to 10 minutes. Seldom they took up to 30 minutes when a more complicated situation was staged.

\section{Results}

The result has shown that undergraduates of Philology, PR, History and Political Science Departments were responsive to the elements of theatre techniques introduced to L2 classroom. Situation scenes staged with the purpose to facilitate L2 acquisition neutralized negative emotions that undergraduates brought to the class from the outside. Extraverts and introverts both equally contribute to L2 educational mise en scène. By changing words and gestures, the undergraduates change the micro scene, micro situations and the course of actions. Undergraduates use their creativity to propose the originality and novelty for their mise-en-scène.

\section{Discussion}

\subsection{Modern methods of education}

Modern methods of L2 teaching are designed to meet several ends:

(1) To create a favorable climate in the class for the undergraduates to feel happy and be motivated to L2 learning. Motivation is the driving force of L2 learning, which is successful when emotions, feelings, and needs of undergraduates are taken into account. The educator should stimulate the undergraduates' cognitive and creative abilities by making them play in class, stimulating them actively interact with other participants in this process;

(2) To create situations in which the educator is not the central figure; the undergraduates should realize that L2 learning is dependent on his personality and interests, rather than on the educator's educational techniques and teaching tools;

(3) To teach the undergraduates to work independently with regard to their physical, intellectual and emotional capabilities, to provide for various forms of work (individual, pair, group) by stimulating the undergraduates' creativity, thus securing the sustainable L2 acquisition; 
(4) The novel approach to L2 language acquisition also deals with effective use of distance learning and online application of technologies, as well as the involvement of computermediated interactivity and gamification into the educational process.

\subsection{The importance of emotions in L2 teaching}

There are a lot of emotions that the undergraduates can experience during L2 classes. As a result of the research it has been discerned that such emotions as enjoyment, anger, hope, pride and boredom affect the process of learning in numerous ways (Pekrun et al., 2002). Emotions are defined as multifaceted phenomena involving sets of coordinated psychological processes including affective, cognitive, physiological motivational and expressive components (Kleinginna \& Kleinginna, 1981). It should be said that the terms "emotions" and "mood" are regarded by some researchers as interchangeable, as both of them show similar profile components and similar qualitative differences (Pekrun, 2006). Attempts to classify emotions and moods have been made for ages. However, none of the classifications has been universally accepted. One of the most accepted classification is the one that follows. Researchers distinguish four types of emotions. They are: achievement emotions, topic emotions, epistemic emotions and social emotions (Pekrun \& Linnenbrink-Garcia, 2014: 3).

Some other classifications suggest a different vision and terminology used to define the effect of emotions on the knowledge acquisition. For the purpose of schematic representation of the influence of different emotions on the process of L2 learning a circular scheme was worked see Picture 1.

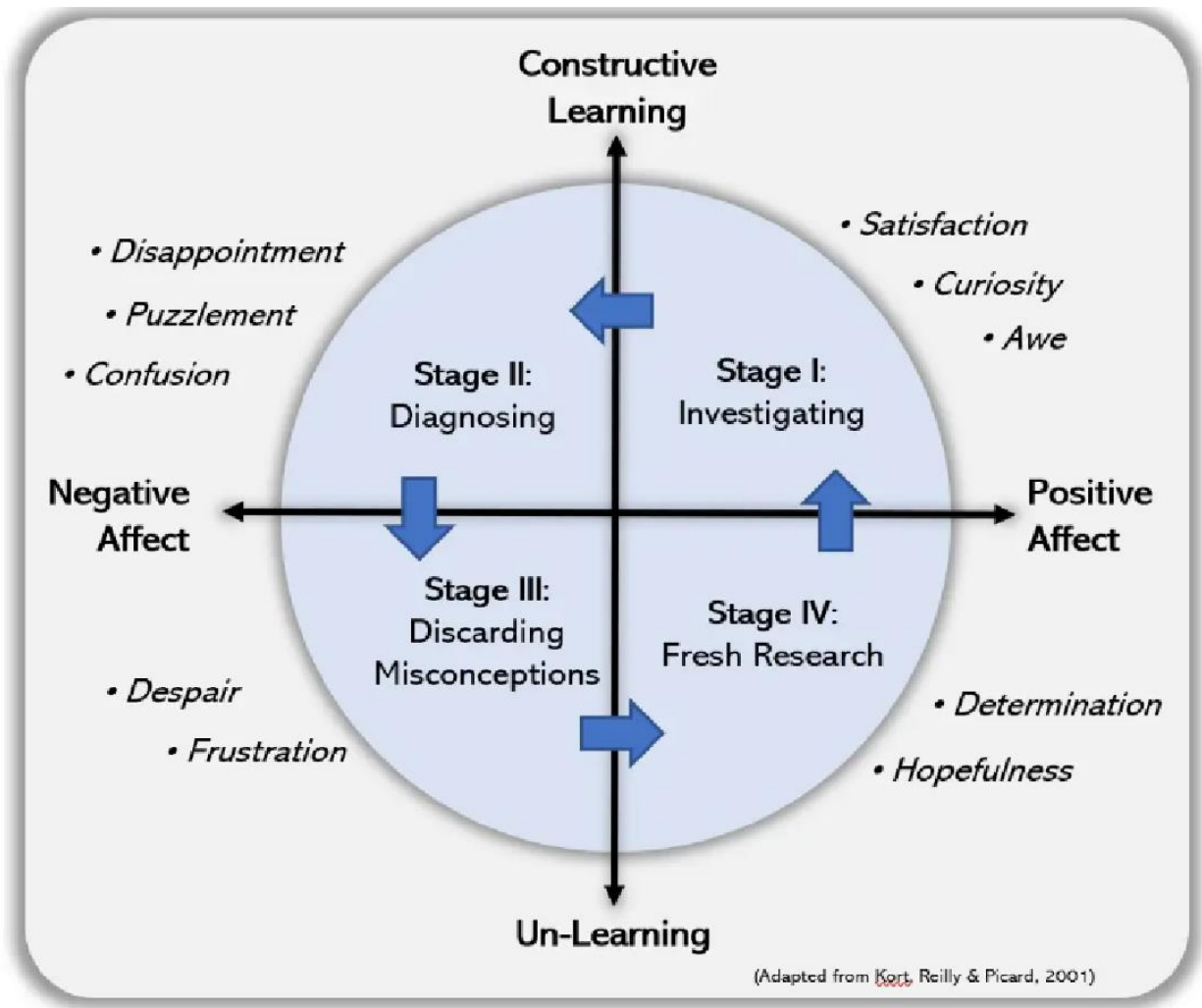

Picture 1. An effective model of interplay between emotions and learning (Adapted from Kort, Reilly \& Picard, 2001)

As seen from Picture 1, worked out by Ch. Drew (Drew, URL), emotions and learning correlate in a certain way with each other, stimulating or hindering the process of L2 acquisition. 
Such positive emotions, as enjoyment, pride, satisfaction, curiosity and awe cause determination and hopefulness that bring about Constructive Learning. Negative emotions including anger, anxiety, frustration, puzzlement, confusion, and disappointment cause despair and frustration that are not favorable for learning and lead to Un-Learning.

The most important form of expression of emotions of humans is speech. Emotions can be expressed in words through short exclamations and more detailed statements (expressions of gratitude, resentment, delight, etc.). Emotions can also be expressed in writing, for example, in the form of diary entries, poems, letters. The expression of emotions in words can take two different forms, including utterances in response to emotions experienced by the undergraduates and the words that evoke emotions on the part of others. In both cases undergraduates tend to express their emotions in speech. Under the influence of emotions, all types of cognitive processes - perception, imagination, memory, thinking-undergo certain modifications.

Undergraduates' emotions such as hope, pride, and anxiety are related to academic accomplishments. Achievement emotions, as considered by researchers, determine the academic activities (Pekrun \& Linnenbrink-Garcia, 2014: 3) are connected with the process of L2 learning. During L2 classwork the undergraduates can experience achievement emotions such as enjoyment or boredom. According to researchers, the enumerated emotions can be caused by different classroom factors, including curriculum content, environment, the undergraduates' individual differences comprising genetic factors, general tendencies, and external factors such as social interactions, home environment (Pekrun \& Linnenbrink-Garcia, 2014). Educators are not expected to cope with a variety of emotions caused by different factors. The only way for them is their naturalization by distracting the undergraduates' attention from their feelings by involving them in mini L2 education scenes or performances.

When we discuss the feeling of anxiety during L2 class, we are to mention both the result of positive emotions, when the undergraduate is eager to answer and the result of negative emotions caused by worries about a possible failure to answer correctly. Positive emotions are important for fostering L2 acquisition. Nonetheless, they are often interconnected with negative emotions, brought by the undergraduates from external emotions. However, emotions that accompany the educational process are seldom taken into account by the educators. For years the model of L2 learning was grounded on the postulation that L2 learners' neutral emotions can be the best psychological state of L2 acquisition. The creation of the favorable climate that causes positive emotions facilitates the work of the educator and motivates the undergraduates' interest in L2 educational activities. It is recommended to neutralize negative emotions which decline the undergraduates' cognitive capacity (Trezise \& Reeve, 2014).

It has been established yet that some undergraduates manage to participate in L2 activities despite their negative emotions. In this case the undergraduates' individual characteristics, if the person is an extravert, will dominate over and neutralize negative emotions. Nevertheless, the educators should do their best to neutralize negative emotions, although some researchers consider that "interventions targeting problematic emotions alone are unlikely to be effective long-term, and students may continue to experience educational difficulties" (Trezise, 2017).

Both emotion and mood play an important role in the L2 learning and teaching process. During L2 classes, the undergraduates and educators frequently experience emotions caused by the events that are not related to academic activities, but political or social events occurred outside university. Both undergraduate and educators' feelings can be influenced by worries about their friends and relatives, and this mood often shapes the way of academic engagement in general. All the worries should be left outside L2 classwork as the main task of the educator is creating the emotions and mood favorable for L2 acquisition by the undergraduates. Educational emotions can be caused by the quality of the assignment given to them by the 
educator. Thus, the inability of the undergraduates to properly pronounce words or give a grammatically and topically proper answer are epistemic emotions as they are connected with their cognitive incongruity. During L2 classwork emotions can be prompted by the content covered by learning material (Pekrun \& Linnenbrink-Garcia, 2014: 4). To create positive emotions, the content of the learning material should arouse surprise and curiosity.

Within the frame of competence-based approach the development of communicative competences is most challenging for L2 educators. To successfully resolve the issue, it is necessary to master new teaching methods aimed at developing all four types of language proficiency, and provide undergraduates with new educational materials fostering positive emotions that can develop communication skills.

Concentration on the emotional sphere of undergraduates and organization of communicative activities demand special efforts. Elements of theatrical techniques used in class can be effective instruments to improve the emotions in class. Elements of theatrical techniques can improve both learning and negative emotional states of L2 undergraduates. The educator's task is to minimize the outside university factors not by neglecting the undergraduates' emotions by supporting their L2 learning by introducing Stanislavsky's devices. L2 Situational scenes can be based either on the obligatory leaning material or on its variations.

\subsection{Theatrical technologies introduced to L2 classes in theory and practice}

\subsubsection{Theoretical reflection on theatrical techniques used in L2 learning}

It is necessary to point out that L2 educators to avoid monotonous teaching occasionally introduce theatrical technologies into their pedagogical process. The division of the undergraduates into different groups and roles as well as actors is an essential part. According to K. S. Stanislavsky, a true artist doesn't like to adhere to one and the same role in the theatre. The same can be applied to the university classroom, where the undergraduates and the educator are the main participants. There is a failure opinion that pedagogical activity is a boring routine, with the educators lacking imagination and creativity. In reality every L2 teaching class is a miniperformance in which a true L2 educator is a director, and a playwright. One of the ideas conveyed by K. S. Stanislavsky deals with physical activity of the actors on the stage which is true for L2 teaching classes. Physical activity facilitates the memorizing of new words, including neologisms and abbreviations (Minyar-Beloroucheva et al., 2020), constructions, speaking and communication in general, for both actors and L2 undergraduates.

That is why successful L2 educators include some elements of theatrical techniques in their educational process. This leads to the possibility to call the process "directing of a class", because some educators regard it as innovative approaches to L2 teaching, moving them away from the traditional teaching methods.

We are aware that it isn't possible to transfer the theatrical techniques into the L2 teaching class the way they are accepted and recognized in theatrical colleges. Unlike theatre directors who try to demonstrate the struggle of ideas, L2 educators try to impose on the undergraduates the images through which they can express their opinion, critical thinking (Minyar-Beloroucheva, 2016a) in the best possible way. According to K. S. Stanislavsky (Stanislavsky, 1988), an educator is a mirror, but not a play actor in front of the mirror. Therefore, L2 university classes are not theatre colleges, and that is why theatrical techniques can only partially be introduced. 


\subsubsection{Mask as a teaching and theatre element}

It is generally known that a mask is an indispensable element of theatrical performance. It is common knowledge that in the historical past the actors of Antiquity performed their roles by changing their masks. In the Middle Ages and early Modern Times, it was still popular in the theatre and even at the time of Shakespeare for male actors to play female roles by disguising themselves behind the masks.

Historically the first masks were used exclusively for hunting purposes to disguise a person who was watching the habits of different animals to imitate them. The disguise hunting mask was a prerequisite for the hunting dance, which was the first stage on the way to theatre emergence. Man was transformed into an animal not in the process of hunting, but before it. It was the first fixed performance scenario that was played out and implemented by certain actorsanimals and hunters. They danced to the tune of music and singing. The performance was watched by spectators including women and children. This is one of the earliest forms of theatrical art, but it is also a pedagogical art in a certain sense, since the young members of the tribe were educated in the art of hunting wild animals, imitating their habits and developing flexibility and strength in their own bodies.

Of great interest were initiation rites, which were conducted for educational purposes. They were aimed at developing the outlook of the young generation and instilling morality. The power of the visual methods of teaching in upbringing by means of such performances has been evaluated since early times. Theatrical performances were staged before the initiation rites. The actor was disguised and stood on a special platform or appeared from behind the scenes, holding the necessary accessories in the form of weapons or instruments.

\subsubsection{A class after theatrical performance}

The present-day educator should be ready to work in the context of constantly changing curricula, numerous alternative textbooks, and on-line international contacts. Within the competence-based approach theorists speak about the development of specific professional competences of educators to be able to organize communication and educational process in the classroom, to arise positive emotions among undergraduates for them to be able to express themselves by means of verbal and non-verbal activity in L2 teaching/learning classes.

An L2 lesson integrates a number of activities. Since communication is a dialogue, the L2 class work can be presented as a kind of drama. Since drama is emotionally and aesthetically charged, L2 educators should be cautious to introduce its elements in the L2 class. To be successful in this activity L2 educator should be careful to select the plot for the undergraduates to role-play as a necessary instrument either to introduce new lexical and grammatical material or to revise it. Moreover, the plot should be all-of-a-piece to present the unity of activity by means of logic, harmony, concentration and humor.

This, first of all, means that a class is the practice of communication, a complex process of developing skills and abilities including speaking, listening, reading and writing. The teacher acts as a director of communication in these conditions, creating a special linguistic and favorable psychological climate. Taking into account Stanislavsky's approach to the theory and practice of theatrical art used in pedagogical practice, physical actions are essential for memorizing lexical units and Grammar. The "method of physical actions" introduced by Stanislavsky, can be used in L2 classes to switch the activities from revising to learning.

Emotions affect communication during L2 intra-group interaction. Emotions bring about positive feedback from role-playing situations helping to establish a sustainable channel of L2 acquisition. People involved in emotional relationships tend to rate each other more positively. 
The effect of peer-assessment has been studied in educational science (Ellman, 1975). At the verbal level, this is manifested in a friendly style of communication and positive characteristics of partners in conversations.

Like the director of a theatrical performance, an L2 educator can use the language of action to regulate the behavior of L2 undergraduates. The Language of Action permits the L2 educator to evaluate the process of L2 acquisition by the undergraduates.

Every culture is noted for its language of emotions. L2 undergraduates should get familiar with emotional meanings contained in the facial expressions, gestures, and voice of the classmate that can be useful in their future profession. Excessive or insufficient emotional expressiveness can cause conflicts in interpersonal and intercultural communication.

When an L2 class is a drama, the educator is a playwright and a director who plunges the undergraduates (actors) into the creative atmosphere for them to develop their imagination, artistry and situational fluency. By practicing gestures and facial expressions they learn to manage their emotions and understand their peers. Thus, the l2 educator's activity is aimed at structuring the classes on the basis of dramatization, where emotions play the key role.

From an educational perspective, one more factor could not be ignored. Namely, undergraduates' personality should be taken into consideration when theatrical techniques are introduced in L2 classes. Every undergraduate is noted for her/his individual characteristics. Personality factors play an important role in the L2 teaching/learning process. Researchers identify three main types of personality, they are extraversion vs. introversion; neuroticism vs. emotionality with emotional stability; psychoticism vs. tough mindedness with tendermindedness (Eysenck, 1994). Personality is not less important than motivation and emotions, because not all the undergraduates easily adopt the roles ascribed to them by the educator during L2 classes. Moreover, it has been stated that the undergraduates' personalities correlate with their academic achievements. The tasks of the educator to involve the undergraduates into certain learning situation scenes during L2 classes are accepted differently by L2 learners. It has been established that extraverts are easy-going, open to experience and readily respond to the educational roles offered to them by the educators. Extraverts tend to perform well to acquire L2 material, especially under conditions of high motivation, while introverts can impair the performance staged by the educator in L2 class (Matthews et al., 2000) as they adhere to the traditional process of L2 learning. To engage the introvert undergraduates in the L2 educational process, the educators can ask them to carry out peer assessment of L2 situational scenes or to invent some situations to foster L2 learning.

\subsubsection{Practical ideas of applying theatrical methods}

Stanislavsky's system per se cannot be applied to L2 teaching, especially the techniques called the "art of experiencing" contrasting with the "art of representation". According to Stanislavsky, the "art of experiencing" activates the actor's conscious thought and will in order to mobilize other psychological processes that are less-controllable including emotional experience and subconscious behavior - compassionately and indirectly. The task of the actor is connected with the search of internal motives to justify the character's action at any given moment (a "task") (Stanislavsky, 1988). Nobody can expect from undergraduates to play "credibly", by which he implied thinking, wanting, striving, behaving truthfully, in logical sequence in a human way, within the character, and in complete parallel to it (Stanislavsky, 1988). There is no need for undergraduates to feel "as one with" the role, i.e. identify oneself with the given part, as their roles are based on the content of L2 learning material.

However, Stanislavsky's system that he later worked out was more physically grounded. It is known as the "Method of Physical Action" that encourages an "active 
representative", aimed at improvising the sequence of dramatic situations, when actions are taken in the given circumstances. It should be underlined that the "Method of Physical Action" is applicable for L2 teaching as the gestures help to memorize and review lexical and grammar material. In Stanislavsky's vision, a true L2 educator is the one who can take every undergraduate as an individual. In theatre techniques it is to learn to pronounce a simple phrase with twenty-six different intonations and emotion. For example, the phrase "come here" may have different shades of meaning. Moreover, mimics and gestures should also be given special attention (Wu, 2019; Negretti \& McGrath, 2020). Thus, the main principle of theatre is not to be oneself but create a mask to become different in every situation.

The best way to start applying Stanislavsky's "Method of Physical Action" (Stanislavsky, 1988) to the L2 educational process is to discuss topical one page stories dealing with everyday subjects. The participants of two teams should put forward opposing opinions to discuss debatable issues, as:

- Advantages and Disadvantages of Advertising;

- Is the Internet doing an irreparable harm?

- Should dangerous sports be forbidden by law?

- Is childhood the happiest time in a human's life?

- Are examinations damaging for the undergraduate's emotions and psychology? Etc.

After learning the vocabulary and reading the texts connected to certain topics, the undergraduates are divided into two teams, one of which supports the issue, the other objects to it. A moderator is appointed to say which team is more persuasive. The educator sets a topic and stimulates the discussion. The undergraduates can put forward arguments that depend upon their knowledge of the topic, command of English, interests, emotions and mood. During L2 discussions mise en scène should correspond to the classroom environment. The members of the teams can sit facing one another, where some undergraduates can dominate others by putting forward their "for" and "against" arguments. In the main, extroverts can put forward numerous ideas to the table and talk out loud as they brainstorm (Tracey, 2018). Introverts are not numerous. One of them can be a moderator or assist the educator in writing the scenario. Other introverts, if there are such, should not be ignored as their ideas are inquisitive, reflective and they can help find spot solutions. Together, extroverts and introverts can make powerful teams (Tracey, 2018). But the general arguments are supported by hybrid personalities combining the traits of extroverts and introverts, who are named ambiverts. Ambiverts engage in flexible patterns of talking and listening and are able to express assertiveness while also being reflective (Tracey, 2018). During L2 discussion the undergraduates gesticulate, use facial mimics, they can even walk in the classroom. This "Method of Physical Action" fosters L2 learning.

\section{Conclusion}

Drawing up a conclusion, it should be stated that theatre techniques elements are universal and can be applied to L2 classes of undergraduates at PR, Philology, History and Political Science Departments, as the practice proves the hypothesis of the techniques to be effective and enjoyable at the same time. This approach combines the emotional L2 learning and a high level of cognition by bringing closer the professionally oriented L2 material and life experience of the undergraduates.

Theatricality in professional-pedagogical activity is a type of communication, expressiveness of activities that fosters L2 acquisition in the positive emotional milieu that is modeled by Stanislavsky's methods applied to L2 teaching. A feature of theater pedagogy is the educational and training interaction. Creativity is the mode of life of contemporary 
undergraduates and their educators who try to meet their needs. It should be said that creativity can be developed by solving didactic, methodological, and psychological tasks. Creativity as a process of solving problems implies the creation of an original educational accomplishment as a manifestation of the undergraduates' creativity achieved in the course of artistic activities of L2 undergraduates and the educators' ingenuity.

The culture of expression of emotions by the educator affects the result of the L2 educational process. Effective L2 acquisition by PR undergraduates is based on the interest, curiosity and motivation of the undergraduate, which implies the development of the most complex emotions and their expression in the situation scenes with the involvement of theatre techniques.

L2 Educational process includes a number of tasks that are solved by way of improvisation. So far we have applied the elements of theatre techniques to review some modules of the learning material, although the effect has proved it crucial to introduce of the elements of theatre-like technologies into L2 curricula. In the course of L2 teaching it is recommended to activate undergraduates' internal capabilities with the help of dramatic techniques that develop spontaneity, creativity, readiness to engage in pedagogical configurations, relieve tension, and form role behavior. Mastering the technique of role behavior can create positive emotions in L2 class and secure effective results, when used on a regular basis. Positive emotions alongside the theatre techniques elements as determinants of L2 educational process remain to be seen.

\section{Acknowledgements}

This research did not receive any specific grant from funding agencies in the public commercial, or not-for-profit sectors.

The authors declare no competing interests.

\section{References}

Bolton, G. (1986). Selected writings on drama and education. New York: Longman Group Limited.

Bolton, G. (1999). Acting in classroom drama. A critical analysis. Maine: Calendar Islands Publishers.

Drew, Ch. (2020). What is the Importance of Emotions in Education \& Learning? ULR: https://helpfulprofessor.com/emotion-in-education (accessed 08.08.2020).

Eysenck, M. W. (1994). Individual differences: Normal and abnormal. Hove: Lawrence Erlbaum Associates.

Friedman, L. M. (1997). Psychopedagogy in general education. Moscow: Institut prakticheskoi psikhologii.

Galton, F. (1892). Hereditary genius: An inquiry into its laws and consequences. London: Macmillan. Available at: http://galton.org.

Ellman, N. (1975). Peer evaluation and peer grading. The English Journal, 64(3), 79-80.

Kapterev, P. F. (1914). Educational psychology. St. Petersburg: Zemlya.

Kleinginna, P. R., \& Kleinginna, A. M. (1981). A categorized list of emotion definitions, with suggestions for consensual definition. Motivation and Emotion, 5, 345-379. 
E. Vishnyakova et al. - L2 Teaching to PR Undergraduates through Theatre Techniques Elements

Kort, B., Reilly, R., Picard, R. W. (2001). An affective model of interplay between emotions and learning: reengineering educational pedagogy-building a learning companion. In 2001 Proceedings of the IEEE International Conference on Advanced Learning Technologies (pp. 43-46).

Matthews, G., Davies, D. R., Westerman, S. J., \& Stammers, R. B. (2000). Human performance: Cognition, stress and individual differences. Hove: Psychology Press.

McGuinn, N. (2014). The English teacher's drama handbook. New York: Routledge.

Minyar-Beloroucheva, A. P. (2015). Teoriya i praktika kriticheskogo analiza istoricheskogo diskursa [Theory and practice of critical analysis of historical discourse]. In LATEUM 2015 Research and Practice in Multidisciplinary Discourse (69-72). Moscow: Universitetskaya kniga.

Minyar-Beloroucheva, A. (2016). Teaching critical analysis of historical discourse to History students. ICERI2016. In The $9^{\text {th }}$ annual International Conference of Education, Research and Innovation: Transforming education, transforming lives (pp. 4210-4215). 14-16 November 2016, Seville, Spain. https://doi.org/10.21125/iceri.2016.1982

Minyar-Beloroucheva, A. (2016). Constructing creative environment for teaching English to History Students. In The $9^{\text {th }}$ annual International Conference of Education, Research and Innovation: Transforming education, transforming lives (pp. 3684-3689). 14-16 November 2016, Seville, Spain. https://doi.org/10.21125/iceri.2016.1871

Minyar-Beloroucheva, A., Sergienko, P., Vishnyakova, O., \& Vishnyakova, E. (2018). Modern technologies in teaching professionally oriented foreign language to the students of politics. In L. Gómez Chova, A. López Martínez \& I. Candel Torres (Eds.), ICERI2O18 Proceedings. 11th International Conference of Education, Research and Innovation (pp. 7967-7975). 12-14 November 2018 - Seville, Spain: IATED Academy. https://doi.org/10.21125/iceri.2018.0043

Minyar-Beloroucheva A. P. (2019). Vocabulary features of historical discourse. In O. D. Vishnyakova (Ed.), Language, Literature and Culture as Domains of Intercultural Communication. The Fifth and Sixth International Scientific Seminars Proceedings (pp. 24-29). University of West Bohemia in Pilsen, Pilsen, Czech Republic.

Minyar-Beloroucheva, A., Sergienko, P., Vishnyakova, E., \& Vishnyakova, O. (2020). Semantic and cognitive communicative aspects of abbreviation in the modern English discourse varieties. International Journal of English Linguistics, 1O(1), 26-36. https://doi.org/10.5539/ijel.v10n1p26

Negretti, R, McGrath, L. (2020). English for specific playfulness? How doctoral students in Science, Technology, Engineering and Mathematics manipulate genre. English for Specific Purposes, 6o, 26-39, https://doi.org/10.1016/j.esp.2020.04.004

O’Neill, C. (Ed.) (2015): Dorothy Heathcote on education and drama. New York: Routledge.

O'Toole, J. (1992). The process of drama: Negotiating art and meaning. London: Routledge.

Pekrun, R., Goetz, Th., Titz, W., \& Perry, R. P. (2002). Academic emotions in students' self-regulated learning and achievement: A program of qualitative and quantitative research. Educational Psychology, 37(2), 91-105. https://doi.org/10.1207/S15326985EP3702 4

Pekrun, R. (2006). The control-valued theory of achievement emotions: assumptions, corollaries, and implications for educational research and practice. Educational psychological Review, 8, 215341.

Pekrun, R., Linnenbrink-Garcia, L. (2014). International handbook of emotions in education. New York, London: Routledge.

Sergienko P. I. (2019). Osobennosti perevoda leksicheskikh ediniz v tekstakh politicheskogo diskursa [Translation peculiarities of linguistic units within texts of political discourse]. Research Result. Theoretical and Applied Linguistics, 5(3), 71-81. www.doi.org/10.18413/231389122019-5-3-0-7, URL: http://rrlinguistics.ru/journal/annotation/1775/. 
Stanislavsky, K. S. (1988). Sobranije sochinenij [A collection of works]. In 9 Vol. M: Iskusstvo. V.1 Moja zhizn'v iskisstve [My life in art]. Commented by I. S. Solov'eva.

Stone, E. (1984). Psychopedagogy. Psychological theory and the practice of teaching. Moscow: Pedagogyka.

Swale, J. (2009). Drama games for classrooms and workshops. London: Nick Hern Books Limited.

Sweet, H. (1899). The practical study of languages. London: Oxford University Press.

Trezise, K., \& Reeve R. A. (2014). Cognition-emotion interactions: patterns of change and implications for math problem solving. Frontiers in Psychology, 31 July 2014. https://doi.org/10.3389/fpsyg.2014.00840

Trezise, K. (2017). Emotions in classrooms: The need to understand how emotions affect learning and education. URL: https://npjscilearncommunity.nature.com/posts/18507-emotions-inclassrooms-the-need-to-understand-how-emotions-affect-learning-and-education.

Tracey, M. D. (2018). Introverts vs. Extroverts: Who's Really Better at Sales? Realtor Magazine. 12 December. URL: $\quad$ https://magazine.realtor/sales-and-marketing/relationshipmanagement/article/2018/12/introverts-vs-extroverts-who-s-really (accessed 08.08.2020).

Vishnyakova, O., Minyar-Beloroucheva, A., Sergienko, P., \& Vishnyakova, E. (2020). Harmonizing different cognitive styles through reading. In T. V. Petkova \& V. S. Chukov (Eds.), 5th International eConference on Studies in Humanities and Social Sciences: Conference Proceedings (pp. 1730). Belgrade: Center for Open Access in Science. https://doi.org/10.32591/coas.econf.05.02017V

Vishnyakova, O. D. (2019). Discursive and heuristic approaches to LSP. In Language, Literature and Culture as Domains of Intercultural Communication. The Fifth and Sixth International Scientific Seminars Proceedings (pp. 20-24.). Pilsen, Czech Republic: University of West Bohemia in Pilsen.

Vygotsky, L. (1978). Mind in society: The development of higher psychological processes. Cambridge: Harvard University Press.

Wagner, B. J. (1999). Dorothy Heathcote. Drama as a learning medium. Maine: Calendar Publishers LLC.

$\mathrm{Wu}, \mathrm{Zh}$. (2019). Understanding students' mimicry, emulation and imitation of genre exemplars: An exploratory study. English for Specific Purposes, 54, 127-138. https://doi.org/10.1016/j.esp.2019.02.002

Zhang, X., Ardasheva, Y., \& Austin, B. W. (2020). Self-efficacy and English public speaking performance: A mixed method approach. English for Specific Purposes, 59, 1-16, https://doi.org/10.1016/j.esp.2020.02.001 
E. Vishnyakova et al. - L2 Teaching to PR Undergraduates through Theatre Techniques Elements 


\title{
Adaptation Studies in Europe
}

\author{
Colleen Kennedy-Karpat \\ Bilkent University, Faculty of Art, Design and Architecture, Ankara, TURKEY \\ Department of Communication and Design
}

Received: 5 October 2020 - Accepted: 10 December 2020 - Published Online: 25 December 2020

\begin{abstract}
Adaptation is a creative process that crosses and blurs boundaries: from page to stage, from small screen to big screen - and then, sometimes, back again. Beyond questions of form and medium, many adaptations also cross national borders and language barriers, making them important tools for intercultural communication and identity formation. This paper calls for a more intensive, transnational study of adaptation across print, stage, and screens in EU member and affiliate countries. For the highest possible effectiveness, interdisciplinarity is key; as a cultural phenomenon, adaptation benefits from perspectives rooted in a variety of fields and research methods. Its influence over transnational media flows, with patterns in production and reception across European culture industries, offers scholars a better understanding of how narratives are transformed into cultural exports and how these exchanges affect transnational relationships. The following questions are proposed to shape this avenue for research: (1) How do adaptations track narrative and media flows within and across national, linguistic, and regional boundaries? (2) To what extent do adapted narratives reflect transnational relationships, and how might they help construct Europeanness? (3) How do audiences in the EU respond to transnational adaptation, and how are European adaptations circulated and received outside Europe? (4) What impact does adaptation have in the culture industries, and what industrial practices might facilitate adaptation across media platforms and/or national boundaries? The future of adaptation studies and of adaptation as a cultural practice in Europe depends on the development of innovative, comparative, and interdisciplinary approaches to adaptation. The outcomes of future research can hold significant value for European media industries seeking to expand their market reach, as well as for scholars of adaptation, theater, literature, translation, and screen media.
\end{abstract}

Keywords: adaptation, European Union, media industries, cultural studies.

This paper proposes new directions for adaptation studies based on contemporary cultural and media industries in EU member and affiliate states. Considering the corpus-based methodology proposed by Cattrysse (2014) in Descriptive Adaptation Studies, this model advances data-driven methods that would build an informed, empirically significant platform that can serve as a foundation for the kind of qualitative analyses that have defined the bulk of academic adaptation studies. Such research would also help estimate the financial impact of adaptation in media industries, touching on both production and reception contexts across the European Union and affiliate countries. The goal of such transnational, cross-platform research is to explore how narratives transcend linguistic, cultural, and formal boundaries in contemporary European culture, and how these multiple crossings foster both national and European identities.

(c) Authors. Terms and conditions of Creative Commons Attribution 4.0 International (CC BY 4.0) apply. Correspondence: Colleen Kennedy-Karpat (PhD), Bilkent University, Faculty of Art, Design and Architecture, Department of Communication and Design (FADA-COMD), Çankaya, o680o Ankara, TURKEY. E-mail: kenkar@bilkent.edu.tr. 
- The notion of textuality can serve as a defining prerequisite for determining what is and is not an adaptation: both source and adaptation must have clearly documented, possibly shared or collective authorship; each text's creative genesis must develop over a discrete, though possibly prolonged period of time; and this process must culminate in clear date(s) of public release as a complete text.

- For a trans-European study rooted in content analysis, the necessary data for each adaptation and its source text(s) falls under three primary headings: economic-industrial, nationalcultural, and narrative content.

- A key question is the extent to which an adaptation's national or transnational bona fides are invoked in assessing its public impact and general reception.

- Academic adaptation studies would do well to consider adaptation from an industrial angle.

\section{Locating adaptation}

By definition, the creativity of adaptation is defined by crossing boundaries: from one medium to another, from one socio-historic moment to another, from one genre to another, and so on. Beyond questions of form and time, many adaptations also cross national boundaries, targeting different populations, and frequently crossing language barriers as well. Sharing narratives across these boundaries through adaptation can create and/or strengthen a sense of community; conversely, the differences made visible by adaptation can also highlight areas of cultural specificity.

There is no existing, reliable estimate of how many adaptations are produced annually by any given national culture industry. Considering the current number of EU member states (28) plus additional countries connected to the EU by candidacy, treaty or other agreement, the raw number should reach into the thousands just considering releases since the year 2000. Furthermore, the term "culture industry" suggests a broad category, one whose baseline alone encompasses print publication, theater, film, and television.

One, or perhaps the major deterrent to producing a workable number of adaptations is the mutable definition of adaptation; what "counts" can vary considerably. It is certainly a subcategory of intertextuality as Genette (1982) defines the term, but there is no firm line separating adaptation from other kinds of intertexts. This problem of categories and terminology stems in large part from the interdisciplinary nature of adaptation, and the differing agendas imposed by literary studies, theater studies, screen studies, and translation studies. Terms that make sense in one field as proximate, if not equivalent to adaptation (e.g., revival in theater; remake in screen studies) often have limited relevance in other contexts, and methodologies that are well-established in one area may not be applied so readily to others. Studying multiple forms in the context of adaptation studies therefore demands an interdisciplinary approach, one that recognizes a degree of medium specificity while seeking common patterns across distinct creative forms (Hutcheon, 2006).

In academia, the grounding of adaptation as an offshoot of literary studies means that scholars of adaptation have been primed to prioritize literature, especially prose fiction, over the cultural forms that have adapted it (Leitch, 2003). Meanwhile, media studies have increasingly dealt with various forms of intertextuality-such as the reboot and the spinoff, for example-while not necessarily considering them as or alongside adaptations (Klein \& Palmer, 2016). The field of translation studies has also been brought into productive dialogue with adaptation, particularly in terms of scholarly methodology (e.g., Cattrysse 2014; Raw, 2013). Yet the scholarly focus of translation studies vis-à-vis adaptation-exploring their shared and distinct qualities as both creative processes and cultural products-has touched only rarely on other fields. Exceptionally, Krebs (2014) links translation with adaptation through case studies culled from both theater and 
cinema; Grossman (2015) advances her notion of "elasTEXTity" using examples from stage and screen; however, such cross-medium attention is rare.

It is therefore crucial to establish a definition of adaptation that can cover interdisciplinary territories while still delimiting a workable corpus. Following Leitch's (2007) observation that the process of adaptation requires at least one text to stand as its source, the notion of textuality can serve as a defining prerequisite. Importantly, the form of the source text(s) here is far less significant than the conditions of its production: it must have clearly documented, possibly shared or collective authorship; its creative genesis must develop over a discrete, though possibly prolonged period of time; and this process must culminate in clear date(s) of public release as a complete text. The same criteria should apply to the adapted text. This definition of textuality would disqualify, for example, historical narratives, which some scholars have treated as adaptations solely by virtue of their basis on historical fact (e.g. Tutan \& Raw, 2013); and narratives "based on a true story" without a single text or author of origin credited or widely identified in the new text (Leitch, 2007). While what Constandinides (2012) calls paraadaptations-that is, fan works and other amateur transformations of popular culture-may readily fit the above criteria establishing their textuality, in the interest of maintaining a manageable scope, this project will not include them.

Furthermore, source texts that meet this definition of textuality must be credited either by the creators or by a broad critical consensus for a text to be considered as "adapted." Following Grant (2002), while there is no such thing as a crypto-adaptation, not every adaptation presents itself overtly as such, nor does it necessarily credit its source. In cases where there is no official acknowledgment of adaptation or inspiration, critical consensus could be established through, for example: published reviews; programming notes for festivals or exhibitions; marketing materials and paratexts (e.g., blurbs, synopses, creator interviews); and/or scholarly criticism (Grant, 2002).

The requirement that a text be complete is subject to conventions of its form. For example, a playwright's published work could be considered complete in itself, without a single stage performance. A screenwriter could sell a teleplay that never makes it to studio production. But neither of these would demonstrate full achievement of the form as intended for popular consumption. In cases of allographic arts-that is, artistic expression with multiple phases of creative intervention, with performance and/or exhibition as the ideal vehicle for public engagement-completeness must require full market realization, e.g.: plays and musicals performed on stage; television series or miniseries that release a full run of episodes; films that have been released through theatrical and/or streaming distribution. Literary manuscripts, as an autographic or monophasic art form, must be affiliated with a publisher and released in some conventional form (bound book, magazine, e-book, etc.) for public circulation.

\section{National and transnational adaptation}

Beyond the questions of textuality and completion, both sources and adaptations must face the question of national origin. This, too, does not always produce a straightforward answer, especially for collective productions like film and television. But this national backdrop is important, and can refract to produce a spectrum of transnationality by which some texts will occupy a single national context more comfortably than other, more internationally collaborative texts. This exploration would be usefully driven by data gathered under three main headings:

- Economic-industrial;

- National-cultural;

- Narrative. 
On the national-cultural end of the spectrum, adaptation has long been understood to play a role in creating and enforcing discourses of national and ethnic identity, particularly in cases where it dovetails with the literary canon (e.g. Haltof, 2011; Vidal, 2012; Sen, 2017). But transnationality has gained wider attention in media studies, particularly in cinema. Bergfelder (2005) notes that finding a transnational lens through which to study mediated narrative "can be seen to mirror the central debate of the European project [...], namely to negotiate and reconcile the desires for cultural specificity and national identity with the larger ideal of a supranational community" (315). Adaptation can be transnational in myriad ways, each of which can complicate national discourses-even, sometimes, while enforcing them.

The rise of transnational media studies has not yet been brought fully to bear on adaptation, particularly where industries are concerned (Murray, 2012). Expressing a common viewpoint in the field, Iordanova (2016) emphasizes how transnationality affects the viewing experience, with audiences cultivating transnational subjectivity through contact with particular texts. She acknowledges that "contemporary cinema's way of being is transnational-from how it is conceived to how it travels, from how it is made to how it is seen." But Iordanova's primary focus is on the viewer, asserting that "if you [as a viewer] anchor yourself supranationally, you see different things" than you would with a purview limited to nationally specific media. While this is certainly not incorrect, there is more to transnationality than how it informs media consumers, and adaptation offers a productive way to join reception studies with media production practices. One must "anchor" adaptation practices in the European Union by exploring how media industries' interconnections contribute to the transnational sphere that Iordanova (2016) perceives. Yet, conversely, such a study may also reveal how adaptation is used to retreat from transnationality and instead work to reinforce national discourses. It is important to understand both of these trends in their various contexts.

\section{Reception and (cross-) cultural value(s)}

The third research question deals with the market impact and reception of adapted texts. Like adaptation, media reception and audience studies comprise an area of scholarship that has seen a recent push for heightened awareness of its own interdisciplinary applications, and a concomitant effort to innovate the methods that various disciplines use to approach it (Zeller, Ponte \& O’Neill, 2015). One study that anticipates applications for adaptation studies is Hujanen and Kangastpunta's (2015) examination of contemporary audiences faced with intermediality, that is, the condition of different media platforms situated alongside and in hierarchical relation to one another. While Hujanen and Kangastpunta are concerned with media convergence and the shift to digital television, the notion of intermediality that their work explores can be extended beyond technological advancement and into discourses of prestige and cultural value.

Value, too, is an area of reception study that has recently seen increased activity. In the Literary Lab at Stanford University, J. D. Porter (2018) has developed a quantitative approach to measuring the popularity and prestige of canonical literary prose published in English. While this study offers an innovative approach to a thorny question, Porter's formula overlooks the impact of adaptation on these measurements. Surely, for example, J. R. R. Tolkien and J. K. Rowling have secured their respective positions along both these axes in part because their stories, already widely read in print, have also been brought to film; but to what extent has, say, Thomas Pynchon gained in either popularity or prestige thanks to Paul Thomas Anderson's adaptation of Inherent Vice (novel 2009, film 2014)? Elsewhere, I have already underscored how media forms are granted or denied certain kinds of attention and acclaim, considering particularly how adaptation plays into assessments of cultural value (Kennedy-Karpat \& Sandberg, 2017). Such questions can be further explored through cross-cultural comparison: Do cultures experience similar shifts in value as narratives move from one form to another? Are narratives that cross 
cultures through adaptation valued differently from narratives that stay within their cultural context across forms? The content analysis and detailed coding in data-driven adaptation studies would help identify shared characteristics across media types and across national industries, ultimately visualizing adaptation networks across the EU.

European culture industries are not short on adaptations both transmedial and transnational: from Belgian director Ivo van Hove's 2018 stage adaptation of Hollywood classic All About Eve (dir. Joseph L. Mankiewicz, 1950), to the musical adaptation of Jean-Pierre Jeunet's film Amélie (2001; originally Le Fabuleux destin d'Amélie Poulin), a production that may have been short-lived on Broadway-just six weeks in 2017-but has since been staged in Japan, Germany, the United Kingdom, and Finland. Swedish author Stieg Larsson's bestselling Millennium series of novels was first adapted in Sweden for the cinema (2009) and for television (2010); Hollywood then came out with its own adaptation of The Girl with the Dragon Tattoo (2011). Reception studies focused on these and similar adaptations, along with their respective source texts, would productively expand current approaches to intermediality and systems of cultural value.

\section{Industrial best practices}

The final research question aims to apply this broad view of adaptation to industrial practice in the EU. Studies of cultural production have had limited impact in adaptation scholarship, which tends to describe what existing adaptations do rather than how they came to exist. Such work is rarely prescriptive, ill-suited to offering new or more marketable ways of adapting material. But recent work has carved significant inroads into the political economies of adaptation. Murray's (2012) The Adaptation Industry unpacks the commercial and creative strategies involved in selecting material from one industry-here, literary fiction-as fodder for adaptations in other media. But Murray's limiting focus on print culture and her emphasis on the Anglosphere (US-UK-Australia) leaves the transnational angle unexamined. Expanding such a study along both these axes would require looking at multiple industries as points of origin for textual sources-and polyglot Europe lends itself well to establishing itself as the core geographic center of such a study.

Taking a different angle on commercial interests in adaptation practice, Jeannelle (2016) studies a French company, Best Seller to Box Office, whose business is in calculating "adaptability quotients" for texts under consideration as sources for cross-media adaptation. This suggests, first, that Murray's notion of an adaptation industry should be taken very literally indeed; second, that much more could be done to study and promote adaptation as a vehicle for reaching audiences in Europe and beyond. It is not an empty pipe dream to seek to identify patterns of success in European adaptation, as such a dataset would serve a purpose not unlike the proprietary formula of Best Seller to Box Office. Moreover, such results could be useful not only for media industries, but also for nonprofit or government institutions dedicated to funding cultural production, particularly those with an eye to drawing transnational audiences.

By collecting and analyzing quantifiable data from different kinds of adapted texts along three key axes-economic-industrial, national-cultural, and narrative-adaptation research program could generate new, actionable knowledge about where, how, and for whom adaptation holds appeal across Europe. The implications of these findings could help shape EU media policy and funding practices in both the public and private sector, while also contributing to ongoing scholarly work in the literary, performing, and media arts. 
5. Key questions

In order to trace these adaptive dynamics, I propose the following key questions to guide future research in trans-European adaptation studies:

(1) How do adaptations track narrative and media flows within and across national, linguistic, and regional boundaries?

(2)To what extent do adapted narratives reflect transnational relationships, and how might they help construct Europeanness?

(3) How do audiences in the EU respond to transnational adaptation, and how are European adaptations circulated and received outside Europe?

(4) What impact does adaptation have in the culture industries, and what industrial practices might facilitate adaptation across media platforms and/or national boundaries?

This section will consider each of the four key research questions by presenting the state of current scholarship along with recommended methodologies to expand on these academic discussions.

\subsection{Narrative flows and transnational relationships in Europe}

The first two questions are intertwined with one another, both in the existing literature and in the methods proposed to address them. They also establish the parameters for a key dataset in quantitative adaptation studies. The first question develops the what and who of adaptation: What narratives are being adapted? What is their original language? What is their new form, and what was the old? Who (and where) are the audiences receiving this narrative? The answers to these questions present emergent patterns in the data and use them to consider the role(s) of adaptations in constructing and critiquing both national and transnational European cultural identities.

Like translation, whose academic study has recently been brought into productive dialogue with adaptation studies (e.g., Venuti, 2007; Cattrysse, 2014; Krebs, 2014; Raw, 2013), adaptation brings a known or knowable source text into a new context, thereby creating a different but inextricably related text with potential to reach new audiences. Both adaptation and translation are predicated on coexistence, although the nature of this coexistence can differ significantly. Translation generally presumes that a text and its translation will reach distinct populations with limited overlap, while adaptation across media forms often presumes the source and its adaptation to share the same cultural space(s) and, therefore, the same audience(s).

But not every model of adaptation fits this description. Some frameworks, such as cross-cultural screen remakes, can closely resemble translation in that the adapted/remade text aims to attract audiences that are presumed to be unfamiliar with the source. This presumption is not entirely unfounded. While the rise of digital streaming and content-sharing has, to some extent, cracked longstanding barriers to cross-cultural media exposure, Kustritz (2015) asserts that many people relying on industry-sanctioned points of access (e.g. satellite television, subscription streaming services, theatrical distribution, etc.) find their choices limited to, on the one hand, immediately local productions; on the other, mainstream American films and television. Such consumption patterns are further shaped by national preferences for dubbing versus subtitling (Pelletier, 2012). While individual texts, with or without their modifications (dubbing, subtitling, etc.), may cross borders more easily than ever, the tendency for local productions to dominate media markets opens a window for adaptations and remakes to contribute to the transnational media landscape. To emphasize: adaptation is not concerned with how texts are 
spreading transnationally; rather, its purpose is to examine the flow of narratives as they generate multiple, intertextually related texts across forms and/or cultures.

Following Jenkins, Ford and Green (2013), narratives can be more spreadable in one form than another-even though, importantly, their focus on digital networks in coining this term leaves out, for example, theatrical performance. This notion of "spreadability" contrasts with a major limitation of current adaptation studies, where scholarship tends to focus on a few or even just one of the various forms involved in cross-media adaptation (e.g., literature, theater, screens, digital media). Such single- or strictly dual-platform studies do not necessarily adhere to a methodology, theory, or research agenda that transcends the selected form(s). The very term "adaptation studies" can carry different connotations across disciplinary divides, even if intertextuality, multimodality, and intermodality are of keen interest to a number of fields (Elleström, 2010). Promoting a shared critical vocabulary would emphasize the common ground to which adaptation studies can lay claim.

Examples of cross-media adaptations that enact this spreadability would include the Royal Shakespeare Company's staging of Hilary Mantel's historical novels Wolf Hall (2010) and Bring up the Bodies (2014); Wolf Hall was also adapted for television (Sandberg, 2017). Stephen Daldry's film Billy Elliot (2000) was adapted into a stage musical that debuted in 2008 and played for 11 years in London; additional productions came to the stage in Japan and South Korea (billyelliotthemusical.com). Similarly, Jean-Pierre Jeunet's film Amélie (original French title Le Fabuleux destin d'Amélie Poulin, 2001) inspired a musical that was short-lived on Broadwayrunning only six weeks in spring 2017-but has since seen new productions in Japan, Germany, the United Kingdom, and Finland (Wikipedia). Swedish author Stieg Larsson's bestselling Millennium series was first adapted in Sweden for the cinema (2009) and then for television (2010); Hollywood followed with its own adaptation of The Girl with the Dragon Tattoo (2011). Such transnational, cross-media reach exemplifies the kind of spreadable narrative that has inspired the questions posed in this project.

\subsection{Determining textuality}

The question of what counts as an adaptation also must not be taken for granted. Following Leitch (2007), this project will take the notion of textuality as a defining prerequisite both for sources and their adaptations. Importantly, neither the form nor the platform of a text are crucial; a "film" can be screened in a 35mm print or streamed online; likewise, "television" need not be limited to broadcast models. What remains essential no matter its finished form are the conditions of a text's production: it must have clearly documented, though possibly shared authorship; its creative genesis must occur over a set, though perhaps prolonged period of time; and this process must culminate in clear date(s) of public release as a complete text.

This completeness is subject to conventions of each text's respective form, and as stated above, only texts which have reached full market realization will be considered complete. This would include, for example: plays and musicals performed on stage; series or miniseries that have released a full season/run of episodes; films that have secured distribution, whether theatrical or streaming. Print manuscripts without a performative component (e.g., short stories, novels, comics/bande dessinée) must be affiliated with a publisher and released in at least one conventional form (hardcover, magazine, ebook, etc.) for public circulation. Whether as sources or adaptations, incomplete texts-for instance, plays that have been written but never staged; screenplays bought by a studio but never produced; manuscripts never published for commercial consumption-may be reasonably excluded from the corpus in order to keep a feasibly limited scope. 
Emphasizing textuality is crucial to the core methodology of adaptation studies, as the data collected for coding will revolve around texts. Each component of the definition established above situates both sources and adaptations within their respective place(s) and time(s), which are crucial data points for comparative and transnational study. In practical terms, this definition of textuality would not recognize historical narratives, "true stories," and traditional legends as sources for adaptation, although scholars have usefully understood all of these as such (e.g., respectively, Tutan \& Raw, 2013; Leitch, 2007; Thornley, 2018; Krasilovsky, 2018). Such "sourceless" adaptations, as they could be categorized, may still be accounted for in the broadest possible census of adapted texts. However, the lack of precise origins for these narratives means they cannot be subjected to a full content analysis alongside text-to-text adaptations; for reception study, in particular, the textual criteria outlined above must be rigorously applied to both source and adapted texts.

The type of content analysis that I am advocating here has been inspired by Cattrysse (2014), whose work in adaptation studies intersects with his work in translation. Outlining an approach he calls Descriptive Adaptation Studies (hereafter DAS), Cattrysse advocates for research based on quantifiable, empirical data about adapted texts. Drawing on methods developed in the field of translation studies-an affinity between fields that is also explored in Venuti (2007), Raw (2013), and Krebs (2014) -DAS requires an expansive but carefully defined corpus of adapted texts that aims to discern trends that a more limited scope, or a single text, could not capture alone. By using data to establish a broader outlook on cultural production, Cattrysse argues, adaptation scholars could make more effective choices for the close readings and case studies that remain crucial to the field.

Beyond basic textual identifiers and indicators-such as date(s) of release and key creative personnel (e.g., author[s], director[s], performer[s], production company[-ies])-for a trans-European study, the data for each adaptation and its source text(s) could be collected under three primary headings: economic-industrial, national-cultural, and narrative (Table 1).

Table 1. Data categories for quantitative adaptation study

\begin{tabular}{|c|c|c|}
\hline Economic-industrial & National-cultural & Narrative \\
\hline Ratio of expenditures: intake & Nationality/-ies of key creators & Form (print, stage, screen) \\
\hline Copyright transfers & $\begin{array}{l}\text { Place(s) of publication / } \\
\text { performance / release }\end{array}$ & Time period(s) represented \\
\hline Awards & Original language(s) & Genre(s) \\
\hline Consumer demographics & Translation(s) & Plot keywords \\
\hline $\begin{array}{l}\text { Creative personnel salaries } \\
\text { Sources \& amount of } \\
\text { production funding }\end{array}$ & Reviews in major publications & $\begin{array}{l}\text { Character demographics } \\
\text { (nationality, race/ethnicity, } \\
\text { age, gender, class, etc.) }\end{array}$ \\
\hline
\end{tabular}

Considering (Table 1), it should be immediately clear that not every data point can be applied across all forms. This relates to medium specificity, a term already familiar to adaptation scholars in the context of adaptive aesthetics (Hutcheon, 2006). However, in the quantitative project proposed here, the question of medium holds far greater import for its implications when collecting economic and industrial data. Some of these calculations will be more straightforward than others. While the film industry makes a great deal of useful, regularly collected data freely available (via, for example, the European Audiovisual Observatory), other creative industries are neither as centralized nor as forthcoming with relevant statistics. Indeed, one possible setback for a project like this one may be that certain numbers are simply unavailable or unverifiable; audience numbers for streaming services like Netflix, for example, are notoriously kept secret, 
unlike the generally public release of TV ratings and box office reports in cinema. However, regardless of researchers' access to or general accuracy of viewership numbers, the core question of transnationality remains in play. The data points most likely to turn up missing or incomplete should not impede progress towards the goal of mapping adaptations across the EU.

The national-cultural category listed above emphasizes the transnational component of this approach. National media and area studies have drawn on adaptations from several different angles, but the common practice of adapting a (national) literary canon to screens large and small has been particularly well studied (e.g., Vanoye, 2005; Haltof, 2011; Vidal, 2012; Sen, 2017). Transnational adaptations are also a prominent point of interest, and I have previously published work in this area (Kennedy-Karpat, 2015). Generally, though, beyond text-specific case studies, collected volumes tend to be organized around limited axes of international exchange and/or on a single media form. Durham (1998) and Mazdon (2000) both focus on French films and their US remakes; Smith and Verevis (2017) focus on film in their study of transnational remakes, though without a specific geographic focus. Hills, Hilmes and Pearson (2019) devote their volume to US-UK connections in television; meanwhile, McCabe and Akass (2012) trace the trajectory of a single TV show, Ugly Betty, through its many transnational incarnations. The ongoing "Lost in Translation?" research project at Ghent University's Centre for Cinema and Media Studies-under the direction of Gertjan Willems, Eduard Cuelenaere and Stijn Joyes-is devoted to a contemporary cycle of Dutch-Flemish film remakes.

These projects are valuable in themselves, of course, but to echo Cattrysse (2014) once again, the implications of such findings for wider contexts are presumed or extrapolated rather than supported with empirical contextualization. Do the particular cases represented in these studies matter more (and to whom?) than other examples of adaptation? Can case studies transcend the particular details of their limited corpus? Is there a way to measure and study the full context of adaptations as context, and thereby expand the limited purview of discrete and perhaps too arbitrarily chosen case studies? These are the questions that drive the academic side of quantitative adaptation studies.

\section{$5 \cdot 3$ Reception contexts}

Once the overarching parameters and patterns of contemporary European adaptation have been mapped out, the third key question reintroduces qualitative methods to bring focus to the adapted texts themselves. The core texts for the reception study should represent broader trends; it is impossible to predict how many lines of inquiry might be opened this way, but the aim is to find examples of transnational and national adaptation that demonstrate the patterns revealed through content analysis. Additionally, the intention is to locate examples that, for whatever reason, might not have presented themselves as ideal for a case study without the data to support that choice.

Addressing the question of cultural impact will require some qualitative reception study alongside the content analysis. To start with, cultural response can be measured quantitatively in several ways, by tallying, for example: tickets/copies sold; screens/stages involved; available translations; industry awards. The quantitative approach to popularity and prestige developed at the Stanford Literary Lab shows how such numbers can produce legible data (Porter, 2018). But numbers alone cannot conceptualize a holistic cultural response, especially when the question involves the combination of adaptation and prestige (Kennedy-Karpat \& Sandberg, 2017). Looking past the numbers becomes even more urgent when those adaptations are transnational, as these boundary-crossing trajectories raise further questions about how such texts might cultivate or critique a sense of Europeanness. 
The qualitative reception study-which, once again, should center those texts that best represent the dataset-will focus on this question of transnational identity. This research question builds on my previous work connecting adaptation with prestige (Kennedy-Karpat \& Sandberg, 2017) by examining the specific impact of transnationality on perceptions of value. To what extent is an adaptation's transnationality-or, alternatively, its national specificity-invoked in judging its success (or lack thereof)? Under what (or whose) conditions is an adaptation's transnationality seen as an asset, and when might it be seen as a liability?

In cases where contemporary source text(s) are adapted, reception studies should extend to sources as well, seeking clues or cues that signal its "adaptability." This raises a question that overlaps with the final research question: to what extent, if any, can critics and/or audiences presage future adaptive success?

\subsection{Industrial benefits}

Because culture industries stand to gain from the answers to these questions, academic adaptation studies would do well to consider adaptation more frankly from an industrial angle. Much is at stake in assessing how narratives and media forms cross cultural boundaries, and these stakes are limited neither to academia, nor to the private sector. The stakes here involve stories, which are the fabric of culture and how cultures make sense of themselves; and, as Klein (2019) observes, the stories that bear repeating-through adaptation, remaking, restaging, or simply retelling-are those that wield exceptional social power. Sharing narratives across cultural boundaries therefore suggests, at its best, a correlation with intercultural understanding and cooperation. Conversely, cultural imperialism often involves appropriating narratives from and/or imposing narratives on people who are situated outside the hegemony. As with all intercultural communication, sharing stories is an endeavor that must be undertaken responsibly.

Whether an adaptation is viewed positively or negatively, the power of stories is clear to creators and consumers operating in an increasingly globalized marketplace. As a screenwriter and a scholar, Krasilovsky (2018) advocates for greater transcultural openness, but she targets individual writers rather than framing change as an industry-wide concern. This position runs parallel to Iordanova's (2016) appeal to viewers and scholars who might embrace a transnational perspective-a worthy goal, but one that does not sufficiently address the industrial backdrop against which such individual decisions are made.

Some scholars have begun to recognize these shortcomings in the field of adaptation studies, though only a few have centered the culture industries in their work. Jeannelle (2016) studies one company in France that purports to determine the "adaptability quotient" of texts that have been identified as potential sources for cross-media adaptations. Broadening this spectrum, in The Adaptation Industry, Murray (2012) argues that adaptation offers a useful window through which to view the creative industries as an object of study. While Murray's work has been widely praised and frequently cited, to my knowledge no major follow-up has interrogated cultural spaces beyond the English-language literary publishing world that forms the locus of Murray's "materialization" of adaptation studies. Furthermore, Murray's work replicates a recognized flaw in adaptation studies by figuring a one-way trajectory between print sources and screen adaptations, glossing over screen-to-stage adaptations as well as the long, under-examined history of screen-to-print novelizations (Baetens \& Lits, 2004; Van Parys, 2009). European adaptation studies must seek to fill this gap in industrial study, first by joining print with stage and screens to consider them all valid as source and/or target forms; second, by making a comparative study across national, regional, and international markets. 


\section{Conclusion}

The results of data-driven adaptation studies will generate actionable blueprints for future transnational adaptations across the EU. A richer, crosscutting view of the conditions and measures of success for adaptations would allow creators and producers to sidestep the pitfalls of past attempts and more effectively shape their expectations. A comprehensive and comparative content analysis-one that assembles data across economic-industrial, national-cultural, and narrative axes-would reveal both broad patterns and the inevitable nuances hiding within them. Such models may (or may not) already pass as common knowledge, but the outliers that defy these models might well serve as prototypes that shift the paradigm of future transnational adaptations and bring the European project to life through shared narratives.

\section{Acknowledgements}

This research did not receive any specific grant from funding agencies in the public commercial, or not-for-profit sectors.

The author declares no competing interests.

\section{References}

Baetens, J., \& Lits, M. (2004). La Novellisation: Du film au livre / Novelization: From film to novel. Leuven University Press.

Bergfelder, T. (2005). National, transnational or supranational cinema? Rethinking European film studies. Media, Culture \& Society, 27(3), 315-331.

Cattrysse, P. (2014). Descriptive adaptation studies: Epistemological and methodological issues. Antwerp: Garant.

Constandinides, C. (2012). Para-adaptation: Or how I learned to stop worrying and love convergence culture. Adaptation, 6(2), 143-157.

Durham, C. A. (1998). Double takes: Culture and gender in French films and their American remakes. Hanover: Dartmouth University Press.

Elleström, L. (2010). Media borders, multimodality and intermediality. Basingstoke: Palgrave.

Elleström, L. (2018). A medium-centered model of communication. Semiotica, 224, 269-293.

Genette, G. (1982). Palimpsests: Literature in the second degree. Translated by Channa Newman \& Claude Doubinsky, 1997. Lincoln: University of Nebraska Press.

Grant, C. (2002). Recognizing Billy Budd in Beau Travail: Epistemology and hermeneutics of an auteurist 'free' adaptation. Screen, 43(1), 57-73.

Grossman, J. (2015). Literature, film, and their hideous progeny: Adaptation and ElasTEXTity. London: Palgrave Macmillan.

Halle, R. (2014). The Europeanization of cinema: Interzones and imaginative communities. Champaign: University of Illinois Press.

Haltof, M. (2011). Adapting the national literary canon: Polish heritage cinema. Canadian Review of Comparative Literature/Revue Canadienne de Littérature Comparée, 34(3), 298-306.

Hilmes, M., Hills, M., \& Pearson, R. (2019). Transatlantic television drama: Industries, programs, and fans. Oxford: Oxford University Press. 
Hujanen, T., \& Kangaspunta, S. (2015). The intermediality of cross-media audiences: The case of digital television. In F. Zeller, C. Ponte \& B. O’Neill (Eds.), Revitalising audience research: Innovations in European audience research (pp. 215-235). London: Routledge.

Hutcheon, L. (2006). A theory of adaptation. New York: Routledge.

Iordanova, D. (2016). Choosing the transnational. Frames Cinema Journal, 9. http://framescinemajournal.com/article/choosing-the-transnational/.

Jeannelle, J-L. (2016). Adaptability: Literature and cinema redux. Translated by M. C. Flinn. Studies in French Cinema, 16(2), 95-105.

Jenkins, H., Ford, S., \& Green, J. (2013). Spreadable media: Creating value and meaning in a networked culture. New York: New York University Press.

Kennedy-Karpat, C. (2015). Self-adaptation and transnationality in Marjane Satrapi's Poulet aux prunes (2011). Adaptation, 8(1), 68-88.

Kennedy-Karpat, C., \& Sandberg, E. (2017). Adaptation, awards culture, and the value of prestige. Cham: Palgrave Macmillan.

Klein, A. A. (2019). 'They should never have given us uniforms if they didn't want us to be an army': Media in a Time of Crisis. Literature/Film Association keynote address. Available: https://judgmentalobserver.com/2019/09/15/they-should-never-have-given-us-uniforms-ifthey-didnt-want-us-to-be-an-army-contemporary-media-multiplicities-in-a-time-of-crisis/.

Klein, A. A., \& Palmer, R. B. (2016). Cycles, spinoffs, remakes \& reboots: Multiplicities in film and television. Austin: University of Texas Press.

Krasilovsky, A. (2018). Great adaptations: Screenwriting and global storytelling. New York: Routledge.

Krebs, K. (2014). Translation and adaptation in theatre and film. New York: Routledge.

Kustritz, A. (2015). Transnationalism, localization, and translation in European fandom: Fan studies as global media and audience studies. Transformative Works and Cultures, 19. https://doi.org/10.3983/twc.2015.0682

Leitch, T. (2003). Twelve fallacies in contemporary adaptation theory. Criticism, 45(2), 149-171.

Leitch, T. (2007). Film adaptation and its discontents. Baltimore: Johns Hopkins University Press.

Mazdon, L. (2000). Encore Hollywood: Remaking French cinema. London: BFI.

McCabe, J., \& Akass, K. (2012). TV’s Betty goes global: From telenovela to international brand. London: I. B. Tauris.

Murray, S. (2012). The adaptation industry. London: Routledge.

Pelletier, M. (2012). Subtitling and dubbing: An overview of a few EU countries. Annual of Language and Politics and Politics of Identity, 6, 129-39.

Porter, J. D. (2018). Popularity/Prestige. Literary Lab Pamphlet 17. https://litlab.stanford.edu/LiteraryLabPamphlet17.pdf.

Raw, L. (2013). Translation, adaptation, and transformation. London: Bloomsbury.

Sen, P. (2017). Origins, fidelity, and the auteur: The Bengali films of Tapan Sinha. In C. Kennedy-Karpat \& E. Sandberg (Eds.), Adaptation, awards culture and the value of prestige (pp. 115-131). Cham: Palgrave.

Smith, I. R., \& Verevis, C. (2017). Transnational film remakes. Edinburgh University Press.

Thornley, D. (2018). True event adaptation: Scripting real lives. Palgrave Macmillan.

Tutan, D. E., \& Raw, L. (2013). The adaptation of history: Essays on ways of telling the past. Jefferson, NC: McFarland. 
Vanoye, F. (2005). L'adaptation comme genre du cinéma français. In R. Moine (Ed.), Le Cinéma français face aux genres (119-130). Paris: AFRHC.

Van Parys, T. (2009). The commercial novelization: Research, history, differentiation. Literature/Film Quarterly, 37(4), 305-317.

Venuti, L. (2007). Adaptation, translation, critique. Journal of Visual Culture, 6(1), 25-43.

Vidal, B. (2012). Heritage film: Nation, genre and representation. London: Wallflower.

Zeller, F., Ponte, C., \& O’Neill, B. (2015). Revitalising audience research: Innovations in European audience research. London: Routledge. 
C. Kennedy-Karpat - Adaption Studies in Europe

C O A $\mathrm{s}$ 


\title{
Family life satisfaction - Perception of the youth and their parents
}

\author{
Jasminka Zloković, Zlatka Gregorović Belaić \& Nadja Čekolj \\ University of Rijeka, Faculty of Humanities and Social Sciences, CROATIA \\ Department of Education
}

Received: 29 November 2020 - Accepted: 21 December 2020 • Published Online: 25 December 2020

\section{Abstract}

Family satisfaction is significant and complex concept that includes personal satisfaction and relationship satisfaction among family members. The aim of this paper is to present and discuss the preliminary young people's and their parents' perception family satisfaction analysis. The research was conducted on a convenient sample of students/young people $(\mathrm{N}=5 \mathrm{O})$ and their parents $(\mathrm{N}=84)$. For the purposes of this research The Family Satisfaction Scale from FACES IV instrument (Olson, 2010) was used. The mentioned scale measures the positive aspects of relationship among the family members. The results indicate that young people and their parents are generally satisfied with their family life. On some items of the scale there is statistically significant difference among young people and their parents. Parents are more satisfied with their family life than their children. These results are encouraging especially in the context of COVID 19 pandemics and increasing numbers of undesirable family relationships.

Keywords: family relationships, family life satisfaction, young people, parents.

\section{Introduction}

Considering different approaches in examining family relationships and main aim of this paper, we do not aspire to theoretical comprehensiveness, but refer to the complexity of family relationships and the importance of participants' self-perception of their families. According to both traditional and modern theories (historically - institutional, sociological, structurally functional, psychological approaches, development theories etc.) it can be concluded that family represents a "living organism" which, due to complex interactional relationships and environmental influences, experiences numerous changes and adaptations to the "new" qualities and levels of interactions (Zloković \& Lukajić, 2016). Elkind (1995) and Stacy (1993) consider family as an ideological and symbolic construct determined by the very specific emotional relationships within it, enabling us to understand it as a primary emotional and social community of parents and their children (and the rest of the relatives) that live together and perform their family as well as interpersonal functions in a unique way. After certain period of time and inevitable transformation from "traditional" to "modern" family, it looks as if family life becomes understood as process of a depatriarchalization and detraditionalization of life, the time of distant, shallow and weakened interpersonal relationships as well as weakening of essential parental functions that want to go in the direction of structural transformation, creating of autonomous

(C) Authors. Terms and conditions of Creative Commons Attribution 4.0 International (CC BY 4.0) apply. Correspondence: Jasminka Zloković (PhD), University of Rijeka, Faculty of Humanities and Social Sciences, Department of Education, Rijeka, CROATIA. E-mail: jzlokovic@ffri.hr. 
family area and establishing of more equal and egalitarian relationships between sexes and generations (Milić, 2010; Zloković \& Lukajić, 2016). The variety of structure, relationships, functions and the ways of forming and surviving of the family in regards to external and internal influences provides the diversity of family incidence, implying that every family is unique and that, in line with the postmodern views, a unique definition should be created for each family (Janković, 2008).

- Individual's perspective of life satisfaction represents one of the assumptions for more successful family functioning.

- The youth and their parents are generally satisfied with their families, considering that the parents show higher satisfaction than their children.

- The differences in the participants' perception were found on family structure and total monthly family income variables.

- Participants that live in two-parent families show higher satisfaction than those that live in one-parent families.

- Regarding total monthly family income, the results show that participants with higher income express higher family satisfaction.

Relationships between family members are embedded into broader family system and are more often than not dependent on the relationships with the rest of the family members (Cox \& Paley, 1997). According to Burges (1927) the family is primarily a process, an interactive system affected by all of its members; it is not a simple structure or household - social unit. We cannot understand the behavior of one of the family members if we do not examine one's relationship with the other members of the family, the nature of their interaction, development and the changes in their personality. Additionally, one of the fundamental functions of the family is seeking help as well as support for the individual needs of the other family members. Even though it is difficult to determine the ways which would create a positive family atmosphere, certain strategies such as open communication, mutual respect and the relationship equality, showing mutual interests, encouragement, showing mutual interest and encouraging the expression of one's attitudes and opinions as well as encouraging the need to give an opportunity to every family member to explain their wishes, interests, attitudes and opinions may encourage it. From the problems' perspective, studies of families are often based on the examinations of changes in the family's structure, "separated" family problems, family violence, the influence of trauma on the family members, parents' competencies etc. in order to improve the quality of life within the family. In that context, this paper starts from the questions regarding family life satisfaction in addition to family communication and cohesion with the goal of encouraging future opportunities in the family empowerment as well as finding conceptual methods that would increase the level of positive family relationships and healthy development of children and the youth (Zloković \& Čekolj, 2018). Mutual family cohesion, support, positive and encouraging family atmosphere, the way and level of family communication and its interaction with wider social environment, self-perception of satisfaction with family and family life can encourage, but also slow down and limit one's personality development (Zloković, 2012). According to Čudina-Obradović and Obradović (2003), the experience of parenting consists of the satisfaction with the child, oneself as a parent, established relationship between oneself and one's child and its development. They believe that the experience of parenting can be either positive, negative or with mixed signs.

In the studies examining family relationships, self-perception of personal feelings while performing parental tasks, mutual relationships, satisfaction and quality of family life is often expected and needed. Despite the opportunities to provide socially expected and acceptable answers, self-evaluations of personal emotions often represent valuable source of information. Self-perception testifies on the level of awareness of parents about his role in his child's life. 
Additionally, it stimulates children/young people's questioning of certain personal contributions to the quality of family life.

Margaret Mead claims that "family is the strongest institution that we possess and we owe it our humanity" (Aračić \& Nikodem, 2010: 295). Most of Slavic people share the opinion about the importance of family today where 99\% of Croats define it as common good and hold it in the highest regard (Aračić \& Nikodem, 2010). This represents an optimistic information that represents a basis in many interdisciplinary activities that deal with improvements of family functioning.

Literature review indicates a wide palette of definitions regarding the life satisfaction usually as a both cognitive and affective category. More often than not, life satisfaction, well-being and quality of life are being equated. According to Kočo-Vukadin, Novak and Križan (2016) the life satisfaction construct is positioned in the broader area of subjective wellbeing construct which is being studied within the frame of superior quality of life phenomena. Subjective wellbeing consists of both affective and cognitive component. Campbell, Converse and Rogers (1976, as cited in Diener, 1984) state that satisfaction represents "observed difference between aspirations and achievements that ranges from the perception of fulfillment to the perception of deprivation". Pavot et al. (1991, as cited in Penezić, 2006) define life satisfaction as "individual's global evaluation of their life". Fujita and Diener (2005) regard life satisfaction as a reflection on life in its entirety which transcends the experience of positive emotions. Penezić (2006) claims that life satisfaction represents cognitive evaluation of individual's entire life, through which each individual evaluates their life. Family's perception of life satisfaction is relatively unexplored area, thus making this paper a valuable scientific contribution to the main problem of this scientific project: The family empowerment for the development of positive relationships and family cohesion at the University of Rijeka.

\section{Methodology}

This paper has to aims: (I) to examine the youth and their parents' perception of family satisfaction and (II) analyze the differences in perceptions of family satisfaction in regards to the gender and education of participants, family structure as well as total monthly family income.

From the defined aims of the paper, based on the presented theoretical framework in the previous part of the paper, the following hypotheses have arisen: (I) There is a statistically significant difference in the perception of family satisfaction of the youth and their parents; (II) There is a statistically significant difference in the perception of family satisfaction of the youth and their parents in regards to their socio-demographic and socio-cultural characteristics.

\subsection{Participants/ Sample}

134 students of Pedagogy at the University of Rijeka $(\mathrm{N}=50)$ and their parents $(\mathrm{N}=84)$ participated in the study. The average age of the students, i.e. the youth, is $21.76(\mathrm{SD}=2.28)$, while the average age of their parents is $50.25(\mathrm{SD}=4.80)$. Additionally, 42 female students $(31 \%)$ and 8 male students (6\%) as well as 44 mothers (33\%) and 40 fathers (30\%) participated in the study. Most parents have finished their high school education (69\%), while most of the youth has received their bachelor's degree (46\%). Most of the participants live in two-parent families with two biological parents and there are only few participants that live in one-parent families (6 participants or 3 one-parent families). 


\subsection{Method}

The data was gathered during 2019/2020 academic year using the survey method and convenience sampling. The participants were introduced to the subject as well as the aims of this study. Additionally, they were informed about their right to remain anonymous as well as the possibility to withdraw from the study.

\subsection{Instruments}

This study used Family satisfaction subscale, a fundamental part of FACES IV instrument (Olson, 2010) which examines positive aspects of family relationships. Aforementioned subscale was translated and adapted by Ljubetić, Reić Ercegovac and Mandarić Vukšić. For the purpose of this study, the subscale was taken and used with the authors' consent. The subscale was translated by using the double translation method with the aim of determining the credibility of the translation where the subscale was firstly translated from English to Croatian, followed by the translation from Croatian into English (Ljubetić, Reić Ercegovac \& Mandarić Vukušić, 2020).

Family satisfaction subscale consists of 10 items in which the participants evaluated the degree of satisfaction on the associated assessment scale consisting of five degrees ( 1 - very dissatisfied; 5 - extremely satisfied). Higher result on scale indicated higher family satisfaction.

Data analysis was conducted by using the IBM SPSS Statistics 20 statistics software. Univariate (frequencies and percentages, means, standard deviations and mean ranks) as well as bivariate statistics methods (Mann-Whitney U test and Kruskal-Wallis test) were used in order to determine the differences in attitudes in regards to sex, education, family structure and total monthly family income. All tests and analyses were conducted on the 5\% statistical significance level.

In order to verify the factorial structure of the subscale's Croatian version, exploratory factor analysis with maximum likelihood method of factor extraction was conducted. Verification of suitability of the used analysis has shown that the data is suitable - Kaiser-Meyer-Olkin test value is 0.917 which is in line with the recommended value (o.6) (Table 1.). Moreover, Bartlett's test of sphericity shows the statistical significance of $\mathrm{p}<0.01$. The number of significant factors is determined by Cattell's scree test criteria as well as oblimin rotation of factorial axes.

Table 1. Kaiser-Meyer-Olkin test

\begin{tabular}{lc} 
& MSA \\
\hline Overall MSA & 0.917 \\
The degree of closeness between family members & 0.951 \\
Your family's ability to cope with stress & 0.908 \\
Your family's ability to be flexible & 0.912 \\
Your family's ability to share positive experiences & 0.915 \\
The quality of communication between family members & 0.936 \\
Your family's ability to resolve conflicts & 0.908 \\
The amount of time you spend together as a family & 0.921 \\
The way problems are discussed & 0.897 \\
The fairness of criticism in your family & 0.910 \\
Family members concern for each other & 0.910
\end{tabular}




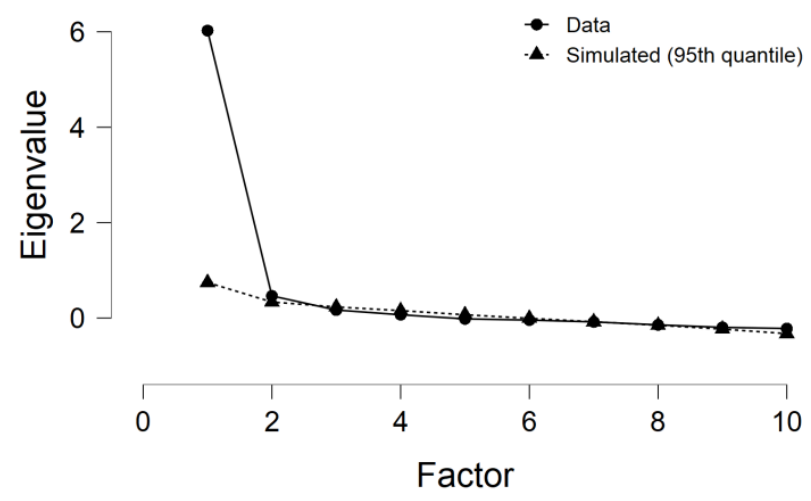

Graph 1. Scree-test - determining the number of significant factors

The starting maximum likelihood extraction of significant factors has shown 2 significant factors (Graph 1). Further examining showed that the "Degree of closeness" item has equal saturation on both factors which led to its removal from the further analysis.

Table 2. Factor extraction - final

Factor Loadings

\begin{tabular}{|c|c|c|c|}
\hline & $\begin{array}{c}\text { Communication } \\
\text { aspects }\end{array}$ & $\begin{array}{l}\text { Affective } \\
\text { aspects }\end{array}$ & Uniqueness \\
\hline $\begin{array}{l}\text { Your family's ability to cope with } \\
\text { stress }\end{array}$ & & 0.773 & 0.322 \\
\hline Your family's ability to be flexible & & 0.902 & 0.280 \\
\hline $\begin{array}{l}\text { Your family's ability to share } \\
\text { positive experiences }\end{array}$ & & 0.692 & 0.307 \\
\hline $\begin{array}{l}\text { The quality of communication } \\
\text { between family members }\end{array}$ & 0.761 & & 0.212 \\
\hline $\begin{array}{l}\text { Your family's ability to resolve } \\
\text { conflicts }\end{array}$ & 0.679 & & 0.215 \\
\hline $\begin{array}{l}\text { The amount of time you spend } \\
\text { together as a family }\end{array}$ & 0.812 & & 0.548 \\
\hline The way problems are discussed & 0.905 & & 0.151 \\
\hline $\begin{array}{l}\text { The fairness of criticism in your } \\
\text { family }\end{array}$ & 0.499 & & 0.536 \\
\hline $\begin{array}{l}\text { Family members concern for each } \\
\text { other }\end{array}$ & & 0.592 & 0.414 \\
\hline
\end{tabular}

Retained factors explain a total of $67 \%$ of the variance of the results, with the $36 \%$ being first factor's contribution while the second factor's contribution scored $31 \%$. Therefore, it can be concluded that no additional factors are present. Exploratory factor analysis showed that two-factor structure is present.

The first factor, which includes communication processes and the abilities to cope resolve conflicts, was named "Communication aspects", while the second factor, which includes the ability to cope with stress, flexibility, positive experiences and family's concern for each other, was named "Affective aspects" (Table 2).

First factor reliability analysis was conducted on a total of 5 items. Cronbach's $\alpha$ showed high reliability value, $\alpha=0.897$. All items were retained because they show similar means. Second factor reliability analysis was conducted on a total of 4 items. Cronbach's $\alpha$ showed high reliability value, $\alpha=0.887$. All items were retained because they show similar means. 


\section{Results}

Before the test results are presented, we are going to show the results of descriptive analysis. Total descriptive results of the youth and their parents show that the satisfaction level is reasonably high throughout all items (over 50\%). The biggest percentage of participants expressed high or extreme satisfaction with the statements about the family's ability to share positive experiences (80.6\%) as well as the level of family members' concern for each other (86.6\%). On the other hand, $20.9 \%$ of participants have expressed dissatisfaction with the statement about the family's ability to resolve conflicts. Apart from that, the similar percentage of participants has expressed dissatisfaction with the statement regarding the fairness of criticism within the family (19.4\%).

Mann-Whitney U test was used in order to determine the differences in family life satisfaction in regards to sex and education of the participants. Results analysis showed that there is no statistically significant difference between the groups.

The aforementioned test was used to determine the differences in family life satisfaction in regards to group affiliation (The youth or parents). Results analysis showed statistically significant difference in the Affective aspect factor ( $U=1507,500, Z=-2,734, p>0.01$ ). The parent express higher satisfaction than the youth as they have higher mean ranks (mean rank of the parents $=74.55$; mean rank of the youth $=55.65)$. Even though the difference between the groups exists, group affiliation has little impact on the family life satisfaction $(r=0,24)$. For more organized view, the results obtained by Likert scale are merged into three categories in which the sum of the results on the first two and the last two levels is presented (Very dissatisfied + somewhat dissatisfied; Generally satisfied; Very satisfied + extremely satisfied). Separated descriptive results are presented in Table 3 and Table 4.

Table 3. Descriptive results of the individual items of the youth $(\mathrm{N}=5 \mathrm{O})$

\begin{tabular}{|l|c|c|c|c|c|}
\hline \multicolumn{1}{|c|}{ ITEM } & \multicolumn{3}{|c|}{ F (\%) } & M & SD \\
\cline { 2 - 4 } & $1+2^{1}$ & $3^{2}$ & $4+5^{3}$ & \\
\hline $\begin{array}{l}\text { Your family's ability to cope } \\
\text { with stress }\end{array}$ & $11(22)$ & $13(26)$ & $26(52)$ & 3.420 & 1.031 \\
\hline $\begin{array}{l}\text { Your family's ability to be } \\
\text { flexible }\end{array}$ & $7(14)$ & $13(26)$ & $30(60)$ & 3.760 & 1.098 \\
\hline $\begin{array}{l}\text { Your family's ability to share } \\
\text { positive experiences }\end{array}$ & $5(10)$ & $8(16)$ & $36(72)$ & 4.000 & 1.099 \\
\hline $\begin{array}{l}\text { The quality of communication } \\
\text { between family members }\end{array}$ & $9(18)$ & $18(36)$ & $23(46)$ & 3.320 & 1.019 \\
\hline $\begin{array}{l}\text { Your family's ability to resolve } \\
\text { conflicts }\end{array}$ & $17(32)$ & $12(24)$ & $21(42)$ & 3.120 & 1.271 \\
\hline $\begin{array}{l}\text { The amount of time you spend } \\
\text { together as a family }\end{array}$ & $7(14)$ & $11(22)$ & $30(64)$ & 3.660 & 1.042 \\
\hline The way problems are discussed & $12(24)$ & $17(34)$ & $21(42)$ & 3.240 & 1.187 \\
\hline $\begin{array}{l}\text { The fairness of criticism in your } \\
\text { family }\end{array}$ & $16(32)$ & $20(40)$ & $14(28)$ & 2.920 & 1.046 \\
\hline $\begin{array}{l}\text { Family members concern for } \\
\text { each other }\end{array}$ & $5(10)$ & $4(8)$ & $41(82)$ & 4.280 & 0.990 \\
\hline
\end{tabular}

\footnotetext{
${ }^{1}$ Very dissatisfied + somewhat dissatisfied.

${ }^{2}$ Generally satisfied.

3 Very satisfied + extremely satisfied.
} 
Table 4. Descriptive results of the individual items of the parents $(\mathrm{N}=84)$

\begin{tabular}{|l|c|c|c|c|c|}
\hline \multicolumn{1}{|c|}{ ITEM } & \multicolumn{3}{c|}{ F (\%) } & M & SD \\
\cline { 2 - 5 } & $1+2^{4}$ & $3^{5}$ & $4+5^{6}$ & \\
\hline $\begin{array}{l}\text { Your family's ability to cope } \\
\text { with stress }\end{array}$ & $5(6)$ & $15(17.9)$ & $64(76.21)$ & 3.892 & 0.864 \\
\hline $\begin{array}{l}\text { Your family's ability to be } \\
\text { flexible }\end{array}$ & $4(4.8)$ & $19(22.6)$ & $61(72.7)$ & 3.964 & 0.884 \\
\hline $\begin{array}{l}\text { Your family's ability to share } \\
\text { positive experiences }\end{array}$ & $1(1.2)$ & $11(13.1)$ & $72(\mathbf{8 5 . 7})$ & 4.4345 & 0.752 \\
\hline $\begin{array}{l}\text { The quality of communication } \\
\text { between family members }\end{array}$ & $10(11.9)$ & $19(22.6)$ & $55(65.5)$ & 3.738 & 1.065 \\
\hline $\begin{array}{l}\text { Your family's ability to resolve } \\
\text { conflicts }\end{array}$ & $11(13.1)$ & $17(20.2)$ & $56(66.7)$ & 3.750 & 1.085 \\
\hline $\begin{array}{l}\text { The amount of time you spend } \\
\text { together as a family }\end{array}$ & $11(13.1)$ & $27(32.1)$ & $46(54.8)$ & 3.631 & 1.169 \\
\hline The way problems are discussed & $10(11.9)$ & $23(27.4)$ & $51(60.7)$ & 3.654 & 1.011 \\
\hline $\begin{array}{l}\text { The fairness of criticism in your } \\
\text { family }\end{array}$ & $10(11.9)$ & $31(36.9)$ & $43(33.1)$ & 3.571 & 0.960 \\
\hline $\begin{array}{l}\text { Family members concern for } \\
\text { each other }\end{array}$ & $6(7.2)$ & $2(2.4)$ & $75(\mathbf{8 9 . 3})$ & 4.494 & 0.902 \\
\hline
\end{tabular}

Due to too small groups, family structure variable was recoded, i.e. "two biological parents" and "two parents (1 biological and foster mother/ foster father)" categories were merged as they both included two parents, while the other category included only one-parent family structure. No participants categorized themselves as "adoptive parents" and "foster parents" due to which both categories got excluded from the analysis. Mann - Whitney U test was used in order to determine the differences in the family life satisfaction in regards to the type of participant's family structure (two-parent or one-parent structure). Statistically significant difference was found between the groups in both factors $(\mathrm{U} 1=225,500, \mathrm{Z}=-2,196, \mathrm{p}<0.05$; U2=209,500, $\mathrm{Z}=-$ 2,332, p<0.05), where members of two-parent families show higher satisfaction (mean rank_factor1 $=69.22$; factor $2=68.32$ ) than the members of one-parent families (mean rank_factor $1=36.21$; factor $2=33.93$ ). Family structure explains small effect of family satisfaction (factor $1-\mathrm{r}=0.19$; factor $2-\mathrm{r}=0.20$ ).

Kruskal-Wallis Test was used in order to verify the difference in family life satisfaction in regards to total monthly family income. Statistically significant difference was found on both factors ( $1<0,01 ; \mathrm{p} 2<0,05)$. Due to the fact that total monthly family income included 9 categories, post-hoc test (Mann-Whitney U test) was performed for each category pair. Statistically significant difference was found between five pairs, while medium effect was found in two pairs (Table 5).

The largest effect size was found between the following categories: 8,100-10,999 kunas $^{7}$ and 16,100 ${ }^{8}$ and more kunas as well as 12,100-14,0999 kunas and 16,100 and more kunas.

4 Very dissatisfied + somewhat dissatisfied.

5 Generally satisfied.

${ }^{6}$ Very satisfied + extremely satisfied.

7 1,070-1335 EUR.

8 2,128 EUR.

9 1,600-1,864 EUR. 
J. Zloković, Z. Gregorović Belajić \& N. Čekolj - Family life satisfaction - Perception of the youth and ...

Table 5. Statistically significant difference between the pairs

\begin{tabular}{|l|c|c|}
\hline \multirow{2}{*}{ Category pairs } & \multicolumn{2}{c|}{ Effect size } \\
\cline { 2 - 3 } & Factor 1 & Factor 2 \\
\hline $\begin{array}{l}\text { (2600kn-4599kn) and (16100kn and } \\
\text { more) }\end{array}$ & 0.22 & 0.21 \\
\hline $\begin{array}{l}\text { (4600kn-6099kn) and (12100kn- } \\
\text { 14099kn) }\end{array}$ & 0.22 & $/$ \\
\hline (8100 -10099) and (16100 and more) & $\mathbf{0 . 3 2}$ & 0.26 \\
\hline (10100-12099) and (16100 and more) & 0.29 & 0.20 \\
\hline (12100-14099) and (16100 and more) & $\mathbf{0 . 3 2}$ & 0.18 \\
\hline
\end{tabular}

\section{Discussion}

Family satisfaction subscale includes a number of various aspects such as cohesion, flexibility and family communication. Additionally, the construct is closely connected with the general life satisfaction that represents a subject of various studies and whose results are implemented in this discussion.

The first hypothesis, which claims that there is a statistically significant difference in the family satisfaction between the youth and their parents, was confirmed in the Affective aspects factor. However, statistically significant difference was found in the family satisfaction perception in regards to group affiliation (the parents vs. the youth) by using Mann-Whitney U test. Furthermore, parents express higher family satisfaction than their children (the youth). This result can be explained by the fact that the participants in this study are students of Pedagogy who are currently in the process of forming their professional identities. It can be assumed that the Pedagogy students approach the evaluation of family satisfaction more critically because they were exposed to the family life themes throughout their study. Similar results that indicate differences in the evaluation of family satisfaction between the youth and their parents can be found in the previous studies. Furthermore, Rogošić (2015) in her study concluded that the youth express higher life satisfaction when they nurture positive relationships with their parents. Additionally, by examining family satisfaction through the communication aspect, results of the previous studies indicate the existence of differences in the youth and their parents' perception where the parents express higher satisfaction with communication in the family than their children (Baxter \& Pederson, 2013; Ljubetić, Reić Ercegovac \& Mandarić Vukušić, 2020). We deem the presented information, which indicates that both the youth and their parents are generally satisfied with family life, to be positive, especially in the context of the fact that our study was conducted during the period of COVID 19 epidemic during which certain studies warned about the presence of certain unwanted family relationships such as difficulties in maintaining family connections and support, inadequate communication patterns, coping with stress as well as increased risk of violence and family abuse (Roje Đapić, Buljan Flander \& Prijatelj, 2020).

The second hypothesis, which claims that there is a statistically significant difference in perception of family satisfaction between the youth and their parents in regards to their sociodemographic and socio-cultural characteristics, was confirmed. No statistically significant difference was found in the evaluation of family satisfaction in regards to participants' sex. Sex variable was not significant in the previous studies as well that examined the same topic, however, the authors of those studies do not offer an explanation for their conclusions (Ljubetic \& Reić Ercegovac, 2010; Zabriskie \& McCormick, 2003). We can assume that the differences in family satisfaction in regards to participant's sex were not found due to family satisfaction subscale's item content. However, it can be assumed that the differences in regards to sex would be found if the subscale examined either division of household chores or balancing between career and family responsibilities. Men express higher family life satisfaction in traditional families that include sexual division of labor (Nordenmark, 2017). Results of this study show that no statistically 
significant difference was found in regards to participant's family satisfaction and their education. Results of a study, which examined family satisfaction from the youth's perspective, conducted by Ljubetić and Reić Ercegovac (2010) indicate that young people whose parents have lower degree of education express higher family dissatisfaction and vice versa. One of the possible reasons why no statistically significant difference was found could lie in the small number of participants in certain groups such as "only finished elementary school".

In addition, examining the connection between family satisfaction and family structure, the results of this study are in accordance with similar studies in this field. For example, results of a study conducted by Antaramin, Huebner and Valois (2008) show the presence of statistically significant difference between the family structure and family satisfaction where young people from two-parent families express higher satisfaction than young people living in one-parent or cohabitation family. Furthermore, in their study, authors Levin, Dallago and Currie (2012) concluded that family structure is connected with life satisfaction of both boys and girls, especially in the age of 13 and 15 . Young people living in one-parent family express significantly higher life dissatisfaction in comparison to other family structures. According to descriptive analysis results, higher levels of dissatisfaction are present on certain subscale items from the members of one-parent families. One-parent families are often exposed to stressors which can lower family satisfaction such as family separation, conflicts between the family members as well as lower socio-economic status (Čudina-Obradović \& Obradović, 2006). However, visible difference in family satisfaction in regards to family structure cannot be determined due to the small number of one-parent families in the study.

Results indicating differences in evaluation of family satisfaction in regards to total monthly family income show the presence of statistically significant difference. To exemplify, the higher the monthly family income, the higher the family satisfaction. The results are in accordance with the results of previous studies conducted by Ajduković and Rajhvan Bulat (2012). The results of their study show that high school students who evaluate financial possibilities of their families as below average, express generally lower level of family satisfaction compared to high school students who evaluate financial possibilities of their families as above average. Additionally, similar results are obtained in the study by Ljubetić and Reić Ercegovac (2010) who concluded that young people living in wealthy families score significantly higher on family relationship and parental behavior satisfaction subscale compared to financially average or poor families. Furthermore, results of the study conducted by Rogošić (2015) showed that sum of family monthly income indicates borderline, but statistically significant, contribution to life satisfaction in which higher sum of monthly family income contributes to the higher level of life satisfaction. Financial satisfaction represents a significant predictor of life satisfaction, i.e. life satisfaction increases with better financial situation (Brkljačić \& Kaliterna Lipovčan, 2010; Knies, 2011). Brkljačić and Kaliterna Lipovčan (2010) emphasize that better financial situation affects life satisfaction only to a certain level after which further improvement of the situation does not affect the abovementioned satisfaction. However, it is important to highlight that the obtained results cannot be clearly interpreted as the categories within "total monthly income" variable were defined too broadly.

Lastly, by incorporating the aspects of family satisfaction into the "experiencing relationships" concepts between family members that include the ability to resolve conflicts, sharing positive experiences, the amount of time spent together as a family, family's concern for each other etc., the results of this study show highly scored items on the Family satisfaction subscale. To conclude, everything presented can be connected with results of a study conducted by Tuce and Fako (2014) that has confirmed the role of family flexibility and cohesion as well as family love and accepting as important protective factors that affect the adolescent's overall sense of life satisfaction. 


\section{Conclusion}

The massage about the importance of family as well as its leading position in the individual's development has been passed on through generations. Cohesion, togetherness, mutual trust, loyalty, support and lasting stability of mutually positive relationships represent expected characteristics of every family (even though, unfortunately, this is not always present). Despite the differences in viewpoints on family relationships, various theoretical analyses emphasize the importance of emotional dimension in parenthood, i.e. the importance of showing love and affection as well as accepting and mutual adapting to other family members. Family and its surroundings represent a discourse where both children and adolescents construct images of surrounding world, relationships within which they develop forms of social interaction. Family represents primary and realistically expected environment to encourage development, achieve satisfaction, acceptance and intimacy. During major life crises, family belonging as well as its support often play key role in one's survival. Individual's perspective of life satisfaction is one of the aspects of more successful functioning. Aims of this study were to examine the youth and their parents' perception of family satisfaction as well as analyze the differences in the mentioned perception in regards to sex and education of the participants, family structure and total family monthly income. The most significant results of the presented study state that both the youth and their parents express general family satisfaction. However, parents express higher satisfaction than the youth. Statistically significant differences in the participant's perception of satisfaction were found on family structure and total monthly family income variables. In that context, participants living in two-parent families express higher satisfaction than those living in oneparent families. Furthermore, the results show that the higher the total monthly family income, the higher the family satisfaction score.

The limitations of the study can be found in the number and the type of sample as higher number of randomly chosen participants is needed. Moreover, one limitation represents the inability to conduct multivariate statistics as the analysis' preconditions were not met. Suggestions for future research include thinking about more defined category specifications within independent variables, especially within total monthly family income variable. Lastly, the inclusion of every household member could potentially show significant results in the context of one's perception of family satisfaction.

\section{Acknowledgements}

This paper is the result of scientific research work on the "Empowering Families for the Development of Positive Relationships and Family Communion" project (led by Jasminka Zloković, code: uniri-societies - 18-6, 1132), which started in March 2019 with the financial support of the project by the University of Rijeka.

The authors declare no competing interests.

\section{References}

Ajduković, M., \& Rajhvajn Bulat, L. (2012). Doživljaj financijskog statusa obitelji i psihosocijalno funkcioniranje srednjoškolaca [Experience of family financial status and psychosocial functioning of high school students]. Revija za socijalnu politiku, 19(3), 233-254.

Antaramian, S. P., Huebner, E. S., \& Valois, R. F. (2008). Adolescent life satisfaction. Applied psychology: An International Review, 57, 112-126. 
Aračić, P., \& Nikodem, K. (2010). Važnost braka i obitelji u hrvatskom društvu. Analiza osnovnih pokazatelja u razdoblju od 1999. do 2008. godine [The importance of marriage and family in Croatian society. Analysis of basic indicators in the period from 1999 to 2008]. Bogoslovna Smotra, 8o(02), 623-642.

Baxter, L. A., \& Pederson, J. R. (2013). Perceived and ideal family communication patterns and family satisfaction for parents and their college-aged children. Journal of Family Communication, 13, 132-149.

Brkljačić, T., \& Kaliterna Lipovčan, Lj. (2010). Zadovoljstvo životom i osjećaj sreće kod studenata [Life satisfaction and a sense of happiness in students]. Suvremena psihologija, 13(2), 189-201.

Burgess, E. W. (Ed.) (1926). The urban community. Selected Papers from the Proceedings of American Sociological Society 1925. Illinois: The University of Chicago Press.

Cox, M. J., \& Paley, B. (1997). Families as systems. Annual Review of Psychology, 48, 243-267.

Čudina-Obradović, M., \& Obradović, J. (2006). Psihologija braka i obitelji [Psychology of marriage and family]. Zagreb: Golden marketing-Tehnička knjiga.

Čudina-Obradović, M., \& Obradović, J. (2003). Potpora roditeljstvu - izazovi i mogućnosti [Parental support - Challenges and opportunities]. Revija socijalne politike, 1O(1), 45-68.

Diener, E. (1984). Subjective well-being. Psychological Bulletin, 95(3), 542-575.

Elkind, D. (1995). The family in the postmodern world. National Forum, 75(3) 24.

Fujita, F., \& Diener, E. (2005). Life satisfaction set point: Stability and change. Journal of Personality and Social Psychology, 88(1), 158-164.

Janković, J. (2008). Obitelj u fokusu [Family in focus]. Zagreb: Etcetera.

Knies, G. (2011). Life satisfaction and material well-being of young people in the UK. In S. L. McFall \& C. Garrington (Eds.), Understanding society: early findings from the first wave of the uk's household longitudinal study (pp. 15-31). Institute for Social and Economic Research, University of Essex.

Kočo-Vukadin, I., Novak, M., \& Križan, H. (2016). Zadovoljstvo životom: individualna i obiteljska perspektiva [Life satisfaction: Individual and family perspective]. Kriminologija \& socijalna integracija: Časopis za kriminologiju, penologïju i poremećaje u ponašanju, 24(1), 84-115.

Levin, K. A., Dallago, L., \& Currie, C. (2012). The association between adolescent life satisfaction, family structure, family affluence and gender differences in parent-child communication. Social Indicators Research, 106(2), 287-305.

Ljubetić, M., \& Reić Ercegovac, I. (2010). Studentska percepcija obitelji i roditeljstva - kroskulturalna perspektiva [Student perception of family and parenthood - A cross-cultural perspective]. Život $i$ škola, 23(5-6), 35-56.

Ljubetić, M., Reić Ercegovac, I. \& Mandarić Vukušić, A. (2020). Percepcija obiteljske komunikacije adolescenata i njihovih roditelja [Perception of family communication of adolescents and their parents]. Nova prisutnost, 18(2), 279-293.

Milić, A. (2010). Porodica i izazovi globalne transformacije [Family and the challenges of global transformation]. In A. Milić et al. (Eds.), Vreme i porodica, Sociološka studija o porodičnoj transformacïi u savremenoj Srbiji (pp. 13-32). Beograd: Čigoja štampa, Insitut za sociološka istraživanja.

Nordenmark, M. (2017). The importance of job and family satisfaction for happiness among women and men in different gender regimes. Societies, 8(1), https://doi.org/10.3390/soc8010001

Olson, D. H. (2010). Family satisfaction scale. Minneapolis, MN, PREPARE/ENRICH, LLC, 2010, 1-6, 6.

Penezić, Z. (2006). Zadovoljstvo životom u adolescentnoj i odrasloj dobi [Life satisfaction in adolescence and adulthood]. Društvena istraživanja, 15(4-5), 643-669. 
J. Zloković, Z. Gregorović Belajić \& N. Čekolj - Family life satisfaction - Perception of the youth and ...

Rogošić, S. (2015). Životno zadovoljstvo budućih odgojitelja: utjecaji socijalnog, ekonomskog i ljudskog kapitala obitelji [Life satisfaction of future educators: the impacts of social, economic and human capital of the family]. Napredak, 156(3), 233-252

Roje Đapić, M., Buljan Flander, G., \& Prijatelj, K. (2020). Children behind closed doors due to COVID-19 isolation: Abuse, neglect and domestic violence. Archives of Psychiatry Research, 56, 181-192 https://doi.org/10.20471/dec.2020.56.02.06

Stacey, J. (1993). Good riddance to "the family": A response to David Pepenoe. Journal of Marriage and the Family, 55, 545-547.

Tuce, Đ., \& Fako, I. (2014). Odrednice zadovoljstva životom kod adolescenata [Determinants of life satisfaction in adolescents]. Psihologijske teme, 23(3), 407-433.

Zabriskie, R. B., \& McCormick, B. P. (2003). Parent and child perspectives of family leisure involvement and satisfaction with family life. Journal of Leisure Research, 35(2), 163-189.

Zloković, J., \& Čekolj, N. (2018). Osnaživanje obitelji za razvoj pozitivnih odnosa [Empowering families to develop positive relationships]. Rijeka: Filozofski fakultet.

Zloković, J., \& Lukajić, A. (2016). Osnaživanje obitelji kroz poticanje pozitivnih odnosa i obiteljske kohezije [Empowering the family through fostering positive relationships and family cohesion]. Zbornik Odseka za pedagogiju, Filozofski fakultet u Novom Sadu, Sveska 25/2016.

Zloković, J., \& Nenadić-Bilan, D. (2012). Neke odrednice zadovoljstva u obnašanju roditeljske uloge u odnosu na odabir odgojnih postupaka, Istraživanje pedagoških aspekata odnosa u obitelji [Some determinants of satisfaction in performing the parental role in relation to the choice of educational procedures. Research of pedagogical aspects of family relationships]. Školski vjesnik - Časopis za pedagoška i školska pitanja, 61(1-2) 191-210.

Zloković, J. (2012). Obiteljska kohezija i pozitivna komunikacija u funkciji osnaživanja suvremene obitelji Prinos istraživanju pedagoških aspekata odnosa u obitelji [Family cohesion and positive communication in the function of empowering the modern family - A contribution to the research of pedagogical aspects of family relationships]. Školski vjesnik - časopis za pedagogijsku teoriju i praksu, 61(3). 


\title{
Situational Map: A Strategy to Develop Critical Thinking in the Teaching of Scientific Research
}

\author{
Cecilia Alejandra Marambio Carrasco \& Carla Lobos \\ Andres Bello University, Santiago, CHILE \\ Faculty of Education and Social Sciences
}

Received: 30 November 2020 - Accepted: 21 December 2020 • Published Online: 25 December 2020

\begin{abstract}
The objective of the study is to support students in the rational, logical, and analytical process that they perform when faced with a scientific problem. This study uses qualitative methodology as its purpose is to present the strategy as learning stemming from the process of analysis, which is rooted on how to detect scientifically the research problem in the field of social sciences. A statistical analysis is made on the use and application of the diagram in a sample of 27 undergraduate students who have used the situational map in the elaboration of their theses. The trend shows that $92.6 \%$ of respondents achieved concluding their research processes of thesis work, at the planned time, and their results were consistent with their hypothesis and/or purposes. The creation of this strategy is a support for students, who have not developed their ability to think critically and establish relationships between concepts and theories in the execution of scientific research.
\end{abstract}

Keywords: cognition, epistemology, information and communication, writing, research work.

\section{Introduction}

University students have weaknesses in the execution of information processing, their deficit to perform abstractions in the reading of theoretical documents and the creation of constructs is very high, therefore, the work to explain the scientific findings is precarious in the process of the written transfer. It is necessary to teach students, who begin the study in scientific processes, to think in a hypothetic-deductive way, to establish discussions concerning the theories, so that they can analyze and create axioms about the studies approached in their investigations. For this, critical thinking must be applied: "Critical Thinking is characterized by being a higherorder thinking skill, in which knowledge, experiences, dispositions (attitudes or habits of the mind) and intellectual abilities are involved" (Carbogim, Oliveira \& Püschel, 2016: 5), such skills are identified as analytical capacity, judging based on criteria or standards, evaluation of the credibility of the evidence, focus on accurate results.

We must teach according to how our brain learns, that is, establishing connections through, the processing of information which performs cognitive thinking tasks of higher-order. If they are properly stimulated, students will be able to implement advanced processes such as critical thinking, which is the ability to process and rework the information received for an adequate resolution of problems and decision making; demonstrating, in turn, a creative thinking,

(C) Authors. Terms and conditions of Creative Commons Attribution 4.0 International (CC BY 4.0) apply. Correspondence: Cecilia Alejandra Marambio Carrasco (PhD), Andres Bello University, Faculty of Education and Social Sciences, Santiago, CHILE. E-mail: cecilia.marambio@unab.cl. 
which is recognized as the ability to generate alternative ideas and divergent solutions. It should be noted that, from this perspective, understanding concepts, theories, and constructs helps to advance problem-solving processes to create new knowledge in the different areas investigated. (Marambio, 2017: 86).

\subsection{Neuroscientific studies that underpin the Situational Map Model}

Life is conceived without the need for a nervous system and a brain, as for example in unicellular organisms, the biological structures in their evolution become more complex and acquire distinctive features. In the case of the human being, his brain has as a distinctive feature the ability to create maps. When the brain produces maps, it is informing itself. This information guides its motor behavior, registers its experiences and archives them to be used when required, to carry out a successful action in front of a certain stimulus.

When the brain creates maps, it conceives them as images applied to reasoning. These images are not photographic records but mental patterns of abstract thought, therefore, when we talk about mental pattern, neuronal pattern or map, we refer to the activity in the brain.

By achieving mastery of learning, maps are constructed, because interactions between the cognoscent object and the cognoscent subject are needed. The brain registers and mimics everything that happens outside of it and archives it inside. The construction of maps never stops and the mind passes to an internal reserve the experiences of the neuronal pattern, they become internal experiences that only the subject can know and interpret. "When maps are entrusted to memory and can be revived through imaginative memory, it is possible to plan and invent better answers" (Damasio, 2012: 123). In this way, the brain activates mental and neuronal processes that allow the subject to think and rationalize his actions to later concretize in learning that will allow him to generate knowledge

Words are mental patterns that transmit ideas, they are auditory and visual images. For Damasio (2012), language flows under this neural map structure: "Likewise, printed letters [...] are first processed by the reader as verbal images (visual images of written language), before the action it exerts on the brain promotes the evocation of other non-verbal images" (p. 120), which allows the mind to expose concepts that correspond to words with an understandable meaning. The mind builds itself, through the combination of real and remembered images, which are always changing, because they correspond to events taking place in the outside world.

This complex process of training cognition is favored by the appearance of neurons, which are described as body cells that carry signals and are capable of transmitting and receiving messages, developing increasingly complex and evolved mental processes that act by emitting electrical impulses to transmit the acquired information.

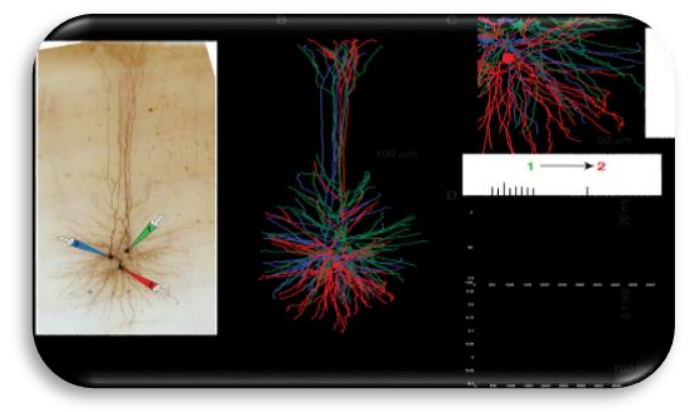

Figure 1. Human Neurons (Source: The Human Brain Proyect, 2020) 
What is known today about the functioning of human neurons is found in the HBP registry (2020). Damasio (2012) explains about their function, the neurons evolved in their functioning and they were multiplying, making complex in the actions until generating mental processes that progressed to the conscience: "Today we know that the secret of this tendency to a growing complexity is closely related to the number of neurons available in a certain organism, and what is not less important, with the patterns according to which these neurons are organized forming circuits whose scale is increasing" (Damasio, 2012: 427), as it can be observed in Figure 1.

These studies provide knowledge about how the brain learns, and how it is possible to enhance thinking skills from the structure of a mental pattern, which allows the creation of pedagogical processes focused on cognition, generating the construction of mental maps to make higher education students who are developing research processes, enhance their scientific critical thinking.

\subsection{Design of the Situational Map}

The objective of the study is to support students in the rational, logical, and analytical process that they perform when faced with a scientific problem, as well as in the development of writing their inquiries. A mental pattern for the organization of ideas on the phenomenon to be investigated called "situational map" is designed. This mental pattern is composed of key elements of the structure of observation of the phenomenon under study and supports the descriptive realization of constructs, which have been elaborated from the same research to generate new knowledge

The situational map is a mental pattern designed by the researcher, to structure research focusing on the applications that affect the interactions of the subject under observation. The application of this strategy provides a formula for analyzing reality to identify, with certainty, the central theme of the phenomenon that will be analysed in the research, with the possibility of giving varied solutions to the problem referred to by designing development projects. Its design responds to an adaptation of the technique "The Tree of Problems" also called "Tree Diagram" (Martín, 2001: 112), a technique that is used for the analysis of the realities of social systems to identify authentic problems that affect an organizational structure, in order to develop solution strategies. Why is this diagram designed with a map structure? It is because it is proven that the brain maps out everything that learns and establishes internal relationships: "The activity of mapping is not limited to visual patterns, but applies to any pattern of sensory type in which the brain intervenes building it" (Damasio, 2010: 116).

The Situational Map is synthesized in a mental pattern that provides a structured and graphic view on the systemic development of the use of means and actions to identify the problem to be investigated, as well as to determine its solutions or achieve study objectives, allowing to organize the research process to give a logical and semantic structure. From this perspective, it is understood that logic represents the structure of human knowledge, but not reality, and semantics is interested in organizing, through language, the constructs that explain reality and thus is also at the service of the development of human knowledge (Bungue, 2004). In this way, the situational map becomes an instrument that helps the researcher to think critically about what and how to approach the research process to make its design and subsequent development.

In the situational map, the itinerary of research work to develop each instance of investigation in a precise way and without distorting the central focus of the study is captured.

Below, the Situational Map is presented, where the research project is defined and the beliefs of the context about the problem to be studied are established. The beliefs generate customs that take root in the educational communities causing authentic problems, which the researchers 
will have to detect through a retrospective analysis. They will then point out the criteria that allow improvements to be made to the phenomenon under study. From this perspective, they will indicate the possible products that from the process of investigation will be contributed to overcome the problems. Then, from a prospective analysis, they will outline the innovation or renewal of the context under study.

Figure 2 shows the structure of the Situational Map and the mental process that the students must undertake to approach their research problem, following steps 1 to 6 as a sequence that allows them to construct the mental map of their research and focus on the real problem of the situated context.

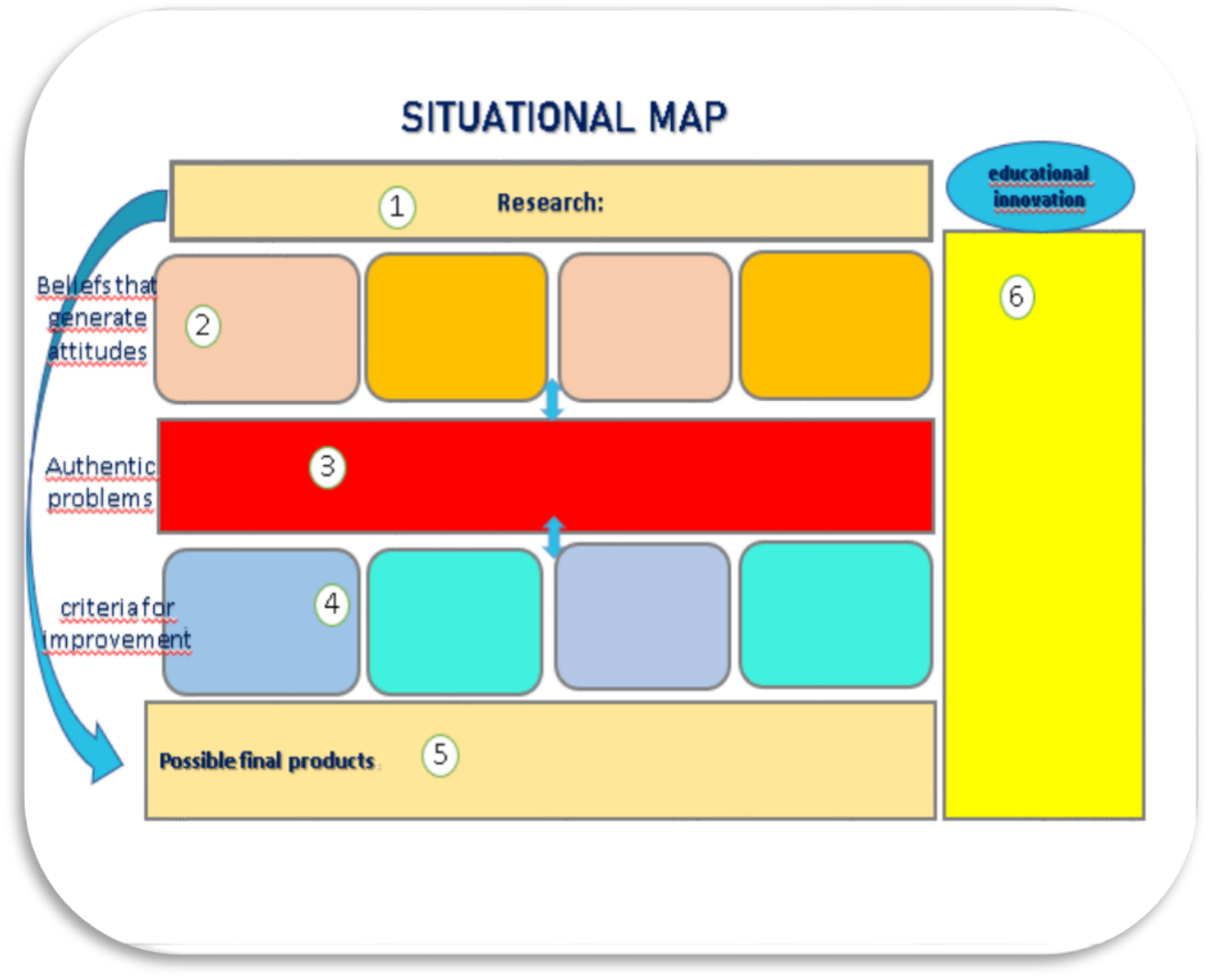

Figure 2. Situational map (Source: Own elaboration)

(1) This is a mental pattern that helps the student to think scientifically about how to define the problem under study by critically analyzing the context to be investigated.

(2) They must think and reflect on the beliefs of the environment in relation to the problem they are going to study.

(3) They then identify the real problems; usually the problems arise from false beliefs that are embedded in the community under study.

(4) The criteria for improvement are the philosophical ideas or theoretical constructs, which will support the search for the solution to the problem.

(5) To consider all the possible ways to solve the problem under study.

(6) The researchers reflect and analyze critically on the context projecting the solution of the problems, exposing; how it would be? Prospective vision of the research result. 


\section{Method}

This study uses qualitative methodology as its purpose is to present the strategy as learning stemming from the process of analysis, which is rooted on how to detect scientifically the research problem in the field of social sciences. To this end, a retrospective analysis of the teacher's diary was carried out, since she has applied this strategy since 2009 to date in its Seminar classes. The purpose of applying this research teaching strategy is for students to focus their problem of inquiry and, in the course of the research process, not to defocus their initial problem. This allows them to advance more quickly in the course of the investigation, be accurate in their hypotheses, and specify their exploration product in a concrete proposal of innovation to the reality in the study of the field of Social Sciences.

\subsection{Research design}

The research design is exploratory and descriptive, because it focuses on providing new knowledge in a new model of development of scientific thought for students in higher education, who begin their research work in their undergraduate thesis. The model called Situational Map is created by the researcher to support her undergraduate students, therefore, it is a new study that does not have reports of previous studies since the researcher is developing with her research theoretical contributions, also, it seeks to "develop a concept, a model, a hypothesis for future research" (McMillan \& Schumacher, 2007: 403).

\subsection{Population and sample}

The sample is purposeful, applying the strategy of Scenario Selection (McMillan \& Schumacher, 2007), which implies that the space where the survey and observation were applied was selected by the researcher. In this case the scenario consisted of 27 students who developed their thesis in the years 2017 to 2020 at the Santiago Campus of the Andrés Bello University in the Early Childhood Education Program.

The total population corresponds to 50 students who applied the Situation Map in the Thesis work, and to whom the survey was sent. 27 of them answered, corresponding to $54 \%$ of the total population.

Table 1 specifies the number of students per year who completed the Seminary Degree in the Nursery Education Program, corresponding to the researcher's courses.

Table 1. Total population

\begin{tabular}{ll}
\hline Year & $\mathbf{N}^{\circ}$ of students \\
\hline 2017 & 12 \\
2018 & 15 \\
2019 & 16 \\
2020 & 7 \\
\hline Total & 50 \\
\hline Fuente: Elaboración propia
\end{tabular}

\subsection{Data collection instrument}

In order to know the students' perceptions about the application of the Situational Map in the process of their thesis research, a mixed opinion survey with 6 indicators is designed and answered under the Likert scale, where the respondent must rate his or her answer from "Totally agree" to "Totally disagree", an item where he or she must rate the use of the Situational 
Map from 1 to 10 being 10 excellent and 1 very deficient, as well as an open question, where the student must express his or her reflective opinion about the usefulness of the Situational Map. The survey is applied via email through Google Documents.

The instrument was validated by expert judgment understanding that this process is a consultation as explained below: "instrument will be submitted to expert judgment. Experts are people whose specialization, professional, academic or research experience related to the topic of research allows them to evaluate, in content and form" (Soriano, 2014: 25).

The characteristic features of the validating judges are the following:

Table 2. Validating judges

\begin{tabular}{|c|c|c|c|c|}
\hline Judge & Degree & University & Position & $\begin{array}{c}\text { Years of } \\
\text { experience }\end{array}$ \\
\hline $\mathbf{1}$ & Phd & UMCE & $\begin{array}{l}\text { Formación } \\
\text { Integra Program } \\
\text { Coordinator }\end{array}$ & 6 \\
\hline 2 & Phd & UCSH & $\begin{array}{l}\text { Academic } \\
\text { Secretary }\end{array}$ & 1 \\
\hline 3 & Phd & $\begin{array}{l}\text { Durango } \\
\text { University, } \\
\text { México }\end{array}$ & $\begin{array}{l}\text { Research } \\
\text { Director }\end{array}$ & 20 \\
\hline 4 & MA & UNAB & $\begin{array}{l}\text { Early Childhood } \\
\text { program } \\
\text { Director }\end{array}$ & 25 \\
\hline 5 & MA & UDLA & $\begin{array}{l}\text { Early Childhood } \\
\text { program } \\
\text { Director }\end{array}$ & 13 \\
\hline 6 & MA & UDP & $\begin{array}{c}\text { Diploma } \\
\text { Coordinator } \\
\text { Center for } \\
\text { Cognitive } \\
\text { Development }\end{array}$ & 9 \\
\hline
\end{tabular}

Source: Own Elaboration

Judges were asked to evaluate each indicator by the criteria of relevance and pertinence, according to the following table of values:

Table 3. Validation protocol for judges

1.- Does not meet the criteria

2.- Meets poorly

3.- Partially Meets

4.- Meets criteria in its main features

5.- Completely meets criteria in all its main features

Source: own elaboration 
Obtaining the following result:

On average, judges validate $\mathrm{r}$ by 4.5 , with a maximum value of 5 .

Figure 3 shows the average value of each indicator, which fluctuates between 4.1 and 4.8, with indicators 9 and 10 being the most relevant.

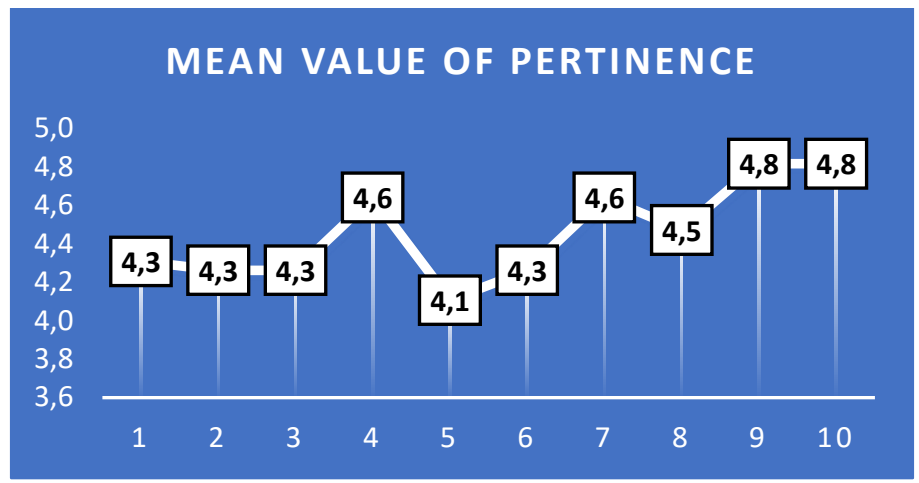

Figure 3. Pertinence criteria validation (Source: Own elaboration)

On average, judges validate pertinence by 4.74, with a maximum value of 5 for the entire instrument. Figure 4 shows that each indicator is evaluated by an average of 4.5 to 5 , according to the evaluation table, with indicators 9 and 10 getting a higher score on relevance than on pertinence.

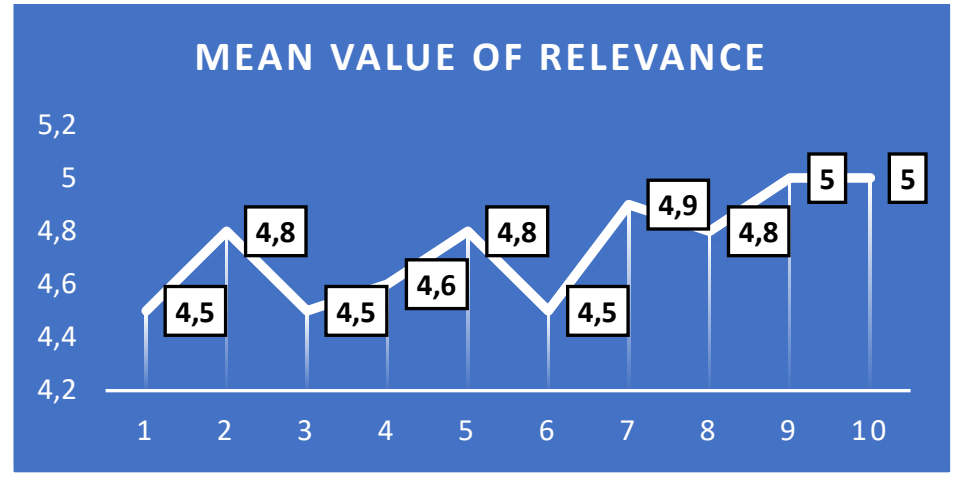

Figure 4. Relevance criteria validation (Source: Own elaboration)

\section{Results}

Below, the most relevant data obtained from the opinion survey of the students who applied the Situational Map in the elaboration of their degree thesis is presented. These students contribute their perspectives of construct in the use of the mental pattern created to support them in their processes of critical thinking in the definition of the problem to be investigated.

\subsection{Opinion survey results}

The results of the survey are analyzed by frequency of responses, identifying the trends of the surveyed population in relation to their opinion on how the Situational Map contributed to their thesis research work.

In response to the questions, $92.6 \%$ of those surveyed expressed complete agreement with the fact that it allowed them to organize their ideas at the beginning of the research process, 
as can be seen in Figure 5. It is noted that students concentrated their response tendencies on the "Agree and Strongly Agree" options, leaving the other options blank.

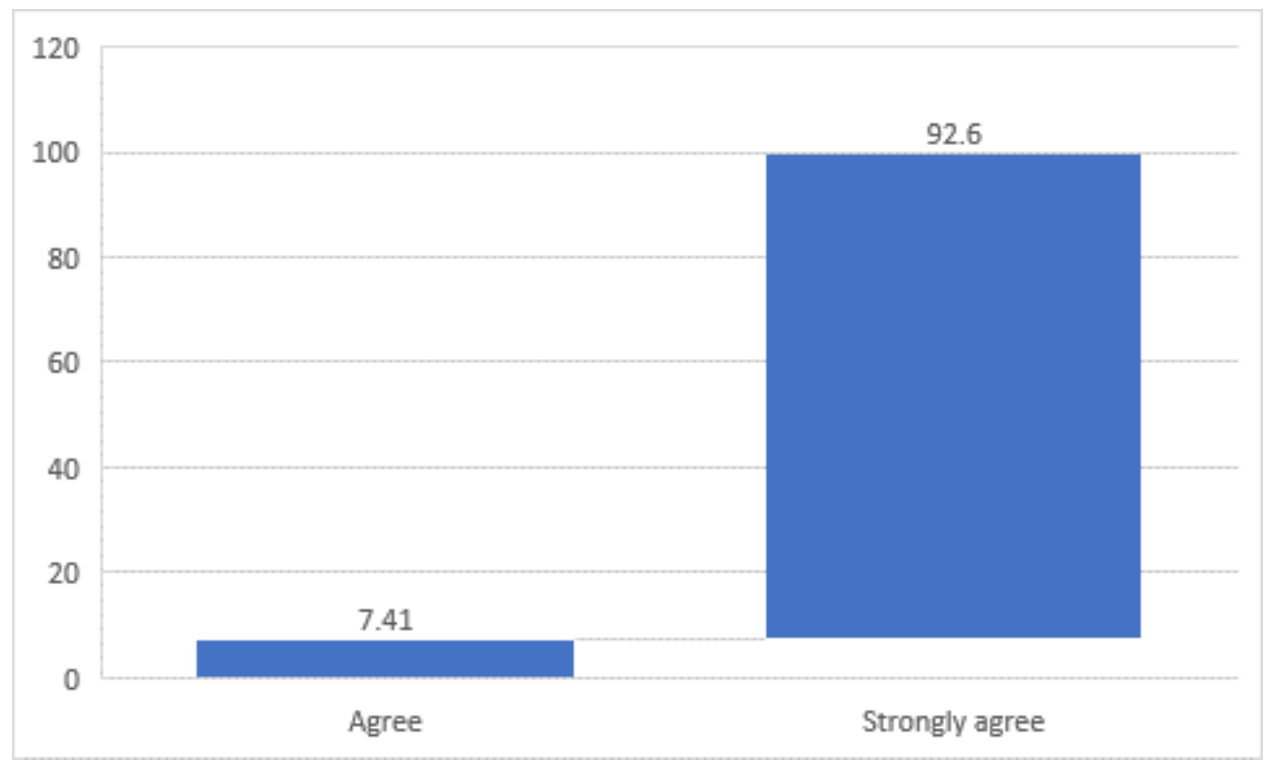

Source: Own elaboration

Figure 5. Question 1: The construction of the map allowed you to organize your research ideas

In response to the question whether in the process of working on the Situational Map they activated their processes of critical thinking, carrying out logical analysis of realities, which implies questioning the situated context in order to accurately define the problem to be investigated, $81.5 \%$ of the population surveyed expressed that they were in total agreement with this indicator, that is, they did achieve processes of logical and critical analysis. The response trend also moves between the "Agree" and "Strongly Agree" options only, as can be seen in Figure 6.

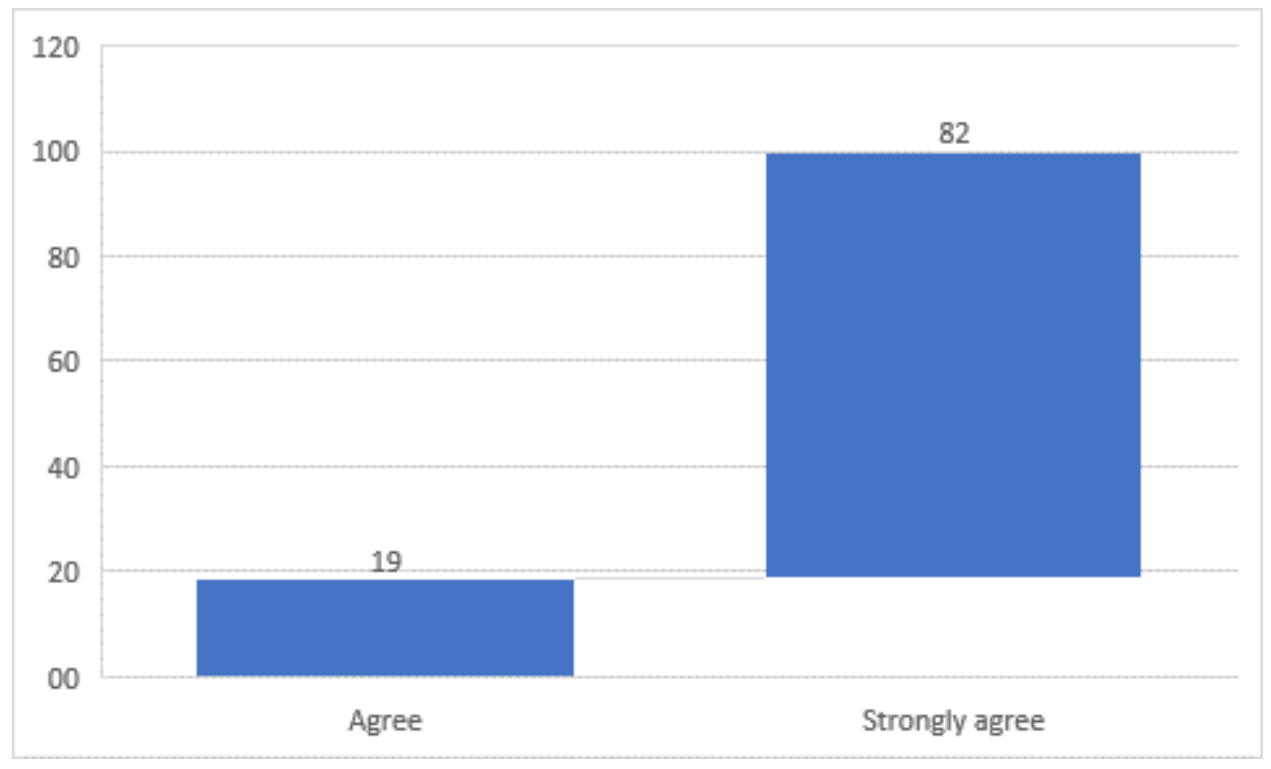

Source: Own elaboration

Figure 6. Question 2: In the process of preparing the situational map, a logical and critical analysis of the reality to be investigated was carried out 
One of the objectives of the situational map is to help students focus on the specific problems of the research, so that when they advance in the development of the reference framework and application of the instruments, they do not lose focus on their main research objective, and thus respond to the needs of the reality under study. In the consultation, 74.1\% of the participants stated that they "totally agree" that the Situation Map allowed them to focus the search for information on the problem detected in their critical analysis, as shown in Figure 7.

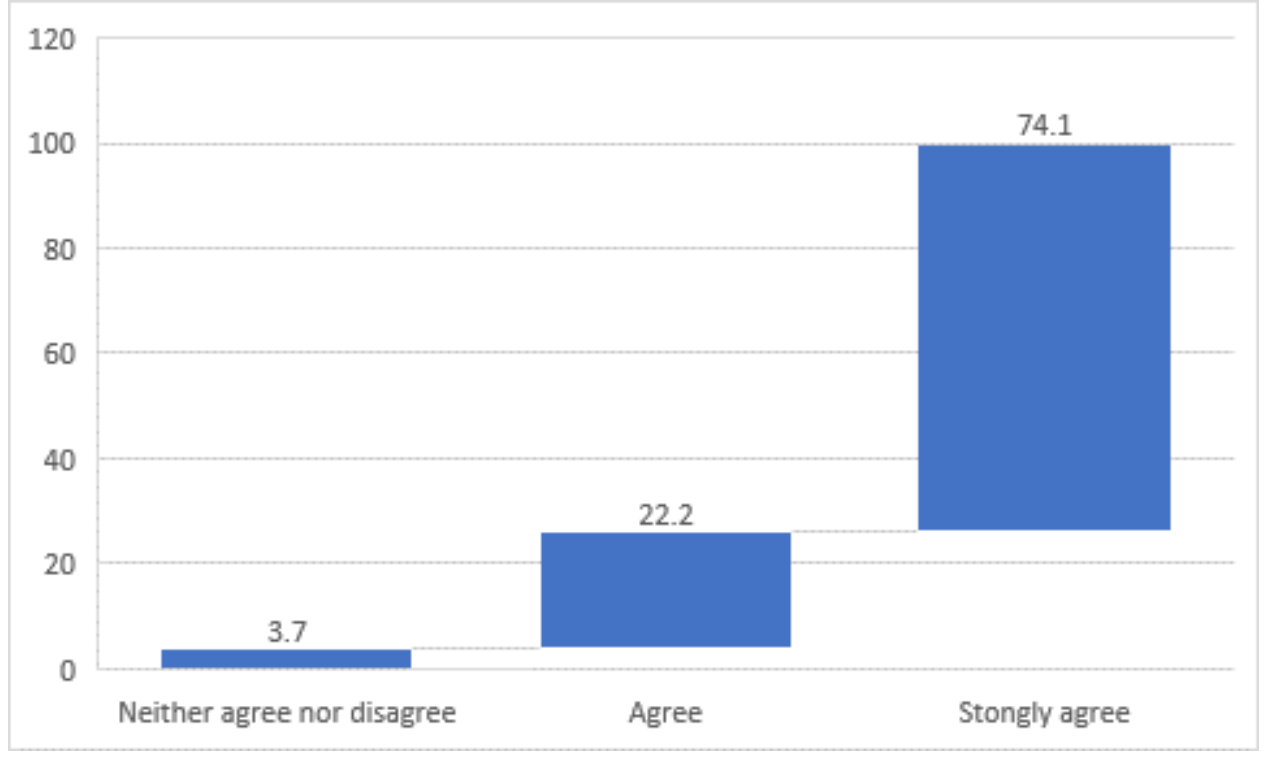

Source: Own elaboration

Figure 7. Question 5: In the development of the theoretical framework, the situational map made it possible to focus the search for information on the specific problem

The participants were asked about the value they assign to the Situational Map. According to their experience of application in the construction of their degree thesis, $81.7 \%$ of the students rated it as excellent. The tendency of the population is to rate the Map between 8 and 10, with positive ratings regarding the vision of the Situational Map as a contribution to their work on the thesis. The $\mathrm{R}$ index indicates at its value of 0,2073 that there is a positive correlation, but with a high dispersion in the trend.

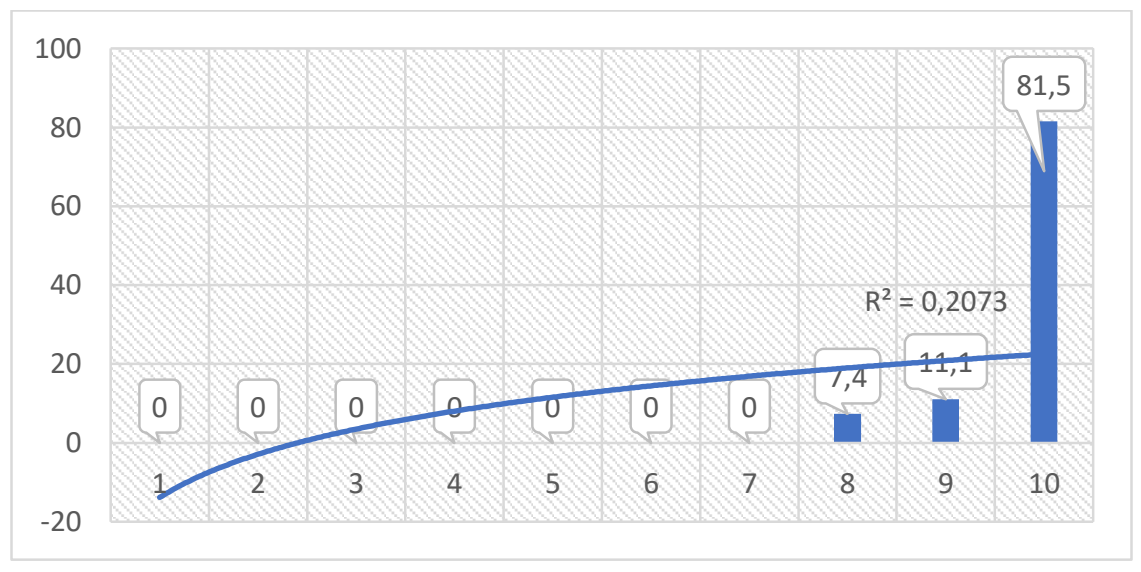

Source: Own Elaboration

Figure 8. Question 9: According to the scale of 1 to 10, how do you evaluate the situational map in the support given in the construction of your thesis? 1 being very deficient and 10 excellent 
In indicator 10 an open-ended question is asked: Explain why you rated the Situation Map in that way, provide reasons. The answers are analyzed by iteration and the most frequent ones are represented in the following student records:

E1. Because it was a tool that made it easier for us to organize the research from the very beginning, it allowed us to point out the path we had to follow in order not to lose the research focus.

E3. Because the situational map was fundamental to guide us in our research and to focus on our research topic and not to deviate from the central theme.

E4. Because it gave us an order, allowed us to organize ideas and guide our research, from where to investigate and the limits to stay within the research topic.

E6. It is an excellent method to plan an investigation, it organizes ideas and key processes for the execution of the investigation.

E7. Although it is true that in order to sort out our thesis it was of great help to us, even so, there were many moments when we got a little lost in terms of the theoretical framework.

E8. The situational map is a tool that allowed us from the beginning to organize the ideas that will carry out the development of the research.

E13. Because the structure was very clear to the reader, and to follow a behavioral line of construction for the thesis.

E19.The situational map, which I have used for the third time, allows me to observe the reality and context of study from an external and objective viewpoint. In this way, the problematization is generated in an easy way, through a logical order, eliminating distracting concepts from the object of study.

E2O. First, it helped us to identify the problem to be studied. To order the ideas, beliefs, to think which are the problems that would be authentic in our research. To search for strategies, improvements and to reach a final product. It is a very good instrument to be able to organize a research since it guides step by step.

E21. Because when researching, a lot of information is collected, therefore, it is easy to lose the initial direction of the research. The situational map allows you not to deviate from your central theme of study.

In the expressions supported by the participants, the usefulness in focusing and identifying the research problem, the organization of ideas and the planning of the research structure stand out.

\subsection{Performance of students in degree seminar}

The evaluations of the students achieved in the final process of the completion of their degree thesis, where they applied the Situational Map, corroborate that the mental pattern allowed them to advance in their research in the estimated time, submitting it on the planned dates. Likewise, their grades reach a percentage of achievement of 80 to $90 \%$ in a scale from 1 to 7 , being the grades from 6 to 7 the maximum of approval and the grade 4 the minimum of approval. Between 1 and 3.9 are failing grades.

In 2017 the application of the Situation Map was carried out with 2 groups of graduate seminar students. Only one of them is applied the Mental Pattern of the Situational Map and is taught to work on critical thinking in the categories of perspective analysis and argumentation. The result is that the group that worked on their research process with the application of the Situational Map obtained a final grade of 6.4 (outstanding), and the control group where the mental pattern was not applied or taught had a high failure rate, as can be seen in Figure 9. 


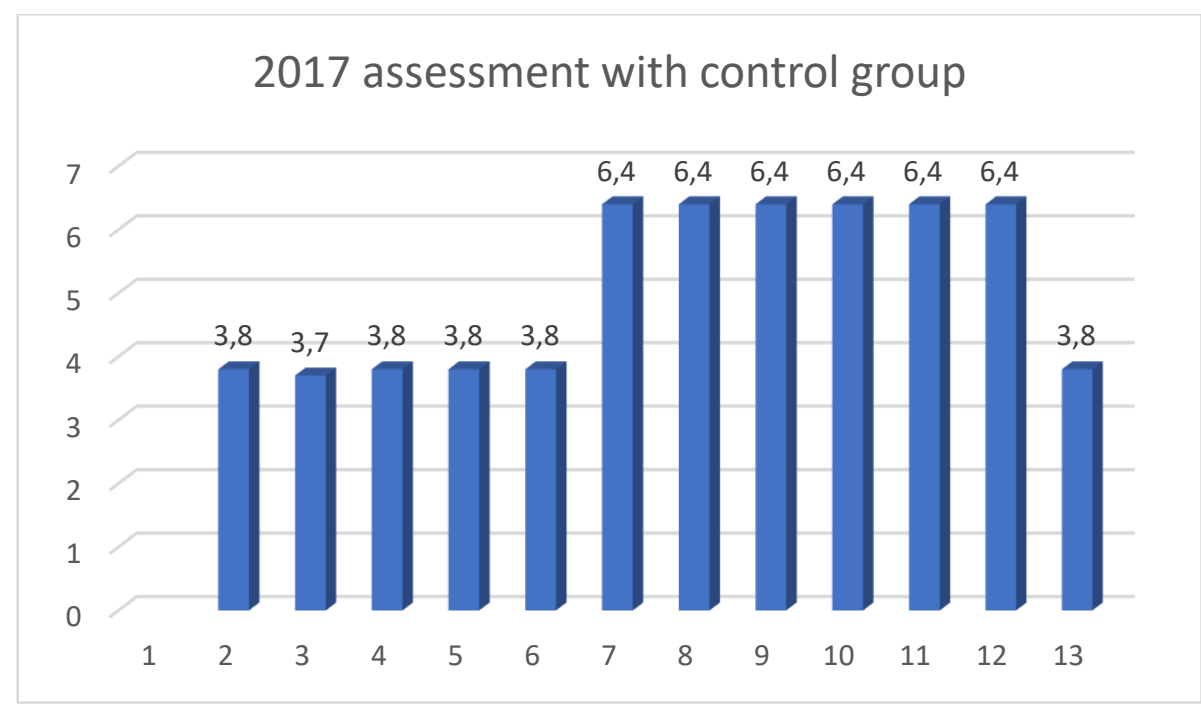

Source: Own elaboration

Figure 9. Degree thesis assessment result

A synthesis of the averages per year is made, with the grades obtained by the 50 students between 2017 and 2020 in the Grade Seminar subject, with which it can be determined that the application of the Situational Map, as a mental pattern helps to develop scientific thinking in higher education students. This is evidenced in the achievements of their evaluations that are increasing as students acquire mastery of critical thinking skills strengthened in the application of the situational map.

Figure 10 shows that the scores increase to 6.61 in the year 2020, and the $\mathrm{R}$ index of correlation corresponds to 0.9907 , which indicates that it shows a positive correlation, with a strong trend among the variables and a lower dispersion.

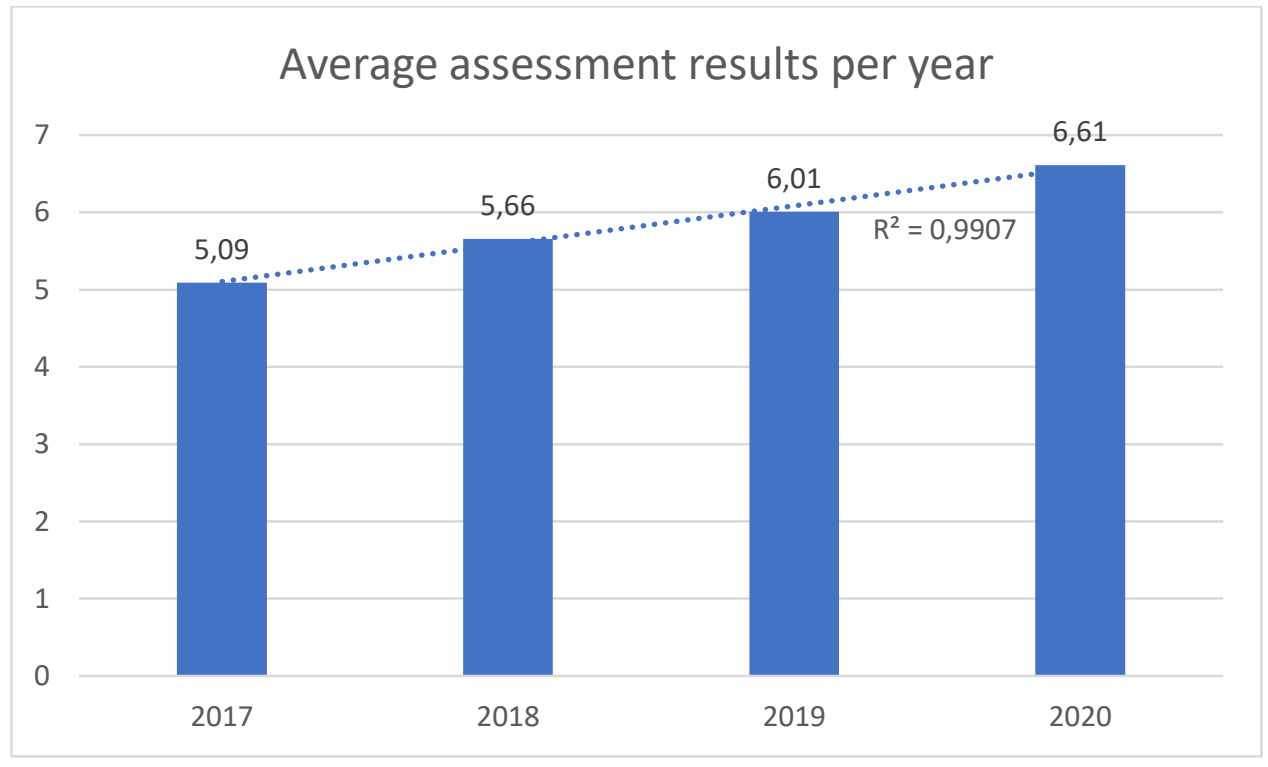

Source: Own elaboration

Figure 10. Thesis average result per year 


\section{Discussion}

According to Barrera (2019), establishing an epistemic turn involves rationalizing all the theories exposed and analyzed with a proper approach to generate a model of change or innovation in the processes being investigated. In the deepening of this analysis, a conceptual turn will be established that implies the ways of interpreting research, considered as a process susceptible of being known and of giving access to significant variants referred to its scientific constitution and of interest to create, construct and propose extensions of new studies, generate new knowledge in this case in the matter of the development of scientific thought in students of higher education. The aim is to strengthen critical thinking, to lead the student to elevated processes of his or her cognition mainly for the development of research in all areas, for which it is explained that:

With the progress of the sciences linked to education, especially the development of neuroscience, a multiplicity of theoretical analyses on learning can be found; today it is understood as mastery, the modification and use of this knowledge with the aim of transforming reality (Marambio, 2017: 85).

Marambio (2017) confirms that learning processes are conducive to the development of new knowledge and as stated by Damasio (2010), subjects learn from the progress of their brain when faced with the plasticity and modification that occurs in mental processes when the person is exposed to new information and the brain records it by creating mental maps. In this way, the brain has acquired the ability to store information in formats called mental patterns, which allows access to all knowledge accumulated throughout his life and are indelible as they are part of a metacognitive learning, processed for a long time. For this reason, the researcher modeled the Situation Map to induce the stimulation of critical thinking and make the brain of her students evolve into mental processes that generate a mental pattern of cognition and mastery of scientific research thinking.

Research results show that the mental pattern manages to give scientific focus to the mental process of students who apply the Situational Map in their undergraduate thesis research, evidenced in their high grades.

\section{Conclusions}

As a result, this strategy, called Situational Map, allows the researcher to achieve a continuous progression of the inquiry that produces a rigorous analytical study with internal and external validity (Reguera, 2008). The trend shows that $92.6 \%$ of respondents have achieved that their research processes of their thesis work, concluded at the planned time, their results were consistent with their hypothesis and/or purposes, and the grades obtained were between 6,0 and 6.61. They observed that their abilities to perform data interpretation and critical analysis of the results evolved.

The creation of this strategy is a support for students, who have not developed their ability to think critically and establish relationships and analysis between concepts and theories in the execution of scientific research. Latin American schools are not training students on this field; therefore, they reach higher education with this deficit in the development of their cognitive skills.

Pedagogues raise the relevance of developing critical thinking with skills of perspective analysis, comparison and abstraction in order to generate scientists who contribute new knowledge in all areas of life and sustainability. 


\section{Acknowledgements}

This research did not receive any specific grant from funding agencies in the public commercial, or not-for-profit sectors.

The authors declare no competing interests.

\section{References}

Barrera, M. (2019). Comunicación: El giro epistémico. LOGOI Revista de Fílosofía, 21(36), 99-106. http://revistasenlinea.saber.ucab.edu.ve/temas/index.php/logoi/article/view/4522.

Bunge, M. (2008). Semántica I. Sentido y referencia. Barcelona: Gedisa editorial.

Carbogim, F. C., Oliveira, L. B., \& Püschel, V. A. A. (2016). Pensamiento crítico: análisis del concepto bajo la óptica evolucionista de Rodgers. Rev. Latino-Am. Enfermagem, 24. https://doi.org/10.1590/1518-8345.1191.2785

Damasio, A. (2010). Y el Cerebro creó al Hombre ¿Cómo pudo el cerebro generar emociones sentimientos, ideas y el yo? Barcelona: Booket.

HBP (2020). Human brain project: Understanding cognition.

https://www.humanbrainproject.eu/en/understanding-cognition/.

McMillan, J., \& Schumcher, S. (2007). Investigación educativa. Madrid: PEARSON/Addison Wesley.

Marambio, C. (2017). Estrategias para estimular competencias cognitivas superiores en estudiantes universitarios. Revista Contextos, 38(2) [en línea]. http://www.revistas.umce.cl/index.php/contextos/article/view/1336/1378.

Martín, E. (2001). Gestión de Instituciones Educativas Inteligentes. Un manual para gestionar cualquier tipo de organización. Madrid: Mc Graw Hill.

Reguera, A. (2008). Metodología de la investigación lingüística: prácticas de la escritura. Córdoba: Editorial Brujas.

Soriano, A. M. (2014). Diseño y validación de instrumentos de medición. Diálogos, 14, 19-40. 
C. A. Marambio Carrasco \& C. Lobos Stevens - Situational Map: A Strategy to Develop Critical Thinking... 


\title{
Application of Problematic Situational Tasks Method at Russian as A Foreign Language Classes in Technical High School
}

\author{
Elena Shtekhman \\ Russian State Academy of Intellectual Property, Moscow, RUSSIAN FEDERATION \\ Yuliya Melnik
}

The Military University of the Ministry of Defense of the Russian Federation, Moscow, RUSSIAN FEDERATION

Anastasia Zhurova

Dostoevsky Omsk State University, Omsk, RUSSIAN FEDERATION

Received: 19 October 2020 • Accepted: 28 November 2020 • Published Online: 25 December 2020

Abstract

The article discusses application of situational tasks method in teaching Russian as a foreign language course in technical high school. Being educational, situational task is formulated in terms and conditions student may face in future professional activity. The task is a problem solution which foreign students need to find by independent analysis and synthesis of necessary information and providing an answer in Russian. Particular emphasis is placed on the improvement of speaking skills. The method promotes vocabulary expansion, vigorous speech development, working out appropriate speech behavior in real communication. Solving problematic situational task students learn about peculiarities of implementation of technical discourse in engineering activity. Practical orientation of situational tasks involves solution of them by using obtained knowledge in different topics in practice. Topics are closely connected with acquiring qualification. Components included into a task, requirements and methodology of tasks development have been described as well as examples of such tasks provided.

Keywords: Russian as a foreign language, situational task, language development, language for specific purposes, technical discourse.

\section{Introduction}

Modern higher school is in the permanent state of redesigning and is a subject to endless changes. So it has to appeal to new forms and methods of teaching that would let achieve its objectives on training highly qualified graduates with developed competences mentioned in the state educational standards on main majors.

Educational process demands permanent improvement since priorities shifting and social values changes are going on. Independent learning activity and creative thinking as the key elements of education result are the main features of it. Both practitioners and theorists of

(C) Authors. Terms and conditions of Creative Commons Attribution 4.0 International (CC BY 4.0) apply. Correspondence: Elena Shtekhman (PhD), Russian State Academy of Intellectual Property, Department of General Education, Moscow, RUSSIAN FEDERATION. E-mail: shte-elena@yandex.ru. 
education started to look for the most effective forms and methods of teaching. Method of situational tasks could be classified as one of the most interesting and demanded. The development of active teaching methods, in particular, situational tasks, stems from the fact that today education has different goals. They are acquisition of knowledge by students as well as professionally oriented thinking, communication and creative skills development and training of personal vision on occurred problems.

- Situational tasks method as a systematic application of tasks aimed at solution of practicable situation that targeted at conscious acquisition by students of the content of studied subject and oriented at building necessary for future profession competences.

- Situational tasks encourage future specialists to activate mental activity and are aimed at selfdetermination of students who create new (heuristics) problem solution.

- Situational tasks let foreign students develop skills which are important for their professional, educational and vocational communication competences.

Teaching in technical higher school is becoming more practically oriented. Application of mentioned situations in higher school let imitate as real as possible the communication in the conditions of professional activity which may happen in real life of future graduates.

For a long time method of situational tasks was used only in teaching technical disciplines (Budarin, 2010; Verevkina, 2014; Vishnyakova, 2011). Nowadays we can notice the tendency of application the mentioned method in foreign languages teaching, in particular, Russian. That is why the goal of our research is to identify the essence and effectiveness of situational tasks method which is applied in the process of teaching in higher school. Also it is used to create a set of situational tasks which helps to build the main language, speech and communication competences at students of technical department studying Russian as a foreign language.

Research objectives:

(1) to determine the content, peculiarities and place of situational tasks method in the system of teaching methods in modern higher school;

(2) to determine the potential of situational tasks method application in teaching Russian as a foreign language.

The present article discusses the potential of situational tasks method application in teaching Russian as a foreign language course. The emphasis is put on practical orientation of situational tasks which let improve speaking skills in classroom conditions almost similar to real ones. In the process of solving a situational task students figure out peculiarities of technical discourse in professional activity.

\section{Methodological procedures and theoretical base of the research}

Two approaches lie at the core of the research. Person activity approach defines subjective position of a student in the process of learning. The development of personality undergoes through enrichment and transformation of subjective experience. Inclusive approach strives to the learning and transforming of pedagogical activity. Ideas of outcome-based approach in education are taken as foundation of selection and content of professional education.

Theoretical base of the research is made up of papers devoted to the development and application of situational tasks method in modern pedagogics (Budarin, 2010; Khalilova, 2012; Ovchinnikova, 2014; Verevkina, 2014; Zapevina, 2014; Zharavina, 2014; Zhuikov, 2014, and others), case method (Adonina, 2012; Fesenko, Fedyaeva \& Bestsennaya, 2017; Leonhard, 2012; Passov, 2010, and others), in teaching foreign languages (Chernyshov, 2015; Glazyrina, 2014; Lah, 
2017; Novikova, Zorina \& Kortunov, 2014). Situational tasks method in teaching Russian as a foreign language hasn't been described in details. So, it is a matter of concern for further studying and description (Kirova \& Melnik, 2019; Shtekhman \& Melnik, 2018; Shtekhman \& Usatuk, 2018; Simulation methods in ..., 2017).

In the process of the research methods such as analysis, synthesis, generalization (after studying scientific literature, regulations, educational standards of higher school, curricular documents), development of experimental situational tasks on topics of practical Russian as a foreign language course were used to solve the problem.

\section{The main body}

\subsection{The method of educational situational tasks}

In the scientific society the question of identifying the place of situational tasks is still being discussed. First of all, there are several names for the mentioned phenomenon in pedagogics. The method of situational tasks may be named as situational analysis (Volkova, 2014; Rozanova, 2013), particular situations analysis (Vishnyakova, 2011), method of solving particular professional situational tasks (Budarin, 2010), method of situational analysis (Sychev, Yakina \& Kurmayeva, 2013), case method (Volkova, 2014), and case-study method (Adonina, 2012). There are examples of simultaneous use of these terms: situational task and case method (Savelyeva, 2013), situational task and case (Poddubnaya, 2015) etc. We believe that situational tasks method is a combination which joins peculiarities of active, interactive and problematic methods of teaching.

Situational task is a teaching method which includes a complex of conditions aimed at the solution of practically important situation with a goal to form components of education. Another definition may be the following. It is a type of an educational exercise imitating situations that may occur in real life.

The solution of situational tasks demands engaging of extra information that makes it effective. It promotes the development of creativity, speech and communication skills of students.

The value of situational tasks is in expanding students' worldview, performing by them intensive cognitive activity in order to apply acquired competences and understand the essence of a task.

Situational tasks are oriented at activating the most universal ways of work with information. Experience has shown that peculiarity of situational task is in its clearly pronounced practical orientation. Still for its solution it is necessary to have particular subject knowledge. A compulsory element of a task is problematic question that should to be formulated in such a way that a student wants to find the answer and becomes aware of work method. In the process of situational task solution both an instructor and a student pursue the objectives. For a student it is finding a solution suitable for the given situation. For an instructor it is learning by a student of the work method and understanding of its essence.

The main goals of situational tasks application are:

- the development of all kinds of speech activity; and

- mastering communication skills. 
E. Shtekhman, Y. Melnik \& A. Zhurova - Application of Problematic Situational Tasks Method at ...

3.2 Structure and components of situational task in Russian as a foreign language

In teaching Russian as a foreign language situational tasks method has some peculiarities. It deals with the structure of the task itself and also with the use of this peculiarity in teaching process. It is explained by the fact that the main goal of situational task is the development of communication skills and text formulation in studied language (even if the material of the task is professional terminology). That is why the professionally-oriented vocabulary isn't used in the problems formulation (A1, A2, B1 level) or becomes secondary (B2, C1, C2) (State Standard in ..., 2009). In other words building of professional competence is not the goal of situational tasks method in teaching Russian as a foreign language. Still, in our opinion, situational tasks may become helpful in teaching professionally-oriented Russian as a foreign language in technical higher school.

The structure of the task could be the following (Zhuikova, 2014: 155):

1. Task name.

2. Personally relevant communication or speech (rarely profession addressed) question, addressed directly to each student. If the content of the question is professionallyoriented, to solve it will be necessary to engage speech and communication experience and skills. This is the most important condition of the formulation of the question in situational tasks in Russian as a foreign language.

3. Set of texts represented in different versions (borrowed from newspapers, mass media, documents, books, diagrams, audio and video materials, template for filling in, etc.). It is worth noticing that modern discursive practices are one of the richest sources of sociolinguistic material in teaching students, including technical major (Issers, 2015, The role of mass media in ..., 2017 ).

4. Text tasks (suggested material) solution consists of introduction, understanding, application, analysis, synthesis, situation evaluation that aimed at building communication skills and competence in general.

5. Final report. The final report after solution of a task is represented in the form of communication and/or text. Both processes are often performed within frames of one task. In this case all formulated goals are reached.

Thus, the logic of situational task is the following: introduction, understanding, application, analysis, synthesis, evaluation (Ovchinnikova, 2014).

(1) Introduction (reproduction or finding exact elements of information).

(2) Understanding (learning the sense of presented material).

(3)Application (use of rules, concepts, principles, theories and ideas in new situations).

(4)Analysis (separation of information into compounds and trace of interconnections).

(5) Synthesis (generation of different ideas about a new and unique product or plan).

(6)Evaluation (evaluation of material importance or ideas based on definite criteria or standards).

The most important issue in the structure of situational task is the problem solving when a student becomes creative individual, who stands on his or her ground, finds solution of 
some problems which all is important in the modern world. It is really important for situational task to be interesting for a student and trigs emotions. The tasks may be oriented on working out the skill of text formulation (both verbal and written), develop communication competence. Examples of situational tasks will be provided below.

\subsection{Types of situational tasks}

According to different researches, there are the following types of situational tasks.

1. On the content (Yusupova, 2010):

- Problematic situation, which is supposed to state and solve a problem;

- Evaluative situation, in which taken solutions need to be evaluated;

- Illustrative situation, which could serve as an example in studying course or topic;

- Situation-exercise, which teaches to solve tasks using analogy method.

2. On the way of representation:

- Classical situation;

- "real";

- Case;

- Analysis of service documentation;

- Following the instructions.

3. On the impact of main sources (Khalilova, 2012: 143):

- Practical situations which reflect real life problems;

- Educational situations, aimed at teaching;

- Scientific and research situations targeted at performance of research activity.

4. On the subject of situation (Khalilova, 2012: 147):

- Personalized situations where particular individuals take part;

- Institutional situations are characterized by the participation of organizations;

- Multu-subjective situations usually involve several acting subjects.

5. On the time needed to solve situation (Khalilova, 2012: 147):

- Mini-situations. Usually it is about one or several pages and is supposed to be worked at the part of two-hours class;

- Middle size situation usually takes 2 hours class;

classes.

- Extended situation is up to several dozen pages and may be used at several practical

6. On the use of appendix (Khalilova, 2012: 147):

- Situations with appendixes (are supposed to form skills in calculations and analysis of statistic information),

- Situations without appendixes. 

as a solution;

7. On type of methodic part (Khalilova, 2012: 147):

- Containing questions, which demand from a student to give answers to the questions

- Situational tasks which formulate target or challenge.

8. In praxeological sense problems an instructor faces with in everyday professional activity might be divided into (Budarin, 2010: 178):

- Typical;

- Non typical;

- Creative;

- Improvisational.

The choice of particular situation type depends on peculiarities and kind of studied topic, goals of topic study, training level of a student and an instructor, requirement to illustrative material and/or technical facilities, computers, etc.

\subsection{Criteria for formulation of situational task}

While selecting material for situational task an instructor should takes into account the following criteria (Budarin, 2010: 178; Ovchinnikova, 2014: 49; Zharavina, 2014: 958).

- Situational task should be formulated in the form of a short text; 2018: 155);

- Topics of situational task should be relevant for a student (Shtekhman \& Melnik,

- The task should reflect a real situation which trigs emotions;

- While creating situational task it is necessary to take into account the age of students;

- Problem stated in the situational task should be clear to students;

- The content of situational task should include issues which demand situation analysis, coming to the logical conclusions, expressing personal opinion, formulating and justifying personal position on stated problem; the best one.

- A task should have several possible solutions which give a student a chance to find

While choosing situations an instructor should take into account interests of students, their willingness to discuss problems and its relevance (Issers, 2019; The role of mass media in ..., 2017). Experience has shown that the most successful topics are connected with professional activity of students. Application of professionally-oriented situational tasks creates the atmosphere of their future activity and promotes professional competences building.

The use of situational tasks at different levels of teaching Russian as a foreign language let improve the quality of education, give a chance to adapt to real and professional lives. In the process of solution of situational task a student shows his or her creativity and increases level of knowledge in studied subject. 


\subsection{Stages of solution}

In order a student has an opportunity to work on situational task successfully it is necessary to make students acquainted with basic stages of solution hitting up in advance.

The basic stages of situational task solution are:

(1) Studying of its content and primary analysis.

(2) Debate. Debate is divided into three stages. The first one is identification of a task problem, opinions exchange, formulation of objectives and demands to the solution. At first, to identify and analyze problems and formulate goals students might consult with an instructor. But later it is really important for students to do it on their own. An instructor should just provide some help. His or her role should only consist of managing the discussion. An instructor should arrange the process of decision making from the systemic approach position.

Using systemic approach students should define the place of analyzing issue as an element in the system, carry out the analysis of general goals and conditions, find the main problems of analyzing issue, levels of problem emergence and decision making, formulate the task, finds restrictions and requirements to the solution, propose ways of search and take into account the analysis of extra information.

In the second stage of debates students with the help of instructor discuss solutions adopted, evaluate them from the point of view of requirements. Students choose one or two variants of solution which are possible to perform in given situation and which meet all requirements as well as evaluate possible consequences of the solution implementation.

Table 1. Scorecard to assess solutions of situational task

\begin{tabular}{|c|c|c|}
\hline & Assessment criteria & 50 points \\
\hline \multirow[t]{4}{*}{ Communication } & $\begin{array}{l}\text { 1.Understanding of presented information (task) } \\
\text { Appropriateness of communication task solution }\end{array}$ & 10 \\
\hline & 2.Suggestion of the way to solve problem & 10 \\
\hline & 3. Reasoning of the ways to solve problem (own choice) & 5 \\
\hline & 4. Suggestion of alternative variants. & 10 \\
\hline \multirow[t]{6}{*}{ Language } & $\begin{array}{l}\text { 1. Completeness of presented information ( }-5 \text { points for } \\
\text { missing out relevant informative fragment, }-2 \text { points for } \\
\text { missing out of an important semantic fragment). }\end{array}$ & 5 \\
\hline & $\begin{array}{l}\text { 2. Accuracy of information presentation ( }-5 \text { points for a } \\
\text { significant misrepresentation, }-2 \text { points for misrepresentation } \\
\text { of an important semantic detail). }\end{array}$ & 5 \\
\hline & $\begin{array}{l}\text { 3. Coherence and consistency of information presentation (-1 } \\
\text { point each mistake). }\end{array}$ & 5 \\
\hline & 4. Communication relevant mistakes (-1 point each). & \\
\hline & 5. Communication nonrevelant mistakes (-0.5 point each). & \\
\hline & $\begin{array}{l}\text { 6. Serious violations of phonetic and intonation standards (up } \\
\text { to }-1 \text { point). }\end{array}$ & \\
\hline Total & & \\
\hline
\end{tabular}

In the third phase of discussion an instructor assesses the quality of done work and some students under the guidance of instructor sum up discussion results. The solution of present of similar manufacturing task (situation) at the particular enterprise might be presented to the audience as well as further discussion of it. It is also recommended to arrange presentations on the problem by a consultant (one or several) and a factory representative, where the task 
E. Shtekhman, Y. Melnik \& A. Zhurova - Application of Problematic Situational Tasks Method at ...

(prototype of the situation) was successfully solved. In the third phase teamwork conclusions are formulated finally.

As an experience has shown after the second class students have already mastered method of systematic solution of problems. As a rule, they don't need further help of instructor.

An instructor fills an assessment list and shows it to students in order to contribute to their motivation to study Russian as a foreign language.

\subsection{Methods of situational tasks solution}

Solution of situational tasks lets to find out the level of familiarity with material and also develop students' skills on usage knowledge in a particular situation. Solution of tasks could be performed verbally or in writing. Methods of solution might be different.

(1) Suggested condition without answer examples so a student has to find the solution himself

(2) Situation might be represented in the form of a picture, photo, graphically. The task and/or question are given. The task of a student is to characterize or analyze the situation, find the correct solution.

(3) Each student is supposed to solve a situational task individually based on studied material.

(4)It is possible to suggest finding the solution of a situational task in groups of 3-5 people.

The work with situational tasks doesn't contradict the principles of professional education, which strives to develop sequential mental action: ability to analyze, determine the main and secondary characteristics, to generalize, to relate on meaning, to coordinate mental process within frames of stated task (the development of cognitive activity, the development of emotional-volitional sphere).

\subsection{Advantages and disadvantages of situational tasks method}

As we can see, the methods of situational tasks application in teaching Russian as a foreign language needs the further elaboration. Nevertheless, there are requirements to the structure of tasks, principles of its formulation are known, and stages of finding solutions have been described. Still before apply the presented method, one should take into account some disadvantages (Balkovskaya, Pankratenko \& Shurakova, 2003: 55; Barbashova, 2014: 16; Budarin, 2010: 178; Zharavina, 2014: 959; Simulation methods in ..., 2017: 30-32).

Advantages of situational tasks method for students:

(1) Encouraging the interest to the subject, stimulation of educational motivation;

(2) Development of students' self-dependence and activity, ability to set realistic goals;

(3) Personal enrichment;

(4) Enhancement of the effectiveness of studied material acquisition;

(5) Development of team work, communication and feedback skills;

(6) Development of skills in problems solution, foreseeing the consequences of made decision, ideas about methods of problem investigation, decisions making and proving; 
(7) Teaching of mechanism of decisions taking and its argumentation scheme;

(8) Activating of students' social position which promotes stress resistance development, ability to react on changes;

(9) Increase of experimental ability, generating hypotheses and finding proves;

(10) Accumulation of experience in working with information, problems solution and decisions making;

(11) Modeling of future professional activity.

Advantages of situational tasks method for an instructor:

(1) Development of creative potential of an instructor while searching new possibilities to demonstrate educational material;

(2)Direct application of science to real situations and conditions;

(3) Performance of integration educational material within frames of particular topic on different levels (cross-curriculum, meta-curriculum, personal). It lets engage several functions such as educational, pedagogical, managing and research).

Difficulties of situational tasks method application:

(1) Creation of situational tasks is always creative process which demands from an instructor "erudition, teaching skills, time to find suitable real life material that may model professional situation and reflect all knowledge and skills student needs to master";

(2) It is impossible to apply the mentioned method at first levels of studying material. The application of situational tasks method is useless without knowledge acquisition in the specific area.

4. Examples of the use of technical problematic situational tasks

As was mentioned above, the use of situational tasks is highly effective only if students are doing well in studied subject. It means that the use of situational tasks will be the most effective at the first certificate level. Situational tasks that have practical orientation doubtlessly help to consolidate professional vocabulary, terms, slang. Let's have a look at some examples of situational tasks connected with technical field.

\section{Situational task 1. “Gold” (Weight of the body)}

Stock company "Gold M" has decided to multiply its capital by buying gold somewhere near the equator and sell it in Antarctic. Help to the management of the company to assess actuality of this idea.

\begin{tabular}{l|l} 
Vocabulary for the task & Spring scales \\
Balance scales \\
Mass of the body \\
Weight of the body \\
Coefficient g \\
Direct method to measure mass \\
Indirect method to measure mass
\end{tabular}


E. Shtekhman, Y. Melnik \& A. Zhurova - Application of Problematic Situational Tasks Method at ...

Answer the questions:

1. Why could such idea arise from physics point of view?

2. What scales (spring or balance) should he use?

3. What scales (spring or balance) measure mass by direct method and which ones by indirect?

4. What physical quantity will be equal body mass if we measure it with the help of spring scales?

5. What formula could be used to calculate weight of the body?

6. What is coefficient $\mathrm{g}$ in the formula?

7. What does g depend on?

8. What is $\mathrm{g}$ at the equator and in Antarctic?

9. Where is the weight greater? At the equator or in Antarctic? How much more?

\section{Situational task 2. "Who is right?" (Non-uniform movement. Speed)}

You have witnessed the conversation between a traffic inspector and a driver.

The inspector has measured the speed of passing by car with the help of a device.

The device has shown the number 70, so it means the speed of 70 kilometers per hour. He stopped the car. The inspector told the driver that he had speeded. The driver disagreed. He left the city at 8 a.m. Now it is 1p.m. He has driven 100 kilometers.

Vocabulary for the task

\begin{tabular}{|l} 
Vehicle \\
Permissible driving speed \\
Speeding \\
Trip ticket \\
Device for speed measurement \\
Speedometer \\
Radar
\end{tabular}

1. Who is wrong in this dispute and why? Explain your point of view.

2. How did the inspector measure the speed?

3. How did the driver measure the speed?

4. What device measures speed in a car?

5. What was the speed measured by driver according to trip ticket? 


\section{Situational task 3. "Mysterious thief" (Thermal phenomena)}

On the road from Saint-Petersburg to Moscow several meters of expensive phone and telegraph wire are gone every winter. An offender is well-known but nobody seeks and punishes him. Why?

\begin{tabular}{l|l} 
Vocabulary for the task & Electric power line \\
& Thermal phenomena \\
Wire \\
& To steal, thief \\
Physical phenomena
\end{tabular}

Answer the questions:

1. Who is to blame for the gone wire?

2. What physical phenomenon is described?

3. Does it influence on the telephone connection?

4. If every winter 500 meters of wire disappear, what time will it take to be completely gone?

5 . Is there a way to prevent the problem?

6. It is possible with other technical objects like rails or bridges?

7. Shall engineers and constructors take into account the fact when they project and construct technical objects and buildings?

\section{Situational task 4. "Natural disaster"}

\section{(Fuel generator work principle)}

A dam failure took place after natural disaster (flood, volcanic eruption, earthquake, industrial disaster etc.). Power plant was out of order. You got a task to arrive to field hospital and provide uninterrupted electrical power supply. You need a fuel generator for this reason. You have an assistant who doesn't know the principle of fuel generator work. Explain to him what is it, its construction, and give examples of this device operation for energy generation.

\begin{tabular}{l|l} 
Vocabulary for the task & Natural disaster \\
& Power plant \\
& Petrol generator \\
& Internal combustion engine \\
& Electronic module \\
& Control devices \\
& Main ring \\
& Fuel tank
\end{tabular}

\footnotetext{
${ }^{1}$ A clue. Copper telephone wire becomes 1.5 times longer than steel because of heat. There are no empty gaps. That is why we may be sure the telephone line Moscow - Saint-Petersburg is 500 meters shorter in winter than in summer. A cold "steals" almost 0.5 meters of wire every winter. When it becomes warm a wire comes back.

But if such shrinkage because of cold happens with bridges, consequences might be tragic. The case reported by newspapers in 1927: "Unusual for France colds for several days caused serious damage to the bridge over the Sienna right in the middle of Paris. Pass through the bridge is temporary restricted".
} 


\section{Situational task 5. "At the university"}

You are the leader in the group of foreign students. The minister is going to visit your university. The meeting with the rector has been planned. An interpreter will accompany the minister. The interpreter is your friend from your country. (A) You need to write a formal letter to the interpreter to give place, time and goal of the meeting with the university rector. Also ask him to help with dormitory problem. (B) Write an informal letter to the interpreter to give place, time and goal of the meeting, tell about how to greet, arrange informal meeting after the event.

\begin{tabular}{l|l} 
Vocabulary for the task & Sir; \\
I bring to your attention; \\
Destination; \\
Specified period; \\
Initiate appropriate activities \\
Please do not ignore; \\
Thank you for cooperation; \\
Dear; \\
Meet; \\
Will have fun; \\
Will be happy; \\
Bye.
\end{tabular}

\section{Situational task 6. "Auto racing"}

In 1990 KAMAZ trucks participated in the most famous and prestigious Paris-Dakar rally. Today the team from Naberezhnye Chelny is the most award-winning rally team in the world among trucks. But in 1990 the main world rally wasn't so easy and not everything was alright so the victory was only a dream. Some technical problems were on the team's road. As you know, the weather in the desert is extremely hot and almost calm. Explain to your friend why the team could win the race and what weather conditions (e.g. high temperature) influence the engine work.

\begin{tabular}{l|l} 
Vocabulary for the task & KAMAZ \\
& Race \\
Dust \\
Sand \\
& Heat \\
& Engine \\
& Engine overheating \\
& Filters \\
& Cooling system \\
& Fuel \\
& Motor oil
\end{tabular}

\section{Situational task 7. "A difficult trip"}

Participants of Paris-Dakar rally got into trouble. Their cars got stuck in the dunes. An engine of one of the cars is seized up, another has its crankshaft broken. Speak about your actions in this situation. 


\begin{tabular}{l|l} 
Vocabulary for the task & KAMAZ \\
Engine \\
& Crankshaft \\
Repair kit \\
& Spare parts and supplies \\
Winch & Tool \\
& Motor oil \\
Repair workshop \\
& Jackscrew \\
& Piston \\
Connecting rod \\
& Inserts \\
& Oil-control ring \\
Compression \\
& Heating plug \\
& Fuel injection pump \\
& Plunger pair \\
& Main filter \\
& Grease pump \\
& Decompression \\
Engine block \\
Camshaft control
\end{tabular}

\section{Situational task 8. "To cross the river"}

You are a participant of an expedition. Your task is to cross the river. Find the most suitable place for crossing (a ford, low coast, hard bottom). Explain your choice to the expedition leader.

\begin{tabular}{l|l} 
Vocabulary for the task & Crossing \\
& To cross \\
& To overcome an obstacle \\
& Water obstacle \\
& A ford \\
& Low coast \\
& Hard bottom
\end{tabular}

\section{Situational task 9. "An advertisement of car accumulators"}

You have decided to buy an accumulator. Read the advertisement. Ask the consultant about extra information.

Dear customers!

Today auto accumulators are the goods in demand for population. It is because every driver knows that there are no cars with eternal accumulator. What accumulator can provide? Sooner or later car owners understand that the life of accumulator is over and it's time to buy a new one. Accumulators for cars have a number of characteristics and features which determine maximum effectiveness. First of all, it is a capacity. Modern car accumulators provide ignition system functioning, as well as electrical equipment, but, the most significant, engine start. What 
shall we know when buying accumulator? While choosing accumulator for a car which often starts in a cold weather, an owner should consider an accumulator with the capacity not less than 5-10 ampere-hour.

Buying accumulators from us you can be sure that it is not counterfeit as we work directly with manufacture and we have distribution certificates. It is also the reason of good prices due to the broker's margin absence.

We are selling high quality accumulators (over 7 years) which quality is confirmed by international standards.

We suggest you to buy an accumulator wholesale and retail. One of advantages of cooperation with us is low prices.

For retailers we provide:

Free accumulator diagnostics if any troubles emerge. You come to us and we find the reasons.

Free assistance in accumulator installation.

In case of defect we are authorized by manufacturer to replace accumulator immediately.

We provide ACCUMULATOR CHARGING. We offer an accumulator for temporary replacement while yours charging, so you can drive your car.

\begin{tabular}{l|l} 
Vocabulary for the task & Accumulator \\
Ampere hour \\
Size \\
Clamp \\
Diameter \\
Battery marking \\
Accumulator service \\
Charging current
\end{tabular}

\section{Situational task 10. "Inspection of mechanisms"}

Everyday technical inspection is necessary process regardless of model or type of the car. Crossovers, electro cars, trucks etc. demand the service. Regular inspection of machines lets prevent potential problems or solve existed ones at the very beginning. It would reduce damage and cost of repair works as well as replacement of spare parts. You are a mechanic (an engineer). Your task is to perform auto inspection and report the result to the chief.

\begin{tabular}{l|l} 
Vocabulary for the task & Everyday technical inspection \\
Walk-around inspection & Oil level \\
Windscreen washer level & Fuel availability \\
Working fluids leakage traces & Typical indications of breakdowns (tear of a dust cap, tubes) \\
& Tyre pressure
\end{tabular}




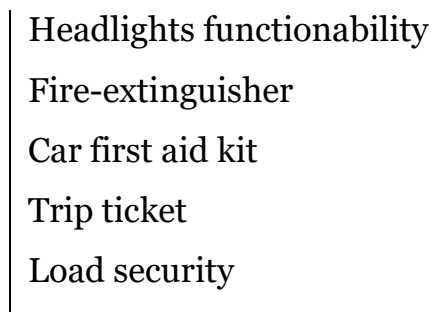

\section{Conclusion}

Modern methods of teaching in higher school vary greatly. They may be classified by different reasons. Situational task is considered as a combination of active, interactive, problematic and professionally-oriented elements of teaching.

We define situational tasks method as a systematic application of tasks aimed at solution of practicable situation. Such situations are targeted at conscious acquisition by students of the content of studied subject. They are also oriented at building necessary for future profession competences.

In the foundations of situational task should be a problem which gives a chance to choose and demands reasoning. Situational tasks don't suppose to have ready solutions and patterns of behavior. They encourage future specialists to activate mental activity. Also they are aimed at self-determination of students who create new (heuristics) problem solution.

Situational tasks let foreign students develop skills which are important for their professional, educational and vocational communication. Also they help to develop the following competences:

(1) Speech (acquaintance with vocabulary for application in verbal and written speech in educational and professional communication);

(2) Discursive (ability to create statements of different type depending on communication situation);

(3) Sociolinguistic (ability to use language means and patterns of etiquette in sociocultural situations properly).

Not each situation may become educational.

In the creation of situational task it is necessary to take into account the specific features of a major, goals and objectives, and peculiarities of application of situational tasks method in the course of Russian as a foreign language. The goal of application is the development of communication skills aimed at formulation of written or verbal texts in Russian.

The application of situational tasks method in teaching Russian as a foreign language should base upon a number of principles differ from each other on priority. On the first place one puts principles of «new versions», "lack of information», «information abundance». Situational tasks are able to realize different educational goals depending on which an instructor always has an opportunity to choose that type of the task that would let obtain the most effective result.

While working in the class a particular attention is paid to the improvement of speech skills as the given method of work promotes vocabulary enrichment, activates speech development, works out an appropriate speech behavior in the conditions of real verbal communication. In the process of solution of situational task students find out peculiarities of technical and engineering discourse. Practical orientation of situational tasks lets apply obtained in studying of different topics knowledge which are closely related to major. 
The present article provides examples of technical tasks. Each described situational task has the following structure:

- Description of the situation;

- Formulation of communication goal(s);

- Vocabulary necessary for communication task solution; and

- Helpful text material (if necessary).

The material of presented research could be useful for practicing instructors of Russian as a foreign language who work in technical higher schools. Research prospects are performance of diagnostic experimental research on application of situational tasks in technical higher school, creation of comprehensive training manual based on the research results.

\section{Acknowledgements}

This research did not receive any specific grant from funding agencies in the public commercial, or not-for-profit sectors.

The authors declare no competing interests.

\section{References}

Adonina, N. P. (2012). Case study: history and present. Higher Education Today, 11, 43-48.

Balkovskaya, T. Z., Pankratenko, T. V., \& Shurakova, O. I. (2003). Application of situational tasks in practical skills training of managers. Problems of Higher Education, 1(1), 55-56.

Barbashova, S. A. (2014). Arrangement of educational process and application of interactive methods. Theoretical and applied aspects of modern science, 3(4), 14-16.

Budarin, E. A. (2010). Use of the method of solution of particular professional situational tasks in training of cadets of navy institutes. Phycology and pedagogics methods and problems of practical application, 11(2), 176-180.

Chernyshov, S. V. (2015). Method of situational analysis (case study) in teaching foreign affective communication. Nizhegorodskoe Eduation, 2, 96-101.

Fesenko, O. P., Fedyaeva, E. V., \& Bestsennaya, V. V. (2017). Cases in methods of teaching Russian as a foreign language. Language and Culture, 9, 104-117. https://doi.org/10.17223/24109266/9/12

Glazyrina, E. S. (2014). Application of situational analysis method (casestudy) at foreign language classes in higher school in the aspect "language of profession". Education and Pedagogics: Methods and Practice, 12, 153-158.

Issers, O. S. (2015). People talk... Discursive practices of our time. Omsk: Omsk state publishing house.

Issers, O. S. (2019). Speech maneuvering as linguistic and didactic problem in course of Russian as a foreign language. In collection Russian word in multilingual world. Proceedings of XIV Congress of MAPRYAL (1074-1078). Editorial staff.

Khalilova, Sh. T. (2012). Technology of designing situational tasks in the content of practical education. National and Foreign Pedagogics, 2, 142-148. 
Kirova A. V., \& Melnik, Yu. A. (2019). Verbal communication skills development in Russian as a foreign language classes by means of situational tasks. Communication studies, 6(1), 223-232. https://doi.org/10.25513/2413-6182.2019.6(1).223-232

Lah, M. (2017). Raising awareness in university students of languages. La conscientisation des apprenants de langue au niveau universitaire, Xlinguae, 10(4), 320-335.

Leonhard, O. A. (2012). To the issue of building crosscultural communication competence by means of case-study. Bulletin of Buryat State University, 15, 130-133.

Novikova, N. G., Zorina, N. M., \& Kortunov, V. V. (2014). Application of situational tasks in teaching students to create business discourse. Education and society, 6(89), 28-32.

Ovchinnikova, L. I. (2014). Situational tasks as an interactive method of teaching geography. In Perspectives of science and education development (pp. 50-52). Moscow, OOO "ARKonsalt”.

Passov, E. I. (2010). Grounds of communication theory and foreign language education technology. Moscow, Russian language. Courses.

Poddubnaya, M. N. (2015). Case 31. Situational task on travel agency management. Workshop on case study solutions for Masters' students (Management and Quality Management majors), Vienna, 104-109.

Rozanova, N. M. (2013). Situational analysis as a method of arrangement of final knowledge test for students. Terraeconomicus, 11(1), 132-148.

Savelyeva, M. G. (2013). Pedagogical cases: Constructing and application in the teaching process and assessment. Izhevsk, 94.

Shtekhman E. A., \& Melnik, Yu. A. (2018). Teaching the language of specialty at preparatory course: from experience of teaching. Newsletter of Omsk State Pedagogical University Humanitarian research, 18(1), 154-156.

Shtekhman E. A., \& Usatuk, N. B. (2018). Situational tasks at Russian as a foreign language classes. In Problems of teaching philological disciplines to foreign students (pp. 164-168).

Simulation methods in teaching Russian language as foreign in military high school: situational tasks and case studies (2017). Fesenko, O. P., Fedyaeva, E. V., Shtekhman, E. A., Bestsennaya, V. V. \& Melnik, Yu. A. Omsk, 139.

State Standard in Russian as a Foreign Language (2009). Breakthrough level. Waystage level. Threshold level. Saint-Petersburg: Zlatoust.

Sychev, A. A., Yakina, L. A., \& Kurmayeva, K. K. (2013). Situational analysis method (case-study) in ecological ethic. In the world of scientific discoveries, 11, 5(47), 329-334.

The role of mass media in democratization and creativization of modern Russian language (round table) (2017). Elena M. Markova, Larisa V. Ratsiburskaya, Oxana S. Issers and others. Bulletin of Moscow Region State University, 1. https://doi.org/10.18384/2224-02092017-1-799

Verevkina, L. E. (2014). Arrangement of students work in situational tasks solutions. Education and Pedagogics Methods and Practice, 13, 141-145.

Vishnyakova, I. V. (2011). Engineers training with application of new technologies. Higher Education Today, 5, 17-19.

Volkova, M. A., \& Rozov, I. I. (2014). Case method and situational analysis in studying cross-cultural communications. Academic Bulletin. Bulletin of Saint-Petersburg Academy of post diploma pedagogical education, 1(24), 87-92.

Yusupova, A. V. (2010). Modern technologies of education and knowledge control: study guide. Kazan: Kazan State Power Engineering University, 88. 
E. Shtekhman, Y. Melnik \& A. Zhurova - Application of Problematic Situational Tasks Method at ...

Zapevina, V. V. (2014). Situational tasks as a method of active teaching and development of professional competence. International Journal of Experimental Education, 41, 108110.

Zharavina, I. A. (2014). Application of situational tasks in adaptation of educational humanities materials in teaching students of technical higher school in external study mode. Fundamental Researches, 8(4), 955-960.

Zhuikova, S. V. (2014). Situational task as a source of education content updates in conditions of FSES implementation. In Relevant issues of the history of natural, mathematical and technical sciences and education: analysis and synthesis of experience. Proceedings of all Russia Scientific-Practical conference (pp. 154-161). Elabuga. 


\title{
Hava Nagila
}

\author{
Tatyana Petkova \& Daniel Galily \\ South-West University "Neofit Rilski”, Blagoevgrad, BULGARIA \\ Faculty of Philosophy, Department of Philosophical and Political Sciences
}

Received: 1 December 2020 - Accepted: 22 December 2020 • Published Online: 25 December 2020

\section{Abstract}

This article is about the story of a favorite Jewish song of many people around the world. Hava Nagila is one of the first modern Israeli folk songs in the Hebrew language. It went on to become a staple of band performers at Jewish weddings and bar/bat (b'nei) mitzvah celebrations. The melody is based on a Hassidic Nigun. According to sources, the melody is taken from a Ukrainian folk song from Bukovina. The text was probably the work of musicologist Abraham Zvi Idelsohn, written in 1918. The text was composed in 1918, to celebrate the Balfour Declaration and the British victory over the Turks in 1917. During World War I, Idelsohn served in the Turkish Army as a bandmaster in Gaza, returning to his research in Jerusalem at the end of the war in 1919. In 1922, he published the Hebrew song book, "Sefer Hashirim", which includes the first publication of his arrangement of the song Hava Nagila.

Keywords: Hava Nagila, Abraham Zvi Idelsohn, Jewish song.

\section{Introduction}

"Let us rejoice" (Hebrew: הבה נגילה, Havah Nagilah) is probably the most famous Israeli song and loved by many people in the world. Hava Nagila is one of the most recognized symbols of Jewish life and culture. When a person hears this joyful and sunny song, immediately his spirit is brightened and one is filled with joy.

Hava Nagila was not always known as this name - in fact, it was originally simply a Nigun or "voiceless melody" that originated among the Jewish people in Eastern Europe. Like many folk songs, no one knew who originally wrote it, but it was just one of many old folk tunes while Abram Zvi Idelsohn kept it. Named the "father of Jewish musicology," A. Idelsohn chose the tune to create a special piece celebrating Britain's victory over the Turks in 1918. He put the words (in Hebrew) from a psalm of celebration and brotherhood that became a hit as the first ordinary people, and then pop stars started singing the song.

The song is reminiscent of sunny Israel and the friendly people of Israel. This song, its lyrics, and its music have their stories, which are just as interesting, although not well known. This article will be an attempt to make these stories more familiar to people. To begin with, let's start by reading the lyrics of the song, which we often call "Hava Nagila".

(C) Authors. Terms and conditions of Creative Commons Attribution 4.0 International (CC BY 4.0) apply. Correspondence: Tatyana Petkova (PhD), South-West University "Neofit Rilski”, Faculty of Philosophy, Department of Philosophical and Political Sciences, Blagoevgrad, BULGARIA. E-mail: tatianavas.tp@gmail.com. 


\section{English translation}

Let's rejoice

Let's rejoice

Let's rejoice and be happy

(repeat)

Let's sing

Let's sing

Let's sing and be happy

(repeat)

Awake, awake, my brothers!

Awake my brothers with a happy heart

(repeat line four times)

Awake, my brothers, awake, my brothers!

With a happy heart

\section{Hebrew text}

הבה נגילה

הבה נגילה

הבה נגילה ונשמחה

הבה נרננה

הבה נרננה

הבה נרננה ונשמחה דהוה

!עורו, עורו אחים

עורו אחים בלב שמח עורום

עורו אחים, עורו אחים

בלב שמח

\section{Hava Nagila}

It is one of the first modern Israeli folk songs in the Hebrew language. It went on to become a staple of band performers at Jewish weddings and bar/bat (b'nei) mitzvah celebrations. The melody is based on a Hassidic Nigun. According to sources, the melody is taken from a Ukrainian folk song from Bukovina. Originally a Hassidic Nigun collected by Idelsohn, Hava Nagila became known as a Jewish folk song that gained popularity amongst the chalutzim. During the 1920's and 1930's, it was published in Jewish children's songbooks in Palestine, Germany, and the United States, and was commercially recorded by a number of cantors and Jewish folk singers. Since then, it has been performed and recorded by Jewish and non-Jewish musicians alike.

Hava Nagila is great popularity and widespread recognition is a demonstration of how the song can become a powerful marker of identity. Its earliest Idelsohn manuscript, kept by the Department of Jewish Music at the Hebrew University of Jerusalem, contains a sketch of the song Hava Nagila for voice and piano. In the upper right-hand corner of the sketch, Idelsohn attributes the melody to a Hasidic Negro, later noted in his Thesaurus, collected by a descendant of the Hasidic court of Sadigora, who resided in Jerusalem. Sadigurer Hasidi took his name from the small town of Sadigura in Bukovina, now in Ukraine.

Although the exact date of the composition is not documented in any of Idelsohn's manuscripts, he claims to have written the first sketch of Hava Nagila in 1915. "After adding lyrics, Idelsohn documented the first performance of the song by his mixed choir in 1918, noting that the implementation prompted Hava Nagila to "spread rapidly throughout the country". These dates are noted in Idelsohn's 1932 article "Musical Characteristics of Eastern European Folk Song," published in The Musical Quarterly" (see Seligman.org, 2009).

"Idelsohn's Hebrew texts reflect the biblical verse: "This is the day which God created. We will rejoice and be glad in it" (Psalm 118: 24). Controversy will later arise after the claim of Moshe Nathanson, a student of Idelsohn, that he wrote the lyrics for the song. The manuscripts here are part of the Idelsohn collection at the Department of Music" (see Seligman.org, 2009) 


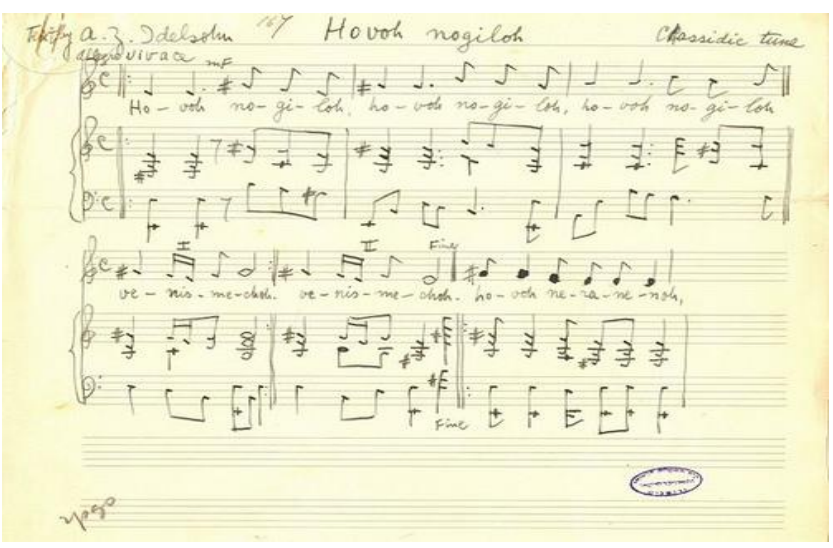

Picture 1. Hava Nagila: Idelsohn's original manuscripts of the Sadigora nigun and his words for the song (photo, see Seligman.org, 2009)

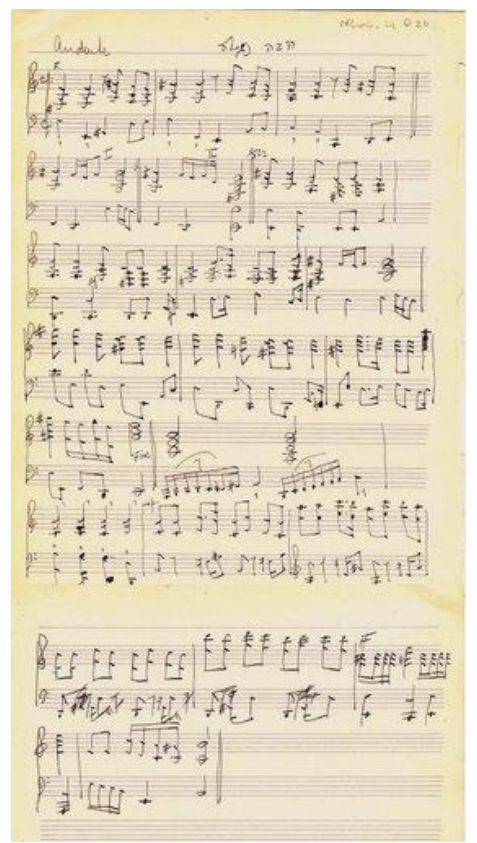

Picture 2. Hava Nagila: Idelsohn's original manuscripts of the Sadigora niggun and his words for the song (photo, see Seligman.org, 2009)

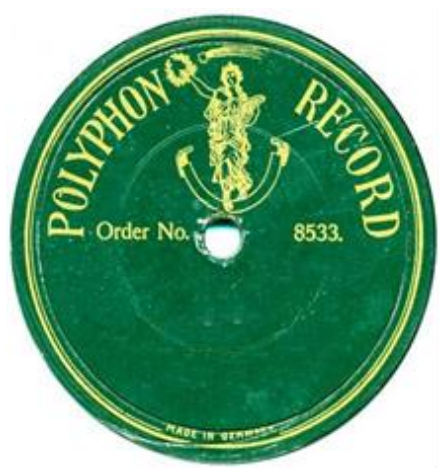

Picture 3. The first recording of Hava Nagila.

http://www.seligman.org.il/Idelsohn_Hava_Nagila.mp3 
In 1922 Idelsohn was contracted by Polyphon Records in Berlin to release a series of records featuring Hebrew folksongs. Idelsohn selected the repertoire of thirty-nine songs. The series included the first commercial recording of Hava Nagila (photo, see Seligman.org, 2009).

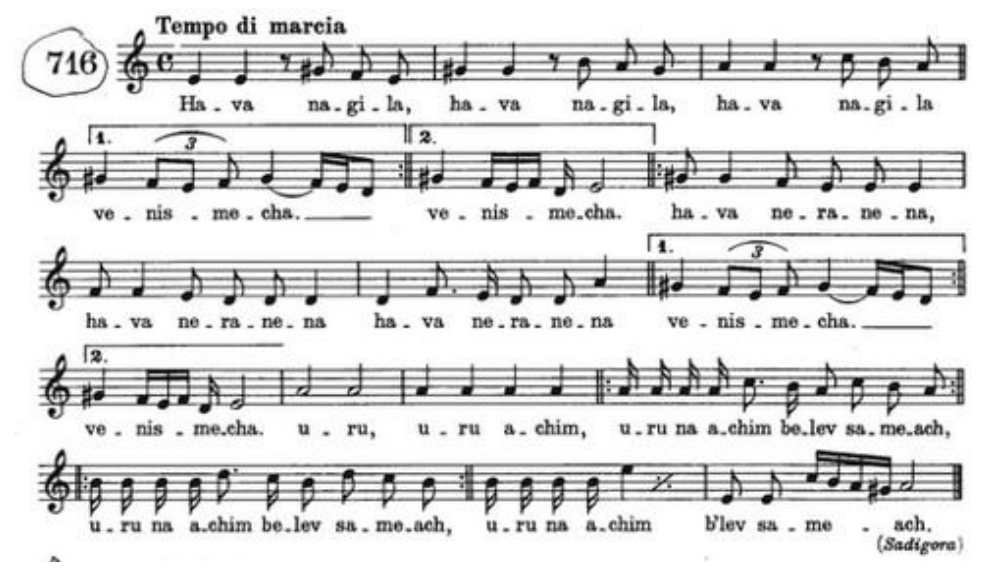

Picture 4. Hava Nagila in Volume IX the Thesaurus

The score of the song in the Thesaurus of Hebrew Oriental Melodies is noted by Idelsohn as having originated in the Sadigora Hasidic Court (photo, see Seligman.org, 2009).

\section{Abraham Zvi Idelsohn}

The text was probably the work of musicologist Abraham Zvi Idelsohn, written in 1918. How is Abraham Zvi Idelsohn? He was born in Felixburg (Jurkalne), Latvia, in 1882 and began his study of Jewish music in Libau where he trained as a chazan (cantor). He continued his education at the Stern Conservatory in Berlin and at the Leipzig Academy. Idelsohn served as a cantor at the Adat Yeshurun Synagogue in Leipzig, in Regensburg and Johannesburg, South Africa before finally settling in Jerusalem in 1906. In Jerusalem, he began working as a cantor and music teacher at Yellins's Hebrew Teacher's college. Idelsohn was impressed by the diversity of the Jewish community living in Palestine, and embarked on a project to record their unique musical and linguistic traditions" (see Seligman.org, 2009).

Idelsohn received an award for research from the Vienna Academy of Sciences, along with a phonograph to use in his fieldwork. Idelsohn published the first volume of his major tenvolume Thesaurus of Hebrew Oriental Melodies in 1914, in which he began a comprehensive study of the Yemeni community in Palestine. He had a keen interest in this community because he perceived the origins of their pronunciation in Hebrew and the musical heritage dating back to the first century. He argues that their musical and linguistic traditions are relatively uninterrupted by external influences and change due to their migratory history and secluded geographical location. In subsequent volumes of his collection "Idelsohn explores the musical traditions of Babylonian, Persian, Bukhara, Oriental Sephardim, Moroccan, German, Eastern European, and Hasidic Jewish communities in Palestine and throughout the diaspora. This vast project spans a period of 20 years with the publication of the last volume in 1932. During World War I, Idelsohn served in the Turkish army as head of an orchestra in Gaza, returning to his research in Jerusalem at the end of the 1919 war. In 1922, he published the Jewish book of songs, Sefer Hashirim, which included the first publication of his arrangement for the song Hava Nagila" (see Seligman.Org, 2009). 


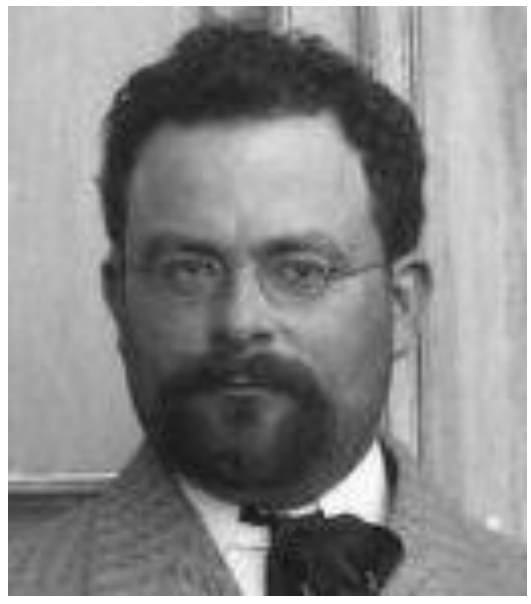

Picture 5. Abraham Zvi Idelsohn, 1882-1938 (photo, see Wikipedia.org, 2013)

Idelsohn contracted to catalogue Eduard Birnbaum's collection of Jewish music at the Hebrew Union College in Cincinnati in 1924. He was contracted to catalogue the Eduard Birnbaum collection of Jewish music at the Hebrew Union College in Cincinnati. Shortly thereafter he was appointed professor of Jewish music and liturgy at HUC, a position he held until his health began to deteriorate in 1934. With access to the Birnbaum collection, Idelsohn wrote extensively on the historical development of Jewish liturgical and cantorial music. During his time at HUC, he published the last five volumes of the Thesaurus of Hebrew Oriental Melodies as well as two other seminal works, Jewish Music in its Historical Development (1929) and Jewish Liturgy (1932).

"Idelsohn also made important contributions in the area of comparative musicological research with his work on the connections between Jewish and Christian liturgical music. Though less well known, Idelsohn also dedicated himself to the study of Near Eastern maqam systems, which is outlined in his work "Die Maqamen der arabischen Musik" (1913). Idelsohn's enormous literary output, as well as his field recordings (which number over 1,000), laid the foundation for the modern study of Jewish musicology. Idelsohn died in Johannesburg in 1938" (see Seligman.org, 2009).

Shortly afterwards, he was appointed professor of Jewish music and liturgy at HUC, a position he held until his health began to deteriorate in 1934. With access to the Birnbaum collection, Idelsohn wrote in detail about the historical development of Jewish liturgical and cantor music. During his stay at the HUC, he published the last five volumes of The Thesaurus of Jewish Oriental Melodies, as well as two other major works, Jewish Music in Its Historical Development (1929) and The Jewish Liturgy (1932). "His contribution to the field of comparative musicology with his work on the connections between Jewish and Christian liturgical music is enormous. Although less well known, Idelsohn also devoted himself to the study of Middle Eastern makam systems, which was outlined in his work Die Maqamen der arabischen Musik (1913). Idelsohn's vast literary output, as well as his field records (numbering over 1,000), laid the foundation for the modern study of Jewish musicology" (see Seligman.org, 2009) 


\section{THESAURUS $0 \mathrm{~F}$ \\ HEBREW ORIENTAL MELODIES}

COLLECTED, CLASSIFIED AND EUITED BY

A. Z. IDELSOHN

VOLUME IX:

THE FOLK SONG OF THE EAST EUROPEAN JEWS

1932

FRIEDRICH HOFMEISTER, LEIPZIG

Picture 6. Thesaurus of Hebrew Oriental Melodies, 1925-1933

This is the ten volumes of Idelsohn's seminal work studies Jewish liturgical and secular music, with cultural, linguistic and theoretical analysis (photo, see Seligman.org, 2009).

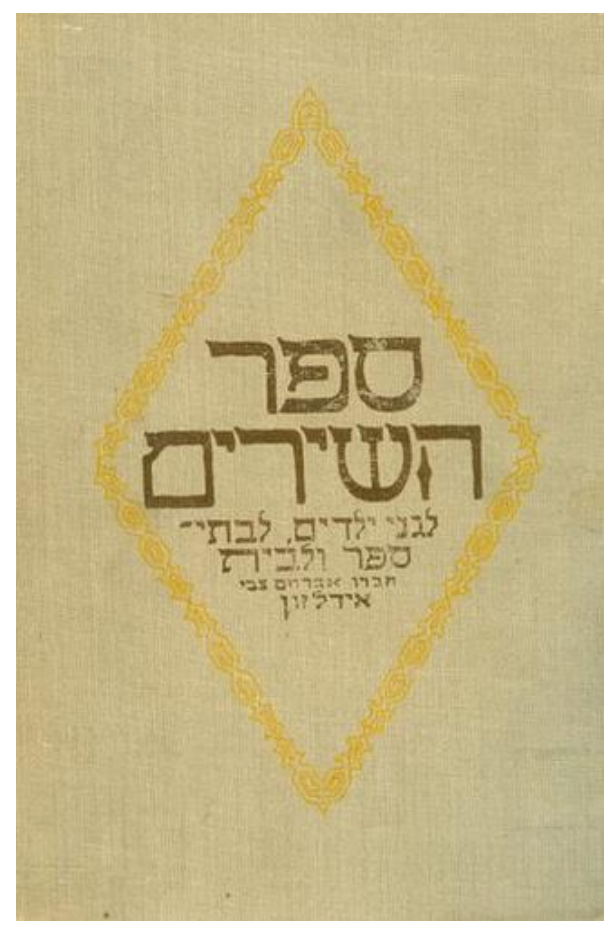

Picture 7. Shir Hashirim - 1922

This is a song book published by Idelsohn for "the Kindergarden, School and Home". It included the first publication of Hava Nagila (photo, see Seligman.org, 2009). 


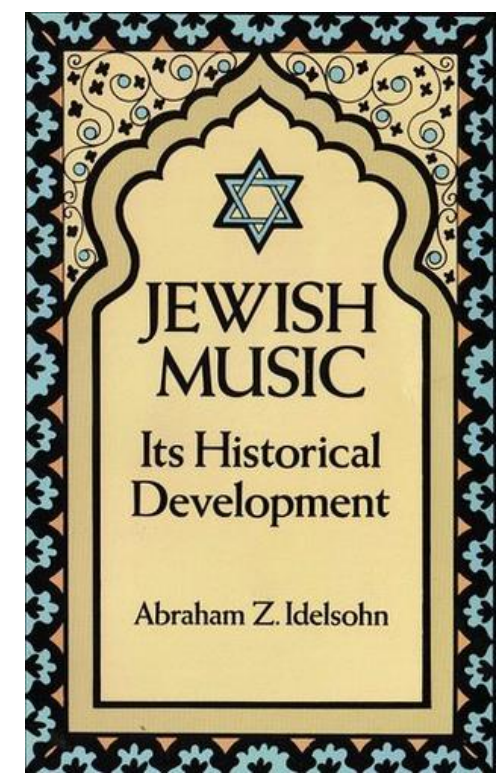

Picture 8. Jewish music in its historical development - 1929

This represents Idelsohn's most widely known work and still a classic in the field of Jewish music (photo, see Seligman.org, 2009).

Part of the whole charm of the song is the dance steps. Learning the dance steps for Hava Nagila is not difficult and can be a lot of fun at any social event. This is also a great introduction to the fun of folk dancing in general. Over the years, starting in Israel, a special kind of dance called Hora is also associated with the song. Starting in kibbutz groups, it spread throughout Israel as an extremely popular Jewish dance. Although she has danced in other Eastern European countries such as Romania, Hora has become almost inextricably linked in the West with Jewish holidays and the song Hava Nagila.

\section{Abraham Zvi Idelsohn about his life}

1986):

Abraham Zvi Idelsohn in his biographical book My life: A sketch writes (see Idelsohn,

I was born in the fisher-hamlet Felixburg (Jurkalne), on the Baltic Sea, between Windau (Ventspils) and Sackenhausen (Saka), Latvia. My father was Schochet (Butcher) and Baal-tefillah (Prayer guide) in the district. When I was less than six months old, my parents moved to Libau, where, due to the efforts of Dr. Philip Klein, then Rabbi in Libau (later in New York), my father was appointed overseer of kosher meat in a non-Jewish butchery. In my early childhood my parents lived next to the "Chor-schul" and my father used to take me over to that cold, unheated house of worship. The chazzan was Abraham Mordechai Rabinovitz. His strong tenor-voice used to chill me; he had no sweetness in his voice. I remember the Congregation preferred to hear Zalman Schochet, though very old, or Orkin of the Zamet Synagogue. Little did I realize that Rabinovitz will later become my teacher. The above mentioned cantors had less voice than he, but much sweeter, and their singing was with more Jewish feeling.

From my father, I learned to love the synagogal modes and "Zemiroth" as well as Jewish Folk-Songs. At home, I received an orthodox education and appreciation for everything Jewish. I visited old-fashioned "Chadorim," although there were many modern ones in Libau (Liepaja); my father wanted to implant within me the genuine Jewish piety. At the age of 12 years, I was sent to Lithuanian yeshivas, where I 
remained for five years. During that period, I acquired a knowledge of Jewish life. Upon my return home, I decided to take an examination at the Gymnasium and prepare for an intelligent profession. I secured a tutor and started studying.

Suddenly I felt an inner call for music and went to the above-mentioned Rabinovitz, who accepted me in his choir. There I remained for a half year, despite my father's protest that I shall become a "chor-chazan." His uncle never entered the Choral-shul because of the ban the ultra-orthodox Rabbis laid upon it when it was built.

Due to my brother-in-law, who came to visit us, but had to stop in Prussia, because he had no legal right to enter Russia, we journeyed there to see him. While in Memel (Klaipeda) (then Prussia), the idea came to me to go to Koenigsberg, to Edward Birnbaum. He accepted me and recommended me to the director of the Conservatory.

At the time I knew nothing of Birnbaum's work, all I knew was that he was the successor to the famous Weintraub. I found him steeped in German music, his voice insignificant, his chazanuth unappealing and not Jewish. I visited him only a few times; he never instructed me and never showed me his collection.

After a few months, I decided to proceed to London, according to my brother-inlaw's advice. Reaching London, I was advised to enter the Jews College, but I had nobody to guarantee my upkeep during my stay there, so my meeting with Dr. M. Friedlaender was of no consequence. My parents wrote to me, that Rabinovitz was willing to take me back, but I had no means to return. In my distress, I turned to Israel Zangwill for help. He recommended me to the Board of Deputies and secured my passage home. Upon Zangwill's question, how can I return to Russia, where Jews were so maltreated, I answered that I prefer to be with my brothers even in a place like Russian than to live in a free country like England and assimilate.

Rabinovitz promised to instruct me in Chazanuth and in European music, and he kept his promise. During that year I again sang in his choir. He taught me a lot of things, such as sight-singing, theory, voice-training, and the beginning of harmony. He acquainted me with the Chazanic literature of Weintraub, Sulzer, Lewandowski, and others. He implanted within me an appreciation for good Jewish melodic taste and he gave me also an idea of classic music from the works of Bach, Handel, Haydn, Mozart, Schubert, etc. At the same time, I was an ardent reader of Modern Hebrew literature, from Moshe Chaim Luzzatto's poetry to the "Hashiloach" and the "Hador." I became an admirer of the style and articles of Achad Ha'am, who became my guide and pathfinder in my confusion - the perplexity of a modern Jew.

My father, regarding me as a hopeless case, stopped interfering with my vocation. Considering that I learned everything possible from Rabinovitz, I left Libau in the spring of 1901 for Berlin to continue my musical education.

The day I arrived in Berlin I was accepted in the Stern'sches Conservatorium in the opera-class of Siedmann. The Director of the institution was Gustav Hollaender, a converted Jew who developed in me Germanistic, chauvinistic ideas. His brother, Victor H., who was also present, engaged me in the choir of the Charlottenburg Synagogue, of which he was the leader.

My first participation in the opera, however, ended badly; disgusted with the immoral conduct of the players, I gave up my studies and, influenced by Tolstoy's ideas, I became a follower of them. I abandoned music, the Conservatorium, and modern luxury and decided to become a farmer in Palestine. For this purpose, I visited S. Bernfeld, who laughed at my fantasies and told me of the struggle of the poor colonists in Palestine. On the other hand, R. Brainin treated me differently; he wrote to a Baron Manteufel in Greece, who maintained a farm school, to accept me. Unfortunately, his reply came too late. The whole summer I lived as a Tolstoian until my meager resources were at an end. At that time there came to Berlin Cantor Boruch 
Schorr, who looked for singers. My colleagues who accepted Schorr's invitation induced me to do likewise in order to earn something. Schorr was already old and he had no voice at all; nevertheless, his Jewish admirers clung to him enthusiastically. The compositions he gave us to sing were of very mediocre musical value, although some expressed the Jewish sentiment.

Soon the High-Holiday season arrived and I was confronted with the question of my existence. My friends recommended me to Frommermann, who maintained a school for cantors. He gave me a place in a Bavarian community. Brainin approved my action in becoming untrue to Tolstoianism. My preparation in a Weintraub-SulzerLewandowski repertoire was of no avail, there in Augsburg, I had to learn the SouthGerman chazanuth, which is German, consisting of German melodies of the 17th and 18th centuries. On my way to Berlin, I learned from Emanuel Kirschner, chazzan in Munich, that in Leipzig a chazzan was sought. I stopped there and was accepted; one of the Board was a disciple of Weintraub in Koenigsberg. There I would sing real Chazonus.

An old dream of mine was to study in the Leipzig Conservatorium, which I could now realize. I went to Prof. Jadassohn, a sincere Jew, born in Breslau from pious parentage. He was very friendly to me until his death in 1902.

While in Leipzig I studied harmony with Jadassohn, counterpoint with S. Krehl, composition with $\mathrm{H}$. Zellner, and history of music with Kretzschmar, besides voicetraining and piano. There I was able to attend the Gewandhaus concerts under A. Nikisch.

I met and married there a daughter of Cantor H. Schnieder. From Schnieder, I learned the real Jewish sentiment in Chazanuth and the melodic line. As a disciple of Achad Haam, I detested the constant chase after Germanism, which I continuously heard in the synagogue song; even Lewandowski seemed Germanized. The life of the Jews in Germany, too, was Germanized. This was not only true of the Liberals, but also of the Orthodox.

At that time, the South-German Chazanuth was considered genuine Jewish. I, therefore, took a position in a Bavarian community, Regensburg, as Chazan and Shochet, but after two years I received a call from my relatives to come to Johannesburg, Africa, to become a chazzan there, which I accepted. I hoped to be able to live there a genuine Jewish life and to sing the Jewish song, but I soon realized my disappointment.

About the time the idea dawned upon me to devote my strength to the research of the Jewish song. This idea ruled my life to such an extent, that I could find no rest. I, therefore, gave up my position and traveled to Jerusalem, without knowing what was in store for me. In Jerusalem, I found about 300 synagogues and some young men eager to study Chazanuth. The various synagogues were conducted according to the customs of the respective countries, and their traditional song varied greatly from one to another. I started collecting traditional songs. In the course of time, the Phonogram-Archives of Vienna and of Berlin came to my help. After a considerable time at the Institution in Vienna invited me to come and present the results of my studies.

As results of my collection and studies the following convictions became crystallized:

- The Jewish song is an amalgamation of non-Jewish and Jewish elements, and despite the former, the Jewish elements are found in all traditions, and only these are of interest to the scholars;

- The Jewish song is a folk-art, created by the people. It has no art-song and no individual composers; 
- Composers of Jewish origin have in their creations nothing of Jewish spirit; they are renegades or assimilates, and detest all Jewish cultural values;

- The few composers who remained within the fold have mostly corrupted the Jewish tradition with their attempts to modernize it, and have added very little toward genuine Jewish song.

I agreed to go to Vienna, where I was given two rooms by Prof. Exner to work out my records. I applied also for a subsidy from the Academy for the publication of my collection, which I called "Thesaurus of Hebrew Melodies" and prepared six volumes. For this purpose, I had to visit the well-known anti-Semite, Prof. Warabazeck, who received me cordially, and due to his influence, the Academy granted me a subsidy for my work. On the other hand, the relation of the Vienna Chazanim was very unfriendly, almost hostile.

At the same time (1913) there took place the Zionist Congress in Vienna, and I met there Chaim Nachman Bialik, who induced me to write some Hebrew essays for his magazine $R$ 'shumoth which he intended to bring out, a request which I fulfilled.

The men friendly to me were Dr. M. Guedemann, Dr. M. Grunewald, Dr. Feuchtwanger - all Rabbis, also Dr. A Kaminka and A Stern (President of the Jewish Community). Very friendly was Prof. G. Adler of the University, who invited me to attend his glasses in Gregorian chant and to deliver some lectures. My work on the recorded songs and pronunciations I finished and submitted to Prof. Exner. It was published in the Academy Proceedings No. 175.

At that time a fight between the Hebraists and the "Hilfsverein" schools in Palestine was going on. I, though an employee of the "Hilfsverein", decided for the Hebraists, although the double salary was promised to my wife by Eph. Cohen. After eight months of stay in Vienna, I returned to Jerusalem and started my work in the Hebrew Schools.

From my "Thesaurus" only the first volume could be printed, for soon the world-war broke out and all cultural activities had to stop. I was enlisted in the Turkish army, first as a clerk in the hospital, later as bandmaster in the trenches in Gaza, from which I emerged after the armistice.

In 1919 I returned to my teaching and research work. The Zionist Commission freed me partly from my work as a teacher and I devoted this time for work on the "Thesaurus," to write the Hebrew introductions, the first of which became very bulky, and I had to separate from it the Yemenite Poetry, which was late published separately under the title "Shire Teman."

In 1921 I decided to go to Europe to publish my works. I took my family with me. I arrived for the Zionist Congress in Carlsbad, where Dr. V. Jacobsohn, then head of the "Juedischer Verlag," bought my manuscripts of "Sepher Hashirim," and Bialik encouraged me to write a history of Jewish Music, the first volume of which he published in the "D'vir," the other four volumes remained in Manuscript. Up to date. Upon sending the second volume, Bialik wrote to me... "Your first volume is still lying in our store, only a few copies are sold ... we have no courage to print the second one."

In Carlsbad I met also the head of the K'lal-Verlag in Berlin, who published my "Z'lile Haaretz" and "Z'lile Aviv"; there I met also B. Cahan (the owner of "Yalkut") who brought out my "Sepher Hashirim" and "Shire T'filloth", 2nd edition. In Berlin in met Benjamin Harz with whom I arranged to publish my "Thesaurus" in Hebrew, German and English, and by the end of 1922 four volumes came out. During the year I was in Berlin, I materialized an old dream, I found a publisher to put out my JEFTAH, of which I wrote both the words and music and which was the first Hebrew opera ever written. Negotiations with the Oxford Press and other publishing companies were unsuccessful. After more than a year's stay in Berlin, my friends 
advised me to go to America on a lecture tour, which I did. Before that, I lectured already in Vienna, Berlin, Breslau, Posen, Leipzig, London, Oxford, Amsterdam, and in other places.

Upon my arrival in the U.S., I found Dr. and Mrs. De Sola Pool, Prof. and Mrs. Samuel S. Cohen, then in Chicago. It was due to their efforts that I was invited to catalog the Birnbaum collection in the Hebrew Union College Library in Cincinnati and later was asked to teach at that college. They furthered my cause in various ways.

In 1924 I settled down in Cincinnati as a Professor of Hebrew and Liturgy, as well as Jewish Music, but before that, I toured the country lecturing, from coast to coast.

During my stay in Cincinnati, I added four more volumes to my "Thesaurus," making it ten volumes. The President of the College, Dr. Morgenstein, secured funds for the $5^{\text {th }}$ and partly for the 6th volume, but the American Council of Learned Societies decided to grant me a subsidy for all the remaining volumes, and thus I was enabled to publish my "Thesaurus" in ten volumes in German and English, the first five volumes also in Hebrew.

From this work grew out several others: research in Liturgy, which I published in the "Thesaurus," Vol. 3 and 4; research into the Poetry, which I published in the "Hator" and "Hashiloah" and separately in book form under the title "Shire Teman"; pronunciation of Hebrew, published in the "Hashiloah" and in the "Monatschrift" 1913, which was put out separately as a reprint; a Manual, published in 1926 by the Hebrew Union College - an extract of the four volumes of the History of Liturgy which Holt published in 1932. The Brotherhood ordered from me the "Ceremonies of Judaism," and these were put out in book form in 1929, a second enlarged edition in 1930, and the third edition in 1932.

My activity as a teacher of singing and Chazan gave me ample opportunity to create along these lines. Already in 1908, I published in Jerusalem under my supervision two volumes "Shire Zion" for choir and solo, also a theory of music in Hebrew, "Torath Han'gina" (1910), and "Sepher Hashirim," vol. 1, likewise several essays in various periodicals, and "Shire T'filla". While in America, considering the situation in which Judaism placed, I composed and published two Friday-evening Services and one Sabbath-morning Service for four-part choir with organ accompaniment, according to the Reform ritual; "Jewish Song-Book," two editions, the third edition is being delayed due to my illness. I also put out a Friday-evening Service for one voice with accompaniment.

In 1929 I was taken sick with a coronary-vessel disease and was laid up for six months. But in $1931 \mathrm{I}$ had a paralytic stroke on my left side. This repeated several times, so that I could not teach any more, nor write, now move about, nor read much. The Board of the College granted me a pension, for the rest of my life. I can do nothing, but waste my time in reflection.

In 1938 he died in Johannesburg.

\section{Conclusion}

Hava Nagila is a demonstration of how the song can become a powerful marker of identity, it is also a sign of the whole culture of the Jewish people. Along with the song, its author came to the following main conclusion from the research he does on the overall musical creativity of the Jewish people. The conclusion can be summarized as follows:

The Jewish song is an amalgamation of non-Jewish and Jewish elements, and despite the former, the Jewish elements are found in all traditions. This tradition is a kind of Jewish cultural code that unites the Jewish settlements scattered around the world. Although Jewish 
music is largely influenced by the local traditions of non-Jews, it largely preserves the Jewish worldview, cultural framework, and description of the world.

\section{Acknowledgements}

This research did not receive any specific grant from funding agencies in the public commercial, or not-for-profit sectors.

The authors declare no competing interests.

\section{References}

Idelsohn, Z. A. (1986). My Life: A Sketch. Jerusalem, Israel. https://www.jewishmusic.huji.ac.il/yuval/22818 . music.huji.ac.il/sites/default/files/O2\%20E\%20My\%20Life\%20-\%20A\%20Sketch\%20\%20AZ\%20Idelsohn\%20p18-23\%20plus\%20title\%20p.pdf.

Seligman.org (2009). Abraham Zvi Idelsohn. The Thesaraus of Jewish Music \& Hava Nagila. Abraham Zvi Idelsohn on the website of the Jewish Music Research Centre of the Hebrew University of Jerusalem. http://www.seligman.org.il/joffe AZIdelsohn.html.

Wikipedia.org (2013). Abraham Zevi Idelsohn. https://pt.wikipedia.org/wiki/Abraham Zevi Idelsohn. 


\title{
Kurdish Migration Waves to Rojava (Northern Syria)
}

\author{
Vladimir Stefanov Chukov \\ University of Ruse "Angel Kanchev", Ruse, BULGARIA \\ Faculty of Business and Management, European Studies Department
}

Received: 15 October 2020 • Accepted: 10 December 2020 • Published Online: 25 December 2020

Abstract

This study aims to present the Kurds and the Kurdish migration waves to Rojava (Northern Syria). The accumulation of huge Kurdish masses on the territory of today's Syria is the result of millennial waves of migration caused by the turbulent events in the Middle East. The article analyzes: The Kurdish settlements in Syria; The French colonial authorities; The French colonial policy in the Middle East; The migration flow to Syria. The authors of the in-depth study of modern Syrian Kurdistan, The Question of Syrian Kurdistan - Reality, History, Mythologisation, argue that in the twentieth century there were two main waves of migration to northern Syria. One is expansionist and the other is restrictive. They form the current profile of the Kurdish community in Syria.

Keywords: Syria, Kurdish refugees, Kurdish migration waves, Rojava.

\section{Introduction}

The accumulation of huge Kurdish masses on the territory of modern Syria is the result of millennial waves of migration, selected by the turbulent events in the Middle East. Famous French Orientalist Olivier Roa uses the word "macro-ethnicity" to refer to the Kurds during the French mandate in Syria. ${ }^{i}$ To explain the meaning of the term, the researcher uses the methodological tool "comparison". In this regard, he deals with two geometrically located communities, each of which has its own structure. Roa accepts the hypothesis that the diverse internal structure of the Kurds is very similar to the incredible Central Asian ethnic palette. In itself, it is a fan of many social groups of different sizes, before flowing into the even larger ethnoreligious fan of Syria and the entire Middle East.

\section{The Kurdish settlements in Syria}

The first permanent Kurdish settlements in Syria are associated with the stay of Kurdish military garrisons in Damascus. It is about the $13^{\text {th }}$ century and the wars that Saladin waged against the Crusaders. In addition, individual small groups of Kurds have often been deported outside the lands of their historic homeland. Most often this was due to punishment. This is how Kurdish communities emerged in Damascus, Horan, the northern part of the West Bank, and even in Jordan. This most often happened on the way of pilgrims traveling to the holy lands of Mecca and Medina. Kurdish troops have enforced the settlement they have inhabited, but

(C) Authors. Terms and conditions of Creative Commons Attribution 4.0 International (CC BY 4.0) apply. Correspondence: Vladimir Stefanov Chukov (PhD), University of Ruse "Angel Kanchev", Faculty of Business and Management, European Studies Department, Ruse, BULGARIA. E-mail: vladimir_chukov@abv.bg. 
have also provided security for the pilgrimage column. Very often Kurds from other countries have joined the Kurdish core of the local janissary corps, perceiving it as a specific social environment. Thus, over time and the constant influx of Kurds from Diyarbakir, Erbil, and Kirkuk, the famous Hai al-Akrad, the Kurdish district of Damascus, was formed. In 1930 it numbered 12,0oo people. ${ }^{\text {ii }}$

During the $17^{\text {th }}$ and $18^{\text {th }}$ centuries, the High Gate sought to settle by force in various areas, in accordance with its plans for a well-structured tribal settlement throughout the Middle East. For example, the concentration of the Kurds in Diyarbakir was planned by the Ottoman authorities, as it was strictly monitored by the governor Mardin. One of the areas to which some of the tribes were sent was Raqqa. However, they did not stay there for long, as apparently the land there was not suitable for grazing the herds with which a significant part of the Kurdish tribes in Syria subsisted. The High Gate often used the services of the Shamar Arab tribe, which attacked the Kurds in northern Syria when they refused to pay taxes to the sultan. An important role in warming relations between the Ottoman authorities and a kind of federation of Kurdish tribes was played by its new leader, Ibrahim Pasha. In the process of improving relations, it came to the point that Ibrahim Pasha committed himself in front of the High Gate to fill with Kurds the composition of the elite Ottoman Hamidiya, created in the late $19^{\text {th }}$ century. It is no coincidence that some of these elite soldiers of the sultan joined the Kurdish uprisings against the Young Turks. According to Rondot, his successor, Mahmoud Bey has never had such authority among the Kurdish tribe.iii This is the reason why the Kurds began to look at the sultan with hostility.

Towards the end of the $19^{\text {th }}$ century, the Kurds in Damascus also established their own urban Notabilitet. These are people who manage to reach a high-status social status. Such were the landowners who managed to buy large tracts of land around the Syrian capital. In addition to the activities of such large Kurdish clans as Yusuf, Shamsedin, and Abid, a second neighborhood with a predominantly ethnic population was formed. Its name was Suk Saruja, whose name suggested that there were more people living there who were engaged in trade. This was the first neighborhood built in the 19th century outside the walls of the Old City of Damascus. According to the Lebanese Philip Huri, the creation of the neighborhood in question was not so much an expression of the desire for ethnic identification of the community, as the formation of a clientelistic network in the literal sense of the word of wealthy Kurdish landowners and pastoralists. ${ }^{\text {iv }}$

At the same time, such a significant Kurdish community was formed in Syria's secondlargest city, Aleppo. The internal migration waves of Afrin and Jazeera, mainly due to economic reasons, strengthened the presence of the Kurds in the village. ${ }^{v}$ Thus emerged the Kurdish neighborhood of Sheikh Maksud, which played a key role in the division of Aleppo between the opposition and the regime in 2013-2016 during the country's civil war.

In the first half of the $20^{\text {th }}$ century, it was very difficult to talk about the Kurds in Syria as a whole. It is about groups/tribe, clan, or family, as well as individuals. Ethnic qualifications remain in the background. Due to their strong fragmentation, it was much more relevant for the Kurds to have some social, political, geographical, regional, or sectarian characteristics in order to identify the group. For example, in the Kurd Doug region alone, there are reports of the existence of five major Kurdish tribes, namely the Amikan, Bian, Sheikhan, Shikakan, and Jam. Other, smaller tribes were Robaria, Harzan, Koshar, and Hastian. At the same time, there were twentysix Yazidi tribes in the region with a total population of just over 1,000, who were vassals of the already mentioned small tribe of Robaria.vi

This feature of the community has long influenced the assessment of external factors towards the Kurds. Such an approach has been noticeable since the time of the French mandate in Syria. Probably this feature distinguishes the Kurds from other large local communities and therefore their minority status brings them significantly more privileges. 
The authors of the in-depth study of modern Syrian Kurdistan The question of Syrian Kurdistan - reality, history, Mythologisation argue that in the twentieth century there are two main waves of migration to northern Syria. One is expansionist and the other is restrictive. ${ }^{\text {vii }}$ They form the current profile of the Kurdish community in Syria.

\section{The French colonial authorities}

The first took place during the French colonial mandate, namely in the period 19251939. The French authorities not only organized local life, but also introduced new concepts and ideas about the relationship between center and periphery, which are an important component in building each of the new power mechanisms. Instead of the traditionally strong vertical ties typical of Eastern states and, in this case, the Ottoman Empire, the colonial authorities tried to encourage an alternative model based on "horizontal, corporate, and national lines."viii To a large extent, it is a question of institutionalizing the European formula for the nation-state in the Syrian and Lebanese case, looking for the appropriate place for minorities in it. Concretizing the place of the latter is a difficult moment of transition from the Ottoman-Turkish Millis system, in which the ethnoreligious political center is located high above the governed, to the new homogeneously built Middle Eastern states. The Kurdish community, the largest ethnic non-Arab minority in the Middle East since the first decade of the $20^{\text {th }}$ century, plays a key role in the rapidly accelerating nation and state building process.

The vast majority of Syrian Kurds speak the Kurmanji dialect and practice Sunni Islam. However, there is a difference between the Turks, who are followers of the Hanafi legal dogmatic school, while the Kurds - of the Shafait. In the early twentieth century, they were concentrated in three enclaves along the northern border of the Syrian state - Jazeera, Jarablus, and Kurd Dag (Jebel al-Akrad, the mountainous areas around Afrin).

It is noteworthy that they inhabit isolated areas, either mountainous or peripheral to the center of power. The Yazidi minority, unlike their compatriots, is more "social." It is more likely to mix with non-Kurdish people, Arabs, Christians, Turkmen, and others. In this regard, the Yazidis inhabit areas along the Turkish-Syrian border. The three above-mentioned places become a kind of "corridors" to which the Kurds fleeing from Turkey head and pass.

\section{The French colonial policy in the Middle East}

The policy of complete Turkification of all communities inhabiting republican Turkey, adopted by the Young Turks and later adopted by Kemal Ataturk, is the reason for the constant riots of the resisting minorities, including the Kurds. During the period 1925-1938, they raised seventeen revolts against the assimilation actions of the Turkish national state. The uprisings began in 1925 with that of Sheikh Said Biran ${ }^{\text {ix }}$ and ended in 1938 with the Kurdish revolt of the Alevi Zaza, led by Seyed Riza in Dersim. ${ }^{x}$ The latter was suppressed in a particularly cruel manner. In 2019, information came out that this was done with chemical weapons imported from Nazi Germany.

The Yeni Ozgur Politika and Junde Welt gazeteleri newspapers, published in Germany, published documents accusing the Hitlerite government of selling mustard gas and polyvinyl chloride to Turkey. The purchase invoices bear the signature of Mustafa Kemal Ataturk himself. According to the same information, the Nazis also sold the planes, known during World War II, Heinkel He 111, with which the chemical weapons were thrown in the Kurdish areas. In July 2019, three parliamentarians from the left-wing Die Linke party addressed questions to the federal government of Angela Markel. ${ }^{\mathrm{xi}}$ 
Seyed Riza's revolt puts an end to a wave of riots by individual Kurdish tribes in southern Turkey. After each of them passes thousands of Kurdish, persecuted by the Turkish state, rebels in Syria. However, the main flow of ethnic Kurdish refugees from Turkey is directed to al Jazeera, called by the French Upper al Jazeera. The latter was later organized by the colonial authorities in the northeastern province of Hasaka. Unlike the Kurds, the Armenian refugee flow also pushed out of Turkey, is inland, and especially in major Syrian cities. ${ }^{x i i}$ If the first group is somewhere around 120,000, then the second is only 9,788 people. The information is based on data from the Syrian civil register in al Jazeera until 1943. ${ }^{\text {xiii }}$

An important reference point for the direction of the Kurdish migration waves from Turkey to Syria is the line following the extension of the railway connecting Europe with Istanbul and Nusaybin in the direction of Aleppo, and from there to the cities of Ras al-Ain, Darbasia, Amuda, Kamishli, and Kakhtania. ${ }^{\text {xiv }}$ In practice, before the official international borders were delineated, the system of national citizenship was introduced, the first national censuses were carried out, a civil register was established, etc., these lines followed the natural flow of human migration. It has existed since the emergence of the first state formations in the region, based on purely economic and trade principles. The delineation of national borders in the region, following the Syke-Spiko Treaty of 1916, is the circumstance that gives the always existing, until now, in this part of the Middle East, economic and trade movements of huge masses of people, the status of migration wave. The thesis is that in addition to the purely political impetus to cross the TurkishSyrian border, formed after the collapse of Ottoman Turkey, there has always been an economic factor for such movements.

The Kurds first met with French colonial troops in 1919. They penetrated relatively easily into the mountainous areas of the Kurd Doug. According to Philip Huri, it was noticeable that not only this Kurdish community but also the one in Damascus very quickly turned their backs on their former metropolis. But it also seems that despite its apparent "Arabization", it has been felt that the Damascus Kurds were not strong supporters of Arab nationalism. The Kurds form special military formations within the French army in Syria. They took an active part in the suppression of the revolt of the local Arabs in $1925^{\mathrm{xv}}$

The situation with the Kurds around the city of Jarablus was a little different. A powerful tribal federation has lived in the region between the present-day city of Suruj and the Syrian city of Jarablus on both banks of the Euphrates River since the $17^{\text {th }}$ century. Some of the tribalist formations were Arab. Especially around Jarablus lived about 16,0oo Kurds, divided into five large tribes - Alaedinan, Bijan, Kitkan, Sheikhan, and Shedanan. When the colonial army arrived on the scene in 1920, members of the Kitkan tribe immediately joined it. The other tribes, however, were not so friendly. Those in Urfa, Enteb, and Marash joined the units of the new Turkish republic commanded by Mustafa Kemal Ataturk. The French tried to form a local gendarmerie, including Kurds, Alawites, and Circassians. However, it was not as effective as the foreign corps in the French army as the Algerians and Armenians. This led to a great battle in Marash between France and Turkey.xvi

The strongest resistance to the French army came from the relatively large, compact Kurdish community in al Jazeera. Two region-specific factors contributed to this.

The first is that the Kurds there were heavily influenced by the Pan-Islamic propaganda of Kemal Ataturk's government. This was partly true of some Kurdish communities in Aleppo province. For example, Kurdish riots there were raised under Islamic-motivated slogans such as those for "war against infidels."xvii

The second is related to the strong instinct to uphold the specific way of life, to the resistance of the colonial desire to destroy the tribal-clan way of social organization. In fact, in relatively larger minority groups, as was the case with the Kurdish community in al Jazeera, tribalism reflexively spilled over into local patriotism. Thus, the status quo achieved by the fragile 
balance between the various local Kurdish tribes or between the various smaller clans in the region was equated with the ethnicity's understanding of local patriotism. ${ }^{\text {xviii }}$

However, it was applicable to the colonization troops, not to the Arabs, with whom they achieved an incredible tribalistic cocktail. In this case, N. Fucaro uses the term "Arab-Kurdish hybrid socio-political subject", in which each of the two components has its own function. According to him, the Kurds are a binary minority and the Arabs an opposition majority ${ }_{\text {xix }}$ Thus, in al Jazeera, a multi-layered original socially constructed matrix is created, in which the three ethnic groups (French, Arabic, and Kurdish) layer a tangle of dynamic, social interrelations. In it, the external, colonial, non-Islamic, and politically powerful factor stimulates the processes of homogenization of a visibly homogeneous, politically subordinated mass. However, the cohesion between Kurds and Arabs is temporary, but it leaves a strong imprint on the way their own nationalist ideologies are formed.

The French colonial authorities played a major role in directing individual migration flows to parts of their mandated Syria. They tried to create separate territories in which certain ethnic and confessional groups would dominate. Thus, separate autonomous regions were created, which differed in the size of the territory and the population. At the same time, the French governor-general in Damascus granted varying degrees of powers to local ethnoreligious authorities. Examples in this regard are the formed confessional districts - Alawitistan (the state of Jebel Al-Alauin), with capital Latakia (1920-1936) and Durzistan (state of Jebel ad Druz), with capital Sueida (1921-1936). ${ }^{x}$ It is noteworthy that these two large minority groups, which are part of the Arab ethnic group but do not belong to the Sunni religion, are given enormous powers by the colonial authorities. They had their own flags and coats of arms, the right to choose their own local authorities, to issue their own passports, and other similar powers within the mandated Syrian territory. The Kurds, as a compact population and independent territory, were not given this. The Kurdish ethnic territories were divided administratively, and so the Jarablus and Azaz districts were initially formed. Within the province of Al Jazeera, which included the present-day Syrian provinces of Hasaka, Raqqa, and Deyrezor, three separate administrative districts were established - Kurdish, Christian, and Arab. This happened in the 1930s, thus counteracting the aspirations of the Kurdish ethnic element to receive such administrative freedom to encourage its aspirations for future secession from mandated Syria. It is not clear exactly why the French authorities did not give the Kurds as much confidence as the Druids and Alawites. It is possible that they feared that they were too close in mentality, national ideas, and historical ties to the Turks. It is possible that they simply considered that the Kurds were not in a position to organize themselves to such a high level that they could call themselves a "state" and be granted privileges corresponding to proto-statehood. However, it is noteworthy that all the more compact minorities during the period were encouraged to create their own ethnic territories along the borders of French Syria. In this way, they become a kind of buffer and a security barrier in the event of a collision with neighbors. Alawitistan is in the northwest corner, Druzistan is in the south, and Kurdistan (al Jazeera) is in the northeast of the country.

Undoubtedly, at that time the majority of the population in al Jazeera was Bedouin, and what was settled in the urban agglomerations was relatively small. This was due to the fact that, regardless of the demarcated border, the pastoralists, who were a large part of the Bedouins, continued to search freely for their animals on both sides of the border. Usually, the climatic conditions were the ones that determined in which season of the year where they would be with their herds - in the Turkish or Syrian part.

Over time, the population of al Jazeera has multiplied. The first data were for 1938. Statistics show that then the number of all inhabitants of this Syrian region was 105,513 people. The enumerators specify that the figure does not include Bedouins, be they Kurds or Arabs. xxi In 1943 the population was already 146,001 people and annually it increased by 5.6\%.xxii This was the province in mandated Syria until 1943, which saw the fastest increase in population. During this 
period, the French colonial authorities quickly granted citizenship to immigrants, thus trying to quell any looming social riots.

The interesting thing, in this case, was that the Kurds who took advantage of this policy of the French governor-general were much more than the Bedouin Arabs. Despite the liberal migration policy during this period, a significant part of the Arabs, faithful to their sedentary lifestyle, remained without official documents of belonging to the Syrian state. According to the authors of the collective work The Question of Syrian Kurdistan - Reality, History, Mythologizing, the Arabs began to be recorded en masse in the registers of Al Jazeera only in the second half of the 40 s of the $20^{\text {th }}$ century.xxiii

French colonial policy in the Middle East relied much more on the export of its own nationalism than on the actual introduction of market economic and social relations. In the colonized area between the Mediterranean and the province of Mosul in Iraq, Paris placed a strong emphasis on its traditional "civilization" mission, which yielded much more visible results in Africa than in the Arab Middle East. However, all this led to traditional assimilation, not so much to integration.

After all, France carried out trivial colonial actions based on the principle of "divide and rule." They opposed the urban against the rural elite, the individual minorities in between, but mostly the minorities against the Sunni majority. The approach of the French colonial school in the Levant is based on the so-called "Lyautey-system" in which the main idea is to isolate the representatives of local nationalism. ${ }^{\text {xiv }}$ French colonial policy in the Middle East was based on completely opposite principles to that of Britain's rival in Iraq. London sought the support of the Sunni community, while Paris sought the support of non-Sunni minorities - Alawites, Druze, Christians, and others. The slogans raised by Arab nationalists to create Arab unity were perceived by the French colonizers as a hidden tool of their British rivals to damage Paris' ambitions in the region. However, this also left lasting traces in the policies of the two colonial states. France remained in the minds of the peoples of the Middle East as defenders (and dissenters) of minorities, while Britain - of the Arab nation-state, and subsequently of those circles that later embraced the ideas of Islamic (especially) Sunni radicalism. ${ }^{\mathrm{xxv}}$

After 1943, the independent Syrian government tried to change migration policy in areas with a compact Kurdish population. It made an effort to quickly establish control over local registers. However, this did not happen to him quickly, as the final and complete withdrawal of French troops took place only in April 1946. However, the national government tried to obtain all the documentation, especially that concerning the Bedouins, as far as the colonial authorities were able to register them. The Syrian government feared that the former metropolis could use this information to stimulate separatist sentiment in this part of the country. These were mainly the Assyrian-Christian and Jurassic communities, which were the subject of special encouragement for the acquisition of Syrian citizenship by France.

\section{The migration flow to Syria}

At the beginning of the transition period 1943-1946, the new rulers in Damascus quickly began to apply a restrictive policy towards migrants coming from Turkey, but there was no significant restriction of the flow to northern Syria. In fact, the momentum was so great that the only thing the Syrian authorities did was to suspend the entry in the official register of new residents of the Syrian Arab Republic. However, at the end of 1947, these actions of the government in Damascus began to bear fruit. Al Jazeera's population growth has dropped to about $1 \%$ a year. According to statistics, the Kurds already numbered 151,946.xxvi In the next five years (1947-1952) the pace of the immigration process increased again, but with moderate values. It became $1.3 \%$, with a registered Kurdish community of 162,145 . This was mainly due to external 
migration and not to natural growth. xxvii It should be noted that these are official statistics, without taking into account the unregistered, be it those who settled in the cities or the Bedouins, whom no government could force to obtain documents.

The migration flow to Syria directly depended on the political, economic, and social situation in neighboring Turkey. In a worsening situation, a huge group appeared there, wanting to cross the border and which the Syrian authorities usually tried to bring back to Turkey. A very strong factor for Kurdish immigration to Syria was the compulsory military service in Turkey. For this reason, the young people who were to enter the Turkish barracks were particularly active. In fact, there was a kind of migration rotation of Kurdish groups between the two neighboring countries.

Something like the secondary resettlement of these Kurdish masses was reproduced, as some of them were sent not to their native places, but too large cities in the north such as Ankara and Istanbul. The main reason for this was that their houses were destroyed by the Turkish authorities in order not to return once they had left. The Kurds, who still managed to escape forced return to Turkey, usually followed their tribal, clan, or family ties to settle in one of Syria's three already established Kurdish enclaves. Thus, individual Kurdish villages or urban neighborhoods were "transferred" from Turkey to the Arab country. On the other hand, however, this population became a prerequisite for the emergence and accelerated development of hitherto unknown crafts in Syria. There was also a rapid development of agriculture, whose main engine was the Kurds who emigrated from Turkey. In the 1950s, northern Syria marked the characteristics of an economic boom that required more and more labor, which in turn was located in the southern regions of Turkey.

A classic example in this regard is the accelerated development of cotton production. In the 1950s, there was an increased demand for world stock markets due to the three-year war on the Korean Peninsula (1950-1953). The land in northern Syria has proved very suitable for sowing this technical crop, which has led many entrepreneurs and investors to attract additional labor. The agricultural workers were of different ethnicities - Kurds, Arabs, and Christians. At the same time, the leaders of two large Kurdish tribes, namely Malia and Huirkia, turned mainly to their compatriots in Turkey. They signed a contract for the provision of labor with the leaders of the leading company "Asfar wa Nudjar".

Thus, the latter undertook to provide more competitive pay and working conditions in the area of the city of Ras Al-Ain to the members of the Kurdish tribe in question, which inhabits mainly southeastern Turkey. Moreover, tribal chiefs began to compete in this occupation and even began to call them "cotton sheiks". The latter received a high social status, which directly made them the last between the Kurdish tribes and the political regime in Damascus.

At the same time, the expanded commercial railway station in Kamishli, the city became the subject of a serious influx of economic immigrants. In the early 1950s, it had a population of over 30,000. This fact made it the economic center of the region and the future capital of Syrian Kurdistan. Once in Syria, the Turkish Kurds did their best to meet the conditions for obtaining Syrian citizenship. For them, the Arab country was a kind of "paradise" compared to the extremely difficult living conditions they had in Turkey.

Serious social transformations began in Syria in the 1950s, thanks to dynamic agrarian reforms. The stratification among the farming class has already become visible. A stratum of landowners also emerged, including large Kurdish owners. The agricultural infrastructure is constantly being improved. For example, in 1951, the pumping stations doubled to 5,068. Irrigation of thousands of hectares of Syrian fertile land, more than half of which was along the Euphrates and $\mathrm{Al}$ Jazeera rivers, was ensured. 
The Syrian authorities continued to take all possible measures to limit the immigration of Turkish Kurds and encouraged the settlement of Arabs in this most northeastern region of the country. The rulers of Damascus feared ethnic-separatism. The latter believed that many soldiers in the Syrian army, recruited since the French term, have Turkish roots, but have successfully disguised their Turkish names.

The Syrian government feared that Kurdish migrants and Turkish officers who hid their real names could create many headaches for the independent Arab state if they united in their actions. In addition, participants in the highly destabilized regime in Damascus under Hosni Zaim, Hashim al-Athasi, Fawzi al-Sulu and Adib al-Shishekli (1949-1954) had doubts that it was the Kurds who would be the target of active communist propaganda in Syria. of the USSR, at the beginning of the Cold War. Moreover, the latter two were Syrian Kurds formed as officers in the former French colonial army. ${ }^{x x v i i i}$ However, they did not rule differently from the other Syrian presidents who came to power through a coup.

\section{Conclusion}

As the country's health system has improved, the average age of the Syrian population has been gradually increasing. During the period 1952-1963 al Jazeera was constantly in the first place of all provinces in the country in terms of population growth. In a period of seven years, it has almost doubled. For example, in 1952 the total number of people living in this northeastern part of Syria was 162,145, while in 1959 they numbered 293,140. In just four years, the registered population of al Jazeera was 316,083 . Thus, for the period under review, the population there increased by as much as 3.6\%. According to the Ministry of Interior, the demographic situation there is an unprecedented example, as Al-Jazeera had the highest population growth rate in the world. xxix Thus, gradually, at the end of the fifth decade of the twentieth century and the beginning of the sixth, official documents in Syria began to mention the existence of two categories of citizens, namely those living in Syria and Syrian citizens. At the same time, there was talk of "extraordinary statistics", the purpose of which was to provide information both to those who have regular documents and to those who obtained passports illegally. All this was due to the fact that the Syrian authorities began to automatically refuse to grant citizenship to the incoming Kurds. Initially, this happened after a period of five years, but over time it was extended to ten years.

Thus, in the 1960s, a stratification began within the Kurdish Syrian community itself. Those who have lived in this country for centuries have been grouped mainly in large cities, mostly Damascus. They were radically different from those living in the areas bordering Turkey. Normally, over time, they will be classified as "internal" and "external".

\section{Acknowledgements}

This research did not receive any specific grant from funding agencies in the public commercial, or not-for-profit sectors.

The author declares no competing interests.

\footnotetext{
i Roy, O. (1991). Ethnicities and Politics in Central Asia [Ethnies et politique en Asie centrale], REMMM. pp. 59-60: pp. 17-36.

ii Zelter, M., Minorities in Iraq and Syria, Peoples and Cultures of the Middle East, New York: Random House. 1969. pp. 17-22.

iii Rondot, P. (1937). The hill tribes of earlier Asia. Some social aspects of the Kurdish and Assyrian populations, Bulletin d'Études Orientales [Les tribus montagnardes de l'Asie antérieure. Quelques aspects sociaux des populations kurdes et assyriennes, Bulletin d'Études Orientalesq], VI. pp. 1-49.
} 
iv Khoury, P.S. (1984). Syrian urban politics in transition: the quarter of Damascus during the French Mandate, IJMES, pp. 507-540.

v Op. cit.

vi Lescot, R. (1940/1988). Kurd Dagh and the Moraud movement, Studia Kurdica [Le Kurd Dagh et le mouvement Mouroud, Studia Kurdica], pp. 1-5, pp. 101-26.

vii Masalat al akrad Surya - al wakaya, at tarih, al ustura, The Question of Syrian Kurdistan - Reality, History, Mythologisation, Markaz al Arabi lil abhat wa dirasat al siyasat, Beirut, pp. 5-31.

viii Gelvin, J. L. (1994). The Social Origins of Popular Nationalism in Syria: Evidence for a New Framework, IJMES, 1994, 26(4), pp. 645-661.

ix The Kurdish Zaza and Kormanji tribes, backed by former soldiers of the Hamidian corps formed during the reign of Sultan Abdul Hamid in 1891, revolted to restore the caliphate. This is happening in the area of Diyarbakir, Elazig, Bingöl, and Mersin. After the defeat, the survivors fled to Syria, where French authorities gave them protection. For more information see Hakan Ozeglu, From Caliphate to Secular State: Power Struggle in the Early Turkish Republic, 2011, p. 147. https://books.google.bg/books?id=Cw5V1c1ej_cC\&pg=PA147\&redir_esc=y\#v=onepage\&q\&f=false, 2.02.2019.

x Talji, M., Ezmat al-Hawiya fi Turkey: Turuk Jadida Lil Moyalaja, The Identity Crisis in Turkey: New Approaches, Cit. by Abdel Ati, M., Turkey beyna tahadiyat at tahil wa rihanat al harij, Turkey between internal challenges and external influences, Dar al arabiya lil ulum nashirun, Beirut, 2010. p. 97-100.

xi The Kurds accuse Germany of being permanently involved in the production of the chemical weapons used to kill the Kurds. It is not only Dirsim, but also Aleppo in 1988, thrown by Saddam Hussein's government in Iraq. For more information see: Almania mutauarita fi mazjazir Dirsum wa Halebcha, Germany was involved in the massacres in Dirsum and Halebcha, AFN news, https://anfarabic.com/\%D9\%, 9.08.2019.

xii Between 1919 and 1930, Armenians fleeing Turkey to the south were estimated at approximately 120,000. About 107,000 settles in Syria, the rest move to Lebanon. For more information see Longrigg, S., Syria and Lebanon under French Mandate, New Impression Edition, 1968, pp. 177-200. By 1940, more than 400,000 people were thought to have crossed from Turkey to Syria following the surrender of the province of Hatay (Escanderun County) to Turkey by the French colonial authorities. The Lebanese researcher of this period, Filih Huri, speaks of a similar number. For more information see: Surya wa al intidab al france: as siyasa al kaumiya al arabia 1920-1940, Syria and the French mandate: Arab national policy 1920-1940, translation Muasas al abhat al arabiya, Beirut 1998. p. 568-570.

xiii For more information in Dalil Cumhuriya Surya: Yusdar Sanauyan an Jaridatei Ahbar wa Nizam bi Dimashk 1939-1940, Directory of the Syrian Republic: published annually in the two newspapers Ahbar and Nizam, Damascus, 1939-1940, Damascus, Matbaa alif ba al a 1940, p. 527.

xiv Mardini, A.Sh., Muhafazat Hasaka, dirasat tabiya, tarihiya, bashariya, iktisadiya, tahualat wa afak mustakebeliya, Hasaka Province, natural, historical, demographic, economic research: transformations and future perspectives, Damascus, Wizara al saha 348. Quote from Masalat al akrad Surya ... p. 20.

xv Khoury, P.S., Syrian urban. p. 526.

xvi Kerr, S. (1973). The Lions of Marash, pp. 195-212.

xvii Lawson, F.H. The Northern Syrian Revolts of 1919-1921 and the Sharifian Regime: Congruence or Conflict of Interests and Ideologies? in T. Philipp \& C. Schumann (Eds.), From the Syrian Land to the States of Syria and Lebanon, Beirut, Orient-Institute, 2004, pp. 46-77.

xviii Méouchy, N. France and Lebanon 1918-1946. The ambiguities and dynamics of the agent relationship, Damascus: French Institute of Arab Studies of Damascus [France et Liban 1918-46. Les ambiguités et les dynamiques de la relation mandataire, Damascus: Institut Français d'Etudes Arabes de Damas], 2002, p. 286. 
xix Fuccaro, N., Kurds and Kurdish Nationalism in Mandatory Syria: Politics, Culture and Identity, The Kurds, An Encyclopedia of Life, Culture, and Society, Mazda Publishers, 2003, pp. 279-282.

xx Rabinovich, I., The Compact Minorities and the Syrian State, 1918-45, Journal of Contemporary History, Vol. 14, No. 4, p. 690-711, 1979; Taura Jebel Druze, The Druze Mountain Revolution, Maraa Ash Shark, 1925 ,

http://jrayed.org/Olive/APA/APRESS ar/sharedpages/SharedView.Page.aspx?sk=6oEDCCBE\&href=me raatalsherk/1925/09/12\&page $=3,2.02 .2019$.

xxi Murad bek, S. (1994).Istiklal Surya: aurak dmamil murad bek, Independence of Syria: documents of Jamil Murad bek, Beirut, sharika al matbuat lil tauzia wa nasher, p. 81.

xxii Dalil al-Jumhuria al-Suriyah fi Fajr al-Siyada wa al Istiklal, Handbook of the Syrian Republic on the Eve of Sovereignty and Independence, Damascus, Dar wa Matbaa Yakza Lil Nasher, 1946, p. 536.

xxii Masalat Akrad Surya al - al wakaya ad tarih. p. 21.

xxiv Hubert Liotti (1854-1934) was a French general and creator of a special approach in the French colonial school. He was the first governor-general of Morocco to rule in the light of the local Moroccan sultan (19121925). His management methods were perceived as very successful and applied in other colonies. He believes that military force should be used only as a last resort, as it is expensive and alienates the local population. He aims to win over local leaders and erase the social divisions that already exist in society. Liotti claims that he can receive the status of a legitimate ruler when he controls public authorities. Having won the trust of local tribal chiefs, he worked to create modern infrastructure - roads, medical and educational institutions, agricultural facilities, and more. All this is combined with respect for local customs, institutions, religion, and language. He obliged the French governors-general to learn the local language and to respect the local religion. Although the Lyautey system has been touted as humane, it essentially encourages paternalism and exploitation. The system works well to deal with traditional societies that have relatively underdeveloped political systems but are unable to overcome the resistance of nationalist movements. For more information see: Verlin, P., Privilege and Power in North Africa, Journal of International Relations, 18 March 2015. http://www.sirjournal.org/research/2015/3/18/privilege-andpower-in-colonized-north-africa, 21.02.2019; Slavin, D. H. (2001). Colonial Cinema and Imperial France 1919-1939. In White Blind Spots, Male Fantasies, Settler Myths, The John Hopkins Univ. Press, p. 120.

xxv Such sentiments in Middle Eastern society were aided by the five-volume Memoirs of Mr. Humfer in 1888. According to them, this agent of the British services acknowledged his role in creating a conservative Islamic movement called Uhabism. According to experts, the real author of the study is the Turkish traveler and military Ayyub Sabri Pasha. Rather, this work reflects the intensification of the struggle between Ottoman Turkey and Britain to win the sympathy of the Arabs seeking their independence in the late nineteenth century. For more information see: Kitab Mudakriyat al Jesus al Britani Hamfer maa music al harakat al Wahabiya Mohammed bin Abdel Wahab, Book of Memoirs of the British Agent Humfer with the founder of Wahhabism Mohammed bin Abdel Wahab, Sahnun, http://www.souhnoun.com/\%D8\%A7, 11.02.2019.

xxvi Hana, A. F. Malamih min tarih al filahiin fi al uotan al arabi wa nidalihim fi kutr ala arabi as suri, Scars from the history of the settlement in the Arab homeland and their struggles in Syria, Damascus, Dar al baat lil tibaa, Tom. 4. p. 293.

xxvii Sukan wa al ahual al madania: adad al sukan dzhumhuriya al arabia as suria, Population and marital status: population of the Syrian Arab Republic, Aleppo, Dar al-Dad. 1953. p. 209.

xxvii Al Aluani, R., Adib ash Shishakli rajol al hadidi, Adib Shishekli - the Iron Man, Jirun. https://geiroon.net/archives/66625, 10.02.2019.

xxix Takrir Halat al amn al aam, Report on the State of Public Security, Damascus, Al Wizara at Dahiliya. 1963. p. 23-24. 


\title{
The Problem of Intersubjectivity in Western Philosophy: Boundaries of the Communicative Approach
}

\author{
Oksana Somova
}

\author{
Saratov State University (SSU), Saratov, RUSSIAN FEDERATION \\ Department of theoretical and social philosophy
}

Pavel Vladimirov

\author{
The Peoples' Friendship University of Russia (RUDN), RUSSIAN FEDERATION \\ Department of ontology and theory of knowledge, Moscow
}

Received: 29 November 2020 - Accepted: 21 December 2020 • Published Online: 25 December 2020

\section{Abstract}

\begin{abstract}
The article defines the meaning of the phenomenological approach to the analysis of the concept of intersubjectivity in the context of social and philosophical problems of the balance of the Self and the Other. The discourse is based on the correlation of phenomenological orientation and communicative action in determining the mechanisms of identity of the Self in relation to the Other in the inseparability of social reality. A sequential analysis of prerequisites and research approaches aimed at testing the problem of intersubjectivity is carried out. The focus is placed on social phenomenological research of A. Schutz and the theory of communicative action of J. Habermas, which are aimed at understanding the correlation between the peculiarities of human existence, his life-world and the area of social relations or the inevitability of establishing over individual patterns. Relevance of the research lies in elaborating the issue of establishing intersubjectivity under the fundamental non-identity of the subjects of communication and their predetermined attitudes. The article concludes by outlining the feasibility of expanding the rational predetermination of the subject-subjective structure of communicative action with the research area of social phenomenology.
\end{abstract}

Keywords: intersubjectivity, social phenomenology, communication theory, the problem of the Other, communicative approach, the problem of discourse ringing.

\section{Introduction}

The problem of intersubjectivity emerges as an answer to the possibility of building a coherent structure of communicative rules and norms that can regulate the communication process itself. Currently, the notion of the complex and ambiguous role of the organizing principles of the origin of communication themselves is being developed upon rethinking communication as a linear model of Ch. Cooley and G. Lasswell. Moreover, the question of adequate formation of meanings and their interpretations in the process of transmission arises if the premise initially contained predetermined unique components of personal experience or individualization. Another equally important aspect is the possibility of expanding the meaning of the existence of

(C) Authors. Terms and conditions of Creative Commons Attribution 4.0 International (CC BY 4.0) apply. Correspondence: Pavel Vladimirov (PhD), The Peoples' Friendship University of Russia (RUDN), Department of ontology and theory of knowledge, Moscow, RUSSIAN FEDERATION. E-mail: vladimirov_pa@pfur.ru. 
communication itself as a primary horizon that differs from the category of intersubjectivity. It appears pertinent to define the boundaries of applicability of the communicative approach and to test the phenomenological approach in the area of social philosophy using an interdisciplinary approach to reveal the various strategies of philosophical search. The key objective is to analyze the applicability of the category of intersubjectivity in revealing the correlation between the Self and the Other from the perspective of social phenomenology and its methodological basis.

In modern philosophy, the category of intersubjectivity is associated with the ontology of the social world and is defined as the possibility of human interaction with each other based on common attitudes, intentional objects (Husserl, 2019) and meanings that are attributed to them. Examination of the foundations of social interaction requires the analysis of two interrelated aspects - the formation of the Self against the background society, and the substratum, which ensures the interpretive potential and interaction within society. The subject of intersubjectivity was defined within the movement of phenomenology, although for the phenomenology itself the subject of socially oriented interpretation of consciousness is not of paramount importance. The research of the foundations of social interaction can be found in the works of M. Scheler, E. Stein, E. Levinas and J-P. Sartre that address the concept of the Other. The Other is perceived as the one in whom the Self finds its opposite, as the one who disturbs the Self, and in this disturbance the Self turns to reflection about the Self.

\section{Philosophical approbation of the concept of the Other}

It is generally believed that society originates from the phenomenon of the Other. The existential interpretation of the Other and the Self relations fails to capture the entire breadth of interaction in instances where the mass subject is intended, since such an approach explains the intimacy of the experience of both sides. Meeting with the Other, with the Body, presupposes a considerable separation from (Zahavi, 2015:37), and the sense of separation of the world between many people is evidently not the same. The number of philosophers who addressed the subject of the sociality of consciousness is extremely limited, and their work coincides mainly with the postHusserl period of development of phenomenology, which is referred to as phenomenological sociology.

Direct prerequisites that influenced the phenomenological sociology are contained in the works of German classical philosophers. For instance, to Hegel, a consciousness that does not understand its objectivity cannot recognize true freedom and cannot comprehend its historical destiny (Hegel, 1990). Outside the society, an individual has no possibility to exceed his limits; he remains in the universality of his thoughts, as an impersonal point devoid of qualities. That is, an individual is incapable of self-determination and is doomed to a solipsistic abstraction of existence without correlation with his negativity. An individual is distinguished by the capacity for the experience of the Other, and without cognizing it, he remains at the level of an animal. Subsequently, Marx, reinterpreting Hegel's legacy in a social context, developed these theses into the dialectic of sociality - the alienation of the individual from himself in the form of activity and the subsequent finding of himself through overcoming this alienation in the community (Gasparyan, 2007: 25-32). From a negative standpoint of human self-determination, the intersubjective world represents a set of objects created by human hands that share values that are common to people. The substantive similarity of phenomenological and Marxist interpretations of intersubjectivity has become the subject of numerous research studies (Waldenfels \& Broekman, 1977).

Immanence of sociality is stated in the works of M. Heidegger, whose mentor was Husserl, in his Mitsein concept. Coexistence is a condition of being-in-the-world and its attribute, rooted in the very structure of being, and it does not require identification of its genesis. The Other is found in the communal objects, it is always implied by them even in the modus of indifference 
on the part of the existent. Heidegger did not aim to study social problems, but he is credited with the initial understanding of the inevitable fitting into society, expressed in the concept of das Man. Das Man represents a social construct, an impersonal public nature, an "unsilent" majority that exists in everyday life. Das Man is the opposite of "one's". "Some people believe", "someone once said", "it is believed that" indicate the introduction of common ideas and meanings into the mind of an individual, and the task of the latter is to overcome the dissolution of himself in public opinion. It is possible to say that das Man is an inverted understanding of the Frank's "we" - only among other people the Self is able to truly find its own, and here it is able to lose itself. The specific nature of the discussed question invariably leads to the fundamental ontology of M. Heidegger, which is identified as merely one of the possible ways of philosophical reflection of the category of intersubjectivity. However, the scope of the subject cannot be limited only to describing the specifics of an individual's existence without disclosing the organizing function of social reality.

In the modern Western philosophy two aspects - what is the Self and what is the society-in-itself - tend to merge in a unified interpretation of the communicative reality that consists of a set of meanings shared by each individual. Essentially, intersubjectivity becomes synonymous with social communication (Burova, 2016: 52). This interpretation of intersubjectivity was developed largely due to the works of A. Schütz. Schütz explored and developed the concept of intersubjectivity formulated by Husserl. Following him, the sociologist acknowledges the Others' active and constitutive intentionality. Coexistence of meanings defines the perceived world and the subjects of action that exist in it. Thus, the world always acts as a world of the Other Selves, a world of cultural patterns and structures of interactions (Schutz, 2004).

Within the framework of phenomenological sociology, Schütz studied the concept of intersubjectivity in terms of everyday social behavior/reflections of individuals and sought to establish the ordinary in the diversity of social interactions. The subject area of phenomenological sociology and the essence of social life becomes what Heidegger opposed. According to O. E. Burova, the problem field of the intersubjectivity phenomenon changes its vector of development - interest of researchers shifts from the realm of ideal (spiritual unity) to the realm of practical and semantic (the world of bodies, things and words) (Burova, 2016: 51). Indeed, as evidenced by the general situation in the social sciences of the second half of the twentieth century, the social exteriorizes into everyday interactions - H. Garfinkel's ethnomethodology, P. Bourdieu's genetic structuralism, A. Touraine's actionalism, etc. The basis of intersubjective relations is isolated in selected studies of phenomenologists (M. Merleau-Ponty, M. Richir, M. Henri); humanitarian studies operate in the natural setting of unreduced reality and explore relations within the already existing society.

3. Specificity of revealing identity in social constructivism of P. Berger and T. Luckmann

In the framework of social and philosophical theories, the approach of P. Berger and T. Luckmann is remarkable in its originality, which is reflected in revealing the correlation between the function and structural organization of any social phenomenon or event. Implicitly based on the phenomenological approach, the inseparability of subjective and objective in the social environment is distinguished. Ultimately, social phenomena represent a variety of functions and structures that fill social reality. A hermeneutic circle is formed, which breaks in social and philosophical research by emphasizing a single phenomenon that may be both social institutions and the process of socialization of the individual. The latter case reveals the initial attitude of philosophers to understand the mechanisms of establishing a unified space of interpersonal interaction. By eliminating the opposition of the subject to the object, Berger and Luckmann argue that all phenomena are completely interconnected in the context of the unified social reality. It is 
notable to identify the problem of reducing the personality to a social phenomenon, but it is resolved by highlighting a different sphere of relations that lie outside the rational context.

To reveal the specificity of a phenomenon, the scientists reason for the existence of a social structure that performs the organizing part in the diversity of social phenomena. In the course of internalization, social structures may be contrasted with social reality as the subject contrasts with its object. Therefore, the subject and the object are correlated, but not as a direct contraposition or otherwise as an equivalence, but rather as a concept that is constantly evolving and dynamical. As is evident, Luckmann and Berger's approach to research is neither structurally functional, since social reality is rooted in a variety of social phenomena that are intentional in relation to the researcher, nor phenomenological in Husserl's interpretation. The scholars define their unique position as social constructivism, thus distancing themselves from both philosophical phenomenology and structuralism.

Social structures emerge not as a result of the work of a scholar who observes social relations, but as a result of the organization of social institutions, groups and societies driven by a desire for self-identity. P. Berger combined the concepts of identity, organization, development and transformation into the concept of internalization. The validity of such term is determined by one of the prerequisites of social constructivism, which is that all social phenomena are interconnected, and only through their constant interaction separate social functions and relations are identified. Society as a whole constitutes a complex construct that consists of two levels of reality - subjective and objective. A "surface level" is added to these levels, which is constantly changing or undergoing social transformation. Meanwhile, revealing the presence of social transformation becomes accessible for analysis only through particular manifestations of internalization. In the course of socialization, an individual perceives the heterogeneity of society (the presence of several levels of organization) and participates in the creation of a "surface level" or in the "constantly recreated experience of other people" (Berger, 1963: 118). It is important to note that at this stage the process of transmitting primary meanings is not revealed; it is acknowledged either as a given or a social fact. It appears beneficial to supplement social constructivism with a developed system of correlation of individual aspirations to identity (in the given context identity is implied as self-identity) and with the existing social area of norms (which is expressed in specific interpretation of the "social control" term) (Berger, 1963: 68-69).

Social constructivism not only criticizes the previous tradition of structuralism, but also provides a crucial assessment of an individual's capacity for self-realization. The process of interaction between society and the individual is reflected in the unfortunate conclusion: "very few people, ..., are in a position to re-evaluate what has thus been imposed on them" (Berger, 1963: 117). By means of the phenomenological approach, an attempt is made to justify the existence of an individual's freedom in society, which may become a condition for the freedom of identifying individuality given the existence of regulatory norms of social reality. From this perspective, Berger and Luckmann's concept correlates with the general intention of social phenomenology and even the theory of communicative action. Yet, it seems appropriate to critically reexamine the process of establishing shared meanings and their subsequent influence on individuality.

There are other examples of synthesis of phenomenological categorical apparatus that was reinterpreted by Schütz with modern actionist philosophical trends. Specifically, M. Geiger and O. Becker unveil the complexity of the process of ontological description of aesthetic aspects (Becker \& Richir, 2019: 99-100). However, their philosophical research is focused on revealing the aesthetic experience and identifying appropriate categories of the fine and the ugly. Theories that reveal correlation of reality of social life and human existence are of interest precisely for social phenomenology, and particularly in the context of intersubjectivity problems. The concept of communicative action of J. Habermas acts as a striking example of communicative interpretation of intersubjectivity that absorbed phenomenological orientations. There, intersubjectivity is expressed in procedural rationality, which is inherent in the subjects of action and ensures the 
ability to communicate. Subjects are capable of communicating and reaching consensus provided that each of them is able to correctly interpret the situation of his position and that of his interlocutor. Communicative situation establishes the area of shared meanings, outlines social roles (points of view) and horizons of mutual perspectives of interlocutors, which Habermas defines as intersubjectivity (Habermas, 2001a: 201). It implies that there have been significant changes in the perception of intersubjectivity. The ability of individuals to understand each other has shifted from the sphere of consciousness by which it was originally justified to the adequately comprehended communicative situation.

\section{Communicative approach and intersubjectivity}

Subsequent developments of the possibility of the existence of social identity of individuals have deviated significantly from the original phenomenological understanding. For instance, intersubjectivity, perceived as culturally conditioned typicalization, emphasizes the fundamental inaccessibility of the Other's experience. In linguistic and socially significant gestures, a shared area is established, the horizon of similarly perceived meanings that provide the potential for contact, but do not guarantee absolute awareness and acceptance of meanings by subjects. In this regard, Goffmann's remark that each participant of the interaction is expected to suppress his immediate inner feelings becomes particularly important. This observation is essential to express such a view of the situation that, according to the scholar's beliefs, will be sufficient to be accepted by others, at least temporarily (Goffman, 2000: 40). Intersubjectivity, as understood by Habermas, represents a universal consensus that equally deprives each subject of sincerity. Consistent behavior of participants in a communicative situation does not imply that the subject indeed understands the purpose of actions, the context of occurring events and the social roles of communicants.

It is necessary to address in greater detail the foundations of the communicative approach and discourse theory of J. Habermas, in which the category of intersubjectivity acquires its specificity. Differences between theoretical and practical discourse are found to be the key element of the entire discourse theory, which is outlined in Theory of Communicative Action (Habermas, 1981) and later in Moral Consciousness and Communicative Action (Habermas, 1988) and Explanation of the Discourse Ethics (Habermas, 1991). Theoretical discourse permits to define the boundaries of knowledge and the requirements that are imposed on the scientific search for reliable knowledge. In turn, practical discourse establishes the normative nature of the pragmatic and, in particular contexts, determines the moral validity of consensus building. Achieving the unified communicative space and, consequently, the equality of all its participants is the most important objective for the communication theory as a whole. Habermas tested transcendental philosophical tradition until the formation of the fundamental foundations of the practical theory of discourse ethics. This results in the formation of a universal theory, which, on the one hand, possesses its own methodological approach (communicative) and, on the other hand, has indisputable practical significance. Intersubjectivity loses its significance when constructing discourse as an ideal model of communication, since the logic of reasoning in theoretical discourse and the logic of moral reasoning in practical discourse take precedence. The situation of consensus in a well-structured communication means coherence between theoretical and practical discourse. It seems reasonable to assume that the ideal model of exactly pragmatic structure of communication has been achieved, which is considerably broader than just practice and which differs from theory. The unifying basis for theoretical and practical discourse is not the problem of constructing social reality, but the principle of universalization. In Moral Consciousness and Communicative Action Habermas explicitly stipulates that with the "introduction of the principle of universalization, the first step to justify the discourse ethics has been taken" (Habermas, 1988: 86). Thus, the discourse and theory of communication that is aimed 
at determining the possibility of discourse itself reveal precisely the normative and ethical foundations of communication.

The German philosopher attempts to solve the alien linguistic situation and introduces the concept of the life-world, which can be defined as a preliminarily comprehensible context of a situation of action. That is, the uncritically perceived set of knowledge and perceptions that is inherent to the agent. However, the ultimate localization of the philosopher's view on a specific subject does not solve the problem of the authenticity of consensus and does not eliminate Goffmann's criticism. The rationalistic approach of Habermas does not address a number of parameters that affect mutual understanding between individuals, from the affectivity of the interlocutors and their irrational urges to the difference in semantic understanding of the same words. Yet the following point is important in the project of communicative action. Habermas relies on the rationality of two people to the extent that communication allows them to interact on the same basis. In the foreword to The Inclusion of the Other, B. V. Markov, following the logic of Habermas' reasoning, notes that communication involves recognition of each other and therefore does not require authority (Habermas, 2001b) . Communication presupposes the creation of such an environment where it is possible to talk and negotiate due to the horizontal positions of its participants. They are able, with varying degrees of success, to reconstruct the situation from which the interlocutor is speaking, and this ability is not determined solely by similar life experiences. When mentioning the theory of communication of Habermas, one cannot help but refer to the theory of the communicative society of C.-O. Apel, his colleague and simultaneously his opponent. In elaborating the concept of communication, Apel emphasized the crucial role of linguistic structures in building a unified sphere of meanings, which is, in turn, connected with the influence of the cultural and historical context on individuality by means of language. The problem lies in the fact that linguistic structures and discourse ultimately inevitably condition the life of every individual, shattering the boundaries of individual perceptions of morality and social norms. The question arises concerning what can be defined as a criterion of morality and normality if social norms can also transform and contradict ethics in its genuine sense. Extrapolating this notion to the problem of intersubjectivity, the question emerges of the possible existence of predetermined conditions of communication that limit the process of transformation of ethical and normative foundations, making both practical and theoretical discourse possible. However, Habermas' primary goal is not to reveal the predetermined nature of the communication process (which explains the lack of emphasis on this topic), but rather to pragmatically formulate communication as a means of implementing social life without violence. Only by ensuring communication between different actors (including states) can mechanisms of "universal reconciliation" be created. By changing the subject-object relation (or linear model) to communication into a subject-subject structure, the possibility of achieving equality of all subjects of communication is postulated, where each participant is able to indicate his active position. Ultimately, it is possible to achieve consensus or moderation, which leads to the emergence of discourse.

\section{Conclusion}

The problem of identifying the definition of intersubjectivity is stipulated by the inevitability of integrating various philosophical strategies of research. On the one hand, initially in Husserl's interpretation intersubjectivity exists as a category; on the other hand, in social phenomenology intersubjectivity acquires the meaning of concept (which is determined by the formation of a new model of historical and philosophical research - the problematization of the initial foundations). In Berger's specific theory of social constructivism intersubjectivity is a process that represents the organizing basis for overcoming the opposition of the subject to the object. The definition of intersubjectivity cannot be reduced either to fundamental ontology and trends of existential philosophy or to the theory of communicative action, since Habermas defines 
discourse as a normatively constructed field of communication based on predetermined rules. Normativity establishes boundaries for examining the possibility of distorting and transforming the meaning itself, the initial communication message and its subjective context. Revelation of the definition of intersubjectivity lies in the approbation of normative statements of the discourse, yet at the same time it requires a rational reflection of one's individual perceptions, where the complexity of identifying the Self in relation to the Other is invariably revealed at a deeper level of consideration.

The following three themes constitute an objective enhancement of the content and critical reinterpretation of the category of intersubjectivity: (1) the problem of constructing the Self, (2) the question of the correlation of the Self and the Other in the social sphere of interpersonal relations, and (3) the ambiguity of the impact of historical and cultural context on the formation of intersubjective relations from the standpoint of social and phenomenological analysis. It is probable to solve the problems of intersubjectivity in the field of phenomenology of communication, provided that the issue is resolved as to whether it is possible to assume the meaning of alter ego, what is the mechanism of this assumption and how the other Ego certifies itself as being (Husserl, 2019: 118). That is, it is necessary to research and comprehend the process of establishing the communicative horizon. The shift of research into phenomenological prism cannot rely solely on rationality, as is the case with Habermas. The philosopher replaces active creative consciousness with rationality that is immersed in context, which, in fact, makes the subject a superfluous element. Following this logic, the system of social relations reproduces itself in situational rationality, an individual does not need to find himself in society. In order to reveal the formation of universal mechanisms of communicative situations, it is essential to reconstruct the primary pre-subject intents of communicators, which are identified in the phenomenological system.

\section{Acknowledgements}

This research did not receive any specific grant from funding agencies in the public commercial, or not-for-profit sectors.

The authors declare no competing interests.

\section{References}

Becker, O., \& Richir, M. (2019). Phenomenology and aesthetics. Moscow: Panglos.

Berger, P. (1963). Invitation to sociology. A humanistic perspective. Ney York: A Division of Random house, inc.

Burova, O. E. (2016). Philosophical approaches to determine the intersubject viewpoint essence. Yaroslavl Pedagogical Bulletin, 6, 47-53.

Gasparyan, D. E. (2007). Sociality as negativity. Moscow: Kdu.

Goffman, I. (2000). The presentation self in every day life. Moscow: Kanon-press.

Habermas, J. (1981). Theory of communicative action. Frankfurt Main: Konstants.

Habermas, J. (1988). Moral consciousness and communicative action. Frankfurt Main: Suhrkamp.

Habermas, J. (1991). Explanation of the discourse ethics. Frankfurt Main: Suhrkamp.

Habermas, J. (2001a). Moral consciousness and communicative action. St. Petersburg: Nauka. 
O. Somova \& P. Vladimirov - The Problem of Intersubjectivity in Western Philosophy: Boundaries of ...

Habermas, J. (2001b). The inclusion of the Other. Studies in political theory. St. Petersburg: Nauka.

Hegel, G. (1990). Philosophy of law. Moscow: Mysl.

Heidegger, M. (2002). Being and time. St. Petersburg: Nauka.

Husserl, E. (2000). Ideas to pure phenomenology and phenomenological philosophy. Book one: a General introduction to pure phenomenology. Moscow: Academic project.

Husserl, E. (2019). Cartesian meditations. Moscow: Academic project.

Schutz, A. (2004). Selected works: A world glowing with meaning. Moscow: Rosspen.

Waldenfels, J. M., \& Broekman, A. (1977). Phaenomenologie und Marxismus. Concepts and methods. Frankfurt Main: Suhrkamp.

Zahavi, D. (2015). Self and other: from pure ego to co-constituted we. Continental Philosophy Review, 48, 143-160. https://doi.org/10.1007/s11007-015-9328-2 


\title{
Polish Music Press in the Face of Systemic Change in 1989 as an Example of Cultural Transformation in Post-communist Countries
}

\author{
Konrad Tyszka \& Michał Jagosz \\ University of Warsaw, Warsaw, POLAND \\ Faculty of Culture and Art Studies, Institute of Musicology
}

Received: 1 December 2020 • Accepted: 22 December 2020 • Published Online: 25 December 2020

\section{Abstract}

\begin{abstract}
The systemic transformation has significantly increased and diversified the music press market. Liquidation of the monopoly, privatization, censorship abolition and media pluralism are just some of the factors that contributed to shaping new cultural policy in Poland. The research material used for this paper's analytical purposes consists of Polish music magazines; based on a query covering over 110 journals being published since 1946 to the present, a historical and comparative analysis was made. It allowed to determine what new solutions the publishers started to put into practice to make their magazines more attractive. Moreover, it showed a clear fragmentation of the market. After '89, popular music magazines began to prevail; there are also many specialist journals devoted to a specific topic. A look at cultural transformation from the perspective of the music press is therefore an innovative idea, combining knowledge from the borderline of musicology, cultural studies, and press studies.
\end{abstract}

Keywords: music press, systemic transformation, post-communist countries, cultural policy, Polish publishing market.

\section{Introduction}

The following article is devoted to the functioning of the music press in the face of the systemic transformation in 1989. This interdisciplinary topic covers a significant issue on the border of musicology, history as well as media and social studies. Music press is one of the durable and settled mass media, which makes it an extremely important cultural carrier. Therefore, it hands down the cultural heritage to next generations in an effective and conscious way.

For the further considerations, it is crucial to clarify two concepts: music press and system transformation. The former can be defined as "all newspapers and magazines". Thus, according to Julian Maślanka (1976: 46), the music press is "a set of magazines devoted to the issues of music and musical life with a different level and scope of specialization depending on the circle of readers for whom the journal is intended for". The latter term can be explained as "the transition from centrally planned economy to a market economy, including change of the political system and creation of market conditions for the functioning of all economic entities" (Nasiłowski, 1995: 17). Moreover, the systemic transformation introduces political democracy, freedom of

(C) Authors. Terms and conditions of Creative Commons Attribution 4.0 International (CC BY 4.0) apply. Correspondence: Konrad Tyszka (PhD student), University of Warsaw, Faculty of Culture and Art Studies, Institute of Musicology, Warsaw, POLAND. E-mail: konradmarceli79@gmail.com. 
K. Tyszka \& M. Jagosz - Polish Music Press in the Face of Systemic Change in 1989 as an Example...

speech and new legal forms, while the economic transformation involves activities aimed at creating new operating conditions for economic entities (Bałtowski \& Miszewski, 2015: 23-24).

- The music press plays an important role as a carrier of culture.

- Before 1989, Polish magazines were under constant control of the authorities.

- The system transformation has significantly influenced the shape of the press market in Poland.

- The abolition of the state monopoly opened up the possibility of new publishers entering the market.

- After 1989, pop music magazines started to dominate the Polish press market.

This topic is also important because it has not been thoroughly researched yet both in Polish scientific and popular science literature, especially in such broad perspective. Therefore, the research work should have been started by cumulating as much material as possible, in this case the music press. Searching for magazines that appeared before 1989 was possible thanks to the Włodzimierz Pigła’s (1991) Central Catalogue of Polish Music Magazines and Periodicals on Music: Polish Collections. The periodicals that survived the transformation but were shut down shortly afterwards, were possible to examine thanks to Komorowska's (2001) rather superficial yet useful Polish music press in 1945-200o.

The journals created or reactivated after 1989 were examined during the query in National Library of Poland. When compiling mentioned register, the fact of lacking complete and central catalogue covering post 1989 music magazines was highly inconvenient. Some journals appear irregularly, which makes it impossible to assume when or whether the next issue will appear at all. Moreover, not all of them fulfil the obligation of sending obligatory copies to National Library; it is likely that library's main catalogue is incomplete.

The following paper aims to analyse the music press market before and after 1989 the Autumn of Nations, when Poland, along with other European countries, shed the yoke of communism, and thus initiated the systemic transformation. It is also supposed to classify periodicals being released since 1946. During research we tried to answer significant question: how the transformation influenced the development and shape of Polish music press market as an example of one of the post-communist domestic economies in Europe.

\section{Methods}

The research material used for this paper's analytical purposes consists of Polish music magazines. Conducted query resulted in bringing up roughly 110 journals in total (for the full list along with every issue examined, see appendix), mainly of nationwide and regional coverage. They have been ordered in accordance with the following categorization key:

(a) Periodicals published until $1989-31$;

(b) Periodicals that survived the transformation, but no longer appear - 4;

(c) Periodicals that survived the transformation, but still being published to this day -6 ;

(d) Periodicals reactivated after transformation - 3;

(e) Periodicals created after transformation -64 .

The research method used for the purposes of this paper is primarily a historicalcomparative analysis. It seems to be most precise, as it allows the query to be conducted for the 
past several dozen years and to analyse gathered material considering certain turning point, which in this case is the mentioned systemic change in Poland. Importantly, to obtain the most accurate and valuable results, it was also necessary to analyse the content of each published issue of all 108 titles. On this basis, the structure and general subject was examined, which made possible trying to typologize and classify them. Also, a quantitative analysis was performed to establish their periodicity. Using all the above methods was mandatory, to be able to present the image of the music press market in the most reliable way possible. Therefore, confronting it with the knowledge of cultural and socio-political changes after 1989 allows us to draw specific conclusions.

\section{Results}

\subsection{Periodicals published until 1989}

The conducted query made it possible to collect data on 31 periodicals matching the analysed category. Most of them were nationwide, however, the list also includes several titles issued only on a regional basis. Journals included in the research (see Table 1) appeared on the Polish press market after the end of World War II, from 1946, when the first issue of "Życie Muzyczne" (for title translations see the appropriate table) was released. The closing point of discussed period is the range between 1989 and 1991 - it is the time when Polish government began to implement political, economic, and social reforms. The journals published during this period were often published for a short time, usually for several years. Only 12 (e.g. "Poradnik Muzyczny", "Res Facta") of listed in the table, have been published for more than 10 years. Almost half of the periodicals - 15 (e.g. "Studia Muzykologiczne", "Biblioteka Organisty") - appeared irregularly. The remaining titles are those published monthly, quarterly, and yearly. Almost all the magazines were published by music academies, cultural and educational institutions, and associations. Only "Jazz", "Non Stop" and "Forum Rozrywki" were published by independent publishing houses. As to the magazines subject, the dominant ones were oriented to music culture in general (e.g. "Życie muzyczne") and musicology (e.g. "Forum Musicum”). There were also press releases about music educations ("Śpiew w Szkole"), student songs ("Ballada”) or specialist magazines dealing with a specific topic, e.g. life of Frederic Chopin ("Chopin w Świecie"), religious music ("Muzyka Religijna w Polsce") or the classical guitar ("Wiadomości Gitarowe"). Some magazines were also published as an information bulletin ("Studia i Rozprawy"). What is important, almost all of them were devoted to the classical and contemporary music. The first popular music magazines were "Jazz" followed by the "Non Stop". Then again, some of them, such as "Forum Muzyki", were of marginal importance, because only 2 issues were published.

The circulation of mentioned periodicals was relatively small, ranging from several hundred to several thousand copies. A specific phenomenon in the 1980 os was "Non Stop", which reached the circulation number of over 100,000 copies. It is not without reason considered to be the most influential Polish music magazine of that decade.

Table 1. Periodicals published until 1989

\begin{tabular}{|c|c|c|c|c|}
\hline$\#$ & Name & Years & Periodicity & Subject \\
\hline 1 & $\begin{array}{c}\text { Życie Muzyczne } \\
\text { [Musical Life] }\end{array}$ & $1946-1948$ & irregular & musical culture \\
\hline 2 & $\begin{array}{c}\text { Poradnik Muzyczny } \\
\text { [Musical Guide] }\end{array}$ & $1947-1989$ & monthly & musical culture \\
\hline 3 & $\begin{array}{c}\text { Życie Śpiewacze } \\
\text { [The Singers' Life] }\end{array}$ & $1948-1973$ & monthly & musical culture \\
\hline
\end{tabular}


K. Tyszka \& M. Jagosz - Polish Music Press in the Face of Systemic Change in 1989 as an Example...

\begin{tabular}{|c|c|c|c|c|}
\hline 4 & $\begin{array}{l}\text { Echo Teatralne i Muzyczne } \\
\text { [Theatrical and Musical Echo] }\end{array}$ & $1948-1949$ & quarterly & $\begin{array}{l}\text { musical culture and } \\
\text { theatre }\end{array}$ \\
\hline 5 & $\begin{array}{l}\text { Kwartalnik Muzyczny } \\
\text { [Music Quarterly] }\end{array}$ & $1948-1950$ & quarterly & musicology \\
\hline 6 & $\begin{array}{c}\text { Scena Świetlicowa } \\
\text { [Common Room Scene] }\end{array}$ & $1950-1951$ & monthly & musical culture \\
\hline 7 & $\begin{array}{c}\text { Praca Świetlicowa } \\
\text { [Common Room Work] }\end{array}$ & $1951-1962$ & monthly & musical culture \\
\hline 8 & $\begin{array}{l}\text { Studia Muzykologiczne } \\
\text { [Musicological Studies] }\end{array}$ & $1953-1956$ & irregular & musicology \\
\hline 9 & $\begin{array}{l}\text { Śpiewamy i Tańczymy } \\
\text { [Let’s Sing and Dance] }\end{array}$ & $1954-1987$ & biweekly/monthly & sheet music \\
\hline 10 & $\begin{array}{l}\text { Jazz/Magazyn Muzyczny } \\
\text { [Jazz/Music Magazine] }\end{array}$ & $1956-1991$ & irregular & jazz \\
\hline 11 & $\begin{array}{l}\text { Biblioteka Organisty } \\
\text { [The Organist's Library] }\end{array}$ & $1957-1958$ & irregular & church music \\
\hline 12 & $\begin{array}{l}\text { Wiadomości Gitarowe } \\
\text { [Guitar News] }\end{array}$ & $1957-1966$ & quarterly & $\begin{array}{l}\text { specialist (classical } \\
\text { guitar) }\end{array}$ \\
\hline 13 & $\begin{array}{l}\text { Śpiew w Szkole } \\
\text { [School's Sing] }\end{array}$ & $1957-1967$ & irregular & $\begin{array}{l}\text { music education } \\
\text { (sing) }\end{array}$ \\
\hline 14 & $\begin{array}{l}\text { Amatorski Ruch Artystyczny } \\
\text { [Amateur Art Movement] }\end{array}$ & $1958-1961$ & irregular & newsletter \\
\hline 15 & $\begin{array}{l}\text { Muzyka w Prasie Zagranicznej } \\
\text { [Music in the Foreign Press] }\end{array}$ & 1959-1969 & monthly & newsletter \\
\hline 16 & $\begin{array}{c}\text { Z Dziejów Muzyki Polskiej } \\
\text { [From the History of Polish Music] }\end{array}$ & $1961-1971$ & irregular & $\begin{array}{l}\text { musical culture/18th } \\
\text { and 19th century } \\
\text { music }\end{array}$ \\
\hline 17 & $\begin{array}{c}\text { Informator Polskiego Wydawnictwa } \\
\text { Muzycznego } \\
\text { [Polish Music Publishing House's } \\
\text { Guidebook] }\end{array}$ & $1963-1966$ & annual & musicology \\
\hline 18 & Musica Medii Aevi & $1965-1991$ & irregular & early music \\
\hline 19 & Forum Musicum & $1966-1974$ & irregular & musicology \\
\hline 20 & Polish Music. Polnische Musik & 1966-1992 & quarterly & musicology \\
\hline 21 & Res Facta & $1967-1982$ & irregular & musicology \\
\hline 22 & $\begin{array}{c}\text { Szkice o Kulturze Muzycznej XIX } \\
\text { wieku } \\
\text { [Sketches on the 19th Century } \\
\text { Musical Culture] }\end{array}$ & $1971-1984$ & irregular & musical culture \\
\hline 23 & $\begin{array}{c}\text { Studia i Rozprawy } \\
\text { [Studies and Dissertations] }\end{array}$ & $1971-1973$ & annual & newsletter \\
\hline 24 & Pagine & $1972-1989$ & irregular & musicology \\
\hline
\end{tabular}




\begin{tabular}{|c|c|c|c|c|}
\hline 25 & Non Stop & $1972-1990$ & monthly & music in general \\
\hline 26 & $\begin{array}{c}\text { Taniec } \\
\text { [Dance] }\end{array}$ & $1974-1986$ & irregular & $\begin{array}{c}\text { specialist } \\
\text { (dance/ballet) }\end{array}$ \\
\hline 27 & $\begin{array}{c}\text { Studia z Wychowania Muzycznego } \\
\text { [Studies in Music Education] }\end{array}$ & $1975-1988$ & irregular & $\begin{array}{c}\text { education/music } \\
\text { pedagogy }\end{array}$ \\
\hline 28 & $\begin{array}{c}\text { Muzyka Religijna w Polsce } \\
\text { [Religous Music in Poland] }\end{array}$ & $1975-1988$ & irregular & church music \\
\hline 29 & $\begin{array}{c}\text { Forum Rozrywki } \\
\text { [Entertainment Forum] }\end{array}$ & $1982-1983$ & $\begin{array}{c}\text { only two issues } \\
\text { appeared }\end{array}$ & entertainment \\
\hline 30 & $\begin{array}{c}\text { Ballada } \\
\text { [The Ballad] }\end{array}$ & $1983-1984$ & quarterly & student song \\
\hline 31 & $\begin{array}{c}\text { Chopin w Świecie } \\
\text { [Chopin in the World] }\end{array}$ & $1986-1989$ & annual & $\begin{array}{c}\text { specialist (F. } \\
\text { Chopin) }\end{array}$ \\
\hline
\end{tabular}

\subsection{Periodicals of the transformation era}

This group includes journals that endured the transformation, but no longer appear (see Table 2). To this category covers four journals. "Życie Muzyczne" i "Śpiewak Śląski" were published until 2009 and 2017, respectively. Those were periodicals published by the same organization, except that the latter one was being released regionally - in Silesia. They were both devoted to amateur music movement. Until 2002, the "Kwartalnik Polskiej Sekcji ISME" also managed to survive on the press market, and "Musica Antiqua Europae Orientalis", which was a post-congress magazine, was last published in 2012.

Table 2. Periodicals that survived the transformation but no longer appear

\begin{tabular}{|c|c|c|c|c|}
\hline$\#$ & Name & Years & Periodicity & Subject \\
\hline 1 & $\begin{array}{c}\text { Śpiewak Śląski } \\
\text { [Silesian Singer] }\end{array}$ & $\begin{array}{c}1920- \\
1948 / 1985- \\
2017\end{array}$ & quarterly & $\begin{array}{c}\text { local musical } \\
\text { movement }\end{array}$ \\
\hline 2 & $\begin{array}{c}\text { Życie Muzyczne } \\
\text { [Życie Muzyczne] }\end{array}$ & $1974-2009$ & monthly & $\begin{array}{c}\text { amateur musical } \\
\text { movement/music } \\
\text { education }\end{array}$ \\
\hline 3 & Musica Antiqua Europae Orientalis & $1966-2012$ & irregular & early music \\
\hline 4 & $\begin{array}{c}\text { Sygnały ISME/Kwartalnik Polskiej } \\
\text { Sekcji ISME }\end{array}$ & $1973-2002$ & quarterly & $\begin{array}{c}\text { education/music } \\
\text { pedagogy }\end{array}$ \\
\hline
\end{tabular}

Another detailed category are journals that have survived the transformation and are still being published (see Table 3). The conducted query allowed to indicate 6 of such properties. These are magazines of rich tradition, some of them, such as "Muzyka", having their origins before World War II, or even back in the $19^{\text {th }}$ century ("Ruch Muzyczny"). It is worth mentioning that these periodicals are devoted to classical and contemporary music, only one ("Jazz Forum") is devoted to popular music. 
K. Tyszka \& M. Jagosz - Polish Music Press in the Face of Systemic Change in 1989 as an Example...

Table 3. Periodicals that survived the transformation, but still being published to this day

\begin{tabular}{|c|c|c|c|c|}
\hline$\#$ & Name & Years & Periodicity & Subject \\
\hline 1 & $\begin{array}{c}\text { Muzyka } \\
\text { [Music] }\end{array}$ & since 1928 & quarterly & musicology \\
\hline 2 & $\begin{array}{c}\text { Ruch Muzyczny } \\
\text { [Musical Movement] }\end{array}$ & $\begin{array}{c}\text { since 1945 } \\
(1857- \\
1861)\end{array}$ & $\begin{array}{c}\text { biweekly, } \\
\text { monthly since } \\
2013\end{array}$ & musicology \\
\hline 4 & $\begin{array}{c}\text { Wychowanie Muzyczne w Szkole/ } \\
\text { Wychowanie Muzyczne } \\
\text { [Musical Education in } \\
\text { School/Musical Education] }\end{array}$ & since 1967 & bimonthly 1965 & $\begin{array}{c}\text { monthly since } \\
1993\end{array}$ \\
\hline 5 & $\begin{array}{c}\text { Wiadomości ZAiKSU } \\
\text { [ZAiKS' News] }\end{array}$ & since 1971 & irregular & $\begin{array}{c}\text { newsletter/musical } \\
\text { culture }\end{array}$ \\
\hline 6 & Chopin in the World & since 1986 & annual & specialist (F. Chopin) \\
\hline
\end{tabular}

Despite the opening of the press market and the lifting of many restrictions after 1989, only a few publishers decided to reactivate their magazines. Of the most significant journals published before transformation, three attempted to come back: "Taniec", "Res Facta Nova" (formerly "Res Facta") and "De Musica" (formerly "Pagine"). Only the second one is still present on the press market (see Table 4). All three magazines were focused on classical music and appeared irregularly. They had the same goals as before their first closure and were reactivated by the efforts of the same editors-in-chief as before 1989.

Table 4. Periodicals reactivated after transformation

\begin{tabular}{|c||c|c|c|c|}
\hline$\#$ & Name & Years & Periodicity & Subject \\
\hline 1 & $\begin{array}{c}\text { Taniec } \\
\text { [Dance] }\end{array}$ & $1992-1994$ & irregular & dance \\
\hline 2 & Res Facta Nova (Res Facta) & $\begin{array}{c}1994- \\
\text { today }\end{array}$ & irregular & $\begin{array}{c}\text { musicology/modern } \\
\text { music }\end{array}$ \\
\hline 3 & De Musica (Pagine) & $2006-2012$ & irregular & musicology \\
\hline
\end{tabular}

\subsection{Periodicals founded after transformation}

The systemic transformation that had begun in 1989 have significantly influenced media functioning in Poland, including the segment of social and cultural press, including the music press. It was the time when People's Republic of Poland's government practices such as supervision and central control of press media came to an end. This resulted in liquidation of many magazines, but mew titles began to appear rapidly in their place. They had to adapt to the new realities of the market and, above all, convince readers to their own editorial line. Basing on the query output, the total amount of 64 titles was extracted (for journals founded after 1989, see Table 5). They were assigned to categories based on the subject matter. First group covers musicological (e.g. "Forum Muzykologiczne") and university magazines (e.g. "Klucz"). The second one includes general music journals (such as "Gazeta Magnetofonowa"), music and cultural magazines ("Piosenka"), periodicals on church music ("Musice Ecclesiastica") and contemporary music (np. "Kwarta”). In addition, specialist magazines, i.e. those devoted to specific issues, such 
as guitar itself (e.g. "Gitarzysta”) or music equipment (e.g. "Audio”), constitute a separate category. Another group of periodicals was created by gathering those of objects of interests covering popular and youth music (e.g. "Bravo") and folk music (e.g. "Pismo Folkowe"), as well as rock or metal music and industry (e.g. "Mystic Art"). Magazines devoted to other music genres, e.g. electronic music ("Techno Party"), were also included. The last category consists of printed sheet music (e.g. "Zagraj to Sam"), informational periodicals ("Biuletyn Polskiego Towarzystwa Harfowego") and educational (e.g. "Scala"). Yet his distinction is not rigid or closed. Some of the magazines, such as "Przegląd Muzykologiczny" could also be classified as a university journal, then again "Presto" can be put among music and culture magazines. However, to maintain the clarity of division, periodicals were assigned based on their dominant features.

Table 5. Periodicals created after transformation

\begin{tabular}{|c|c|c|c|c|}
\hline$\#$ & Name & Years & Periodicity & Subject \\
\hline 1 & Popcorn & $1990-2012$ & monthly & entertainment \\
\hline 2 & Metal Hammer & $\begin{array}{l}1990- \\
\text { today }\end{array}$ & monthly & metal, rock \\
\hline 3 & $\begin{array}{c}\text { Tylko Rock (potem Teraz Rock) } \\
\text { [Only Rock (later Now Rock)] }\end{array}$ & 1991-2002 & monthly & rock \\
\hline 4 & Bravo & $1992-2017$ & biweekly & entertainment \\
\hline 5 & Brum & 1993-1999 & monthly & rock \\
\hline 6 & $\begin{array}{c}\text { Muzyk: FCM } \\
\text { [Musician: FCM] }\end{array}$ & $\begin{array}{l}\text { 1993- } \\
\text { today }\end{array}$ & monthly & $\begin{array}{c}\text { specialist } \\
\text { (equipment, } \\
\text { hardware) }\end{array}$ \\
\hline 7 & $\begin{array}{c}\text { Barok } \\
\text { [Baroque] }\end{array}$ & $1994-2015$ & semi-annual & musical culture \\
\hline 8 & $\begin{array}{l}\text { Zagraj to Sam } \\
\text { [Play It Yourself] }\end{array}$ & $\begin{array}{l}\text { 1994- } \\
\text { today }\end{array}$ & quarterly & sheet music \\
\hline 9 & $\begin{array}{l}\text { Ślizg } \\
\text { [Slide] }\end{array}$ & $1995-2007$ & monthly & hip-hop \\
\hline 10 & Atmospheric & $1995-2013$ & irregular & heavy metal \\
\hline 11 & Audio & $\begin{array}{l}\text { 1995- } \\
\text { today }\end{array}$ & monthly & $\begin{array}{l}\text { specialist } \\
\text { (equipment, } \\
\text { hardware) }\end{array}$ \\
\hline 12 & $\begin{array}{l}\text { Hi-Fi i Muzyka } \\
\text { [Hi-Fi and Music] }\end{array}$ & $\begin{array}{l}\text { 1995- } \\
\text { today }\end{array}$ & monthly & $\begin{array}{l}\text { specialist } \\
\text { (equipment, } \\
\text { hardware) }\end{array}$ \\
\hline 13 & $\begin{array}{l}\text { Machina } \\
\text { [Machine] }\end{array}$ & $\begin{array}{l}1996-2002 \\
2006-2011\end{array}$ & monthly & music in general \\
\hline 14 & $\begin{array}{l}\text { Gadki z Chatki (potem Pismo } \\
\text { Folkowe) } \\
\text { [Chats from the Hut (later Folk } \\
\text { Magazine] }\end{array}$ & $1996-2014$ & bimonthly & folk music \\
\hline
\end{tabular}


K. Tyszka \& M. Jagosz - Polish Music Press in the Face of Systemic Change in 1989 as an Example...

\begin{tabular}{|c|c|c|c|c|}
\hline 15 & $\begin{array}{c}\text { Klucz } \\
\text { [The Clef] }\end{array}$ & $1996-2015$ & irregular & academic \\
\hline 16 & $\begin{array}{l}\text { Estrada i Studio } \\
\text { [Stage and Studio] }\end{array}$ & $\begin{array}{l}\text { 1996- } \\
\text { today }\end{array}$ & monthly & $\begin{array}{l}\text { specialist } \\
\text { (equipment, } \\
\text { hardware, sound } \\
\text { production) }\end{array}$ \\
\hline 17 & Mystic Art & $\begin{array}{l}\text { 1996- } \\
\text { today }\end{array}$ & irregular & heavy metal \\
\hline 18 & Musica Galiciana & $\begin{array}{l}\text { 1997- } \\
\text { today }\end{array}$ & irregular & $\begin{array}{l}\text { musicology, musical } \\
\text { culture }\end{array}$ \\
\hline 19 & Techno Party & 1998-2001 & monthly & electronic music \\
\hline 20 & $\begin{array}{c}\text { Kwarta } \\
\text { [The Fourth] }\end{array}$ & $\begin{array}{c}1998- \\
2006 / \\
2011-2013\end{array}$ & irregular & $\begin{array}{l}\text { Polish contemporary } \\
\text { music }\end{array}$ \\
\hline 21 & $\begin{array}{l}\text { Muzyka21 } \\
\text { [Music21] }\end{array}$ & $2000-2017$ & monthly & contemporary music \\
\hline 22 & $\begin{array}{l}\text { Twój Blues } \\
\text { [Your Blues] }\end{array}$ & $\begin{array}{l}200 O- \\
\text { today }\end{array}$ & quarterly & blues \\
\hline 23 & $\begin{array}{l}\text { Przegląd Muzykologiczny } \\
\text { [Musicological Review] }\end{array}$ & $2001-2015$ & irregular & musicology, scientific \\
\hline 24 & Laif & $\begin{array}{l}2001- \\
\text { today }\end{array}$ & bimonthly & music in general \\
\hline 25 & $\begin{array}{l}\text { Wokalistyka w Polsce i na Świecie } \\
\text { [Vocal Studies in Poland and in the } \\
\text { World] }\end{array}$ & $\begin{array}{c}2002- \\
2014\end{array}$ & irregular & $\begin{array}{l}\text { academic/specialist } \\
\text { (singing) }\end{array}$ \\
\hline 26 & $\begin{array}{l}\text { Teraz Rock } \\
\text { [Now Rock] }\end{array}$ & $\begin{array}{l}2003^{-} \\
\text {today }\end{array}$ & monthly & rock \\
\hline 27 & $\begin{array}{l}\text { Twoja Muza } \\
\text { [Your Muse] }\end{array}$ & $\begin{array}{l}2003^{-} \\
\text {today }\end{array}$ & bimonthly & $\begin{array}{l}\text { musical education, } \\
\text { music in general }\end{array}$ \\
\hline 28 & $\begin{array}{l}\text { Polski Rocznik Muzykologiczny } \\
\text { [Polish Musicological Yearbook] }\end{array}$ & $\begin{array}{l}2004- \\
\text { today }\end{array}$ & annual & musicology, scientific \\
\hline 29 & $\begin{array}{c}\text { Biuletyn Polskiego Towarzystwa } \\
\text { Harfowego } \\
\text { [Polish Harp Society Bulletin] }\end{array}$ & $\begin{array}{l}2004- \\
\text { today }\end{array}$ & irregular & newsletter \\
\hline 30 & Glissando & $\begin{array}{l}2004- \\
\text { today }\end{array}$ & quarterly & $\begin{array}{c}\text { modern and } \\
\text { contemporary music }\end{array}$ \\
\hline 31 & Musicology Today & $\begin{array}{l}2004- \\
\text { today }\end{array}$ & annual & musicology, scientific \\
\hline 32 & Free Colours & $2005-2016$ & irregular & reggae \\
\hline 33 & $\begin{array}{l}\text { Forum Muzykologiczne } \\
\text { [Musicological Forum] }\end{array}$ & $\begin{array}{l}2005^{-} \\
\text {today }\end{array}$ & irregular & musicology, scientific \\
\hline 34 & Top Guitar & $\begin{array}{l}2005- \\
\text { today }\end{array}$ & monthly & specialist (guitar) \\
\hline
\end{tabular}




\begin{tabular}{|c|c|c|c|c|}
\hline 35 & Top Drummer & $\begin{array}{l}2006- \\
\text { today }\end{array}$ & bimonthly & specialist (drums) \\
\hline 36 & $\begin{array}{l}\text { Biuletyn Stowarzyszenia Polskich } \\
\text { Muzyków Kościelnych (potem } \\
\text { Musica Ecclesiastica) } \\
\text { Bulletin of Polish Church Musicians } \\
\text { Association (later Musica } \\
\text { Ecclesiastica)] }\end{array}$ & $\begin{array}{c}2006- \\
2014\end{array}$ & annual & church music \\
\hline 37 & $\begin{array}{l}\text { Gitarzysta } \\
\text { [Guitarist] }\end{array}$ & $\begin{array}{l}2006- \\
\text { today }\end{array}$ & monthly & specialist (guitar) \\
\hline 38 & Musica Sacra Nova & $2007-2011$ & annual & religious music \\
\hline 39 & Carillon Review & $\begin{array}{c}2008- \\
2013\end{array}$ & annual & specialist (carillon) \\
\hline 40 & $\begin{array}{c}\text { Perkusista } \\
\text { [Drummer] }\end{array}$ & $\begin{array}{l}2008- \\
\text { today }\end{array}$ & monthly & specialist (drums) \\
\hline 41 & $\begin{array}{l}\text { Studia Gregoriańskie } \\
\text { [Gregorian Studies] }\end{array}$ & $\begin{array}{l}2008- \\
\text { today }\end{array}$ & annual & $\begin{array}{l}\text { Gregorian chant, } \\
\text { church music }\end{array}$ \\
\hline 42 & Beethoven Magazine & $\begin{array}{l}2009- \\
\text { today }\end{array}$ & irregular & musical culture \\
\hline 43 & $\begin{array}{l}\text { Krytyka Muzyczna } \\
\text { [Music Criticism] }\end{array}$ & $2010-2014$ & irregular & musicology \\
\hline 44 & Lizard & $\begin{array}{l}2010- \\
\text { today }\end{array}$ & quarterly & rock, psychedelic \\
\hline 45 & $\begin{array}{c}\text { J Music : magazyn o muzyce } \\
\text { azjatyckiej } \\
\text { [J Music : Magazine on Asian } \\
\text { Music }]\end{array}$ & $2011-2012$ & irregular & Asian music \\
\hline 46 & $\begin{array}{l}\text { Aspekty Muzyki } \\
\text { [Aspects of Music] }\end{array}$ & $\begin{array}{l}2011- \\
\text { today }\end{array}$ & annual & musicology, scientific \\
\hline 47 & JazzPRESS & $\begin{array}{l}2011- \\
\text { today }\end{array}$ & monthly & jazz \\
\hline 48 & Pro Musica Sacra & $\begin{array}{l}2011- \\
\text { today }\end{array}$ & annual & $\begin{array}{l}\text { church music, } \\
\text { scientific }\end{array}$ \\
\hline 49 & $\begin{array}{l}\text { Estrada i Studio Plus } \\
\text { [Stage and Studio Plus] }\end{array}$ & $\begin{array}{l}2012- \\
\text { today }\end{array}$ & irregular & $\begin{array}{l}\text { specialist (sound } \\
\text { production and } \\
\text { equipment) }\end{array}$ \\
\hline 50 & $\begin{array}{l}\text { Muzyka w Mieście } \\
\text { [Music in the City] }\end{array}$ & $\begin{array}{l}2012- \\
\text { today }\end{array}$ & monthly & $\begin{array}{c}\text { classical and } \\
\text { contemporary music }\end{array}$ \\
\hline 51 & Presto & $\begin{array}{l}2012- \\
\text { today }\end{array}$ & quarterly & $\begin{array}{l}\text { musical culture, } \\
\text { contemporary music }\end{array}$ \\
\hline
\end{tabular}


K. Tyszka \& M. Jagosz - Polish Music Press in the Face of Systemic Change in 1989 as an Example...

\begin{tabular}{|c|c|c|c|c|}
\hline 52 & Scala & $\begin{array}{l}2012- \\
\text { today }\end{array}$ & irregular & music education \\
\hline 53 & Scontri & $2013-2016$ & irregular & academic, scientific \\
\hline 54 & $\begin{array}{l}\text { Piosenka } \\
\text { [The Song] }\end{array}$ & $\begin{array}{l}2013^{-} \\
\text {today }\end{array}$ & annual & art song, culture \\
\hline 55 & $\begin{array}{l}\text { Magazyn FOLK24 } \\
\text { [FOLK24 Magazine] }\end{array}$ & $\begin{array}{l}2013^{-} \\
\text {today }\end{array}$ & irregular & folk music \\
\hline 56 & Quarta & $2014-2015$ & quarterly & contemporary music \\
\hline 57 & $\begin{array}{c}\text { Sześć Strun Świata } \\
\text { [Six Strings of the World] }\end{array}$ & $2014-2017$ & quarterly & $\begin{array}{l}\text { specialist (classical } \\
\text { guitar) }\end{array}$ \\
\hline 58 & $\begin{array}{c}\text { Artpost : muzyka i dobre strony } \\
\text { miasta } \\
\text { [Artpost : Music and Good Sides of } \\
\text { the Town] }\end{array}$ & $\begin{array}{l}2014- \\
\text { today }\end{array}$ & bimonthly & $\begin{array}{l}\text { classical and } \\
\text { contemporary music }\end{array}$ \\
\hline 59 & Musica Ecclesiastica & $\begin{array}{l}2014- \\
\text { today }\end{array}$ & annual & church music \\
\hline 60 & Noise Magazine & $\begin{array}{l}2014- \\
\text { today }\end{array}$ & quarterly & $\begin{array}{l}\text { noise music, extreme } \\
\text { music genres }\end{array}$ \\
\hline 61 & $\begin{array}{l}\text { Notes Muzyczny } \\
\text { [Musical Notebook] }\end{array}$ & $\begin{array}{l}2014- \\
\text { today }\end{array}$ & semi-annual & academic, scientific \\
\hline 62 & $\begin{array}{l}\text { Pismo Folkowe } \\
\text { [Folk Magazine] }\end{array}$ & $\begin{array}{l}2015^{-} \\
\text {today }\end{array}$ & bimonthly & folk music \\
\hline 63 & $\begin{array}{c}\text { Vaib : hip-hop magazyn } \\
\text { [Vaib : The Hip-Hop Magazine] }\end{array}$ & $\begin{array}{l}2015^{-} \\
\text {today }\end{array}$ & quarterly & hip-hop \\
\hline 64 & $\begin{array}{c}\text { Gazeta Magnetofonowa } \\
\text { [Tape Recorder Newspaper] }\end{array}$ & $\begin{array}{l}2015^{-} \\
\text {today }\end{array}$ & quarterly & $\begin{array}{l}\text { Polish music in } \\
\text { general }\end{array}$ \\
\hline
\end{tabular}

\section{Discusion}

\subsection{Interpreting the 'before 1989' situation}

All periodicals that appeared until 1989 were published by Polish publishing houses, which was closely related to the policy of the People's Republic of Poland. The government introduced many legal restrictions on the freedom of the press. The creation of a periodical during communism required a permission. Despite the spurious pluralism that was to be provided by i.e. press law of 1984, the state had almost complete control over the officially published press. Content restrictions included preventive and repressive censorship, compulsory publication of certain content, and limitations on provided information. As for Polish national press, repressive censorship in this case was of marginal importance, as all publications first went through the preventive one. On the other hand, the former was widely applied when it comes to foreign press publishers, because only at this stage the authorities could verify the content of such publications. Due to above, the procedure of entering the Polish press market by a foreign publisher was very 
difficult, and the example of domestic magazines clearly shows that it is practically impossible. The issue of controlling and active influencing the content was also important. Magazines like "Poradnik Muzyczny" or "Praca Świetlicowa" explicitly aimed at transmitting ideological values as one of the goals of their activity. Another, "Muzyka", where the chronicle of the concert movement was kept, focused only on Polish composers (of course those not banned by the authorities).

Western music authors were completely omitted, which negatively affected the objectivity of the published articles (Rzanna-Szczepaniak, 2013: 95-97). During the Polish People's Republic, there were also a warning system against the periodicals suspension. It was regulated by the Act of July $31^{\text {st }}, 1891$ on the control of publications and performances. The essence of the system was to issue reminders for publishing undesirable press materials, and repeated reminders resulted in the temporary od permanent publisher's suspension.

Also characteristic for this period in the Polish press in that since most magazines were devoted to musicology or musical culture, articles written by musicologists or instrumentalists dominated there. The music journalist profession was not as popular as it is today. Moreover, many people wrote in several titles at the same time such as Jadwiga and Marian Sobieski (wellknown marriage of Polish ethnomusicologists) or Zofia Lissa (founder of Warsaw Institute of Musicology). Some of the authors also acted as editors-in-chief in several houses, such as Michal Bristiger (musicologist and writer on musical culture) in "Res Facta" or "Pagine" and Józef Chomiński (musicologist and music theorist) in "Muzyka" or "Studia Muzykologiczne". In order to be able to act as the nationwide journal editor-in-chief, it was necessary to be approved by the appropriate party department. This means that the publishing houses' decision makers could be only those suiting the then authorities. It shows the closure and hermetic nature of this market segment, as well as the full control power over the journal's activities.

Also, worth noting is the magazines circulation, which very rarely exceeded the number of several thousand. One of the factors that greatly influenced this was the rationing of paper. By controlling his allocations, it was possible to directly control the circulation of periodicals. Moreover, the use of paper for printing purposes required consent of relevant authority. This issue was regulated by legal provisions, including "Decree of the Council of Ministers of 26 April 1948 on the management of paper" (1948), as well as numerous regulations.

When it comes to the appearance of the periodicals, until 1980 any colour graphics, posters or non-standard fonts appeared in magazines very rarely. It is therefore worth noting that it was the 80 s that brought a remarkable acceleration and development of culture, especially the independent one. On that decade, the legal framework concerning preventive censorship changed several times. They were mainly caused by the economic and political crisis in Poland, which resulted in numerous protests and social demonstrations. Parallel to the development of the political and social affairs in Poland, the music magazine "Non Stop" evolved. It existed since 1972 and initially it was characterized by a rigid language, simple structure, and poor graphic design. In the 1980 s, the language of writing loosened, and in 1988 a colourful graphic design appeared, and the magazine's profile changed - apart from musical topics, a general cultural one began to emerge.

It was thanks to such titles as "Non Stop" and "Magazyn Muzykologicny" that the press addressed to young ones began to develop, attracting people with a certain graphic and rhetorical innovation. It was also the first press dealing with popular music in broader meaning.

\subsection{Understanding the 'in-transformation' case}

Socio-political changes at the end of the 8os led to collapse of the publishing houses controlled by the communist authorities. Therefore, as the query revealed, many journals ended their activities in then decade and at the very beginning of the following one. Moreover, in the 
times of the People's Republic of Poland, there was a common tendency that periodicals appeared irregularly and for short time, which was due to i.a. economic problems. It is worth adding that from the magazines that went bankrupt in the 1980s, only three were finally reactivated after market opening. This means that the editors so far looked for challenges in new magazines or other media formats, in particularly audio-visual, strongly developing at the turn of the $20^{\text {th }}$ and $21^{\text {st }}$ century.

Few magazines have survived the systemic change period. The main motivation for keeping certain titles on the market may have been their rich history and long tradition. "Ruch Muzyczny" and "Muzyka" were in the past and are still most prestigious musicological periodicals in Poland. The Ministry of Culture and Art also contributed to maintaining the publishing continuity of "Ruch Muzyczny", when in 1990, after two-month break in printing, it commissioned the publishing of the Author's Agency magazine (Komorowska, 2001: 8-11).

Importantly, the study showed that there were also journals that survived the transformation and maintained publishing continuity, although they collapsed during the new, post-communist reality. It was caused by being unable to find themselves and adapt to the then situation on the liberal and competitive press market. Moreover, the financial problems of some publishers, as the case of “'̇ycie Muzyczne”, were also a significant cause.

\subsection{Interpreting the 'post 1989' era}

The entire course of systemic changes in Poland had a significant impact on the shape of the press market. New press titles began to appear rapidly, and the vast majority of old periodicals collapsed. The liquidation of the state monopoly and privatization led to the emergence of publishing houses with their own capital. The consequence of this was the phenomenon of press concentration, which resulted in the fact that some of the publishers had many magazines in their portfolio. One of such companies is AVT-Korporacja, which has been operating on the market since 1992. She is the publisher of the magazines "Audio", "Estrada i Studio", "Estrada i Studio Plus", "Gitarzysta" and "Perkusista". In addition, there were also publishers with foreign budgets (Bajka, 1998: 22), but when it comes to the music press, their contribution to this market was minimal, such as Ringier Axel Springer ("Popcorn”) or Bauer Media ("Bravo").

Reading trends also influenced the appearance of an increasing number of magazines in the 1990s. They indicated a shift away from reading the daily press, and thus switching to reading magazines, especially monthly and bimonthly magazines (Secler, 2011: 66-67). This thesis is also confirmed by the result of the conducted query. There are 19 monthly, 6 bimonthly, 10 quarterly, 2 semi-annual, 10 annual and 17 periodicals appearing in 64 journals.

The subject matter of the magazines in question is very diverse. About 23 magazines are devoted exclusively to the contemporary music, 29 is about popular music in general or a hybrid one; there are also 12 specialist journals. However, it should be remembered that this classification is not entirely strict, because the music genres interpenetrate all the time, which means that the content of magazines does not always stick to specific frames. Nevertheless, comparing to the situation before 1989, that magazines dealing with popular music started to prevail.

Another novelty were pop culture magazines ("Bravo" and "Popcorn"). These magazines can be classified as tabloids, geared towards gossip, scandals, colour photos, and huge fonts. Their circulation at the end of the 90s reached almost 500,000 copies, which meant that they were the most popular magazines on the market. However, since the youth moved to the Internet, the circulation of these magazines gradually began to decline, leading to the closure of both magazines. 
The 1990s also brought changes in the structure and appearance of magazines. Compared to periodicals from the pre-transformation period, colour newspapers began to dominate, on slippery paper, often in A4 format, not reaching more than 100 pages. In addition, various gadgets began to be added to magazines, such as CDs, posters, calendars, and key rings. Only magazines classified as musicological, university and church music are usually published in the traditional book form. A novelty are also magazines devoted to classical music, such as "Glissando" and "Presto", which explicitly indicate that they want to write in "loose" language that is understandable for everyone. Such a procedure shows that magazines are trying to adapt to the current market requirements, working out certain compromises, and looking for their own place. It is not without reason that they call themselves popularizing magazines.

Despite the opening of the market described above and the large expansion of new titles, not all of them survived long in the new reality. Some of them have ended their activity (e.g. "Machina"), others have only suspended it (e.g. "Sześć Strun Świata"), and some have moved to the Internet and are only released in electronic form (e.g. "Musicology Today"). Some magazines have closed their publishing activities, but still place their content in the form of articles or posts on their own websites (e.g. "Vaib" or "Laif"). It is worth noting that there are also periodicals that have been operating only on the Internet from the very beginning (e.g. "JazzPRESS").

The main reasons for this may be: very high competition on the press market, financial problems of publishing houses and the amazing development of the Internet medium, which in the $21^{\text {st }}$ century had a significant impact on the decline in the readership of the traditional press. It is true that the influence of the Internet on the condition of the current music press market is a subject so large and autonomous that it would require a separate space to be devoted to it, but in order to maintain the continuity of the argument, it is worth mentioning its extremely important role. Nowadays, the Internet is the dominant medium that we use almost every day. Therefore, music publishers, following the spirit of the times, in addition to traditional editions more and more often decide to publish in various Internet formats, which is also evidenced by the conducted query. As many as 46 magazines out of the 64 analysed have their place in the Internet space, and the list also includes periodicals that have not been published for many years (e.g. "Brum").

\section{Conclusions}

Cultural transformation, which was one of the elements of systemic change in the communist bloc countries, led to great social development. Societies through changes, from the monocultural world, were included in the system of cultural diversity. The analysis of the Polish press market shows exactly how the process of these changes proceeded. The opening of the media market in Poland resulted in a rapid increase in new titles on the press market, while information about foreign musicians, concerts and events was already published in mass. Moreover, privatization has led to the emergence of a large number of new publishers with their own capital. It also opened a gate for foreign publishers. By increasing circulation, the music press became more accessible to people. Therefore, the journals have adapted their language, form of message and graphic structure in such a way that they could reach the largest number of readers. As far as the subject matter is concerned, periodicals about pop music started to dominate, which was a marginal phenomenon even in the pre-transformation times.

The functioning of the music press is an extremely important issue for further work on the border of social sciences, media studies and musicology. This is evidenced by a small number of literature on this subject, as well as the fact that in the era of the expansion of the Internet, the press takes on new shapes, as well as its content and functions. 
K. Tyszka \& M. Jagosz - Polish Music Press in the Face of Systemic Change in 1989 as an Example...

\section{Acknowledgements}

This research did not receive any specific grant from funding agencies in the public commercial, or not-for-profit sectors.

The authors declare no competing interests.

\section{References}

Bajka, Z. (1998). Kapitał zagraniczny w polskiej prasie - lata dziewięćdziesiąte [Foreign capital in the Polish press - the nineties]. Zeszyty Prasoznawcze 1-2, 21-35.

Bałtowski, M., \& Miszewski, M. (2015), Transformacja gospodarcza $w$ Polsce [Economic transformation in Poland]. Warsaw: PWN.

Komorowska, M. (2001). Polska prasa muzyczna $w$ okresie 1945-20oo [Polish music press in the period 1945-2000]. Warsaw: Wydawnictwo Akademii Muzycznej im. F. Chopina.

Maślanka, J. (1976). Encyklopedia wiedzy o praise [Knowledge encyclopedia about praise]. Cracow: Zakład Narodowy im. Ossolińskich.

Nasiłowski, M. (1995). Transformacja systemowa $w$ Polsce [System transformation in Poland]. Warsaw: Key Text.

Pigła, W. (1991). Centralny katalog polskich czasopism muzycznych i wydawnictw ciagtych o tematyce muzycznej: zbiory polskie [Central catalog of Polish music magazines and periodicals on music: Polish collections]. Warsaw: Stowarzyszenie Bibliotekarzy Polskich.

Rzanna-Szczepaniak, E. (2013). Stalinizm a powojenna kultura muzyczna $w$ Polsce [Stalinism and postwar music culture in Poland]. Opole: Wydawnictwo Naukowe Scriptorium.

Secler, B. (2011). Konsekwencje przemian roku 1989 dla środków społecznego przekazu w Polsce - wybrane problem [The consequences of the transformations of 1989 for the media of social communication in Poland - A selected problem]. Media Dawne i Współczesne, 1, 66-67.

Decree of the Council of Ministers of 26 April 1948 on the management of paper for printing (1948). Retrieved 25 November 2020, from: http://isap.sejm.gov.pl/isap.nsf/DocDetails.xsp?id=WDU19480240163

The Act of 26 January 1984 Press Law (1984). Retrieved 26 November 2020, from: http://isap.sejm.gov.pl/isap.nsf/DocDetails.xsp?id=wdu19840050024 
Appendix of the paper:

List of periodicals analysed during the query with every issue examined for the purpose

„Amatorski Ruch Artystyczny”, 1958-1961; 1958, nr 1-4/5; 1959, nr 1-3; 1960, nr 4-5; 1961, nr 6.

„Aspekty Muzyki", 2011-today; T. 1-T. 6.

„Atmospheric", 1995-2013; 1995, nr 1; 1996, nr 2-3/4; 1997, nr 5-6; 1998, nr 7; 1999, nr 8; 2000, nr 9; 2001, nr 10; 2002, nr 11; 2006, nr 12; 2007, nr 13; 2008, nr 14; 2009, nr 15; 2010, nr 16; 2011, $\mathrm{nr} 17 ; 2013, \mathrm{nr} 18$.

„Audio”, 1995-today; 1995, nr 1-3; 1996-2017, nr 1-12; 2018, nr 1-6.

„Ballada”, 1983-1984; 1983, nr 1; 1984, nr 1/2.

„Beethoven Magazine”, 2009-today, 2009, nr 1-2; 2010, nr 6-10; 2011, nr 12-13; 2012, nr 14-16; 2014, nr 19; 2016, nr 21-22; 2017, nr 23.

„Biblioteka Organisty”, 1957-1958, 1957, nr 1-4, 1958, nr 1.

„Biuletyn Polskiego Towarzystwa Harfowego”, 2004-today, 2004, nr 1-2; 2005-2017, nr $1-3 ; 2018, \mathrm{nr} 1$.

„Brum”, 1993-1999, 1993, nr 1-4; 1994-1998, nr 1-12; 1999, nr 1-6.

„Carillon Review”, 2008-2013, nr 1-6.

„Chopin w Świecie”, 1986-1988, nr 1-3.

„De Musica”, 2006-2012, 2006, Vol. 1/3; 2009, Vol. 4/5-7/8; 2011, Vol. 9; 2012, Vol. 10, 1112.

„Echo Teatralne i Muzyczne”, 1948-1949, 1948, nr 1-3/4; 1949, nr 5-7/8.

„Estrada i Studio”, 1996-today, 1996, nr 1; 1997-2017, nr 1-12; 2018, nr 1-7.

„Folk24”, 2013-today,

„Forum Musicum”, 1966-1974, 1966, nr 1/2-6; 1967, nr 1; 1968, nr 2-3; 1969, nr 4-6, 1970, nr 7-8; 1971, nr 9-12; 1972, nr 13; 1973, nr 14-15; 1974, nr 16.

„Forum Muzykologiczne", 2005-dziś, 2005, 2010, 2011, 2012/13, 2014, 2015/16.

„Forum Rozrywki”, 1983, nr 1-2.

„Gadki z Chatki”, 1996-2014, 1996, nr 1-3; 1997, nr 7-15; 1998, nr 16-17; 1999, nr 21-26; 2000, nr 27-31; 2001-2014, nr 1-6.

„Gazeta Magnetofonowa”, 2015-today, 2015, nr 1; 2016, nr 2-5; 2017, nr 1-4; 2018, nr 1.

„Gitarzysta”, 2006-today, 2006-2017, nr 1-12; 2018, nr 1-6.

„Glissando", 2004-today, 2004, nr 1-2; 2005, nr 3-7; 2006, nr 8-9; 2007, nr 10/11-13/14; 2009, nr 15; 2010, nr 16; 2011, nr 17-19; 2012, nr 20; 2014, nr 23-24; 2015, nr 26-27; 2016, nr 28-29. 
K. Tyszka \& M. Jagosz - Polish Music Press in the Face of Systemic Change in 1989 as an Example...

„ISME”, 1973-2002, 1973-1975, nr 1-2; 1976-1978, nr 1-5; 1979, nr 1-4; 1980, nr 1; 1983-2002, nr $1-4$.

„J Music”, 2011-2012, 2011, nr 1; 2012, nr 2.

„Jazz”, 1956-1981, 1956, nr 1-6; 1957-1980, nr 1-12; 1981, nr 1.

„Jazz Forum [ed.international]”, 1967-1992, 1967, nr 1; 1968, nr 1-2; 1969, nr 1-3; 1970, nr $1-4 ; 1971, \mathrm{nr} 1-3 / 4 ; 1972-1992$, nr 1-6.

„Klucz”, 1996-2015, 1996, nr 1; 1997, nr 2; 2003, nr 3; 2006, nr 5; 2008, nr 6; 2009, nr 7; 2010, nr 8; 2011, nr 9-10; 2012, nr 11; 2013, nr 12; 2014, nr 13; 2015, nr 14.

„Kwarta”, 1998-2006, 2011-2013, 1998 nr 1-2; 1999, nr 3; 2000, nr 4-7; 2001, nr 8-9; 2002, nr 10-11; 2003, nr 12; 2004, nr 13, 2005, nr 14; 2006, nr 15; 2011, nr 1-2; 2012, nr 3-4; 2013, nr 5 .

„Kwartalnik Muzyczny”, 1948-1950, 1948, nr 21/22-24; 1949, nr 25-28; 1950, nr 29/30.

„Laif”, 2001-2016, 2001, nr 1-4; 2002, nr 5-10; 2003, nr 11-15; 2005/2006, nr 26-32; 2006, nr 33-38; 2007-2009, nr 1-12; 2010, nr 1/2-3/4; 2011, nr 1-5; 2013, nr 1-4; 2014, 1/2-6; 2015, nr $1-3$.

„Lizard", 2010-today, 2010, nr 1; 2011-2016, nr 1-4; 2017, nr 1.

„Machina”, 1996-2002, 2006-2011, 1996-2001, nr 1-12; 2002, nr 1-3; 2006, nr 0-9; 20072010, nr 1-12; 2011, nr 1-5.

„Magazyn Muzyczny Jazz”, 1981-1991, 1981, nr 2-8; 1982, nr 1-4; 1983-1985, nr 1-6; 19861990, nr 1-12; 1991, nr 1-10.

„Musica Antiqua Europae Orientalis”, 1966-2012, T. 1-T. 16.

„Musica Ecclesiastica”,2014-today, nr 9-13.

„Musica Galiciana”, 1997-today, 1997, T. 1; 1999, T. 3; 2000, T. 5; 2001, T. 6; 2003, T. 7; 2005 , T. 9; 2007, T.10; 2008, T. 11; 2010, T. 12; 2012, T. 13; 2014, T. 14; 2016, T. 15.

„Musica Medii Aevi”, 1965-1991, 1965, T. 1; 1968, T. 2; 1969, T. 3; 1973, T. 4; 1976, T. 5; 1977, T. $6 ; 1986$, T. $7 ; 1991$, T. 8.

„Musica Sacra Nova”, 2007-2011, 2007, nr 1; 2008, nr 2; 2009/10, nr 3/4; 2011, nr 5.

„Muzyk: FCM”, 1993-today, 1993-2017, nr 1-12; 2018, nr 1-6.

„Muzyka21”, 2000-2017, 2000, nr 1-7; 2001-2016, nr 1-12; 2017, nr 1-3.

„Muzyka Religijna w Polsce”, 1975-1988, 1975/76, T. 1; 1978, T. 2; 1979, T. 3; 1980, T. 4; 1983, T. $5 ; 1984$, T. $6 ; 1985$, T. 7-8; 1988, T. 9-10.

„Muzyka w Mieście”, 2012-today, 2012, nr 1-8; 2013-2017, nr 1-12; 2018, nr 1-5.

„Muzyka w Prasie Zagranicznej”, 1959-1969, 1959-1968, nr 1-12; 1969, nr 1-6.

„Noise Magazine”, 2014-today, 2014, nr 1-2; 2015, nr 1-4; 2016, nr 1-5; 2017, nr 1-5; 2018, nr 1-2.

„Non Stop”, 1972-1990, 1972, nr 1-5; 1973-1989, nr 1-12; 1990, nr 1-9.

„Notes Muzyczny”, 2014-today, 2014-2017, nr 1-2.

„Pagine”, 1972-1989, 1972, T. 1; 1974, T. 2; 1979, T. 3; 1980, T. 4; 1989, T. 5.

„Perkusista”, 2008-today, 2008, nr 1; 2009-2011, nr 1-6; 2012, nr 1-8; 2013-2017, nr 1-12; 2018, nr 1-6. 
„Piosenka”, 2013-today, nr 1-5.

„Polnische Musik”, 1966-1992, 1966, nr 1-3; 1967-1992, nr 1-4.

„Popcorn”, 1990-2012, 1990-2011, nr 1-12; 2012, nr 1-7.

„Poradnik Muzyczny”, 1947-1989, 1947, nr 1-10; 1948-1977, nr 1-12; 1978-1982, nr 1-6; 1983-1989, nr 1-12.

„Praca Świetlicowa”, 1951-1962, 1951, nr 1-8; 1952-1961, nr 1-12; 1962, nr 1-7/8.

„Presto", 2012-today, 2012, nr 1-3; 2013-2015, nr 1-4; 2016, nr 2/3; 2017, nr 1-3/4; 2018, nr 1.

„Przegląd Muzykologiczny”, 2001-2015, 2001-2007, nr 1-7; 2011, nr 8; 2013, nr 9; 2015, nr 10.

„Quarta", 2014-2015, 2014, nr 1-3; 2015, nr 1-2.

„Res Facta”, 1967-1982, 1967-1973, nr 1-7; 1977, nr 8; 1982, nr 9.

„Res Facta Nova”, 1994-today, 1994, nr 1; 1997, nr 2; 1999, nr 3; 2001, nr 4; 2002, nr 5; 2003, nr 6; 2004, nr 7; 2005, nr 8; 2007, nr 9; 2008, nr 10; 2010, nr 11; 2011, nr 12; 2012, nr 13; 2013, nr 14; 2014, nr 15 .

„Ruch Muzyczny”, 1957-today, 1957, nr 1-16; 1958, nr 1-24; 1959, nr 1-17/18; 1960-1973, nr 1-24; 1974-80, nr 1-26; 1981, nr 1-25; 1982, nr 1-15; 1983-1991, nr 1-26; 1992, nr 1-14; 19932012, nr 1-26; 2013, nr 1-22; 2014-2017, nr 1-12; 2018, nr 1-6.

„Rytmy”, 1972, nr 1-6.

„Scala”, 2012-today, 2012, nr 1; 2013 nr 2-3; 2014, nr 4; 2015, nr 5-6; 2016, nr 7.

„Scontri”, 2013-2016, 2013, nr 1; 2015, nr 2; 2016, nr 3.

„Studia i Rozprawy”, 1971-1973, nr 1-3.

„Studia Muzykologiczne”, 1953-1956, 1953, nr 1-2; 1954, nr 3; 1955, nr 4; 1956, nr 5.

„Studia z Wychowania Muzycznego”, 1975-1988, 1975, Z. 1; 1977, Z. 2; 1978, Z. 3; 1980, Z. 4; 1981, Z. 5; 1983, Z. 6; 1988, Z. 7/8.

„Sześć Strun Świata”, 2014-2017, 2014, nr 0; 2015-2017, nr 1-4.

„Szkice o Kulturze Muzycznej XIX wieku”, 1971-1984, 1971, T. 1; 1973, T. 2; 1976, T. 3; 1980, T. $4 ; 1984$, T. 5 .

„Ślizg”, 1995-2007, 1995, nr 1-2; 1996, nr 3-11; 1997, nr 1-12; 1998, nr 1-8; 2002-2006, nr 112; 2007, $\mathrm{nr} 1$.

„Śpiew w Szkole”, 1957-1966, 1957, nr 1-4; 1958-1960, nr 1-6; 1961-1966, nr 1-5.

„Śpiewak Śląski”, 1985-2017, 1985/86, nr 1/2; 1986/87, nr 5/6-7; 1988-1993, nr 1-4; 19942011, nr 1-6; 2012-2017, nr 1-4.

„Śpiewamy i Tańczymy”, 1954-1987, 1954-1987.

„Taniec”, 1974-1986, 1974, nr 1; 1975, nr 1-2; 1977, nr 1; 1979, nr 1-2, 1980, nr 1; 1982, nr 1; 1983, nr 1; 1986, nr 1.

„Taniec”, 1992-1994, 1992, nr 1-3/4; 1993, nr 1-3/4; 1994, nr 1-2.

„Techno Party”, 1998-2001, 1998, nr 1-6; 1999, nr 1-10; 2001, nr 7/8, 10.

„Teraz Rock”, 2003-today, 2003, nr 1-10; 2004-2017, nr 1-12; 2018, nr 1-7. 
„Top Drummer”, 2006-2014, 2006, nr 1-4; 2007/08-2012/13, nr 1-6; 2013, nr 1-4.

„Top Guitar”, 2005-today, 2005, nr 1; 2006-2009, nr 1-6; 2010-2017, nr 1-12; 2018, nr 1-6.

„Twoja Muza”, 2003-today, 2003, nr 1; 2004-2017, nr 1-6; 2018, nr 1-2.

„Twoja Muza”, 2003-today, 2003, nr 1; 2004-2017, nr 1-6; 2018, nr 1-2.

„Tylko Rock”, 1991-2002, 1991, nr 1; 1992-2001, nr 1-12; 2002, nr 1-9/10.

„Vaib”, 2015-today, 2015, nr 1-3; 2016, nr 4-8; 2017, nr 9-11.

„Wiadomości Gitarowe”, 1957-1966, 1957, nr 1-2; 1958-1965, nr 1-4; 1966, nr 1.

„Wiadomości ZAIKSU”, 1971-dziś, 1971-1995, nr 1-4; 1996, nr 1-3; 1997-2005, nr 1; 2006, nr 1-3; 2007, nr 1-2; 2008, nr 1; 2009, nr 1-3; 2010-2011, nr 1-2; 2012-2017, nr 1-3; 2018, nr 1.

„Wokalistyka w Polsce i na Świecie”, 2002-2014, 2002, T. 1; 2003, T. 2; 2004, T. 3; 2006, T. 4; 2008, T. 5; 2010, T. 6; 2011, T. 7; 2012, T. 8; 2014, T. 10.

„Wychowanie Muzyczne w Szkole”, 1967-2010, 1967-2010, nr 1-5.

„Z Dziejów Muzyki Polskiej”, 1961-1971, 1961, nr 2-3; 1962, nr 4; 1963, nr 6; 1964, nr 7-8; 1965, nr 9-10; 1966, nr 11-12; 1969, nr 13-14; 1971, nr 15.

68

„Zagraj to Sam”, 1994-today, 1994-2010, nr 1-12; 2011-2017, nr 1-4; 2018, nr 1.

„Życie Muzyczne”, 1946-1948, 1974-2009, 1946, nr 1/2; 1947, nr 3/4-5/6; 1974-2007, nr 112; 2008-2009, $\mathrm{nr} 1-4$.

„Życie Śpiewacze”, 1948-1973, 1948, nr 1-3; 1949-1973, nr 1-12. 


\title{
Word Formative Structure of Words with the Root Lěp- In Old Russian Written Records
}

\author{
Tatiana Galochkina \\ First Moscow State Medical University I. M. Sechenov, RUSSIAN FEDERATION \\ Institute of Linguistics and Intercultural Communication
}

Received: 27 September 2020 - Accepted: 2 December 2020 - Published Online: 25 December 2020

\section{Abstract}

System of derivational morphology of the Old Russian language has its own characteristics based on the origin of the book vocabulary, which consisted mainly of Proto-Slavic words and calques from Greek words. The main morphological way of word formation was the heritage of the ProtoSlavic language, which developed together with the formation of morphemes as a language unit. Active derivation took place during the formation of the Old Russian book vocabulary. During this period an uninterrupted process began the creation of book translations from the Greek into Church Slavonic. The ancient scribes made extensive use of Greek words calquing, which especially intensified the creation of compound words. Compound words were formed according to the models of Greek composites, but using Russian morphemes. As a result of this process, the lexical fund of the literary language was created, which included words with the root *lěp-. Such words are contained in ancient Russian written records ("Life of St. Sava the Sanctified", composed by St. Cyril Skifopolsky, "The Life of St. Andrew the Fool", "The Chronicle" by John Malalas, "The Chronicle" by George Amartol, "History of the Jewish War" by Josephus Flavius, Christianopolis (Acts and Epistles of the Apostles), Uspensky Collection of XII-XIII centuries etc.). In the article will be considered the word formative structure of words with the root lěp-.

Keywords: derivational morphology, root lěp-, calques, Church Slavonic, Old Russian written records.

\section{Introduction}

The words with the Proto-Slavic root *lěp- contained in the Old Russian written records had a developed word-formation structure, which included different ways of creating such words and their word-formation motivation. The purpose of this paper is to show the development level of the word-formation structure in Old Russian period using the example of the words with the root *lěp-. The article considers the relationship between word-formation motivation of derivatives with the root *lěp-, their word-formation meanings and derivational formants.

The problem of word-formation motivation was widely represented in the works of Russian linguists: O. I. Blinova, E. A. Zemskaya, E. S. Kubryakova, V. V. Lopatin, A. N. Tikhonov, I. S. Ulukhanov, I. A. Shirshov and others.

(C) Authors. Terms and conditions of Creative Commons Attribution 4.0 International (CC BY 4.0) apply. Correspondence: Tatiana Galochkina ( $\mathrm{PhD}$ student), First Moscow State Medical University I. M. Sechenov, Institute of Linguistics and Intercultural Communication, Moscow, RUSSIAN FEDERATION. Email: tgalochkina27@gmail.com. 


\section{Sources of analysis}

\subsection{General overview}

As is known, a new concept formation, which is embodied in the word meaning, takes place on the basis of the available linguistic material. The word-formation system is based on the word, which is in a relationship of word-formation motivation with the producing word.

There are full and partial motivation, in each of which there are three types of wordformation motivation. Direct, transferred and peripheral motivation belong to the full motivation. Indirect, metaphorical and associative motivation - to the partial one. Selecting these types of word-formation motivation is due to the correlation of the producing word meaning with the derivative meaning.

Direct motivation is characterized by complete entry of the direct meaning of a producing word into the derivative meaning, and it forms the core of the lexical meaning in the derivative (see Shirshov, 1999: 156). (cf. каменный "stony" (abounding in or having the nature of stone) (URL: https://www.merriam-webster.com/dictionary/stony)).

Full transferred motivation is observed when the figurative meaning of the producing word is completely included in the derivative meaning (cf. in Russian derivatives of the verb кусать "bite". Their meanings are motivated by the second meaning of the producing verb кусать "to grasp with the teeth; to take a bite of something to eat": обкусать "gnaw round", откусить, "bite off”).

In the case of peripheral motivation, the producing word forms only a narrow section of the semantic space or the edge of the semantic field. Motivational meaning moves to the periphery of the semantic space and the core takes on a meaning that has a paradigmatic relationship with motivational meaning, most often - in genus-species relations (cf. белье "white goods". Its motivating core is the generic meaning "color", and the specific meaning "white" moves to the periphery).

Indirect motivation is observed when a direct reference to the producing word is impossible, and semantic relations manifest themselves indirectly through the lexical meaning of the producing word, or rather through its part (see Shirshov, 1999: 199).

Metaphorical motivation is characterized by the fact that only one semantic component is taken from the lexical meaning of the producing word, which becomes the basis of a new nomination (this happens through transferring by similarity). Thus, a new word is born and it is the carrier of the metaphorical meaning. Moreover, comparisons are an intermediary between the producing word and the derivative: "when a word is created, it turns into a metaphor, when describing the derivative meaning, the metaphor unfolds into a comparison" (cf.: каменеть "to turn to stone") (Shirshov, 1995: 52).

Associative motivation might occur in instances where "the lexical meaning of the derivative is based on an associative feature which is in the semantic structure of the producing word in a latent state" (Ibid.: 53). An associative feature is usually not present in the interpretation of a word but accompanies it (ex. gr. сова "owl" is a nocturnal bird with large eyes and a hooked nose". Its associative feature "the way of functioning in the daytime" is in a latent state, however, this feature is used as a basis for the new nomination советь "grow drowsy", i.e. to be in a drowsy state like an owl in the daytime.

When a new word is created, it acquires a derivational meaning that belongs to all words of the same word-formation group within the grammatical class.

M. Dokulil distinguishes the following types of derivational meanings for simple words: transpositional, modificational, and mutational. 
The transpositional derivatives acquire meanings that do not differ from the semantics of the producing words. At the same time, transposition involves the transition of a word from one part of speech to another, i.e. "deadjective quality nouns like Cz. rychlý "quick" $\rightarrow$ rychlost "quickness", (b) "an objectivisation of action", cf. deverbal action nouns (nominalisations) such as Cz. padat "to fall" $\rightarrow$ pád, padnutí, padání "the fall, the falling", (c) derivations such as Cz. statečně (žít) "(to live) bravely” $\rightarrow$ statečný (život) "a brave (life)" ” (Lehmann, 2015: 1023).

The modificational derivatives acquire supplementary modifying marks. Such derivatives belong to the same part of speech as the producing words: родительница "genitrix" (a female genitor), заступьница "protectress" (a female protector).

The mutational derivatives acquire meanings significantly different from the meaning of producing words: творити "create" - творьць "creator" creativity, льпити "glue"льпитель "fowler who caught a tiny bird".

Analysis of the word-formation structure taking into account the types of their wordformation motivation and derivative meaning carried out within the etymological group with the root *lěp-, showed the following results.

\section{Discussion}

We classify the simple words with the root *lěp- by types of motivation.

\section{Direct motivation in the transpositional derivation system.}

льпый "beautiful" $\rightarrow$ льпота "beauty"

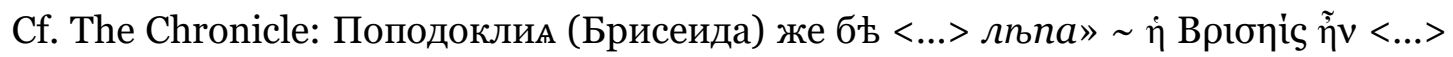

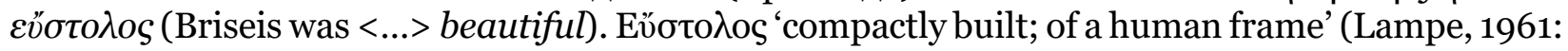
$576)$.

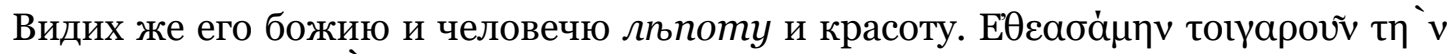

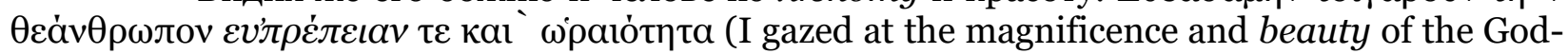
Man) (Rydén, 1995: 56-57).

\section{Direct motivation in the modificational derivation system.}

Льпити "glue" $\rightarrow$ прильпити "adhere"

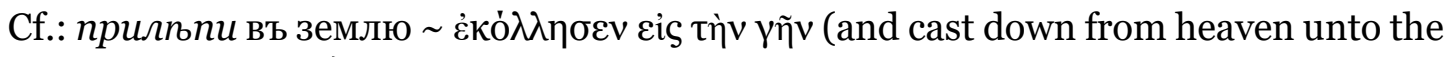
earth) (СлРЯ XI-XVII, 19: 199).

\section{Transferred motivation in the mutational derivation system.}

Льпити "glue"- льпитель "fowler who caught a tiny bird"

Cf.: Глаголаше бо, яко подобнь суть идоломь кланяющиися человеку льпителю, иже устроивъ льпа, ятъ единъ от малых птиць, соловей сию наричють. <...> и глагола

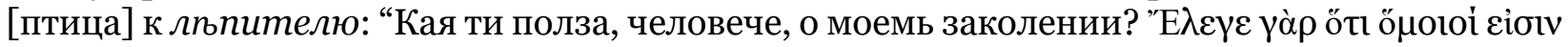

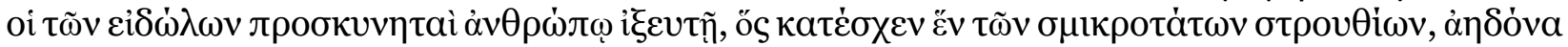

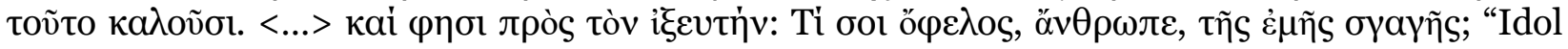
worshippers, said he, are like a foweler who caught a tiny bird, called nightingale $<\ldots>$ the nightingale $<\ldots>$ said to the fowler, Man, what advantageth it thee to slay me?" (Barlaam and Ioasaph: 134, 136-137).

\section{Direct motivation in the mutational derivation system.}

Нельпое (нельпая Plur.) (as a noun) 'smth. bad'. 
162).

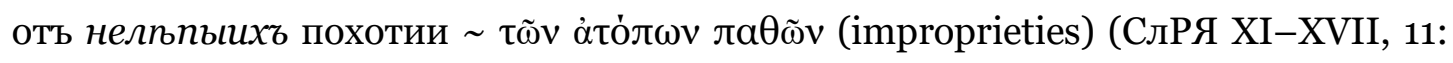

\section{Metaphorical motivation.}

Безльпый “unwise" $\rightarrow$ безльпица "nonsense, blether".

Cf.: безльпицю молвилъ (<he> talked nonsense) [Поуч. Вл. Мон.] (СлРЯ XI-XVII, Вып. 1: 112)

Thus, we find the unity of word-formation motivation, word-formation meaning and derivational formants in the word-formation structure. It is observed in the words with the root* lěp- used in Old Russian written records.

A significant number of new words with the root *lěp- were compound words. One part of such words were calques of Greek complex words and the other compound words were not directly copies, but owed their origin to the influence of the Greek language. However, "the phenomena of calquing were most characteristic feature of Old Slavonic word formation in the creating of two-root lexemes - both in a suffixal-addition way and in a addition method» (Efimova, 2007: 223).

A distinctive feature of compound words is the subordination of the components that make up their composition. Compound words include a supporting component and a previous stem of a "concretizing character", which are combined with the connecting vowel -o- (-e-) (Nizametdinova 2013: 81). as follows:

Models of compound words included in etymological group with the root *lěp- were

$$
\begin{aligned}
& \mathrm{R}_{1}+/ \mathrm{o}(\mathrm{e}) /+\left(\mathrm{R}_{2}+\mathrm{n}\right) \\
& \mathrm{R}_{1}+/ \mathrm{o}(\mathrm{e}) /+\mathrm{R}_{2}+/ \mathrm{o}(\mathrm{e}) / \mathrm{R}_{3}+\mathrm{n} .
\end{aligned}
$$

where $\mathrm{R}_{1}$ and $\mathrm{R} 2$ - root morphemes, $\mathrm{S}$ - suffix, $\mathrm{n}$ - ending of a compound word.

The study of the etymological group with the root *lěp- showed the presence of a large number of compound words in it. The scale of word-formation motivation for such words in 1117th centuries included two stages:

1. Combination of the direct motivation with the direct one;

2. Combination of the indirect motivation with the direct one.

The first stage of motivation includes composites, the meanings of which are formed on the basis of direct meanings of their producing words.

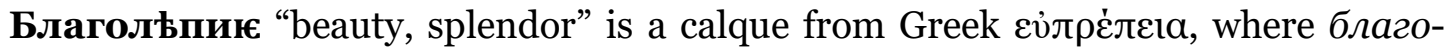

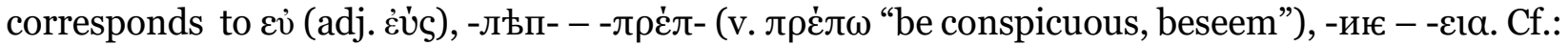
ПомышлАи небесныихъ благолппиє добротъ да тї о земельныихъ не боудеть никоє $\square$ же

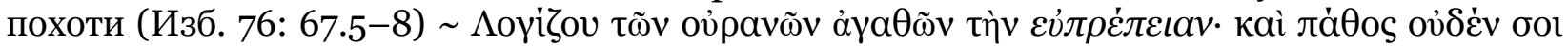

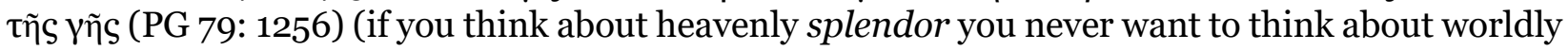
goods).

\section{Word structure: благольпыи + -иј-}

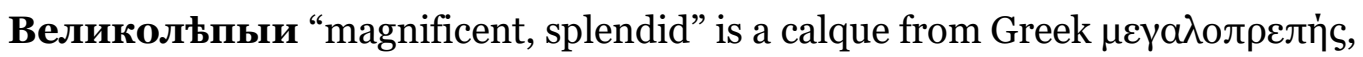

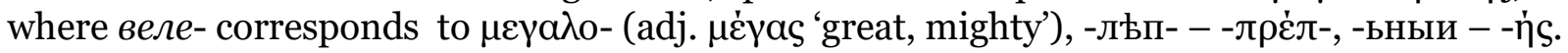

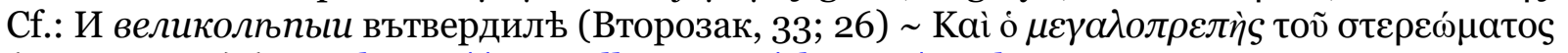
(Deut, 33; 26) (URL: https://www.ellopos.net/elpenor/greektexts/septuagint/chapter.asp?book=5\&page=33). 
Word structure: addition adj.+ adj.

Благольпнь - the same as благольпьно (благольпьно is a calque from Greek adv.

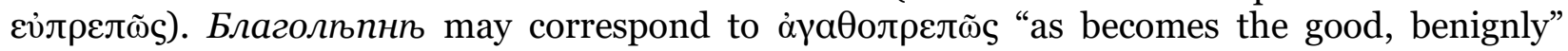
(Lampe, 1961: 4). Cf.: раждаемое отроче благолппнп мирови и спасителнь являемаго

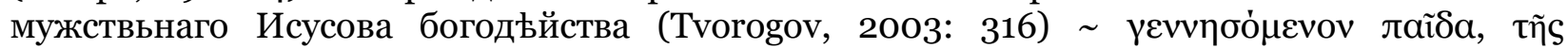

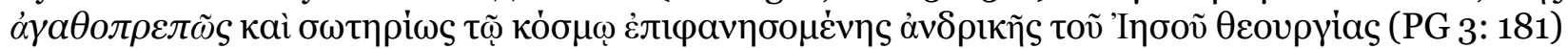
(the son who was to be born <should be a prophet> of the God-incarnate work of the Lord Jesus, to be manifested to the world for its salvation).

\section{Word structure: благольпныи + -\$}

It is important to note some lexemes that do not copy Greek compound words in texts may be influenced by the Greek language. Cf.: hapax legomenon вельльпославьныи is a compound word with three stems recorded in the Christianopolis Apostolos of the 12th cent.: Приимъ бо шт б(ог)а о(ть)ца чьсть и славоу, гласоу же пришьдъшю таковомоу шт вельлппославъны славы: сь єсть с(ы)нъ мой възлюблюный, о нємьже азъ бл(а)говолихъ

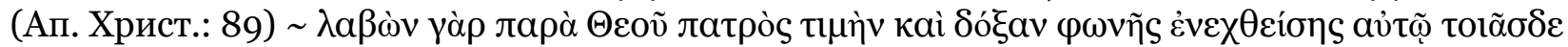

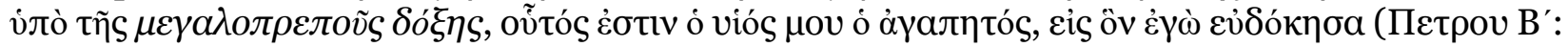
https://www.ellopos.net/elpenor/greek-texts/new-testament/peter 2/1.asp).

The addition of the third component -славьныи 'glory' is probably associated with the syntagmatic neighborhood and an indication of the importance of the word glory

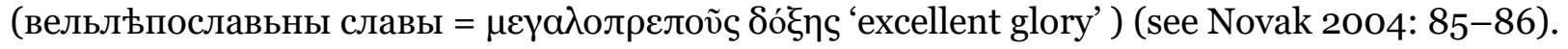

\section{Word structure: addition adj.+ adj. + adj.}

The second stage of motivation includes compound words in which one of the components is motivated by a figurative meaning, and the other by a direct meaning.

The first component of such words may be motivated by its producing word in analogy with metaphorical relations.

As a rule the metaphorization sources are semantic spheres related to the material and animal worlds as well as the human world. Moreover, the most frequent cases of metaphorical transference are observed in spatial and anthropological vocabulary describing the human physiology. Consequently the diachronic analysis of the metaphorical system makes it possible to understand the metaphorization process and its role in the development of the lexical-semantic system (see Balashova, 2014: 55).

An analysis of the compound words with the root *lěp- in Old Russian written records and lexicographic sources shows that metaphorized words were classified as social and family relations as well as religious beliefs.

Religious beliefs: Богъ “God”, ангелъ “angel”, святой “saint”.

Ангелольпотный - $\dot{\gamma \gamma \varepsilon \lambda о л \rho \varepsilon л \eta ่ s ~ " b e f i t t i n g ~ a n g e l s " ~(L a m p e ~ 1961: ~ 9) . ~ T h e ~}$

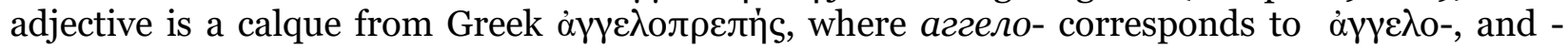
льпотьныи - -лрєли́s. Cf.: видњнияхь аггелольпотныие крьпости (Tvorogov, 2003: 376)

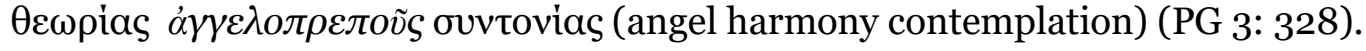

\section{Word structure: addition subst. + adj.}

Богольпыи - the same as боголппный. This adjective is a calque from Greek

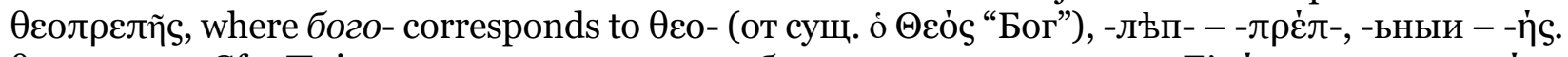

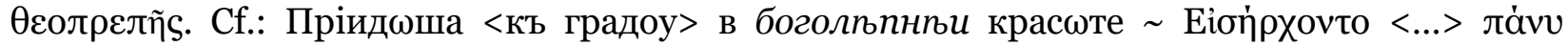

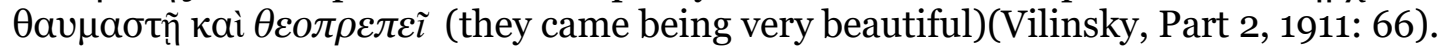


Word structure: addition subst. + adj.

Sibling relationship: мать "mother”, сынъ "son”.

Сынольпно “in a manner befitting a son” (сынольпнь “the same as сынольпнь”) (СлРЯ XI-XVII, 29: 138-139).

Матерольпьно/Матерельпьно is a calque from Greek $\mu \eta \tau \rho о л \rho \varepsilon л \tilde{\varsigma ~ " i n ~ a ~}$ manner befitting a mother” (Lampe, 1961: 870). Cf.: Матерельпьно всехъ родила юси творца (Jagić, 1886: 444) (She gave birth to the Creator in a manner befitting a Mother).

Word structure: addition subst. + adv.

Social relations: рабъ "slave".

Active metaphorization in the vocabulary describing social connections shows how was important the relationship between the individual and society as a whole in the linguistic world-image of the early Slavs. Social distinctions influence the transference creation where the upper class has the best moral and ethical qualities and, on the contrary, the lower social class is associated with moral depravity and absence of will.

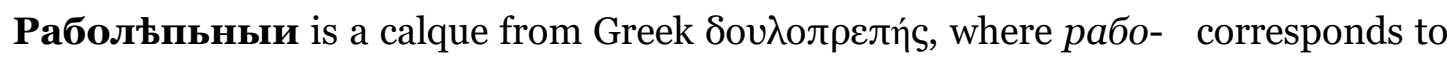

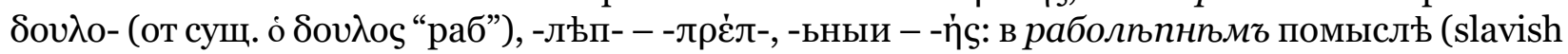
thinking) (

Word structure: addition subst. + adj.

Рабольпие "slavery"

To clarify the derivational structure of this word, it is necessary to take into account etymological data. When analyzing the historical stem-composition, we should look at the Greek

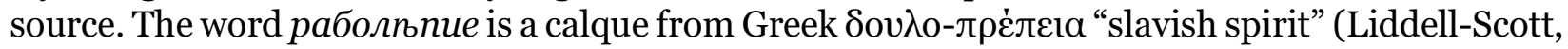

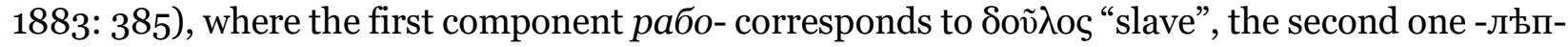

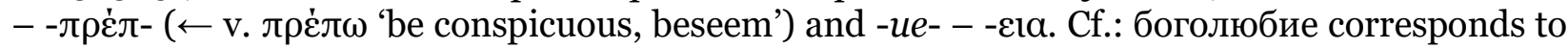

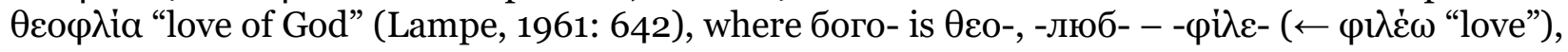
$-u e---1 \alpha$. Compound words of this type defines an abstract action or state, which is called the supporting stem and referring to the substance expressed by the first stem of the word.

\section{Conclusion}

Consequently, the word-formation structure of words with the root *lěp- was heterogeneous and had a systemic character. New words with the root *lěp- were created by prefixal method, terminational manner of derivation, and addition two and more stems.

Word-formation motivation of simple words with the root *lěp- has been classified according to the following types:
1. Direct motivation;
2. Transferred motivation;
3. Metaphorical motivation.

4. Word-formation motivation of compound words with the root *lěp- has been classified according to the following types:

5. Combination of the direct motivation with the direct one;

6. Combination of the indirect motivation with the direct one. 
Derivative meanings of words with the root *lěp- expressed by the word-formation formant belong to the following types: transpositional, modificational, and mutational.

\section{Acknowledgements}

This research did not receive any specific grant from funding agencies in the public commercial, or not-for-profit sectors.

The author declares no competing interests.

\section{References}

Балашова Л. В. (2014). Русская метафора: прошлое, настоящее, будущее [Russian metaphor: past, present, future]. М.: Языки славянской культуры.

Вилинский С. Г. (1911). Житие св. Василия Нового в русской литературе [The life of St. Basil the New in Russian literature]. Ч. 2. Тексты жития. Одесса: тип. «Техник».

Ефимова В. С. (2007). Влияние греческого языка на формирование лексического фонда старославянского языка [The influence of the Greek language on the formation of the lexical fund of the Old Church Slavonic]. Межъязыковое влияние в истории славянских языков и диалектов: социокультурный аспект / Сб. статей. Под ред. и с предисл. Т.И. Вендиной. М.: Институт славяноведения РАН. - С. 196-244.

Низаметдинова Н. Н. (2013). Сложные слова в русском языке XI-XVII вв.: словообразовательная структура, семантика, морфемика: моногр. [Compound words in Russian XI-XVII centuries: derivational structure, semantics, morphemics]. М.: ИИУ МГОУ.

Новак М. О. (2004). «Необходимое» и «прекрасное» в славяно-русском переводе Апостола: динамика семантических изменений ["Necessary" and "beautiful” in the Slavic-Russian translation of the Apostle: dynamics of semantic changes]. Древняя Русь. Вопросы медиевистики, №1. С. 81-86.

... (1975). С л о в а р ь русского языка XI-XVII вв. [Dictionary of the Russian language of XI-XVII centuries]. Под ред. Ф. П. Филина и Г. А. Богатовой. М.: Наука.

Творогов О. В. (2003). Библиотека литературы Древней Руси [Library of Ancient Rus literature]. Т. 8: XIV - первая половина XVI века. СПб.: Наука.

Ширшов И. А. (1995). Типы словообразовательной мотивации [Types of word-formation motivation]. Филологические науки, № 1. С. 41-55.

Ширшов И. А. (1999). Теоретические проблемы гнездования [Theoretical problems of nesting]. Монография. М.: Прометей.

Ягич И. В. (1886). Служебные мнении за сентябрь, октябрь и ноябрь: В церковнославянском переводе по русским рукописям 1095-1097 г. [Official opinions for September, October and November: In Church Slavonic translation from Russian manuscripts of 1095-1097.]. Труд [по опубликованию и вступ. ст.] орд. акад. И.В. Ягича. СПб. : Отд-ние рус. яз. и словесн. Имп. $\mathrm{AH}$.

Jacques-Paul Migne, J-P. (1857). Patrologia Graeca. T. 3.

Jacques-Paul Migne (1865). Patrologia Graeca. T. 3.

John Damascene (1937). Barlaam and Ioasaph. ed. by T. E. Page, E. Capps, W. H. D. Rouse. London: The Loeb Classical Library. 1914; reprinted in 1937. 
T. Galochkina - Word Formative Structure of Words with the Root Lěp- In Old Russian Written Records

Ioannes Malalas (1865). Chronographus Byzantinus. Patrologia graeca. T. 97. P. 65-71.

Lampe, G. W. H. (1961). A Patristic Greek Lexicon. Oxford: Oxford University Press.

Lehmann V. (2015). Categories of word-formation. In: Peter O. Müller et al. (eds.) Word-Formation: An International Handbook of the Languages of Europe. Vol. 2. P. 1020-1034.

Liddell, H. G., \& Scott, R. (1883). Greek-English Lexicon. New York: Harper \& Brothers.

Rydén, L. (1995). The Life of St. Andrew the Fool. II. Text, Translation and Notes, Appendices. Uppsala: Acta Universitalis Upsaliensis: Studia Byzantina Upsaliensia, 4:2.

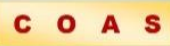




\title{
Cognitive Approach to the Theory of Abbreviation
}

\author{
Tatiana Bychkova \\ Russian State University for the Humanities, Moscow, RUSSIAN FEDERATION \\ Department of Foreign Languages
}

Received: 24 September 2020 - Accepted: 27 November 2020 • Published Online: 25 December 2020

\begin{abstract}
The formation of abbreviations is explained mainly by the action of two factors: extralinguistic and intralinguistic. Extralinguistic factors include social transformations, scientific and technological progress, and interethnic changes. Being qualitative in nature, they are characterized by dialectical dynamics. Intralinguistic factors should be understood as the effect of internal laws that determine the evolution of language. In language there is a dialectical struggle of opposites, which determines its self-development. These opposites can be called language antinomies, each identity is the key to the stability of the system, the specific resolution of any of these opposites generates new collisions, new contradictions in the language (in principle-of the same order) and, consequently, their final resolution is impossible: they are a constant stimulus for the internal development of the language. The stimulus to abbreviate lies with the speaker, who has full knowledge of information, in the process of communication and unilaterally seeks to reduce multi-component and cumbersome terms represented by long words, complex words and phrases. Language signs are replaced with codes by communicants, and familiar words are shortened.
\end{abstract}

Keywords: cognitive science, dialectics, antinomy, abbreviation, structure.

\section{Introduction}

Over the past few years, cognitive science has firmly established itself as the most promising field in linguistics. The cognitive-discursive paradigm of linguistic knowledge covers several areas of research, Cognitive science is interdisciplinary and includes several areas of knowledge related to the ability to think, speak, feel, and express thoughts and emotions in discourse. They are artificial intelligence, linguistics, psychology, and philosophy (Aitchison, 1992: 29).

On the one hand, language affects mental person's ability to think and express their thoughts in speech. The language fulfills a very important function when the thoughts or actions of the mind are drawn into words, and as words they become accessible means of communication for other members of the community. Information about thoughts, feelings, and expressions of will is available not only to participants in a particular act of communication, but can also be stored for future generations.

(C) Authors. Terms and conditions of Creative Commons Attribution 4.0 International (CC BY 4.0) apply. Correspondence: Tatiana Bychkova (PhD), Russian State University for the Humanities, Department of Foreign Languages, Moscow, RUSSIAN FEDERATION. E-mail: tatuana-3V@yandex.ru. 
- The cognitive-discursive paradigm of linguistic knowledge is applied to the study of abbreviation.

- Changes of the language are subject to action of laws of dialectics.

- In linguistics dialectic laws acquire the name of "principle of least efforts", "qualitative peculiarities of opposites", antinomies.

- Abbreviated signs are used widely to nominate entities of the surrounding material world.

- Abbreviations verbalize the complex information about the professional objects perceived by the nominator in their undivided and undifferentiated integrity.

- Structure of abbreviations has been classified into several class-groups.

On the other hand, language conveys feelings, namely the ability to perceive and express the world around us and the expression of will in the form of manifestations of desire, will, or command.

\section{Connection of the language and thinking with psychology}

Language and thinking are inextricably linked with each other and other types of social activities that have different essence. Language according to the classical definition of O. S. Akhmanova is "one of the original semiological systems, which is the main and most important means of communication for members of this human collective, for whom this system is also a means of developing thinking, transmitting cultural and historical traditions from generation to generation, etc." (Akhmanova, 2005: 530)". Language is represented by a system of signs and has a social nature, since it appeared as a means of communication in the process of joint activity.

A. N. Leontiev put forward the following definition of thinking: it is "the process of conscious reflection of reality in such objective properties, connections and relationships that include objects that are inaccessible to direct sensory perception" (Leontiev, 2004: 275). The theory of speech activity was transposed into linguistics and then formed into a separate discipline of psycholinguistics. It is important to note that thinking, in addition to reflecting the surrounding reality, manifests itself in the form of active knowledge of it. In this case, thinking supports the process of human cognitive activities, which is characterized by generalization and indirect reflection of the surrounding picture of the world. Thinking is usually considered as a complex process of human cognition about human existence through the brain in the form of concepts, judgments, and conclusions. Brain activity gets its verbal and logical design through natural language.

During the reflective activity of the brain, the surrounding picture of the world is modeled in all the variety of patterns and connections (Gamezo, 1999: 19). Thinking, which has a psychic nature, allows not only to know the essence of objects and phenomena, but also to analyze the objects of knowledge and predict the laws of evolution.

Mental processes responsible for processing and transforming information are called "cognitions". Cognitive processes associated with the transformation of information are aimed at studying the world view of the individual, as well as understanding human personalities by themselves and their place in the surrounding world. Within the framework of cognitive activities, the individuals study and evaluate themselves. Data coming from the senses to the brain in the form of mental representations are transformed into cognitions, presented in the form of images, frames, and scenarios. Cognitive processes are characterized by mental actions to process and transform information from one structure to another. Thus, cognitive activity combines interrelated mental processes: mental and linguistic.

Within the framework of psychological knowledge, the mental nature of thinking is ideal, while, being a physiological phenomenon, language has a material essence and it is 
implemented as a system of signs. Through language, the material design of mental activity is provided. The nature of language and thinking has been widely studied in linguistics, it is important to mention that, discussing the nature of language and brain activity, German linguist August Schleicher (1821-1868) came to the conclusion about the unity of language and thinking, identifying them through the unity of the content and form of the language sign.

3. Language and thinking in the light of the dialectical-materialistic approach

The concept of development occupies a central position in the dialectics of Georg Hegel (1770-1831), to whom there belongs the statement "language is the body of thought" (Ilyenkov, 1991: 105). Contemporaries of August Schleicher, theoreticians of dialectical materialism Karl Marx (1818-1883), Friedrich Engels (1820-1895), as well as earlier Ludwig Feuerbach (1804-1872) and then V. I. Lenin (1870-1924) shared G. Hegel's doctrine of dialectics, which laid the foundation to the idea of the inevitability of changing the world. F. Engels in several works: "German Ideology", "the Holy Family", "Capital", "Theses on Feuerbach", "Dialectics of Nature", "AntiDüring" further developed the dialectical doctrine of the development of nature and society, the dynamics of human practical activities, and also substantiate the dialectical unity of language and thinking. K. Marx postulates the idea that language acts precisely as "the immediate reality of thought" (Karl Marx, 1934: 720). In general, philosophers- materialists, being followers of the Hegelian dialectics, transformed his ideas. Within the framework of the dialectical materialistic approach to the doctrine of the unity of language and thought, they developed the idea that consciousness exists through knowledge, and in the form of words receives its content,

Let us recall the three laws of dialectics:

(1) The law of mutual transition of quantitative changes to qualitative ones;

(2) The law of unity and struggle of opposites; and

(3) The law of negation of negation.

Dialectical-materialistic teaching postulates the idea of the world around us as a single system in which internal contradictions determine the development of this system. All elements are in dialectical unity, and a change in one component entails a change in the other in order to preserve the overall unity and balance.

4. The law of transition of quantitative changes to qualitative and language changes

"The law of transition of quantitative changes into qualitative ones" is the first and basic law in the dialectics of G. Hegel. Within its framework of this law deals with four main categories: "quality", "quantity", "measure", "leap".

"Quality" is characterized by the functional unity of the essential features of an object (or system of objects) that has a material or spiritual nature and relative stability, which is represented as an integral object with certain parameters. or objects.

"Quantity" is expressed through the external formal relationship of parts of an object

A "measure" is represented by a period of equilibrium between quality and quantity, when the quality remains unchanged for a certain "interval" of time. 
If quantitative changes go beyond certain acceptable limits, qualitative changes are observed, and a new quality is born. The process of converting quantitative changes into qualitative ones occurs in leaps and bounds.

The "leap" breaks the continuity of quantitative changes and reforms the system. In dialectics, a discontinuous violation of an interval with constant qualitative and quantitative changes is considered as a unity of discontinuity and continuity. The abrupt nature of development is evolution. Evolution is a process defined by quantitative changes that lead to qualitative transformations. Since language is a material object, the law of transition as a result of quantitative to qualitative changes has explanatory power for language changes.

Nominative processes provide a person with the opportunity to record fragments of their activity experience, allow them to form a picture of the world, describe their socio-historical structure, and serve scientific and technical development. Due to the rapid information progress and intensive development of science and technology in the world at the present stage, the English language, in particular, registered a "neological boom" (Zabotkina, 2014: 95).

The vocabulary of a language is in a state of continuous development or evolution. The formation of new words is one of the main ways to replenish the vocabulary. Abbreviating or shortening words and phrases is one of the most productive ways to create new words. Following E. S. Kubryakova's ideas, abbreviation should be understood as "the process of creating units of a secondary nomination with the status of words, which is demonstrated by shortening any linear parts of the source unit of motivation and which results in the appearance of a word that in its form reflects any part or parts of the components of the original unit" (Kubryakova, 1981:71).

In linguistic the formation of abbreviations is explained mainly by the action of two factors: extralinguistic and intralinguistic. Extralinguistic factors include social transformations, scientific and technological progress, and international changes. Being qualitative by nature, they are characterized by dialectical dynamics. Intralinguistic factors should be understood as the effect of internal laws that determine the evolution of language.

According to the first law of dialectics, "the Law of the transition of quantitative changes to qualitative ones", a language is an object or system within which all elements are interconnected and are in a state of functional unity and balance over a certain interval. There are four main categories of dialectical development within the language: "quality", "quantity", "measure", "leap", and as long as quantitative changes do not exceed the limits allowed by the "measure", qualitative changes in the form of a "leap" do not occur. Dialectics states that it is the "leap", in which evolution of a new word with the status of the linguistic sign occurs. Nomination is a "leap" as a consequence of quantitative changes into new quality due to the loss of stability in the "measure" of the language in the given "interval" of time.

\section{Language changes in linguistics}

FR. Jespersen wrote about the existence of "universal laws of thought, which are reflected in the laws of language changes" (Jespersen, 1925: 128). Two dialectical factors are recognized in linguistics. The first, the kinematic tendency, which encourages changes in language and contributes to its evolution. The second factor being static by nature, counteracts the excessive volatility of the language and aims to preserve it as a system (Lightfoot, 1925: 45). Thus, on the one hand, language is preserved as a stable system in a state of equilibrium, and, on the other hand, being an open-type system, it is enriched by action of extralinguistic factors associated with changes in the world picture. F. de Saussure also noted that "with any change, the prevailing moment is the stability of the previous material. Infidelity to the past is only relative. That is why the principle of change is based on the principle of continuity" (Saussure, 1999: 107). As another intralinguistic factor, it is appropriate to name the law of saving language resources and speech 
efforts. Martinet attached great importance to this law as the means of language development, since "a language evolution is determined by the constant contradiction between the inherent needs of human communication and expression and their desire to minimize their mental and physical activities. Language behavior is regulated, thus, by the "principle of least effort" (Martinet, 2009: 166). The definition of the principle of economy in a more complete form was proposed by $\mathrm{Yu}$. V. Gorshunov: "The principle of economy is a pragmatic principle of generating an abbreviation, (1) it is caused by the need to update (rationalize) the material shell, (2) further it is associated with the utilitarian factor, and (3) finally it is aimed at obtaining economic benefits (creating a compact duplicate replacement). As a principle of usage, this law reveals a trend aimed at saving time, effort, and paper space" (Gorshunov, 1999: 199).

\section{The law of unity and struggle of opposites and language}

The second law of dialectics "the law of unity and struggle of opposites" serves as another proof to language changes and language development. In accordance with this law, the object of objective reality develops by splitting a single object into different and opposite representations. As a result of the interaction of these two forces, a single object, on the one hand, exists as a whole, and, on the other hand, in the presence of this interaction, an impulse for change and, consequently, development is available. This law is revealed through categories: "identity", "difference", "opposite".

"Identity" defines the relation of an object to its content and other objects and it is the key to the stability of the system.

"Difference" defines the discrepancy, inequality of an object in its content and makes it relative to other objects in the system.

Mutually exclusive relationships are "opposites".

Contradiction is expressed through the relation between opposites.

Let us recall how M. V. Panov characterized the internal causes of language changes: "in a language there is a qualitatively peculiar struggle of opposites, which determines its selfdevelopment. These opposites can be called linguistic antinomies, since each identity is a guarantee of the stability of the system, the concrete resolution of any of these opposites generates new collisions, new contradictions in the language (in principle, of the same order and, therefore, their final resolution is impossible as they are a constant stimulus for the internal development of the language" (Panov, 2007: 17).

\section{Antinomies and translation of abbreviations}

M. V. Panov defined one of the antinomies. This is the antinomy of "the Speaker and the Listener" (or between the Sender and the Addressee). When creating abbreviations, this antinomy is resolved in favor of the Sender, because the law of saving efforts applies. As for the recipient of the information, it is in their interest to get information in a form that is easy to understand, so most abbreviations, with the exception of those assimilated in Russian, are given in parentheses after the motivating word or phrase.

The abbreviation "NATO" almost does not require decoding because of its high recognition. The full name of this block "The North Atlantic Treaty Organization" is transmitted as "The North Atlantic Alliance", "The Atlantic block". While the abbreviation ABEDA - Arab Bank for Economic Development of Africa without decoding in the form of writing the full motivating phrase will be incomprehensible for the Addressee. 
In the last decade, to solve the antinomy of "the Sender and the Addressee" in favor of the Addressee, business terminology has seen the formation of acronyms, abbreviations formed from the initial letters of the motivating phrase, consisting of two or three syllables. They are like words in their form. Source of examples: English-Russian dictionary of acronyms and abbreviations of economic terms (Maksimova, 2002).

SEA - 1. Securities Exchange Act; 2.state economic area;

SCOOP - Scientific calculation of Optimum programs;

SOFA - Society of Financial advisors.

ACT - 1. advance corporation tax - авансовый корпорационный налог 2. Association of Corporate Treasures (GB).

MINI - mortgage intermediary note issue.

BET - book entry transfer.

BAN - bond anticipation note/

AIMS - Amsterdam Interprofessional Market System.

TALISMAN - Transfer Accounting, Lodging for Investor, Stock Management for Jobber, "TALISMAN" - a centralized electronic payment system introduced on the London stock exchange.

ZEBRAS - zero coupon euro sterling bearer or registered accruing securities; "Zebras" - Euro-sterling bonds with zero coupons.

ACES- Advanced Computerized Execution System (US).

(US).

BEACON - Boston Exchange Automated Communication Order-routing Network

SWIFT - Society for Worldwide Interbank Financial Telecommunications.

TAPAC - Transportation Allocations Priorities and Control Committee; Committee for priority, distribution and control of transportation.

TAURUS - Transfer and Automated Registration of Uncertified Stock system for sale and automatic registration of ownership of shares without circulation of share certificates.

In these examples, acronyms formed from initial letters are read as words that match anthroponyms, zoonyms, and other lexical units. It is easier for both the Sender and the Addressee to articulate and remember them. It is possible to borrow acronyms with the spelling that matches the words in Russian: "Talisman", "Zebra", proper name "Taras(c)".

To some extent, the formation of abbreviations of this type helps to resolve the conflict of opposing interests in the antinomy between the Sender and the Addressee and achieve a kind of balance. It is important to note that according to the law of dialectics on "the unity and struggle of opposites" the resolution of a dialectical contradiction in these cases can cause other collisions. As a result, language transformations occur according to the principles considered or by other models.

\section{The structure of the neologisms}

The modern picture of the world is characterized by numerous events that are cognitively perceived and interpreted by a person in an attempt to nominate them; these units of new nomination are based on existing experience and similar situations, solve the problems and 
interpret the changing external world. The language, performing a thought-forming function, has the means and structures for nominating concepts and forming images. Abbreviation is one of these possibilities. Neologisms-abbreviations successfully contribute to solving the problem of nominating new knowledge structures in the outer world.

Neologisms are usually divided into several groups based on the method of their production (Zabotkina, 2014: 101-104). Morphological neologisms belong to one of the groups, they are formed from patterns that exist in English, and mostly according to productive models. Morphological neologisms are classified into the following groups: affixal neologisms (prevailing model $\mathrm{N}+$ Suffix $=\mathrm{N}$ : masculinist), complex words (prevailing model $\mathrm{N}+\mathrm{N}=\mathrm{N}$ : muffin cooker), converted lexical units: (a doctor - to doctor), new words-fusions, for example: slimnastics and abbreviations. In the twentieth century appeared new types of word formation structures: acronyms and telescopes (blends, portmanteau - with omitted middle component words); the need to study them is actualized. Morphological borrowings are characterized by the presence of analogies and typification of word formation structures.

As for the analogy, three types of word-forming processes are identified: (1) "focusing on a unique or almost unique lexical pattern; (2) focusing on a certain model of word-formation derivative relations, i.e. regular correlation between single-root formations; and (3) focusing on the model of transition from a syntactic construction to its collapsed counterpart, "univerb" (Kubryakova, 1978). The reduction of morphological types occupies a special place. They are characterized by "attractiveness" and are far from traditional, which provides them with readers' attention in the mass media.

Examples of such modern neologisms are: Brexit, Nexit, Rexit, and quite recently in the light of the event of the refusal of Prince Harry and his wife Meghan, the Duke and Duchess of Sussex, from the privileges of the Royal family, we recall the gushing "Megxit".

The abbreviations Brexit, Nexit, Rexit and "Megxit" are intended to have a certain pragmatic effect on the reader. The neologism "Brexit" is formed from the first two letters of the word Britain "Britain" and the full lexical unit "exit". The neologism "Brexit" has been well known since 2016, when the UK held a referendum to leave the European Union. Over the past two years, this abbreviation has been widely replicated in all media. As for the abbreviations Nexit, Rexit, they are derivatives "for the evil of the day". They are obvious demonstrations of the linguistic creativity of the publication where they appeared, namely, "the Economist". The leading component of the pragmatics of these new words is the temporal localization component, which is one of the elements of deixis. At the same time, the connotation of novelty actualizes the acute neological power of these words.

Structural types of abbreviations attract the attention of many Russian and foreign linguists. Numerous types of classifications are known (Baranov, 2003; Matthews, 1997; Bychkova, 2018: 14-23). Let's look at some of them. 2013: 357):

G. Marchand identifies three main types of English abbreviated words (Cit. Duzikova,

- clippings - captain = cap;

neologisms Brexit; and

- complex clipping compounds - linoleum + cut = linocut. This type includes the - blendings (telescopes, blends, portmanteau words) + smoke + fog $=$ smog.

102);

L. Soudek also identifies three types of English abbreviated words (Soudek, 1967: 82-

- monosyllabic abbreviations: aboriginal - abo; 
- compound syllabic shortenings: amphibious tractor - amtrack; and

- initial clippings: chief of staff - cos.

Blendings (blends) or telescopes (telescopic words) are allocated to a separate type, for example: smoke + fog $=$ smog. The Brexit unit goes beyond the classification of L. Soudek.

Morphological abbreviation is characterized by the destruction of morphemes traditionally used in the language. A specific feature of morphological abbreviations is the presence of fragments of words in their composition, which, as a rule, do not coincide with either morphemes or words. Morphological abbreviations are divided into clippings, initial abbreviations, and mixed-type abbreviations (with elements of both clipping and initial abbreviation).

Clippings are classified into:

(1) Apocope - clipping of the final part of the word: submarine - sub;

(2) Apheresis - clipping of the initial part of the word: telephone - phone;

(3) Clipping of the beginning and ending parts of word: influence - flu;

(4) Syncope is a phonetic phenomenon that consists in the loss of a usually unstressed sound, or a group of sounds, or even an entire syllable in a word - regulations - regs;

(5) Initial abbreviations are classified according to the way they are pronounced (based on their phonetic structure or alphabet);

(6) Blends (telescopes, blendings, portmanteau words) - a clipping without the middle component - smoke + fog - smog;

(7) Stump compound - clipping made up of initials of two or more words: situation comedy - sitcom.

According to G. Marchand's classification, the neologisms Brexit, Nexit, and Rexit are complex clipping compounds with the following word formation model: clipping of the first unit $+\mathrm{N}$, namely Br(itain) + exit $=$ Brexit. , Nexit, and Rexit have the structure $-\mathrm{N}(\mathrm{o})+$ exit = Nexit; $\mathrm{R}(\mathrm{ex})$ (Tillerson) + exit. In our opinion, in addition to abbreviation, another method of productive word formation is also involved: prefixation. In this case, the model looks like this: Abbr $+\mathrm{N}$ or $\mathrm{Pr}$ (prefix) + R (root).

The neologism "Megxit" has its own structure: Meg + xit = Megan + exit - clipping of the beginning of the first component + the end of the second one. Language signs with a similar structure have different terminology. This is a blend ulending), a hybrid word, a bracket form, a telescopic word. a portmanteau word. Structurally, this language sign is formed from two equivalent words: it is a complex word with the middle component omitted as a result of combining parts of two initial words.

Another interpretation of the structure is possible: $\mathrm{M}+\mathrm{e}+\mathrm{g}+\mathrm{xit}-$ the initial of the first word Megan and the full-value second word exit with the consonant element "g" in the middle.

\section{Conclusion}

Language, performing a thought-forming function, has the means and structures for nominating concepts and forming images. Abbreviation is one of these possibilities. Neologismsabbreviations successfully contribute to solving the problem of nominating new knowledge structures in the concept sphere of the surrounding world. 
Abbreviation is a productive way of word formation. The tendency to simplify language expression while maintaining informative communication is strengthened along with the obvious changes observed in society: the growing popularity of sportswear and fashion for "unisex", changes in social and family relations, etc. The effect of the law of saving speech efforts is clearly shown in the widely used SMS language, which is characterized by the principle: the minimum number of characters and keystrokes with maximum information, for example: TTY (talk to you later), txtspk, etc. Linguistics in the framework of cognitive research involving different areas of knowledge: psychology, cultural studies, philosophy, sociology, and others is faced with the task of tracking current language changes, primarily in English as a global language, the language for international communication which English has become in the twentieth century.

\section{Acknowledgements}

This research did not receive any specific grant from funding agencies in the public commercial, or not-for-profit sectors.

The author declares no competing interests.

\section{References}

Aitchison, J. (1992). Introducing language and mind. Penguin Group.

Akhmanova, O. S. (2009). Dictionary of linguistic terms. Moscow: Komkniga.

Baranov, A. N., Dobrovolsky, D. O., Mikhailov, M. N., Parshin, P. B., \& Romanova, O. I. (2003). EnglishRussian dictionary of linguistics and semiotics. About 9,000 terms.

Bychkova, T. V. (2018). "Brexit", "Nexit", "Rexit": on the problem of neology in anglistics. Collection of scientific articles of the XX International Conf. "Russia and the West: dialogue of cultures". Issue 20. Moscow: LLC “Buki-Vedi”, 658, 74-79.

Bychkova, T. V. (2018). Variety of terms on the topic "reduction of words": clarification of concepts. Scientific notes of the National Society of Applied Linguistics, Moscow: KDU, № 2(22), 14-23.

Dyuzhikova, E. A. (2013). Abbreviations in modern English language (cognitive and discursive aspects). Odintsovo: ANOO VPO "OGI".

Gamezo, M. V. (1999). Atlas of psychology. Moscow: Pedagogical Society of Russia.

Gorshunov, Y. V. (1999). Pragmatics of abbreviations. Moscow: Prometheus, 1999.

Il'enkov, E. V. (1991). Philosophy and culture: collection of articles. Moscow: Politizdat.

Jespersen, O. (1925). Mankind nation and individual from a linguistic point of view. Oslo.

Karl Marx (1934). Karl Marx and the problems of the history of pre-capitalist formations. Collection for the $50^{\text {th }}$ anniversary of the death of Karl Marx. Moscow; Leningrad: State social economy publishing house.

Kubryakova, E. S. (1978). Language nomination. Types of names. Moscow: Nauka

Kubryakova, E. S. (1981). The types of the language values. Semantics of a derived word. Moscow: Nauka.

Leontiev, A .N. (2004). Activity. Consciousness. Sense. Moscow: Academia.

Lightfoot, D. (1991). How to Set Parameters Arguments from Language Change Cambridge. Moscow: The MIT Press. 
T. Bychkova - Cognitive Approach to the Theory of Abbreviation

Martine, A. (2009). Fundamentals of general linguistics. Moscow: Librokom.

Matthews, P. H. (1997). Oxford concise dictionary of linguistics. Oxford: Oxford University Press.

Maximova, T. V. (2002). English-Russian dictionary of acronyms and abbreviations of economic terms. Volgograd: VolGU Publishing House.

Panov, M. V. (2007). Works on general linguistics and the Russian language, Vol. 2. Moscow: Languages of Slavic culture.

Saussure, F. (1999). Course of general linguistics. Yekaterinburg: Urals publishing House.

Soudek, L. (1967). Structure of substandard words in British and American English. Bratislava Slovenska akad. vied.

Zabotkina, V. I. (2014). Word and meaning. Moscow: RSUH. 


\title{
Russian and English Metaphorics: Comparative Analysis of Biathlon Discourse
}

\author{
Liudmila Osinovskaia \\ Northern Trans-Ural State Agricultural University, Tyumen, RUSSIAN FEDERATION \\ Institute of Biotechnology and Veterinary Medicine, Foreign Languages Department \\ Yuliya Shekhovskaya \\ Tyumen State University, Tyumen, RUSSIAN FEDERATION \\ Institute of Humanities and Journalism, English Language Department
}

Received: 29 September 2020 • Accepted: 20 November 2020 • Published Online: 25 December 2020

\section{Abstract}

In this article, the authors consider semantic and structural features of the metaphor use in the Russian and English biathlon discourse, as well as metaphor role and use in the biathlon mass media discourse framework. The research of biathlon discourse enriches metaphor definition. The concept "biathlon" serves the material for the analysis of metaphorical meaning transfer. The authors underline its importance as a basic model of the text formation. The researchers pay much attention to the question of metaphorical formation role and functions within biathlon mass media discourse. The article contains information on the classification of basic metaphorical models. The study defines groups of Russian and English metaphors in biathlon mass media discourse and reveals their linguistic and intercultural differences. To obtain data, the authors use comparative analysis method of Russian and English metaphors. The authors prove the importance of metaphors in biathlon mass media discourse quantitatively. That lets them assume metaphor as a means of avoiding speech monotony therefore enhancing its emotional influence within biathlon mass media discourse.

Keywords: sports discourse, metaphor, metaphorical model, basic.

\section{Introduction}

\subsection{Sport discourse: Focus on defining specific characteristics}

The modern period of human development is characterized by the rapid dissemination of information through print, television, the Internet and radio. Moreover, the role of the media in the life of each person is growing, thus this information is reported to become a tool of control.

Hence there is an increasing interest in studying the media discourse and its varieties. It is worth noting that the media discourse as a type of institutional one is a functionallyconditioned type of discourse. We understand it as a set of speech practices and products of speech

(C) Authors. Terms and conditions of Creative Commons Attribution 4.0 International (CC BY 4.0) apply. Correspondence: Liudmila Osinovskaia (Candidate of Pedagogics Science), Northern Trans-Ural State Agricultural University, Institute of Biotechnology and Veterinary Medicine, Foreign Languages Department, Tyumen, RUSSIAN FEDERATION. E-mail: mila-oss@yandex.ru. 
L. Osinovskaia \& Y. Shekhovskaya - Russian and English Metaphorics: Comparative Analysis...

activities in the sphere of mass communication in all the richness and complexity of interaction. The varieties of media discourse are political, advertising, sports, etc.

Within the framework of this article, sports discourse is of particular interest that is why we are going to consider features of sports discourse in more detail.

Despite the fact that many modern linguists are engaged in the study of it, today there is no generally accepted definition of the concept of "sports discourse".

We have made a review of the scientific literature and could establish that many authors, when defining the concept of "sports discourse", take the definition of the concept of "discourse" proposed by V. Krasnykh (2003). So, for example, K. Snyatkov suggests that sports discourse is meant to be an oral or written speech which renders the meanings determining sports activity (it is discourse as a process). Besides, it is a set of produced texts in which these meanings are represented (it is discourse as a result). So, discourse is a set of speech works that are recorded in the writing or memory (Snyatkov, 2008).

S. Mamaiko considers sports discourse as a special constructor of social, psychological, cognitive and linguistic factors, which in their unique totality are designed to reflect the entire range of expressive-emotional manifestations of sports competition and adventurism that take place in the context of competing (Mamayko, 2014).

S. Kudrin defines sports discourse as a set of communicative practices that characterize sport as a socio-cultural phenomenon, denoted by a number of extralinguistic factors and developed in the process of establishing the institution of sports (Kudrin, 2011).

L. Isaeva and N. Kazarina tend to understand the term "sports discourse" loosely. These researchers consider sports discourse as a single class of various speech genres, united by one social sphere of functioning that it is a sports activity in all its manifestations (Isayeva, 2012). With this approach, the main agents of the sports discourse are all linguistic personalities who professionally communicate in this area. That is why, along with the basic communicants of the sports discourse including athletes, coaches, referees, sports officials, on the basis of the presence / partial presence / absence of professional competence, one can also distinguish non-basic communicants who are peripheral or "semi-professional" / "non-professional" including doctors, massage therapists, mechanics, fans, journalists, television viewers.

\subsection{Goals and genre diversity of sport discourse}

The general goal of sports discourse is to focus the efforts of all professionally united individuals and institutions to achieve the best result. The usage of speech strategies and tactics as well as special speech techniques implemented contribute to achieving victory in the competition.

Sports discourse in most cases is a verbal support for achieving sports goals such as achieving sports form, winning a sports competition, receiving priority in sports events and providing the prestige of the state or sports institution which prepares its representative to participate in competition.

Sports discourse is distinguished by its universal quality, particularly, its focus on the basic (vital) needs of the society. It is represented by genre diversity.

According to V. Karasik, the exact selection of these genres can be done on the basis of a deductive model. It takes into account goals, types of participants, types of scenario, ritualization, as well as real and naturally formed patterns of communication (Karasik, 2000). 
O. A. Pankratova asserts that the number of sports discourse genres is regulated by the ways sports exists in the society. Based on this, the author identifies the following genres of sports discourse (Pankratova, 2005): conditions);

(1) A scientific sports article; e.g. is an article about studies of the athlete's physical

(2) A medical and therapeutic conversation; e.g. a psycho-therapist's conversation with a sportsman;

(3) A physical education lesson at school;

(4) An analysis of a training session or a match;

(5) Instructing the athlete by the coach;

(6) Sports court; e.g. a discussion of sports functionaries regarding the disqualification of an athlete who used doping in a competition or violated sports rules;

(7) A sports interview; e.g. a conversation between sportsmen and journalists immediately after the competition);

(8) Sports memoirs of sportsmen who stopped their sports career;

(9) A sports commentary/ review;

(10) A sports press conference; e.g. a conversation between sportsmen and journalists after a certain time after the competition.

According to K. Snyatkova (2008), the main features of sports discourse include:

- Mental basis;

- Intertextuality;

- Presupposition basis.

To explore this idea, the author denotes the mental base as a set of cognitive structures of different levels in which knowledge about the phenomena of the external world and the features of the speech representation of this knowledge is fixed.

The intertextuality of sports discourse is defined to be the interaction of sports discourse with other types of discourse, including scientific, pedagogical, business, legal, political, military, medical, etc.

As far as the presuppositional basis of sports discourse is concerned, it is manifested in the regular use of sports terminology.

This allows us to say that the conceptual, as well as genre-stylistic and pragmalinguistic originality of texts that relate to sports discourse is largely predetermined by the characteristics of media discourse, where the most important role is given to a stable connection with the audience through information transmission technical means.

Therefore, many researchers studying the features of sports discourse today use the term "media sports" to describe the sociocultural speech activity directly connected with sports topics and objectified in media texts.

Nevertheless, we agree with N. Kuzmina that sports media discourse has not only general characteristics of any media discourse types, due to the mass communication specifics, but it also has its own discursive characteristics determined by the topic of the discussion of the sport in which communication takes place (Kuzmina, 2011). 


\subsection{Biathlon discourse: Definition and speech representation}

Since the material for the practical research part is based on oral and written reports of biathlon competitions, we present our understanding of biathlon discourse. We define biathlon discourse as a speech work in oral or written presentation, created for the purpose of conveying any information from the sphere of biathlon. In a wider sense, biathlon discourse is a coherent text representing the whole complex of interrelationships between man and sport in the creation of which one of the discourse components is related to biathlon (speaker, interlocutor or the content of the message itself).

Among the distinctive features of biathlon discourse as a kind of sports media discourse is its increased expressiveness and emotionality, which is achieved through the use of various means of stylistic imagery, including metaphorization.

The significant quantitative representation of metaphors in the biathlon discourse testifies to the metaphorization of this discourse type and to the virtually limitless potential of the linguistic metaphor as an instrument of sports rhetoric. It is worth paying attention to the fact that metaphor is not just a means of stylistic imagery, but also a cognitive tool based on appealing to objects of a different denotative area and their characteristics in order to more accurately convey information with the simultaneous transmission of emotions, expressiveness, imagery and appraisal.

\subsection{Metaphor as a means of sports rhetoric}

The origins of research interest in metaphor are usually associated with the name of Aristotle. In his Poetics he first described metaphor as a way of rethinking the meaning of a word based on similarities. According to Aristotle, the metaphor makes it possible and right to "speak about the real simultaneously connecting it with the impossible". In other words, it is about a way to name an object "by a name that does not belong to it" through an element of similarity, comparison (Aristotle, 2020).

Since the metaphor is considered within the framework of various academic disciplines, each of them works with a fragment that is significant for it, describing only the sides that are relevant to itself.

So, in the sphere of stylistics, a metaphor is understood as "a trope or a figure of speech, consisting in the use of a word denoting a certain class of objects (objects, persons, phenomena, actions or signs) to designate another, similar to the given class of objects or a single object; for example: "wolf, oak, club, snake, lion, rag", etc. as applied to humans; or "sharp, blunt" - about the properties of the human mind, etc." (Fox, 2020).

G. Sklyarevskaya, exploring the metaphor within the framework of semiotics, defines this concept as having a secondary indirect nomination with the obligatory preservation of semantic duality and the figurative element. According to the author, the metaphor does not indicate the subject of speech as much as it characterizes it. At the same time, the essence of the metaphor consists in understanding and experiencing phenomena of one kind in terms of one of another kind (Sklyarevskaya, 1993).

O. Glazunova believes that a metaphor or a metaphorical model is "the assimilation of one phenomenon to another on the basis of the semantic proximity of states, properties, actions that characterize these phenomena. As a result words (phrases, sentences) intended to nominate certain objects (situations) of reality are used for naming other objects (situations) on the basis of the conditional identity of the predicative attributes attributed to them" (Glazunova, 2002). 
In modern cognitive science, a metaphor is usually defined as a mental operation on conceptual structures (domains, frames, gestalts, mental spaces, etc.), as a way of cognition, categorization, conceptualization, assessment and explanation of the world.

According to J. Lakoff and M. Johnson's cognitive theory, the metaphor, being a component of not only language, but also thinking, determines the main ways of interpreting reality and has a significant impact on the decision-making process. The metaphor in this case is understood widely. It represents a wide class of cases where we understanding the essences of one conceptual area in terms of another conceptual area that is significantly different from it (Lakoff, 2004).

Metaphor is a way of categorizing reality. R. Hoffman writes about this and draws attention to the fact that regardless of where metaphor is found or used, it always contributes to the enrichment of understanding human actions, knowledge and language (Hoffman, 1987).

Having analyzed all the above definitions, we come to conclusion that the metaphor contributes to the disclosure of the reflected reality features. It is possible since the secondary signs that are presented in the metaphor express moments of sensory clarity. Thanks to the metaphor, our idea of a described object is enriched. The fact is the following. To characterize the object, new phenomena are involved so the existing understanding of the object properties expands. It is where the cognitive significance of the metaphor is. It turns out that besides supplanting the original word meaning, the metaphor constantly participates in the development of language, speech and culture in general.

Metaphors are not only complicated in their structure, but also semantically diverse. Therefore, to systematize metaphors encountered in speech somehow, linguists offer various classifications or typologies of metaphors. Within the framework of this work, consideration of the metaphor classifications allows us to form a more complete idea of how the categorization of reality in sports discourse is carried out through metaphor.

\subsection{Metaphor classification diversity}

One of the most common classifications was proposed by N. Arutyunova. In this classification, the following types of metaphor were identified (Arutyunova, 1990):

- A nominative metaphor, a feature of which is the name transfer. This type of metaphor consists in replacing one meaning with another;

- A figurative metaphor, which is formed by the transition of the identifying meaning to the predicative and which develops figurative meanings and synonymous means of language;

- A cognitive metaphor based on the shift in the combinability of predicative words; it creates polysemy;

- A generalizing metaphor that erases the boundaries between logical orders in the lexical meaning of the word and stimulates the emergence of logical polysemy.

Another typology of metaphors is proposed by M. Nikitin. This typology is based on the variety of the sign similarity in denotations. It is basic for transferring a name and for metaphorical reconstruction of the direct meaning. So, the linguist identifies the following types of metaphors (Nikitin, 2008):

(1) An ontological metaphor (the similarity is contained in the things themselves being similarly compared): 
L. Osinovskaia \& Y. Shekhovskaya - Russian and English Metaphorics: Comparative Analysis...

(a) A direct metaphor (signs have the same physical nature, for example, "bear" - (1) a clumsy animal, (2) an awkward person);

(b) A structural metaphor (the similarity is structural in nature, particularly, there is structural identity of two denotations, for example: receiving presents, receiving guests, receiving information).

(2) Synesthetic metaphor (signs of similarity are found in compared entities, but are different ontologically and in physical nature) - a linguistic metaphor that verbally reinforces intersensory transferences;

(3) Emotive-evaluative metaphor (similarity is generated not by the ontology of things, but by the mechanisms of information processing) - the metaphor is aimed to produce an expressive effect and becomes a means of emotional impact.

A. Maslennikova notes that grammar can act as a means of conveying metaphorical meaning. Therefore, the author deduces such a type of metaphor as a grammatical metaphor. The speaker transfers features from one grammatical category to the sphere of another in order to create a new additional meaning, which may no longer be grammatical (Maslennikova, 2006).

M. A. Smirnova defines living and linguistic metaphors. So, the author notes that a feature of a living metaphor is that at the moment of the generation and comprehension of the metaphor, the interaction of two denotations takes place (what is compared and the one which it is compared with). The name of the latter becomes the name of the first in the process of acquiring a metaphorical value. As for the linguistic metaphor, it is an important factor in the development of the language. According to M. Smirnova, it is the linguistic metaphor that is the basis of many linguistic processes, including the development of synonymous means, the emergence of new meanings and their nuances, the creation of polysemy, the development of emotionally expressive vocabulary. Thanks to the metaphor, ideas are verbalized thus materializing the inner world of a person (Smirnova, 2014). (Lakoff, 2004):

In J. Lakoff and M. Johnson's classification two types of metaphors are presented

- Ontological metaphors that allow you to see events, actions, emotions, ideas, etc. as a kind of substance (the mind is an entity, the mind is a fragile thing);

- Orientational metaphors that do not define one concept in terms of another, but organize the entire system of concepts in relation to each other (happy is up, sad is down; conscious is up, unconscious is down).

According to N. Belozerova (2009), a conceptual metaphor described by J. Lakoff is a clot of information fixed in images. It can be divided into two types:

- "Basic metaphor" based on the processing of information about the world;

- Metaphor of the self (metaself), which arose in the earliest periods of human existence and is based on the assimilation of all phenomena to man, his morphology and behavior.

$\mathrm{N}$. Belozerova describes another ancient type of conceptual metaphor which is a synthesis of the basic metaphor and the metaphor of the self. This synthesis is due to the idea of the inseparability of man and nature. According to N. Belozerova (2010), it was this metaphor that became the basis of various mythological representations.

With all the variety of different approaches to the definition, categorization and classification of metaphor, all authors emphasize the fact that metaphor acts as a way of categorizing reality. Metaphor is not just a linguistic means by which speech is decorated and an 
image is made more understandable, but a form of thinking. In order to present concepts that are not conditioned by experience, a person uses a metaphor.

With the help of metaphor, the mechanisms of mental processes that form the basis of our subconscious are set in motion. The metaphor as the entire part of person's life manifests itself both in language and in the manner of thinking and action. Metaphor acts as a means of expressing mental processes that are based on cultural, national and social characteristics.

\section{Data and method}

This article deals with semantic and structural features of the metaphor in the Russian and English languages, and their role and use in biathlon media discourse.

The research was based on scripts of video reports about the biathlon World Championships 2012-16, men, mass start, $15 \mathrm{~km}$ by Russian commentator Dmitry Guberniev as well as about the biathlon World Cups 2013-16, men, mass start, $15 \mathrm{~km}$ by English commentators Patrick Winterton and Mike Dixon. The total duration of reports is 13 hours 52 minutes (8 hours o6 minutes and 5 hours 46 minutes correspondingly). The reports are taken from the video hosting service YouTube.

The research of semantic and structural features of Russian and English metaphors in the framework of biathlon media discourse has shown the need for a step-by-step solution of the problem.

The goal of first stage was to identify the ethno-cultural parameters of the Russianlanguage and English-language sports commentary of international biathlon competitions.

The goal of the second stage was to analyze the features of metaphorization in the biathlon media discourse.

\section{Quantitative and qualitative results}

\subsection{Results of frame-slot comparative analysis}

Realizing the goal of the first stage, we studied the speech of commentators using frame-slot analysis as the main one, since according to V. Demyankov (1994), a frame is "a data structure that condenses large amounts of memory and is used to represent stereotypical situations".

We found that frames are universal for the speech of sports commentators in both cultures: "Description of a sporting event", "Representation of athletes", "Athletes' skills", "Competing", "Reference to the coach", "Reference to an authoritative opinion", "Audience reaction", "Contact with the addressee", "Commentator's own opinion and feelings", "Race results" (Demyankov, 1994). This result shows that sports commentary is a fairly structured text with constant components.

Along with this, we found that some universal frames differ in the compared languages by additional semantic representations in terms of quantity and/or quality.

Thus, in D. Guberniev's speech, ethnocultural specificity is formed by representative frames in the following quantitative correlation: "Commentator's own opinion and feelings" 27.5\%, "Representation of the athlete" $-15.8 \%$ and "Contact with the addressee" $-15.4 \%$. In the English comments, the rating of universal categories is presented as follows: "Competing" - 37\%, "Commentator's own opinion and feelings" - 15\%, "Representation of the athlete" - 10\% and "Description of a sporting event" - 10\% 
As for the content side of the universal frames, we can see the biggest contrast between the compared frames "Commentator's own opinion and feelings" and "Competing".

The frame "Commentator's own opinion and feelings" is expressed in slots in both cultures:

"Praise, approval",

"The desire to give advice",

“The expression of hope, expectation".

However, in D. Guberniev's commentaries additional slots were further revealed, they are "Desire to explain an unsuccessful performance", "Worrying about our athletes", "Criticism, reproach, disapproval". In English commentaries, the same dominant frame is represented by the slots "Desire to cheer up an unsuccessful athlete", "Expression of confidence", "Expression of doubt", "Expression of regret".

In the statements collected in the frame "Sport competition", D. Guberniev shows the athletes' desire to win, the intensity of the competitive struggle. In the same frame of the English commentary, the slot "Impact of failure on the race result" prevails, and the slots "Mutual assistance of opposing teams" and "Unsportsmanlike behavior", typical for a Russian commentator, are absent.

Let us have a closer look at some examples.

In the dominant frames "Expression of the commentator's own opinion and experiences" and "Representation of athletes", the Russian sports commentator uses the speech of a panegyric in relation to both the athletes themselves and the teams of the countries they represent. The linguistic implementation of these parameters occurs through the use of the epithets "incredible", "brilliant", metaphors "cream of biathlon society", "king of races with the general start", hyperboles "racing genius", 'super-prestigious history", "dramatic beginning", "incredibly big lag", "got together by the moment". This ethnocultural parameter indicates the orientation of Russian culture to a person, and not to a result. D. Guberniev's speech clearly demonstrates the commentator's interest in the performance of athletes and teams, his feelings for the Russian team, the desire to praise and give advice. This mental category is also realized with the help of the emotionally colored vocabulary "bravo', the personal pronoun "I". The expression of the commentator's own opinion in this case is a sign of the genre - sports commenting presupposes subjectivity of statements.

Unlike Russian one, English sports commentary is dominated by a competitive attitude. This is evidenced by the dominant ethnocultural parameter "Sport competition", the linguistic realization of which occurs through the use of the epithets "extraordinary", "sensational", "fantastic". English commentators describe competing at the track in much more detail, express their desire to cheer up an unsuccessful athlete through repetition: "And that's really- really disappointing for Tim. But he's got a long long way to go and plenty of opportunities will come his way."

The ethnocultural parameter "Expression of the commentator's own opinion and feelings" in the English sports commentary is also representative. Commentators express their own opinion using the personal pronoun "I" and the expressions "Perhaps", "Amazing thing", "Hope", "It's great to see", "Fancy that". As we can see even from these examples, statements are more restrained emotionally and less categorical.

In both lingua cultures, the use of professional vocabulary is an integral part of commenting. In the Russian linguistic culture, the commentator, describing the intensity of the struggle in the mass start, uses the professionalisms "shot to zero", "best skiing technique", "shot 
himself (missed 3-4 times)", "first shooting", epithets "phenomenal shooting", "Good race! Cool race! And educative!", metaphors «Сегодня гнулись остальные» / “The rest were bent today”, «два промаха в индивидуалке» / "two misses in an individual”, «они просто сошли с ума после вчерашней победы в эстафете» / "they just went crazy after yesterday's victory in the relay”, «однозначная, в одну калитку победа» / “an unambiguous one-sided victory”. English commentaries also have examples of sports terminology "be relaxed on the rifle", "hit twenty of twenty".

A distinctive ethnocultural feature in English linguoculture is "Commentator's Humor". According to Keith Fox, "English conversations are almost always filled with teasing, irony, derogatory remarks, humorous self-flagellation, ridicule, or just plain silly remarks" (Fox, 2020). In the commentaries under study, humor is aimed at emphasizing the complexity of the track: "Once round this three- kilometer- track, Patrick is tiring enough. - As you said "five times" - they're exhausted already. - That's the feeling I'm getting from talking to some of the athletes". This indicates the ease of speech of the English commentators, while the Russian sports commentator is more formal.

In Russian culture, the relationship between the commentator and the audience is more visible. He uses the pronoun "we", a direct appeal to the viewer throughout the commentary, making the latter a direct observer of events: «Гараничев идет 20-м...- представляете, только 20-й!..» / "Garanichev is $20^{\text {th }} . .$. - can you imagine, only $20^{\text {th }}$ !..”; «Вспомните Ханты-Мансийск» / "Remember Khanty-Mansiysk"; «Но сейчас мы видим очень большое отставание» / "But now we see a very big gap".

All this shows the collectivist attitude of Russian culture.

In English commentary, for more lively communication with TV/radio listeners, a technique is used such as reporting with the participation of two commentators. Another distinctive feature of English commentating on a sporting event is the participation of an authoritative person in it, an interview with whom also makes the report more "lively" and exciting.

The data provided by comparing sports comments belonging to different linguistic cultures allows us to conclude that the Russian sports commentator makes an accent on the personality of the athlete, praises him, and subjectively evaluates the competition. In addition, the commentator's speech is dominated by self-awareness at the "we" level. The English comments are based on practical results; the commentator evaluates the actions and skills of the athlete, and not his personality. This approach allows the English commentator to use humor and irony more often.

\subsection{Role of metaphor in Russian and English biathlon discourses}

Analysis of the language material has led us to the conclusion that the role of metaphors in Russian and English sports discourses is quite large. Sports journalists strive for emotional expressiveness in their reports. This is confirmed by the fact that in their reports they use a large number of artistic and expressive means: metaphors, metonymies, comparisons, hyperboles, personifications. But the most frequent are metaphors and hyperbole (for example, they occupy $76 \%$ in the speech of Dmitry Guberniev).

These conclusions allowed us to proceed to the realization of the second stage of our research, namely, to analyze the features of metaphorization in the biathlon media discourse.

As a result of analyzing a significant body of texts that are the core of biathlon media discourse, we have identified a number of basic metaphors that allow us to turn a dry, purely informational description of an event into a story that can attract the addressee not only by its 
L. Osinovskaia \& Y. Shekhovskaya - Russian and English Metaphorics: Comparative Analysis...

sports component, but also by the author's manner of presenting the event, expressing a certain assessment. The classification of basic metaphors of the studied discourse consists of 7 main metaphorical models, namely "biathlon is a war", "team is a mechanism", "game/competition is a way", "game/competition is a construction", "team is a society", "team is an organism", "biathlon is an art".

In the following table there are examples to illustrate each metaphorical model.

\begin{tabular}{|c|c|c|}
\hline Metaphorical model & Russian variant & English variant \\
\hline war & 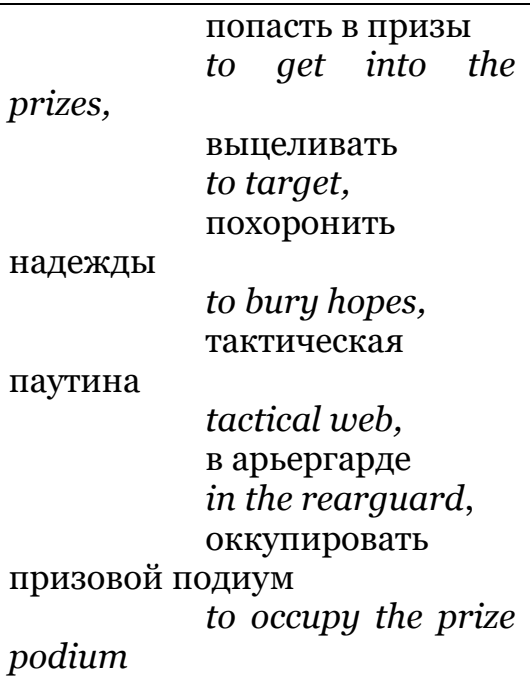 & $\begin{array}{l}\text { veteran } \\
\text { rearguard } \\
\text { win the season-long }\end{array}$ \\
\hline mechanism & $\begin{array}{l}\text { Эта Палка } \\
\text { стреляет не раз в год - гораздо } \\
\text { чаще! This Palka shoots more } \\
\text { than once a year - much more } \\
\text { often! (Kristine Palka is a Polish } \\
\text { biathlete. + palka = stick + } \\
\text { Russian proverb "Even a stick } \\
\text { shoots once a year") }\end{array}$ & $\begin{array}{l}\text { When all cylinders } \\
\text { are firing, she can be a } \\
\text { dominating force }\end{array}$ \\
\hline way & $\begin{array}{l}\text { финиша пересечь линию } \\
\text { to cross the finish } \\
\text { совершить } \\
\text { большой скачок } \\
\text { to take the big leap. } \\
\text { "Наш Зайчик уже } \\
\text { давно от волка убежал вот и } \\
\text { сегодня от Швеции" } \\
\text { "Our Zaichik ran } \\
\text { away from the wolf for a long } \\
\text { time ago and now from Sweden } \\
\text { as well" (Zaichik is a short name } \\
\text { of Russian biathlete Olga } \\
\text { Zaitseva + zaichik = bunny) }\end{array}$ & $\begin{array}{l}\text { to cross the } \\
\text { finishing line journey to the } \\
\text { podium make the biggest } \\
\text { jump put on a big push. }\end{array}$ \\
\hline construction & $\begin{array}{l}\text {...они и днём и } \\
\text { ночью строят стадион в Сочи... } \\
\text {... they are building a stadium in } \\
\text { Sochi day and night } \\
\text { всё время в гуще } \\
\text { событий }\end{array}$ & $\begin{array}{l}\text { golden with each } \\
\text { to bank the points }\end{array}$ \\
\hline
\end{tabular}




\begin{tabular}{|c|c|c|}
\hline & $\begin{array}{l}\text {... always in the } \\
\text { thick of things } \\
\text {..то раствор } \\
\text { мешают, то кирпичи кладут... } \\
\text { (про тренеров сборной). } \\
\text {... then they mix the } \\
\text { solution, then they put bricks ... } \\
\text { (about the national team } \\
\text { coaches). }\end{array}$ & \\
\hline society & $\begin{array}{ll} & \begin{array}{l}\text { явный претендент } \\
\text { clear contender; } \\
\text { подвал турнирной }\end{array} \\
\text { таблицы } & \text { basement of the } \\
\text { standings; } & \begin{array}{l}\text { биатлонный бог } \\
\text { biathlon god; } \\
\text { Зайка Bceя Pуси } \\
\text { Bunny of All Russia }\end{array} \\
\text { (about Olga Zaitseva) } \\
\text { Ленин мирового } \\
\text { биатлона } \\
\text { biathlon }\end{array}$ & $\begin{array}{c}\text { firm favorite } \\
\text { performance- } \\
\text { obsessed player } \\
\text { brilliant player }\end{array}$ \\
\hline organism & $\begin{array}{l}\text { нервы навыпуск } \\
\text { nerves out; } \\
\text { командный дух } \\
\text { team spirit; } \\
\text { последний } \\
\text { the last shot limped; } \\
\text { "Замри! Умри! } \\
\text { выстрел захромал } \\
\text { Воскресни!" ( стрельба) } \\
\text { "Freeze! Die! } \\
\text { Resurrect” (shooting) }\end{array}$ & \begin{tabular}{ll} 
& \multicolumn{2}{c}{ team spirit } \\
& fade $\quad$ out \\
contention &
\end{tabular} \\
\hline art & 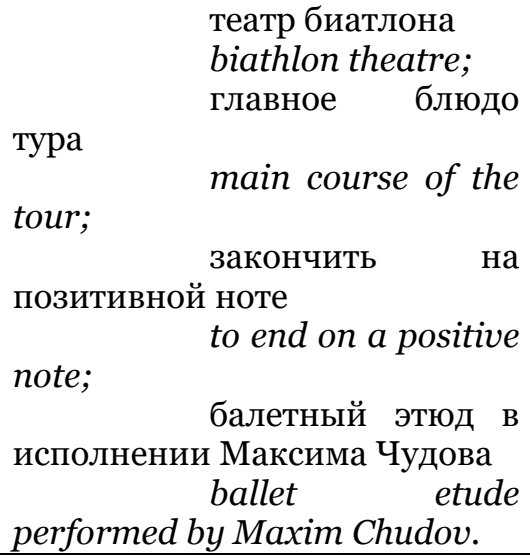 & $\begin{array}{l}\text { end the year on a } \\
\text { positive note, podium }\end{array}$ \\
\hline
\end{tabular}

The central and most influential metaphor for sports discourse is military metaphor. The sport conflict potential explains such a wide expansion of this model into sports discourse. The verbal presentation of sports discourse key elements in military terms is due to the proximity of the scenarios of war and the biathlon race. 
The metaphorical model "team is a mechanism" is effective for expressions of the utilitarian, normative and teleological evaluation of the country's biathletes performance as one team. Sports activity can be conceptualized as a technological process. Team players are presented as parts of the mechanism.

The basic metaphor "the game \competition is the path" implements mainly a teleological evaluation, reflecting the progress of the team towards the goal. The normative time span of matches and tournaments becomes the empirical basis for the metaphor of the path.

The metaphorical "game\competition is construction" model is functional for expressions of normative and teleological evaluation of the team's creative and tactic actions. The team itself, as well as the components of its game and tactics, can be represented in the construction. The Coach is the person who erects the building, constructs the competition, and is responsible for the final result.

The basic metaphor "team is society" is rather functional in sports discourse. A projection of institutional concepts becomes expression of the normative evaluation of events. The concept of power is one of the central ones in the social model. The most authoritative key players and the coach himself are the most powerful team members. The concept of work also plays an important role in the structure of social metaphor. The player on the field works hard, does all his best, and is engaged in getting balls. Depending on the nature of the work performed on the field, various characteristics of the players' actions are explicated. The scored points and time spent have material value.

The organism metaphor, like the military one, is universal, the use of the basic concepts of life and death in relation to events makes one perceive the founding of a club (birth), the formation of a team (growth), a non-confident performance (illness), loss (death) as something more significant and valuable than they really are. The player is considered to be part of the organism.

The use of elements of the metaphorical model "biathlon is art" brings the aesthetic evaluation of the event to the foreground. The entertainment component of sports, to some extent, comes into conflict with the agonal, conflictogenic components of sports, as well as pragmatic and utilitarian ones. The theatrical and musical metaphors are included in the structure of the metaphorical model of art, as well as literary, cinematic and dance metaphors are added. The use of the metaphor of art seems appropriate for expressing extraordinary actions on the track and evaluating the aesthetic component of the competition.

\section{Conclusion}

A comparative analysis of biathlon metaphors in the Russian and English-language sports reportage revealed a number of semantically and structurally similar units in English and Russian languages: team spirit -командный дух, to cross the finishing line - пересечь линию финиша, firm favorite - явный претендент, home-field advantage - преимущество своего поля, end the year on a positive note - закончить на позитивной ноте; make the biggest jump - совершить большой скачок.

At the same time, the group of unique English sports metaphors that do not have Russian equivalents is quite representative: "Her journey to the podium continued to look golden with each step"; "A medal of any color would brighten their day"; "She won the ladies 7,500 $\mathrm{m}$ in dominant fashion"; "Ole Einar Bjoerndalen might be the most performance-obsessed player in the history of the sport”.

The group of Russian biathlon metaphors that have no English counterparts turned out to be the most numerous and diverse in terms of spheres of metaphorical projection: 
«Цветков долго выцеливает» / "Tsvetkov takes a long time to heal”; «Неужели и к нему пришел, как к Гараничеву в прошлом году, шведский стояк» / "Is it possible that a Swedish stanchion came to him, as to Garanichev last year"; «Последний выстрел захромал у Иннерхофер» / "The last Innerhofer's shot limped"; «Не самая удачная стрельба едва не похоронила российские надежды на медаль» / "The poor shooting almost buried Russian hopes for a medal"; «Возможностей попасть в призы у украинских биатлонистов сегодня вовсе не было» / "Today, Ukrainian biathletes did not have any opportunities to get into the prizes".

Summing up the results of the research, we came to the following conclusions:

Firstly, metaphorics (imagery) is a significant component in biathlon media discourse, since the purpose of the metaphor of this discourse is to represent a sporting event figuratively, as well as to provide feedback and reflection from listeners / readers / viewers.

Secondly, the specific character of the biathlon discourse metaphor is revealed in the fact that under the influence of extralinguistic factors, metaphorical transference can occur at almost any lexical level, i.e. phraseological unity, sports terms, jargon of fans, proper names can be metaphorized.

Thirdly, depending on the kind of sport, metaphors are distinguished and can be united by one thematic group, but these groups can vary depending on the sport.

Finally, some metaphors are very often used in the media. In recent years, these are primarily military metaphors. Other metaphors are used less frequently, most often occasionally. But there is a trend towards their more regular use in sports discourse.

The role of metaphors in sports discourse, particularly in biathlon discourse, is not limited to the journalist's wish to avoid schematic and monotonous style. There is enormous potential to enhance the current aspects of various sports concepts hidden in each metaphor.

\section{Acknowledgements}

This research did not receive any specific grant from funding agencies in the public commercial, or not-for-profit sectors.

The authors declare no competing interests.

\section{References}

Aristotle (2020). Poetika. Retrieved 4 March 2020, from http://philosophy.ru/library/aristotle/poet.html. Arutyunova, N. D. (1990) Teoriya metafory / N.D. Arutyunova; pod red. M. A. Zhurinskoy. M.: Progress.

Belozerova, N. N. (2010). Mir realnyy i mir virtualnyy: dve ekologicheskiye sistemy? monografiya / N. N. Belozerova. Tyumen: Izdatelstvo Tyumenskogo gosudarstvennogo universiteta,

Demyankov, V. Z. (1994). Teoriya prototipov $v$ semantike $i$ pragmatike yazyka. // Struktury predstavleniya znaniy $v$ yazyke. M.: Progress.

Entsiklopediya (2010). «Krugosvet». Retrieved 21 March 2010, from http://www.krugosvet.ru/articles/82/1008255/print.htm.

Glazunova, O. I. (2002). Logika metaforicheskikh preobrazovaniy / O. I. Glazunova. - SPb: Piter. 
L. Osinovskaia \& Y. Shekhovskaya - Russian and English Metaphorics: Comparative Analysis...

Hoffman, R. R. (1987). What could reaction-time studies be telling us about metaphor comprehension? // Metaphor and symbolic activity. / R.R. Hoffman.

Isayeva, L. A. (2012). Sportivnyy diskurs: diskretizatsiya kontinuuma / L. A. Isayeva, N. B. Kazarina, Journal of Vestnik Adygeyskogo gosudarstvennogo universiteta. Seriya 2: Filologiya i iskusstvovedeniye, 188-191.

Karasik, V. I. (2000). Struktura institutsionalnogo diskursa Journal of Problemy rechevoy kommunikatsii. Saratov: Izd-vo SGU, - S. 25-33.

Krasnykh, V. V. (2003). «Svoy» sredi «chuzhikh»: mif ili realnost? M.: YTDGK «Gnozis».

Kudrin, S. A. (2011). Bazovyye metafory sportivnogo diskursa kak tekstoporozhdayushchiye modeli. Avtoref. dis. kand. filol. nauk. Moskva.

Kuzmina, N. A. (2011). Sovremennyy mediatekst: uchebnoye posobiye. Omsk.

Lakoff, Dzh. (2004). Metafory, kotorymi my zhivem / Dzh. Lakoff, M. Dzhonson; per. s angl. A. N. Baranova i A. V. Morozovoy; pod red. i s predisl. A. N. Baranova. - Moskva: URSS, (OOO ROKHOS).

Malysheva, Ye. G. (2011). Russkiy sportivnyy diskurs: teoriya i metodologiya lingvokognitivnogo issledovaniya. M.: FLINTA.

Mamayko, S. G. (2014). Realizatsiya ekspressivnoy ustanovki v zagolovkakh sportivnogo diskursa. Journal of Lingvisticheskaya teoriya i obrazovatelnaya praktika, 232-237.

Maslennikova, A. A. (2006) Osobennosti grammaticheskoy metafory. SPb: SPbGU.

Maslova, A. S. (2017). Perevod voyennoy metafory v sportivnom diskurse (na materiale angliyskikh SMI// Nauchnoye soobshchestvo studentov: Mezhdistsiplinarnyye issledovaniya: sb. st. po mat. XIV mezhdunar. stud. nauch.-prakt. konf. № 3(14). Retrieved 22 October 2017, from https://sibac.info/archive/meghdis/3(14).pdf.

Nikitin, M. V. (2008). Kurs lingvisticheskoy semantiki: ucheb. posobiye $k$ kursam yazykoznaniya, leksikologii i teoret. grammatiki. M.: RGB.

Pankratova, O. A. (2005). Lingvosemioticheskiye kharakteristiki sportivnogo diskursa: dis. ... kand. filol. nauk. Volgograd.

Sklyarevskaya, G. N. (1993). Metafora $v$ sisteme yazyka. SPb.: Nauka.

Smirnova, M. A. (2014). Ponyatiye «metafora» i podkhody k yeye izucheniyu / M. A. Smirnova // Filologiya i literaturovedeniye. - 2014. - № 9 Retrieved 4 January 2020, from http://philology.snauka.ru/2014/09/960.

Snyatkov, K. V. (2008). Kommunikativno-pragmaticheskiye kharakteristiki televizionnogo sportivnogo diskursa. Vologda.

Ulanovich, O. I. (2016). Metafora kak sredstvo obraznoy vyrazitelnosti v sportivnom diskurse / O. I. Ulanovich, Ye. I. Stefanovskaya // Aktual'nyye voprosy germanskoy filologii i lingvodidaktiki: Materialy XX Respubl. nauch.-prakt. konf., BrGU im. A. S. Pushkina, 26 fevr. 2016 g., Brest, 103-106.

Fox, K. (2020). Nablyudaya za anglichanami. Retrieved 4 September 2020, from http://www.ereading.co.uk/book.php?book=149596. 


\title{
The Studying of Russian Phraseological Units and Paroemias in English Speaking Audience
}

\author{
Anna Baskakova \\ The Military University of the Ministry of Defense of the Russian Federation \\ $10^{\text {th }}$ department (Russian philology), Moscow, RUSSIAN FEDERATION
}

Received: 29 October 2020 • Accepted: 27 November 2020 • Published Online: 25 December 2020

\section{Abstract}

\begin{abstract}
A working mechanism during the comparative analysis of phraseological units and paroemias (proverbs and aphorisms) at the classes of Russian as foreign language with English speaking learners is presented in the article. While working in the audience, the attention is being paid to the comparative analysis of phraseological units and paroemias in Russian and foreign students' native language from a semantical point of view. Such concepts and ideas as family, homeland, work / service / profession, studying, friendship, human flaws and virtues, represented in the proverbs and paroemias, are being analyzed. The similarities and differences in semantic field of phraseological units and paroemias of different cultures' speakers are found. A parallel attitude to the main categories as family, home and friendship among Russian and English speakers is shown up. During a comparative analysis, it is being observed that in definite cases similar meanings can be expressed by different lexis typical for the concrete nation. Studying of this topic promotes the dialogue of cultures.
\end{abstract}

Keywords: English speaking audience, nationally-cultural semantics, meanings of phraseological units and paroemias, term, Russian as foreign.

\section{Introduction}

This article is dedicated to the problem of understanding Russian phraseological units and paroemias by foreign learners, knowing English language. During the process of studying any foreign language students meet with the problem of understanding not only grammatical and lexical material, but also definite language phenomena which have the feature to inscribe and to transfer information connected with the history of studying language, its traditions and customs, way of nation's thinking, culture and other facts. As the result of an analysis of such phenomena comes up an interest to a nationally - cultural side of language semantics.

It is known, that source of nationally-cultural semantics is in stable phrases phraseological units and aphorisms (paroemias, proverbs and bywords), which get a double meaning while the process of forming one separate nation: interactive - way of speaking and informative - the source of different information, necessary for society's development and life. That is why phraseological units have a capacity to transfer information, pawned by ancestors of one nation, from one generation to another and implement the function of preserving a definite

(C) Authors. Terms and conditions of Creative Commons Attribution 4.0 International (CC BY 4.0) apply. Correspondence: Anna Baskakova (MA), The Military University of the Ministry of Defense of the Russian Federation, 10 $^{\text {th }}$ department (Russian philology), Moscow, RUSSIAN FEDERATION. E-mail: annavlz@mail.ru. 
cultural and genetic code inside the language and consequently inside cultural memory of an ethnos.

- Learning of Russian phraseological units and paroemias help foreign students to grow their desire to know more about Russia.

- Comparing of lexical units promotes comparing of cultures.

- Maintenance and propagation of worldly wisdom through paroemias is the best way to save the nation.

Each language is a reflection of mentality, culture and history of a nation. These life aspects, proper to an enormous number of world nations, are extremely shown in paroemias (proverbs and bywords). A great Russian writer, ethnographer and folklorist, V. I. Dal wrote about them in a such way: “... the color of nation's mind, of an original form, this is the living nation's truth, a regulation by itself, which cannot be judged by anyone" (Dal, 1984). From the point of view of another Russian linguist and a historian of literature and arts F. I. Buslaev the proverbs and regarded as "art pieces of an own word, expressing the mode of life of the nation, its sound sense and moral interests" (Buslaev, 2015: 17). In our article, the proverb is being understood as "a short folk saying with an edifying sense, having a worldly wisdom in it" (Ozhegov, 1981: 503).

During the process on an analysis of proverbs, we can deduce that they have two main functions: firstly, they fill up the speech with expression and emotionality and, secondly, they play the role of a transfer of life wisdom and knowledge from an old generation to a young one, which are much needed in an everyday life. To our opinion, the language base of all world nations has phases full of wisdom, which due to their capacity, retain unchanged in their meaning and functionality for long.

\section{Method}

\subsection{Comparison of Russian and English cultures}

As the objects of comparison, we consider it expedient to take two linguistic cultures - Russian and English. The choice of the studying of this topic was not picked up accidently. From one side, many foreign cadets from Africa, Asia and Middle East, studying in the Military University of the Ministry of Defense of the Russian Federation, speak not only the language of their little tribes and races, but also English language being main for them. In this case, the teacher should have some knowledge about the culture and traditions of the learners for realization of an effective communication. From another side, the mode of life of different folks, who speak different languages, is reflected in Russian and English culture. The existence of two man languages, uniting Russian and English cultures - Russian and English - is a good bit of a help for a deep analysis, because these languages have an old history and as the result have a deep layer of nation's wisdom, which is being kept inside the paroemias of these languages.

The relevance of our study is caused by a such fact, that during the process of a comparative analysis of Russian and English phraseological units and paroemias from a semantical point of view it is possible to find some similarities and differences in definite features and traits, typical for one or another language, including the national originality of the units, being also under the study. The determination of definite characteristics promotes the deeper understanding of the specific features of another culture's representatives and, as the result, a successful cultural interaction between Russian and English spokespersons. 
3. Results

\subsection{Observing phraseological units}

Starting from observing the phraseological units, it is important to say, that the explanation of the difference between free and bound collocations is an essential condition for that. So, the fund of free collocations form the words, which have saved their individual lexical meaning: during the process of usage in a concrete communicative situation such collocations are being constructed for purpose, when their components can be changed by the lexemes of one category. For example: good-fellowship, bed-fellowship, woman-fellowship; to defend one's country, to defend a post, to defend a dissertation, to defend oneselffrom a criminal. In this way, these collocations have such components, which while using can be changed and switched, and this process will not affect their ability to keep their meaning as inside a concrete collocation, as separately from it.

The composition of bound collocations comprises the words, which lose their ability to operate undependably, being out of such constructions. That is to say, the entire inseparable collocation is being formed, where switching the components or changing its form is impossible. Specifically, the phraseological unit does not have a direct meaning of words inside of it, but another, which is peculiar only for a concrete collocation.

It should be noted that while working on studying of phraseological units in English speaking audience the teacher of Russian as foreign language needs to pay attention to the fact of similarity of bound collocations in different languages, which promotes better understanding and digestion of Russian lexis.

This kind of collocations, like the words, operates in a complete form and is not being reconstructed in a speech: they are not separated and are being interpreted as full units. Because of that, the collocation should be fixed in a full form while memorizing. Separate words, being inside bound collocation, lose their first lexical meaning and compose a new meaningful construction, having a synonymic meaning of the word.

For example, at the lesson of Russian as foreign language to learners with the First Certificate level can be offered to complete the task directed to understanding the phrases from the poem of Russian poet A. T. Tvardovsky "Vasili Tyorkin: A Book About A Soldier" as a variant for analyzing of phraseological units (http://www.sovlit.net/tyorkin/wounded.html).

Tell, from which lexemes the collocation "ashen - faced" is formed? How do you think, which people can have this description? Why?

Ashen-faced, he lies unmoving,

Doesn't even blink an eye.

In the nick of time they found him,

Hauled him in, drove him away.

Having the definition found, the learners can make up their own examples with the same phraseological unit from their language. Here is also is important to mention that there is an antonymic variant to a such lexeme: ashen - faced - dead, sick, ruddy-faced-alive, healthy.

From the mentioned above, it is needed to say, that for phraseological unit's uprising the definite situation should exist, where the words lose their lexical meaning in a full gage or partly.

Phraseological units help to make the speech more beautiful, not only richer, brighter and diverse overall, but also more accurate in definite situations, when it is necessary to provide the listener with a definite sense, to make the phrase more concrete for understanding. Therefore, 
for example, a phraseological unit at the top of one's lungs sounds much brighter than calm down or get free. Using this expression in a speech, the learner can both show his high level of operating with the language and express the grade of his thoughts' depth.

\subsection{Components of phraseological units}

The components, forming the semantics of phraseological units, are divided at logically-dedicated and connotative. By the degree of importance they can be distributed into: (a) the component of indirect or figurative meaning; (b) the component of direct or objective meaning, forming the basis of the meaning; (c) the component on a nationally-ethnic meaning; and (d) the component of an emotional meaning.

A main meaning of a phraseological unit - figurative - is a required component, which is proper to a complete phraseological unit and does not go out from the combination of words' meaning, forming it. Figurative meaning of the phraseological unit should be interpreted in the translation. For example, in a Russian proverb Saved ahead is saved by God it is told that it is easier to avoid any danger for a careful person than for that who acts thoughtlessly. A direct translation of this phraseological unit It is s better to be safe than sorry will sound like It is better to be careful (save yourself) than to be sorry. Although, if an English speaking learner translates a Russian variant in a direct way not leaning on an English version, in case of knowing a synonymic row to care - to save he will be able to understand a main meaning of a phraseological unit and understand the closeness of the meanings in both Russian and English variants. Interestingly, that there are other variants of this proverb in English language: God helps those who help themselves that in Russian translation will sound absolutely alike and Caution is the parent of safety where in a Russian variant the word parent is switched to mother, that can bring some difficulties to learners while the process of comparison with a Russian variant, but during the construction of a synonymic row caution - security - safety the sense can be finally found.

Thus, making up the comparative analysis of figurative meaning of Russian and learners' own phraseological units and aphorisms, can improve the process of a language material learning.

The base of phraseological unit's direct meaning can be formed by a definite image, associated with a definite form of behavior or person's way of life. For example, a proverb in English As cool a cucumber in Russian variant will be interpreted as calm as a boa. This fact of different interpretation tells about different understanding and perception of a term calmness in Russian and English cultures. In addition, an English phraseological unit Hungry as a hunter in Russian will sound like Hungry as a wolf. The difference between words hunter and wolf directs at opposite understanding of a sense of a word hungry: in Russian variant, a wolf is associated with the word hunger in a first row, because wolf is a dangerous vermin, constantly being in search for food and as a result being always hungry. Also, an image of a wolf appears because of a connection with geographical location of our country, where the biggest part of a territory is taken by pine and leafy forests, which are the wolves' habitat. In an English variant of a proverb, the word hunter directs at association of hunger from a point of view of a person, having passion to get off the feeling of hunger with a help of searching food in wild conditions. The culture of hunting in English world outlook takes an important place from ancient times, so using exactly this lexeme in structure of this phraseological unit is explainable.

Understanding the difference and similarity between the figures, which make up the base of own phraseological units, foreign learners can faster and more effectively fixate in memory Russian phraseological units and aphorisms while studying. Meanwhile, it is important to take into consideration the fact of a probability in cases of a big difference between original figures, which give a direct meaning. 
As an example, it is possible to point at the difference in parallel of a Russian proverb The root of education is bitter, but its fruit is sweet and English - The roots of education are bitter, but the fruit is sweet. Here we can persuade that understanding of that concrete variant in Russian will not be difficult because of a direct translation, which is definitely seen by using the same lexemes, keeping their meaning in both languages.

Observing the proverb in a Russian variant The learning is a light but non-learning is a darkness, we can ensure that an English variant Learning is the eye of the mind, differs from a Russian variant by a quantity of figures and its connotations: in a Russian variant the meaning of a proverb opens by separation of two opposite images of light and darkness in a combination with learning and non-learning, whiles in an English variant there is only one image of learning in a combination with a phrase the eye of the mind. In this case, the learners have a possibility to memorize a Russian equivalent of a proverb with a help of dividing the images, forming its sense, being similar to an English variant.

The component of a nationally-ethnic meaning, often included into a structure of phraseological constructions, can help with understanding of the place of its origin. Thus, a Russian aphorism Moscow was not at once corresponds an English variant Rome was not built in a day. Having only names of the cities as an aspect of difference, the learners can define the meaning of this proverb unmistakably and memorize it without difficulties.

A big amount of phraseological units has a feature of expressing of an emotional attitude to what is being described in them: acceptance or judgment, advice or warning. Quite often, a phraseological combination presents by itself a completed sentence with a statement, edification or conclusion. The proverbs and aphorisms can be examples of such combinations. If a phraseological combination does not have an element of edification or has an element of understatement, it will be a proverb or an aphorism. Another source of phraseological combinations is a professional speech (Ryzhov \& Ryzhova, 2004). For example, a Russian phraseological unit To kill two hares tells about a successful ending of a business. The same meaning will have an English variant To kill two birds with one stone.

It is clear, that many phraseological units have such features as imagery and expression, which let an oral or written communication have active and alive character: phraseological units and aphorisms are able "liven up" a monotonous saying of a speaker, turn listener's mind to participation in a discussion. In addition, phraseological combinations make a written text more attractive for reading. In view of that, the stable phrases are often used by authors in belles-lettres, journalism and oral speech.

Meanwhile, working in English speaking audience the teacher should pay learners' attention to the fact, that in a process of pronouncing of phraseological units in Russian it is not necessary to say them fully, because the vocabulary of an adult native speaker consists of a big amount of well-known phraseological units which are needed for usage in everyday oral speaking: if in a process of communication a Russian man hears the phrase the apple doesn't fall..., he will not have difficulties with understanding the ending of the phrase and defining the meaning, placed in a saying. At the same time, the learner should take into the consideration an opposite situation, when while speaking a Russian native speaker can tell an aphorism without a full completing, what can cause a misunderstanding from a foreigner's side in case of poor knowledge of Russian language.

However, there are such phraseological units in Russian language, which can bring some difficulties in understanding even for native speakers because of having archaisms and their forms in their structure. For example, twiddle one's fingers, to be made of something, put one's foot in it. If in a process of communication such constructions are used, it can bring even a bigger difficulty for a foreigner, having a weak background knowledge. In this case, it is advised to use the method of lingua-geographical comment, which was first explained by the authors of a book 
Language and culture: Lingua-geography in teaching of Russian as foreign, E. M. Vereshagin and V. G. Kostomarov. Following their definition, "the comment which has a goal to explain outlingual cases, can be named differently - real, historico-literary, domestic, social, textual. As long as it reduces to a lingua-geographical semantization, this king of a comment should be properly named as a lingua-geographical” (Vereshagin \& Kostomarov, 1990: 135).

\section{Discussion}

\subsection{Division of paroemias by values and concepts}

While studying paroemias at the lessons of Russian as foreign language at Waystage and Threshold Levels English speaking foreign learners often pay attention to existence of similar concepts of language in Russian and their own languages. As the examples, some Russian paroemias were being analyzed, which show an attitude of a person to basic values, typical for any nation: family, motherland, work / service / profession, education, friendship, vices and virtues. After that, the learners were finding the same proverbs by the meaning in their language and made a comparison.

The peculiarities of paroemiac units of Russian and English languages are shortness, rhythmic order, and wideness of a topic and also an ability to give a deeper culturally caused characteristics of both different sides of person's life and occurrences of the surrounding world: an earthy living wisdom and a moral personality of a simple person are exactly put in paroemias (Krylova, 2014: 146).

There are many proverbs about motherland and home in Russian and English languages. A tremulant attitude to homeland, which is presented as the best place in the world, is observed in Russian paroemias. Foreign learners also love their homelands, which are always remembered: There is no place like home, Dry bread at home is better than roast meat abroad, East or West home is best.

The concept family is closely connected with a concept home. In Russian culture family is being understood as a one organism, implying living in a peace, love and agreement, support, protection, passing priceless experience from adults to youngsters, what is shown in proverbs: Every mother thinks her own gosling a swan, Choose your wife on Saturday, not on Sunday, A good Jack makes a good Jill.

In English culture, a family is considered to be an example of strong, stable and traditional relation. The countries, enculturated to English world view through a language, origin or a territory of living lean on English values, which are characterized by a high morality in complex with worship of ancient traditions and foundations. In spite of a modern western approach to life, spread because of globalization, which influences hardly a way of people's life living in civilized and developed countries, a unique, stable and even old-fashioned attitude to an understanding of a concept family and family traditions is still as strong as before in an English speaking society and tends to support of a strong and a harmonious family.

Since the family life involves by itself not only a friendly cooperation between spouses, but also a process of upbringing and educating children, what is hard and long peculiar work by itself, and a terms education and work are connected with a concept family too. The matches between the questions about upbringing and educating children in Russian and English cultures are also noted: it is often met, that upbringing of a young generation is long and laborious process, success of which depends on a start of upbringing. Russian and English proverbs have identical variants in both languages: Live and learn, Learning is the eye of the mind, Learn - sharpen the mind. Such similarities in a direct translation tell about a connection between Russian and English culture in a question of upbringing and education, because the last one has always played a big 
role in life for Russian and English speaking nations, what makes the process of these aspects' understanding easier and clearer through analysis of Russian proverbs for English speaking learners.

After a brief observation of terms education and upbringing through an analysis of proverbs it is advisable to turn to the term work in these units. An attitude to work in notion of a Russian and English person also has similarities and it is equal to a serious business, which does not tolerate with a rush and demands skills, experience and knowledge for its realization: Business before pleasure, Score twice before you cut once, No sweet without some sweat. While translation of English and Russian variants of these proverbs learners can also find connection between Russian and their outlooks.

Talking about a concept work in different cultures, it is impossible to leave the term profession, because the first is inseparably connected with the second, being depended on each other. Citing an instance Russian proverbs about professions and taking into consideration a specialization of learners (military economists, journalists and jurists), the teacher motivates an audience to not only compare Russian and English proverbs about profession, but also think about its role in their life and professional activity: use them?

(1) Read the proverbs about different professions. In which cases of speaking can you

(2) What analogs can you find in Russian language? Make the examples. Tell in which situations they can be used.

1. The words of an officer go along with his actions.

2. Officer - is the paragon of virtue.

3. A good marksman may miss.

4. The good workman does a good job.

5. It is better to do something than nothing at all.

After reading, the students can meet with a such thing, that abovementioned proverbs have a specific relation to a definite kind of work in a concrete culture. That case can bring some difficulties in searching for an analog in a needed language and it is possible either to find a direct translation for understanding the meaning of words or find a variant that is similar by sense but antonymic by a content.

Further, it is logically to step to observing of the proverbs reflecting the character of a person, his vices and virtues. A big amount of both Russian and English paroemias of this semantical group has the topic of censure, derision of laziness, foolishness and ignorance: It is not the gay coat that makes the gentleman, Modesty adorns the person, A fool may throw a stone into a well which a hundred wise men cannot pull out.

It is also possible to meet a similarity in opening of such a terms as kindness, sympathy and bravery: Nothing venture, nothing have, Fortune favors the brave, Two heads are better than one, United we stand, divided we fall.

Doubtless, that a term friendship and partnership have a big importance in any person's life, especially for the learners with a military specialization because cooperation and solidarity stand at the heart of their profession. In fact, there are many proverbs about friendship in a paroemialogical base of Russian and English variants.

For a majority of people friendship plays a bigger role than a material worth, what is supported by examples of Russian and English proverbs: Friendship, the older it grows, the stronger it is, A friend in court is better than a penny in purse. 
In addition, the idea that friendship should be saved and appreciated and support of a friend is the most valuable thing in a hard moment is also being observed in a process of proverb analysis: A friend in need is a friend indeed. In English culture the searching for a friendship is taken as a difficult task and finding it as a big luck: Prosperity makes friends but adversity tries them.

It is important to note, that while a comparison of Russian and English paroemias, the learners often meet with a problem of a bad orientation in this topic: they need a collective discussion of the meaning of some proverbs and a further self-work when doing they need advice and help from an older generation with finding a sense of some proverbs.

The significance of the results, got while the process of a comparative analysis of Russian and English phraseological units and paroemias, is shown in that during finding similarities and differences in them promotes English speaking learners not only a better understanding of the specific things about studying language, its culture and nation, but also helps to build a stronger relation between the inhabitants of a country and learners of a studying language.

\section{Conclusion}

The substance of above mentioned information reduces to that in a process of working with English speaking learners the teacher of Russian as foreign should take into consideration the fact that while studying such a difficult and extensive partition of linguistics as phraseology much attention should be paid to knowledge of learners in history, language and culture of their own country. The mechanism of working comprises analysis of background knowledge, comparison them with knowledge about another country and language with a following digestion of linguistic units. Undoubtedly, as a result of successful learning of Russian phraseology, foreign learners will be able to enrich their vocabulary that let them not only reflect their thought in a saying more concrete, beautify it, add accuracy and imagery, but also will promote a more thoughtful dipping into a culture of a studying language.

Issuing from abovementioned material, we concluded that exactly the fact of transmission of wisdom from one generation to another through paroemias place a big role in formation of each person. It proves that a younger generation needs help of an older one, caring a living experience.

The majority of young people from a modern generation actually do not have proverbs in their vocabulary or uses them very seldom. English speaking learners from Africa, Asia and Middle East while working with Russian proverbs made examples well known English idioms. Certainly, this is explained by that foreign learners speak in English mainly and a local language of their folks or territory of their living is used too rarely and by an older generation: the more educative person is and the more he works or studies with a usage of English language, the faster he forgets his local language and drifts away from it and becomes forgetful of wisdom and experience, passing through many generations for many ages on end.

Finally, it is important to note, that while comparing of main concepts and terms, reflected in Russian and English outlooks, despite the fact of some differences between English speaking countries of Africa and Russia in their location, climate conditions, history and traditions, understanding and sense of such aspects as friendship, work and family coincides in a majority of times.

In summary, the dialogue of cultures plays an important role in building a global interactive relation. This dialogue can be caused by different actions, as verbal as nonverbal. The way of construction of this dialogue through a linguistic work makes this process more interesting 
for a researcher and, as the result, motivates him to search for another methods to make the others think about the topic of a global relation in a deeper way.

\section{Acknowledgements}

This research did not receive any specific grant from funding agencies in the public commercial, or not-for-profit sectors.

The author declares no competing interests.

\section{References}

Buslaev, F. I. (2015). Russian mode of life and spiritual culture. Moscow: Institute of Russian civilization.

Dal, V. I. (1984). The proverbs of Russian folks: a selection of V. Dal in 2 vol. Moscow: Belles - letters.

Krylova, E. O. (2014). Semantical understanding of proverbs and bywords about labor in Russian and English languages. International Journal of Experimental Education, 6 (part 2), 146-147.

Modestov, V. S. (2003). English proverbs and their correspondences. Moscow: Russian language: Media.

Ozhegov, S. I. (1981). The dictionary of Russian language. Moscow: Russian language.

Phraseologism (2017). Big Russian encyclopedia. Vol. 33.

Ryzhov, V. A., \& Ryzhova, S. V. (2004). About an origin and meaning of some phraseological units. Moscow: First September.

Tvardovsky, A. (1942-1945). A bilingual edition of: Tyorkin wounded from: Vasili Tyorkin: A book about soldier. Taken from http://www.sovlit.net/tyorkin/wounded.html.

Vereshagin, E. M., \& Kostomarov, V. G. (1990). Language and culture: Lingua-geography in teaching Russian as foreign. Moscow: Russian language. 
A. Baskakova - The Studying of Russian Phraseological Units and Paroemias in...

C O A $\mathbf{s}$ 


\title{
Word-image Interaction in the Treatise "Voyage en Sibérie"
}

\author{
Elizaveta Panova \\ Lomonosov Moscow State University, Moscow, RUSSIAN FEDERATION \\ History Faculty, Art History Department
}

Received: 24 November 2020 • Accepted: 21 December 2020 - Published Online: 25 December 2020

\section{Abstract}

Voyage en Sibérie describes a journey through Russia carried out by Jean Chappe d'Auteroche to observe the passage of Venus across the Sun. Besides the description of this phenomenon the book contains the author's travel notes and study of the Russian political, historical, geographic and military conditions in the middle of the $18^{\text {th }}$ century. Voyage en Sibérie was accompanied by the cycle of illustrations performed by Jean-Baptiste Le Prince. As these works were among the first examples of the costume images on the Russian subject, they became crucial in the career of the artist who is considered to be the creator of "Russerie" in French art. This paper discusses the nature of the text and illustrations developing according to the logic of ideas of the Enlightenment. The author intends to show that although Chappe d'Auteroche and Le Prince worked together on the book they had different visions of the problem.

Keywords: Enlightenment, costume book, "Russerie”, travel notes, illustration, etching.

\section{Introduction}

The treatise Voyage en Sibérie (Fig. 1.1 in presentation) was written by the French abbot and astronomer, member of the French Academy of Sciences Jean Chappe d'Auteroche (1722-1769). It was mostly decorated with the etchings by the drawings of the French painter and etcher Jean-Baptiste Le Prince (1734-1781).

Jean Chappe d'Auteroche (Fig. 1.2) came from a noble Cantal family, he received a religious education at a Jesuit college in Moryak. He was admitted to the Royal Academy of Science on 14 January 1759. He was also appointed assistant astronomer at the Royal Observatory. In 1760 he went to Russia, to Tobolsk, to observe the passage of Venus across the Sun, which was to take place on 6 June 1761. He returned to Paris in 1762 and started working at Voyage en Sibérie. A year after the book was finished, he took a trip to California, intending to observe a similar astronomical phenomenon. During the trip, the abbot died. And, thus, Voyage en Sibérie remained the most significant abbot's work.

Jean-Baptiste Le Prince (Fig. 1.3) was born in the city of Metz, in the family of a wood carver. He first studied painting in his native town, but in 1750 he moved to Paris and entered the workshop of Francois Boucher (1703-1770). He also took some lessons from Joseph-Marie Vien (1716-1809). In 1757 he arrived in St. Petersburg, where for the next six years he was working at the order of the imperial court of the Russian Empress Elizaveta Petrovna (1741-1761). He was an active member of the "Kanselary ot stroeniy", a state institution in charge of the development of

(C) Authors. Terms and conditions of Creative Commons Attribution 4.0 International (CC BY 4.0) apply. Correspondence: Elizaveta Panova (MA), Lomonosov Moscow State University, History Faculty, Art History Department, Moscow, RUSSIAN FEDERATION. E-mail: liza.panova97@mail.ru. 
St. Petersburg and played an important role in the decoration of the new-built Winter Palace in St. Petersburg. At that time, he painted some views of the famous Russian coasts and harbors and he created a number of sketches, reflecting his "Russian impressions". Nowadays, it seems almost impossible to reliably establish all places that the artist visited, however, some scholars believe that in addition to St. Petersburg and Moscow, Le Prince also travelled to some remote territories of the Russian Empire and might have accompanied Chappe d'Auteroche during his journey to Tobolsk. Then in 1763 Le Prince returned to Paris and in 1765 he presented at the Salon a painting "Le baptême russe", for this picture the artist was admitted to the French Academy of Arts. Shortly afterwards Le Prince created a special appellation to his works of art, dealing with the Russian subject - "Russerie". While creating this concept, Le Prince, apparently, linked it with earlier examples of the names of exoticisms in European art, namely, with "Chinoiserie" and "Turquerie", which received pan-European distribution in the $18^{\text {th }}$ century. Another important step in his career was the publication of Voyage en Sibérie.

- The treatise Voyage en Sibérie had a Europe-wide response in the first years after its publication. The content of the book and its design (illustrations) received the opposite assessments.

- While working on the text, Chappe d'Auteroche adhered to the most advanced ideas of his time, but wasn't quite objective on a number of issues.

- Jean-Baptiste Le Prince, while working on the illustrations, presented his own vision of the Russian reality. He made illustrations which can be considered as one of the first examples of the costume images on the Russian theme, which were widespread in Europe.

- On the basis of the word-image interaction it was shown that, despite the fact that the text and illustrations rely on the ideas of the Enlightenment, they ultimately contradict each other.

It was published for the first time in Paris in 1768 and since that time it had a Europewide response. Since the beginning of the $18^{\text {th }}$ century Russia, afterwards the Russian Empire, had become a powerful player of the European politics, it gained an immense interest in on the part of the European public. Voyage en Sibérie came out just on time to satisfy that interest. Unlike many works on Russian subject produced in Europe at that time, this book was based on the abbot's travel notes and therefore was regarded as the source of reliable information about Russia and its population.

The first edition of the treatise was accompanied by the French Academy of Sciences resolution conforming that Voyage en Siberrie can be regarded as the piece of academic papers. Jean Leron d'Alembert (1717-1783), Bernard de Jussieu (1699-1777) and Etienne Bezout (17301783), all three members of the Academy, acted as guarantors. But when the book reached its readers it received extremely contradictory reviews. On the one hand, people extolled the treatise, on the other - teared it to pieces.

\subsection{Public opinion}

One example of the appreciation can be found in the Le Journal encyclopédique ou universel, 1716-1785. According the book review of 1770 (Liechtenhan, 2002), Chappe d'Auteroche was even more important than all ancient philosophers, [Il meritait] a preference sur tous les sages les plus célèbrede l'antiquité (p. 37). "Voyage..." was considered as an important source of knowledge for Europeans who wanted to see the real matter of state in Russia.

At the same time a review came out in the "Correspondence littéraire, philosophique et critique" written by Friedrich Melchior, Baron von Grimm (1723-1807). In 1769 (Proskurina, 2017) he told his readers that Voyage en Sibérie was a "great example of ignorance, arrogance, platitude, light-mindedness, immature and petty taste and indifference to truth" (p. 26). He also 
pointed out that Chappe d'Auteroche didn't try to understand the essence of the phenomena he described.

But the greatest reaction on Voyage en Sibérie was Antidot ou Réfutation du mauvais livre superbement imprimé intitulé: Voyage en Sibérie, etc., a book by an anonymous, published in 1770 without indication of locus sigilli (place of publication). According to the majority of the researchers this text belonged to the group of authors with the Russian Empress Catherine the Great, 1762-1796, at the head. Count Andrei Petrovitch Chouvalov (1743-1789), Russian diplomat and gallophile, and Grigory Vasilievitch Kositsky (1724-1776), cabinet secretary of Catherine the Great, editor of the magazine Vsyakaya vsyachina (can be translated as "All Sorts and Sundries") are considered to have been working on "The Antidote" as well. This book presents a meticulous analysis of Voyage en Sibérie. It examines every line of the treatise and draws attention to the minute details of the narrative. The author quotes and makes fun of Chappe d'Autroche and gives his own interpretation of the described phenomena.

Also, for the first time a question was raised in "The Antidote" concerning the connection of Voyage en Sibérie with the French Ministry of Foreign Affairs headed by Étienne François de Choiseul (1719-1785). According to the "author" of "The Antidote" the Chappe d'Autroche's work was part of the Ministry of Propaganda aimed at setting up the minds of the Europeans against the Russia which in perspective was leading to political isolation of the Russian Empire on the eve of the Russo-Turkish War, 1768-1774.

However, the design of the treatise Voyage en Sibérie performed by Jean-Baptiste Le Prince received complements from both sides of the discussion who appreciated the artistic value of the illustrations. In the introduction to the book Chappe d'Auteroche acknowledged the talent of Le Prince and expressed his gratitude to the artist for the well-done work. According to Chappe d'Auteroche (1768) the drawings were essential for the description of the Russian people: "Les dessins nécessaires à la description des moeurs font de M. Le Prince, de l'Académie de Peinture : on reconnoît dans la beauté de ses compositions la fécondité de son genie \& son rare talent pour rendre le costume \& la nature, qu'il a étudié en Russie” (Chappe d'Autroche, 1768: 2).

The "author" of "The Antidot" (1770) also underlined the high quality of the illustrations. In the introduction to "The Antidot" he, while having an imagery discussion with Chappe d'Autroche, ironically pointed out that Le Prince's etchings were the best part of the treatise: "The best in your book are the drawings of Mr. Leprince. It is a pity that in our time all bad compositions are adorned with such magnificent prints" (Carrère d'Encausse, 2005: 227).

Taking into consideration the historical background I intend to consider the text written by Chappe d'Autroche and illustrations performed by Le Prince as an example of two interacting phenomena that have their own laws and principles of existence and form differently the image of the Russian Empire.

\section{Method}

The research methods are of a complex nature. They are based on a combination of linguistic, cultural-philosophical, historical methods, as well as on one of the art history methods of iconographic analysis. Special attention is paid to the linguistic analysis of the text, namely to the interpretation of the image of Russia and the Russian people, presented in the text by Jean Chappe d'Autroche and the iconographic analysis of the illustrations created by Jean-Baptiste Le Prince as well as the study of artist's individual manner. Besides, the article contains a fairly complete historical material that makes it possible to show the history of the creation of the treatise Voyage en Sibérie, its further destiny, as well as the reconstruction of the contemporaries' ideas concerning the features of the text, its illustrations, and to show their assessment in Russia and in France. Thus, the study examines the interaction of literature and graphic arts, 
(illustrations). On the one hand, this process seems to be the result of the literary sources influence on the artistic samples, which is due to the main features of the illustration art. On the other hand, I think that this process is not so simple as the illustrations for the treatise Voyage en Sibérie can also be treated as an example of the costume image, independent genre of fine arts. The study attempts to show the methods and tools for shaping the image of Russia and the Russian people, which are used by Chappe d'Autroche and Le Prince, as well as to show the mechanisms of the interconnection of literature and the text in interpreting the Russian subject.

\section{Text analysis}

Despite the fact that the recent research of Chappe d'Autroche's treatise is regarded politically engaged, I think that it still remains a striking example of work of the Age of Enlightenment.

This work consists of three volumes and includes the observation of the passage of Venus across the Sun, as well as Chappe d'Autroche's travel notes that he produced during his journey from Paris to Tobolsk, the place of his scientific research. It, also, includes the "Description of the land of Kamchatka" written by Stepan Petrovitch Krasheninnikov (1711-1755), an important Russian ethnographer and explorer of the distant lands of Siberia and Kamchatka. This work was published in France for the first time together with Voyage en Sibérie.

Although the main theme of the treatise was the study of the astronomical phenomenon, Chappe d'Auteroche still paid special attention to the observation and description of the life of the Russian population, and in particular to that of the peasants. He also included his thoroughly collected and classified information, about the structure of the Russian state its geography and history (Fig. 3.1).

This immense interest in the description of the "voyage" can be explained by the fact that in the $18^{\text {th }}$ century travelling was considered as a kind of research that contributed to the development of the traveler's personality, the broadening of his horizons and the enrichment of his knowledge and helped him to get rid of prejudices. This idea was stated in the article by chevalier Louis de Jaucourt (1704-1779) for the Encyclopédie, or a Systematic Dictionary of the Sciences, Arts, and Crafts (1751-1772): “Aujourd'hui les voyages dans les États polices de l'Europe (car il ne s'agit pas ici des voyages de long cours), sont au jugement des personnes éclairées, une partie des plus importantes de l'éducation dans la jeunesse,\& une partie de l'expérience dans les vieillards. Les voyages étendent l'esprit, l'élevent, l'enrichissent de connaissances, \& le guérissent des préjugés nationnaux... Ainfi le principal bit qu'on doit se proposer dans les voyages est sans contredit d'examiner les mœurs, les costumes, le génie d'autres nations, leur goût dominant, leurs arts, leurs sciences, leurs manufactures \& leur commerce” (De Jaucourt et al., 1754: 477). Travel literature seems to have played the same role. According to the historian Daniel Roche (Roche, 2003), reading such texts was equated with the travel itself in the $18^{\text {th }}$ century (Roche, 2003: 359-360). Therefore, I think that travel literature is noted for the same "developing" qualities as the travelling itself.

Apparently, this peculiarity of perception determines the fact that in Voyage en Siberrie the scientific reasoning, an astronomical observations and descriptions of natural electricity, coexists almost on par with the observations of everyday life, issued as a travel diary or travel notes. This diary contain extremely diverse information. Chappe d'Auteroche draws readers' attention to the structure of the Russian hut, to the design of the sleigh, to the features of the Russian bath. He also introduces original Russian words into the description of various phenomena, such as pirozhki, snetki, luchina, kvas, tulup, balalajka, and tries to explain the meaning of these words to the reader. But the people with whom he had to interact during his journey played the main role in his narrative. In the Introduction to his book, Chappe d'Auteroche) 
explains his interest in the Russian people as follows: "humanity, considered in the voyages from different points of view, offers the most interesting picture, and the most suitable for the education of men \& to direct them towards happiness" (d'Auteroche, 1768: 1). These ideas correspond closely to the texts of chevalier de Jaucourt.

However, in his strive to pursue educational goals, the abbot remains subjective in his statements: the ignorance of the Russian language did not allow him to understand the essence of national Russian culture and many its phenomena. He reduced the description of Easter to a farce, and the traditions of the Russian wedding seem to him rather meaningless. At the same time while analyzing the way of life of the peasants, Chappe d'Auteroche used a completely traditional method dealing with the extrapolation of the traits and qualities of individuals for the whole population.

The language of Voyage en Sibérie is vivid, the text is built on the principle of a constant change of scenery, and the lengthy descriptions that sometimes occur in it are interpreted by the author ironically.

\section{Illustrations to the text}

Illustrations by J.-B. Le Prince, provide visual accompaniment to the text. In the Rosenbach Museum and Library in Philadelphia are preserved 32 preparatory drawings created by Le Prince as samples for future illustrations. It is these drawings that will become the object of this research.

During the work on the book the drawings were etched by various masters, among whom it is necessary to name J.-B. Tilliard (1740-1830), who made 32 etchings, independently and 2 in collaboration with his wife, and J.-F. Le Bas (1707-1783), to whose cutting tool belong 4 engravings.

The drawings later became a part of the Roederer Collection, that was, according to Kimerly Rorschach (Rorschach, 1985), one of the finest and most comprehensive collections of eighteenth-century French drawings, prints, and illustrated books ever assembled. According to some documents of the Rosenbach Company archives at the Rosenbach Museum and Library this collection contained some 6000 books, 1000 drawings, and 750 prints. In. 1922 it was acquired by Dr. A. S. W. Rosenbach. This important American rare book dealer and collector sold many items from this collection; However, he kept a few drawings, prints, and books for himself. Nowadays these works belong to the Rosenbach Museum and Library, among which are Le Prince's drawings.

Although Le Prince's drawings are connected with the text, they do not strictly follow the logic of the narrative, they create their own narrative series. Just like the text, these images are aimed at solving the educational problem by visual means. I strongly believe that these works correspond to the genre of costume images that was widespread in $18^{\text {th }}$ century art in Europe.

The first definition of costume images translated into Russian language can be found in the dictionary part of the Dmitrij Alekseevich Golisyn's book (Golisyn, 1767-1768). At present "The description of the prominent schools and their painters and about others" of 1767-1768 by Golisyn is considered to be one of the first essays on art history in Russia. According to Golisyn, the term "costume" was taken from the Italian language and "signified the similarity of the presented plot with a historical adventure on the occasion of manners, characters, fashions, customs, clothes, weapons, structures, laws, tastes, fruits, fruits, animals, circumstances of the place, and time where the action took place, etc." (Kaganovich, 1963: 312).

A more detailed description of this genre can be found in an article written by Louis de Jaucourt for the Encyclopédie (de Jaucourt, 1754). According to de Jaucourt, the costume assumes an accurate and detailed display of the inclinations, mores, laws, characters and habits 
of the inhabitants of the depicted country. The costume has to correspond to a certain epoch not to distort the historical facts, and properly depict the material objects. At the same time, Chevalier de Jaucourt notes that the author of the costume had to clearly define the scene, time and occupation of the characters represented.

\begin{abstract}
"Le costume est l'art de traiter un sujet dans toute la vérité historique : c'est donc, comme le définit fort bien l'auteur du dictionnaire des Beaux-arts, l'observation exacte de ce qui est, suivant le tem, le génie, les mœurs, les lois, le goût, les richesses, le caractere \& les habitudes d'un pays où l'on place la scene d'un tableau. Le costume renferme encore tout ce qui regarde la chronologie, \& la vérité de certains faits connus de tout le monde ; enfin tout ce qui concerne la qualité, la nature, \& la propriété essentielle des objets qu'on représente... Il faut de plus représenter les lieux où l'action s'est passée, tels qu'ils ont été, si nous en avons connoissance ; \& quand il n'en est pas demeuré de notion précise, il faut, en imaginant leur disposition, prendre garde à ne se point trouver en contradiction avec ce qu'on en peut savoir" (de Jaucourt, 1754: 298).
\end{abstract}

Such definitions of the costume genre allow us to speak of it as a kind of "protoethnography" and "the foundation of ethnography". After all, it is due to the wide development of the costume genre and competent descriptions of the far away countries it was possible to accumulate material and written sources to become the foundation of Modern history, and ethnography as well.

It is interesting to notice that the definitions of costume image do not regulate its formal features and construction, that allows us to interpret this genre extremely widely. Costume genre is used in the scenes dealing with interior, pastorals, landscape, one-figure and multi-figure compositions, as well as a portrait.

Although, the feature of the costume is the most accurate and detailed fixation of the most typical lifestyle, as well as the creation of unique collective characters, it does not transfer the individuality of a person. In this case, the artistic image is created within the framework of scientific interests in collecting information.

It is noteworthy that Le Prince was not the first foreign artist to use costume genre for the Russian peasants' representation. A. Dalshtein dealt with it. However, it was Le Prince who, for certain reasons, came down in history as the initiator of the "Russian theme" in Western art. Unlike A. Dahlstein, whose engravings remained unknown to the general public and researchers for a long time, Le Prince's series were very popular among his contemporaries, both in France and in Russia. The treatise Voyage en Sibérie was reprinted several times: in 1771 in Amsterdam and in 1772 in London. Both books are smaller in size and accompanied by a selected number of Le Prince's illustrations. It is noteworthy that while working on the illustrations commissioned by the Chappe d'Auteroche, Le Prince created several independent series of costumes depicting Russian townspeople and villagers. These series, while creating additional illustrative material to the text, fueled the interest of the treatise's potential readers.

While working on the illustrations, Le Prince focuses on the detailed rendering of the space surrounding the personages and with its help he characterizes the way of life of the Russian people.

In numerous drawings one can find recurring motifs that move from image to image, becoming indispensable attributes of peasant life. It was typical for Le Prince in his representation of the Russian stove, the baby cradle suspended from the ceiling and a plank-bed under the ceiling (Fig. 4.1).

Le Prince endows his figures with typical qualities and poses, showing them and their costumes. The clothes of his figures are detailed but their poses are often frozen, and their faces do not express any individualized emotions. It is interesting to notice that while creating 
preparatory drawings for etchings, Le Prince sketches the faces as schematically as possible, leaving their details to the etchers (Fig. 4.2-4.4).

At the same time, these illustrations have a certain artistic merit. In terms of style, they can be considered as an example of the Rococo style, flourishing at that time in European arts. The painter focuses on female and child images correlating with the style's aesthetics (Fig. 4.5). While working with the nude, Le Prince creates figures that tease with their sensuality and graceful tenderness and captivate with their charming roundness (Fig. 4.6). At the same time, developing multi-figured compositions, the artist creates idyllic scenes filled with universal peace, which corresponds to the tasks of the rocaille pastoral.

I believe that it is the direct comparison of text and drawings that helps reveal the relationship between the images of Russia and the Russian people, created by Le Prince and Chappe d'Auteroche. In his travel notes, Chappe d'Auteroche leaves a detailed description of a peasant family with which he once stayed for the night: "The first thing that struck me when I stepped inside was the figure of an old woman. Swinging the child in the hanging box, she dozed off. Her wrinkled smoked with stove smoke skin, was a disgusting sight, and the ridiculous outfit further aggravated the ugliness. Nearby, a young woman rose on a bench, more eager to satisfy her curiosity than to bring her open shirt back into proper shape, except for which she was wearing nothing. This mess in clothes and free behavior revealed all the delights inherent in her years... Near the bench the small children were sleeping right on the floor, just like calves in a barn; the rest of the household huddled side by side on the stove and the plank-beds, some were asleep, others were staring at me, surprised at the invasion of their home no less than I was by the entire scene and faces of the people in front of me" (d'Auteroche, 1768: 63-64).

Following the narrative of the abbot, Le Prince creates an interior scene of the Russian dwelling (Fig. 4.7) that fully corresponds to the content of the text. However, despite the detailed specification, the image makes a different impression than the text. The old woman, whose appearance so strongly impressed Chappe d'Auteroche, is represented as a neutral character. The artist is not interested in the theme of ugliness; in her depiction, Le Prince focuses on the peculiarities of her dress. The figures of the mother and children in the center of the composition can hardly be perceived as the representation of the Russian peasantry. Yakov Bruk, an important Russian art historian, noticed that in terms of style they resemble the characters of Fragonard and Boucher (Bruk, 1990: 67). The artist ennobles his figures. Their gestures are theatrical, so are their emotions. The exotic world of the Russian hut plays an important role in Le Prince's conception: the stove, the plank-beds, the wooden floors, as well as pots scattered on the floor create a sense of contrast and further emphasize the alien character of the characters. That seems to be the consequence the French artist's perception of the peculiarities of the life of Russian peasants through the prism of the Rococo style.

\section{Results}

While working on the first edition of the Voyage en Sibérie, abbot Jean Chappe d'Auteroche and Jean Baptiste Le Prince pursued the same educational and enlightening goals consistent with the ideas of the European Enlightenment. The abbot's travel notes, and the artist's costume images are traced same source and their desire to know and understand a distant, littlestudied country. However, while the work of Chappe d'Auteroche seems to be a meticulous but sometimes haphazard collection of information on the basis of which a scholar seeks to construct casual relationships. And in his language, there is clearly a sense of the superiority of an enlightened European man over ignorant peasant. In Le Prince's drawings, the cognitive and artistic aspects are merged into one. The goals of literal similarity and closeness to nature in his works are closely intertwined with the aesthetic views of the Rococo master. His figures are interesting and pleasant, and the place of action is sometimes perceived as a kind of fantasy which 
completely contradicts to the vision to the down-to-earth approach of Chappe d'Auteroche. Thus, we can say that on the pages of the treatise Voyage en Sibérie there are two phenomena related to each other by their tasks, but at the same time, fundamentally opposed to each other in their attitude towards the subject.

\section{Discussion}

The significance of this research lies in two main ideas.

Firstly, I have made an attempt to understand and explain the essentials of the costume image based on the theoretical works of the Age of Enlightenment. Such a research seems to be timely, as at present the costume images are most often considered as an important source of information for the ethnography dealing with the life and appearance of different nations' representatives. However, these images are rarely considered as an inherently valuable, independent phenomenon, standing at the intersection of fine arts and science. This article is intended to show the characteristic features of these images and partly reconstruct their functions and comprehensions in the $18^{\text {th }}$ century. It is important to notice that costume images were really closely interacted with the text in the $18^{\text {th }}$ century. The role of the text in this case was quite variable: the costume images could act as illustrations, complementing detailed travel notes or they could be bound into a separate album and were accompanied by captions explaining the content. In this work, I would like to present one of the possible ways of talking about this type of images, based on the word-image interaction.

Secondly, I think that this work can be considered as a significant step in the research of Le Prince's "Russerie" which is becoming an important artistic genre consisting in a detailed depiction of Russian reality seen by the French artist. It is noteworthy that in the following decade after returning to France, Le Prince was totally absorbed with this theme. It became the main one in his work and united different types of fine arts: graphics and painting. The illustrations for the treatise Voyage en Sibérie were among the first examples of "Russerie" in Le Prince's career. And, thus, we can say that it was during the work on the book that Le Prince first found a theme that would become the key to his further work.

\section{Conclusion}

This article presents the research of the treatise Voyage en Sibérie, its content and decoration, created by Jean Chappe d'Auteroche and by Jean-Baptiste Le Prince. Particular attention is paid to the decoration of the first edition of the treatise, made by M. Le Prince. In this article, for the first time, is raised the idea that Le Prince's illustrations can be considered as an example of the costume genre, which tasks were correlating with the ideas of the Age of Enlightenment about the knowledge of the world. Le Prince's illustrations thus enter into dialogue with the travel notes and sometimes even create an image completely opposite to the narrative.

\section{Acknowledgements}

I would like to thank PhD in Philology, Dr. Habil, Professor Alla Petrovna MinyarBeloroucheva and Professor Andrey Aleksandrovich Karev, holder of an Advanced Doctorate in Art History, for their support and encouragement in the publication of this article. I would also like to mention the support from Elizabeth E. Fuller from the Rosenbach Museum and Library in Philadelphia, who gave me an access to amazing Le Prince's drawings.

This research did not receive any specific grant from funding agencies in the public commercial, or not-for-profit sectors.

The author declares no competing interests. 


\section{References}

Brook, Ya. (1990). U istokov russkogo zhanra. XVIII vek [At the origins of the Russian genre]. Moscow: "Art".

Carrer d `Ancos, E. (2005). Imperatricza i abbat. Neizdannaya literaturnaya due `l Ekateriny `II i abbata Shappa d'Otrosha [The Empress and the Abbot. An unpublished literary duel between Catherine II and the Abbe Chappe d'Auteroche]. Moscow: OLMA-press.

D'Auteroche Chappe, J. (1768).Voyage en Sibérie fait par ordre du roi en 1761. Paris: Chez Debure.

Ferrone, V., \& Roche, D. (2003). Mir Prosveshcheniya. Istoricheskiy slovar [The World of Enlightenment. Historical dictionary]. Moscow: Monuments of historical thought.

Guilbaud, A., Leca-Tsimonis, M., Passeron, I., Cernuschi, A., Hain, M., Le Sueur, C., \& Sandried, A. (2017). L'Édition numérique collaborative et critique de l'Encyclopédie (ENCCRE) Retrieved 15 November 2020, from http://enccre.academie-sciences.fr/encyclopedie/.

Kaganovich, A. (1963). Anton Losenko i russkoe iskusstvo serediny `XVIII stoletiya [Anton Losenko and Russian art of the mid-18 $8^{\text {th }}$ century]. Moscow: Publishing house of the USSR Academy of arts.

Liechtenhan, F. (2002). Le mythe russe, ou l’esprit philosophique. Pinakotheke, №13-14, 36-42.

Proskurina, V. (2017). Imperiya pera Ekateriny `II: literatura kak politika [The Empire of Catherine II's pen: Literature as politics]. Moscow: New literary review.

Rorschach, K. (1985). Eighteenth-century French book illustration. Philadelphia: Rosenbach Museum and Library.

Rorschach, K. (1986). Drawings by Jean-Baptiste Le Prince for the Voyage en Sibérie. Philadelphia: Rosenbach Museum \& Library. 
E. Panova - Word-image Interaction in the Treatise "Voyage en Sibérie"

C O A $\mathrm{s}$ 


\title{
Particularities of Defense in Judicial Rhetoric
}

\author{
Ekaterina Korobova \\ The Military University of the Ministry of Defense of the Russian Federation \\ Department of Foreign Languages, Moscow, RUSSIAN FEDERATION
}

Received: 28 November 2020 - Accepted: 22 December 2020 - Published Online: 25 December 2020

\section{Abstract}

\begin{abstract}
The article examines the linguistic particularities of defense in judicial rhetoric that have not considerably changed since Antiquity. As at present the interest in judicial rhetoric has increased, it is necessary to carry out its comprehensive analysis with the consideration of its modern modifications. In the course of history, judicial rhetoric has preserved its main rules to be used in Modern Times by Western culture advocates for defense purposes. Special attention is paid to stylistic devices, phonetic means and linguistic features to discern that are most frequently used by the advocates in their defense speeches. As stylistic devices are the best means of persuasion of the jurors and public in court, they are indispensable in advocates' defense speeches and are the focus of the given paper. As the advocates' defense speeches concentrate mainly on persuasion and thus with emotions rather than reason the author focuses on the expressive language means.
\end{abstract}

Keywords: judicial rhetoric, defense speeches, persuasion, stylistic devices.

\section{Introduction}

At present judicial rhetoric is the focus of research interest of linguists and lawyers. Traditionally judicial rhetoric is classified into accusatory rhetoric and defending rhetoric. The aim of judicial rhetoric is to persuade the jurors and public of the innocence of the defendants. Court speeches of talented defense counsels are deeply psychological, as their purpose is persuasion. In this case, evidentiary material of defense counsels' speeches is more important than psychological analysis.

The basis of any defense counsels' speech is a literary language. However, the specificity of legal speech is that it combines elements of different functional styles: conversational, artistic, journalistic, and official. Judicial speech, being one of the most striking, is also the most responsible, since the life and fate of a person depends on it. The communicative qualities of judicial speech: clarity (accessibility, simplicity), precision, persuasiveness, logic, emotionality and expressiveness allow the court speaker to make the speech truly evidentiary. These qualities of judicial speech are closely interrelated and in dialectical unity.

Features of legal speech as a type of oral public statements are determined by the general goals and specific tasks of justice. A high professional level of judicial rhetoric can be achieved only if the speaker abides not only by legal, but stylistic and linguistic norms as well. The quality of legal speech delivery is influenced by the speaker's erudition and professional skills, his

(C) Authors. Terms and conditions of Creative Commons Attribution 4.0 International (CC BY 4.0) apply. Correspondence: Ekaterina Korobova (MA), The Military University of the Ministry of Defense of the Russian Federation, Department of Foreign Languages, Moscow, RUSSIAN FEDERATION. E-mail: katherinaoo@mail.ru. 
ability to speak publicly, and his preparation for speech. The speaker must take into account the time and place of the speech, the composition and mood of the target audience. Only real speakers know when to strictly follow the rules, and when they can be slightly violated.

- Rhetoric, which is now regarded as an art of effective communication, was studied in Ancient Greece and Rome from about the fifth century BCE until the early Middle Ages, primarily intended to help citizens assert their rights in court.

- Court speech can be accusatory or defense. The content of the defense speech usually consists of a brief social and political description of the case and a detailed analysis of factual data and analysis of evidence with conclusions about the event of the crime and the defendant's guilt, the qualification of the crime and conclusions about the measure of punishment from the point of view of a defendant's interests.

- A court speech is a monologue that forms a part of the dialogue that is conducted between the Prosecutor and the lawyers throughout the entire judicial investigation. The dialogue manifests itself in the investigation of the case materials from the point of view of the prosecution and defense, in the application of petitions. It ends in court debates, when opinions of the opponents are finally determined and argued.

\section{Methods of investigation}

To analyze judicial rhetoric in particular a speech for defense, such methods of investigation as rhetoric, stylistic, component, contextual and structural text analysis were used. When identifying interpretative axiological markers of judicial rhetoric, the method of content analysis was applied, with the basis on which conceptual maps of the texts for defense were compiled. The method of identifying words, i.e. the method of semantic prototype was also used to identify the levels of interpretative understanding of axiological markers of the judicial discourse.

\section{Results and discussion}

\subsection{Rhetoric as theory and art of speech}

Rhetoric is the theory and art of speech, a fundamental science that studies the objective laws and rules of speech, since speech is a tool for managing and organizing social and industrial processes. The word rhetoric originates from Greek "rhetorike", which came into use in Socrates' circle in the fifth century BCE. It first appears in Plato's dialogue Gorgias, created around 385 BCE. Rhetoric means the art of public speaking, which developed at different meetings, in courts, and other official cases under the constitutional government in the Greek Polis during the Athenian democracy.

Rhetoric, which is now regarded as an art of effective communication, was studied in Ancient Greece and Rome from about the fifth century BCE until the early Middle Ages, primarily intended to help citizens assert their rights in court. Although the first teachers of rhetoric, known as sophists, were criticized by Plato and other philosophers, the study of rhetoric soon became the cornerstone of classical education. Modern theories of oral and written communication are still strongly influenced by the basic rhetorical principles introduced in Ancient Greece by Plato, Isocrates, and Aristotle, and in Rome by Cicero and Quintilian. Here we will briefly introduce these key figures and identify some of their Central ideas.

Plato (428-348 BCE), a disciple (or at least like-minded person) of the great Athenian philosopher Socrates, expressed his disdain for false rhetoric in his early work Gorgias. In a later work, Phaedrus, he developed a philosophical rhetoric that called for studying the souls of people in order to discover the truth. 
"[Rhetoric] it seems to me then ... to be a pursuit that is not a matter of art, but shows a shrewd, gallant spirit that has a natural tendency to treat humanity intelligently, and I sum up its essence in the name of flattery. Well, you've heard what I call rhetoric - the equivalent of cooking in the soul, acting here as it does to the body" (Plato, 1987).

Even in antiquity, philosophers clearly realized that speech is perceived differently by each person. Thus, Plato in his work Phaedrus writes about the need to know the speaker, to know what types of soul exist, since the function of oratory is to influence the souls of people so that they can be easily persuaded (Plato, 1997).

Aristotle (384-322 BCE), Plato's best disciple, was the first to work out the first systematic and comprehensive treatise of rhetoric. In his lectures known as Rhetoric Aristotle developed the principles of argumentation that are still valid at present. In the preface to Aristotle's treatise Rhetoric it is written that rhetoric may seem a curious medley of literary criticism with second-rate logic, ethics, politics, and jurisprudence, mixed with the cunning of one who knows well how to play on the weaknesses of the human heart. The treatise was written only for practical purpose to be a guideline for an orator. Although Aristotle's work intended for Greek society, it is used at present as well. Aristotle defined rhetoric as the ability to see what is possibly persuasive in every given case (Aristotle, 1978).

Cicero (106-43 BCE), a Roman politician, was the greatest orator and theoretician of ancient rhetoric of all times. In his treatise De Oratore Cicero established the qualities indispensable for an ideal orator (Cicero, 2001).

"There is a scientific system of policy that includes many important departments. One of these departments - large and important - is eloquence based on the rules of the art, which they call rhetoric. For I do not agree with those who think that political science does not need eloquence, and I strongly disagree with those who think that it is fully comprehended by the power and skill of the rhetorician. Therefore, we will classify oratorical ability as a part of political science. The function of eloquence seems to be to speak in a manner suitable for persuading the audience, and the goal is to persuade by speech.” (Cicero, 2002)

"The man of eloquence whom we seek, following the advice of Antony, will be one who is able to speak in court or in deliberative bodies to prove, please or persuade. To prove is the first necessity, to please is the charm, to incline is the victory, for this is the only thing that helps most in the verdicts of the winners. For these three functions of the speaker, there are three styles: the simple style for proof, the medium style for pleasure, and the vigorous style for persuasion; and in the latter the whole virtue of the speaker is summed up. Now the man who controls and combines these three different styles needs rare judgment and great endowment; for he will decide what is necessary at any moment, and will be able to speak in any way that the case requires. For, after all, the foundation of eloquence, like everything else, is wisdom. In speech, as in life, nothing is more difficult than to determine what is appropriate." (Cicero, 2001)

The fame of Marcus Fabius Quintilianus (35-10o CE), a Roman rhetorician, is based on his work Institutio Oratoria, a collection of the best examples of ancient rhetorical theory. "For my part, I have taken it upon myself to form an ideal speaker, and since my first wish is for him to be a good person, I will return to those who have more sound opinions on the subject... The definition that best matches its real character is what makes rhetoric the science of good speaking. For this definition includes all the virtues of oratory, as well as the character of the speaker, since no one can speak well if he is not a good person" (Quintilian, 2016).

Saint Augustine of Hippo (lat. Aurelius Augustinus Hipponensis) (354-430) had studied law and had been teaching rhetoric in North Africa for ten years before he began his 
studies with Ambrose, Bishop of Milan and an eloquent orator. In the fourth book of De Doctrina Christiana, Augustine justifies the use of rhetoric to spread Christianity. "After all, the universal task of eloquence, in any of these three styles, is to speak in a way that is persuasive. The goal... is to convince by speaking. In any of these three styles, it is true that an eloquent person speaks in a way that is oriented towards persuasion, but if he does not actually convince, he does not achieve the goal of eloquence" (Augustine, 1995).

There were textbooks on oratory in Ancient Greece and teaching rhetoric was the crown of ancient education. In the book Rhetoric written in the $4^{\text {th }}$ century BCE, Aristotle summarized and developed the theoretical aspects of oratory. According to the classification adopted by Aristotle, all public speeches were divided into three types: deliberative, judicial, and ceremonial (Aristotle, 1978). The task of deliberative speeches is to incline or reject, judicial speeches - to accuse or justify, ceremonial speeches - to praise or blame. A particularly common type of oratory was judicial speech.

\subsection{The essence of judicial rhetoric}

Judicial speech is determined by the specifics of its content (Minyar-Beloroucheva et al., 2010). Law is nothing more than a set of rules and norms of behavior established and protected by the state that regulate public relations between people and express the will of the state (Marchenko, 2017: 76; Nersesyants, 2005: 48). The formation and formulation of such rules requires a comprehensive knowledge of various aspects of language culture. For a lawyer, perfect language proficiency is one of the primary professional needs. This was well understood in Ancient Greece, where the art of public speaking was highly valued and opened the way to power. Political figures had to influence the People's Assembly, which consisted of free citizens, who, in their turn, periodically had to appear in court.

The court speaker analyzes and evaluates the circumstances of the case and formulates certain conclusions that may be ambiguous. One and the same fact can be presented differently by participants in court debates, without being distorted. The content of a court speech should be understood primarily as the information contained in this public speech (Gorsky et al., 1973). Informative public speaking, in its turn, is determined by a number of characteristics, among which are: the relevance (social value) of the subject statements, informativeness, credibility, coherence and language precision. Elements of colloquial, artistic, official and journalistic speech are synthesized in court speech. The latter is addressed to specific individuals in order to inform the audience of certain information, to convince them of something, to encourage them to commit certain actions. In the court speech, the speaker's attitude to a committed crime is necessarily expressed. Thus, in judicial speech, the function of communication and the function of influence are in dialectical unity and maintain a certain balance.

\subsection{Types of court speeches}

Court speech can be accusatory or defense. After a few introductory remarks, the speaker proceeds to examine the facts of the case directly. The content of the accusatory speech usually consists of a brief social and political description of the case, a detailed analysis of factual data and analysis of evidence with conclusions about the event of the crime and the defendant's guilt, the qualification of the crime and conclusions about the measure of punishment. The same elements should be present in the content of the defense speech, with the only difference that all the facts in the defense speech are considered from the point of view of a defendant's interests. Judicial speech is the most important means of argumentation, so it is unacceptable to violate the basic laws of logic. 
The most important characteristics of the form of judicial speech are compositional and logical construction, expressiveness, purity, precision, emotionality, elocution, speech technique, audience management technique. Three main parts are distinguished in the compositional and logical construction of judicial speech. They are the introduction, the main part, and the conclusion (Gubaeva, 1990).

The purpose of the speech, which determines its introductory part, contains initial provisions for further study of the circumstances of the case and a problem for which it is necessary to find a solution. A conflict which the court speech is based on must necessarily be reproduced in the introduction and connected with the main part, and at the same time be concise. However, the speaker needs to keep it throughout the speech by focusing the court's attention on the introduction. This is facilitated by the logic of the statement, when the speaker's thought should move from the old to the new, from the familiar to the unknown, from weaker arguments to stronger ones. The presence of a conflict situation, the presentation of facts in opposition also contribute to maintaining attention.

Judicial speech is a combination of logical units that manifest some of its microthemes, meaningfully and syntactically combined with one another. These parts consist of: (1) a Statement of the actual circumstances of the case; (2) Analysis of the evidence collected in the case; (3) Justification of the crime qualification; (4) Characteristics of the defendant's personality; (5) Reasons for committing the crime; and (6) Considerations on the punishment (Kokhtev, 1992).

The main part of the court speech is based on the rules determined by its purpose. The logic of reasoning goes from statement to refutation and proof, with the strongest arguments and proofs given at the end of the speech. Since the audience listens most attentively in the middle of the time allotted for the speech, all the most important and complex things that the speaker has to present fall on the main part, which consists of analyzing and evaluating the evidence. The conclusion is usually concise, summarizing what has been said, and ending with an appeal to the jury for a fair verdict. The introduction and conclusion are designed to have a psychological effect on the jurors.

\subsection{Types of rhetorical persuasion}

The court speech must be convincing. Persuasion is achieved in two ways - rational and emotional (Odintsovo, 1973). The analysis of indirect evidence is believed to use logical methods of influence with a clear plot of the case - emotional and expressive means of influence. Undoubtedly, rational influence is the main thing in judicial speech, it is achieved by organizing the material on the basis of reliable facts, logical evidence. At the same time, the court speaker must take into account the age, emotional state, level of attention, degree of fatigue, readiness to interact and interest of his listeners (Alekseev et al., 1989).

Expressive and emotional impact in judicial speech is achieved by using visual and expressive means of language, such as metaphor, antithesis, parallelism, hyperbole, comparison, irony, etc. (Odintsovo, 1973).

Methods of expressive and emotional influence also include addressing to the judge and jury: "Your Honor, Mr. Foreman and Gentlemen!", using pronouns: You, Your, imperative and motivational verbs: “...bring your hearts and your homes and your intellects here”, “... let us talk to you as men...”, expressing a personal attitude to the analyzed material: I say, I think, intimization, etc. The lawyer always seeks to involve the members of the court in the course of their arguments, and this is why he uses intimization. Using the "inclusive" pronoun "we", the lawyer thus unconsciously unites himself with the jury, puts himself and them on the same side, and simultaneously opposes himself to the Prosecutor and his supporters with the pronoun "they". 
It should be noted that the accusatory speech is characterized by a more categorical judgment than the defense one. In defense speech, categorical language is not always present. Modal verbs make advocates' statements less categorical: "He might have done it for pure deviltry, without a motive" or: "He may have done it in insanity".

The speaker resorts to the use of rhetorical questions that convey affirmative or negative information in an expressive form in order to maintain interest in speech, activate the attention of listeners, and promote a lively perception of the message (Shustova, 1990). When discussing with his opponent, a judicial speaker often turns to rhetorical questions that allow the listeners to convincingly deny the opposite point of view in an expressive and emotional form.

"Who could have done such an act?"

"In the quiet of the home, in the broad day light of an August day, on the street of a popular city, with houses within a stone's throw, nay, almost within touch, who could have done it?"

"Who are you twelve men, and how come you here? Selected out of 150 that were drawn from the body of this county, passing the gauntlet of criticisms, questions, and objections put upon you by the Court or the attorneys, you are sworn here in this cause. Who are you?" (Lizzie Andrew, URL).

It is noteworthy that in the last example, the defender uses the old English form of constructing the question "how come you here" - there is no auxiliary verb. If we take into account the following metaphor "the gauntlet of criticisms" ("gauntlet" - a knight's glove), we can assume that the speaker thereby seeks to evoke associations with the old English traditions of chivalry and justice.

\subsubsection{Linguistic features of court speeches}

The personification of inanimate objects is quite common technique in English: blood speaks out; murders did not tell any tales.

In order to influence the court audience, lawyers use irony. By means of ridiculing they can achieve an objective assessment of the actions of the defendants by the jury. In this example, an American lawyer is ironic about the Prosecutor and the police of the small city where the crime occurred, and about their evidence concerning guilt of the accused:

"In the first place, they say she was in the house in the forenoon. Well, that may look to you like a very wrong place for her to be in. But it is her own home. I suspect you have a kind of an impression that it would be a little better for her than it would be to be out traveling the streets. I don't know where I would want my daughter to be, at home ordinarily, or where it would speak more for her honor and care, and reflect somewhat of credit upon me and her mother, (who is my wife, I want to say), than to say that she was at home, attending to the ordinary vocations of life, as a dutiful member of the household, as belonging there. So, I do not think there is any criminal look about that. She was at home?" (Lizzie Andrew, URL).

Arguing about one of the theories put forward by the police, the lawyer openly mocks the prosecution:

"Well, we thought the handle was in there. We thought that was the plan, that the Government possessed itself with the idea that that handle was rolled up by the defendant in a piece of paper and put down in there to burn, and it had all burned up except the envelope of paper. Did you ever see such a funny fire in the world? What a funny fire that was! A hardwood stick inside the newspaper, and the hard wood stick would go out beyond recall, and the newspaper that lives forever would stay there! What a funny idea! What a theory that is!" (Lizzie Andrew, URL).

In this way the defense lawyer discredits the prosecution in the eyes of the jury: 
"Well, they will go another step yet in their theory, I think likely. I would not wonder if they are going to claim that this woman denuded herself and did not have any dress on at all when she committed either murder. The heart waits to learn what theories they will get up about this woman without evidence. First, create your monster, and then put into him the devil's instincts and purposes, and you have created a character. But start with a woman, with woman's impulses and a daughter's love, and your imaginings are foreign and base" (Lizzie Andrew, URL).

Judicial speech addressed primarily to the court is focused on establishing the truth. The response to this truth is the verdict brought by the court, in which qualification of the crime and penalty are largely determined by the speech of the lawyer. A court speech is a monologue that forms a part of the dialogue that is conducted between the Prosecutor and the lawyers throughout the entire judicial investigation. The dialogue manifests itself in the investigation of the case materials from the point of view of the prosecution and defense, in the application of petitions. It ends in court debates, when opinions of the opponents are finally determined and argued (Roman, 1990).

\subsubsection{Stylistic devices of judicial rhetoric}

As a rule, attention of the audience is drawn to what the speaker emphasizes. This can be achieved through the use of anaphora, which increases not only the expression, but also the persuasiveness of speech:

"You come here in obedience to the law that we prescribe for the orderly administration of our courts. You come here because, in answer to the demand, you feel that you must render this great service, unpleasant and trying as it may be, exhaustive as are its labors; you come here because you are loyal men to the State" (Lizzie Andrew, URL).

Along with anaphora, this example clearly shows gradation.

A quotation is often used in court speech. Since it comes from an authoritative person it confirms the speaker's point of view, convinces the audience. The speakers should not only include quotes in their speech, but also comment on them and express their attitude to them. Thus, it becomes easier to convey a certain message to the audience. But quotes are not always appropriate and not everywhere. A speech exaggerated with quotes reduces its expressiveness and perception. The listener can't understand where the thoughts of the speaker are, and, of course, begins to feel distrust of him. Besides, the listener can associate the case with the cited work and its heroes, find an additional meaning, which is not a matter of law but is connected with the source of the quotation, and transfer this meaning into the spoken speech.

When using various speaking techniques, the court speaker should remember that they are determined by the content of speech. They are not prior but additional ones and are completely subordinate to the speaker's intention. Court speech that evokes emotions in the audience is perceived as emotionally expressive.

The language of law reflects the specifics of the subject. The formal nature of the language of law makes it less dependent on the context and situation of communication. At the same time, a widespread use of legal terms in the spoken language creates great opportunities for subjective assessment of their interpretation in the context of non-professional communication. The lawyer applies the means of legal technique in such a way that his reasoning is clearly constructed and connected with what has been mentioned before. It is built up in accordance with certain principles, the sequence of which will lead to conclusions and decisions. Legal inferences are not identical in legislative or judicial law, in abstract or casuistic law. The reasoning technique of a judge and that of a lawyer are not identical and differ from each other, just as the reasoning technique of a lawyer differs from that of a legal adviser or a legal scholar. But in any case, lawyers 
will rely primarily on legal logic, which includes two main elements: the technique of interpretation and the logic of argumentation, when they use various means and methods of constructing their reasoning (Vlasenko et al., 2001: 183-191).

In legal speech, cliches are often used. They have an imprint of the legal sphere of communication. Cliche is a mandatory item of a piece of legislation and procedural act and it promotes unambiguous compact expression of thought.

In his speech, the lawyer must select words carefully in order to reflect the rules of law correctly, when describing the actions of the accused or the defendant, when justifying the qualification of a crime. A lack of precision in the choice of words can lead to distorted conclusions.

Functional motivation is a general principle of using rhetorical figures in judicial speech. The speaker should use only appropriate rhetorical figures, which can be explained from emotional or semantic point of view, and are not used as a decoration of speech. Judicial rhetoric uses the technique of including "pictures" in speech to create the necessary emotional atmosphere. They are small artistically expressive sketches of individual episodes of the case. A court speaker must be a skilled storyteller when using this technique. If the objective facts of the process are expressive enough, they should be conveyed to the listener with the utmost directness, i.e. as simply as possible. If the event lacks emotional expressiveness, the speaker creates it with fictional, assumed sketches of circumstances. The best court speakers in such moments of the process avoid accurate descriptions, detailing, i.e. everything that deprives the "picture" of emotional and artistic expressiveness, which makes the "picture" a "scheme".

The art of conducting a dispute during the hearing of arguments is a special area of judicial rhetoric. Any judicial speech is essentially a dispute, so the ability to conduct a dispute is one of the essential advantages of a judicial speaker. A judicial dispute has its own specifics and particularities, the impossibility of postponement, it must be completed by discovering the truth. The main elements of a legal dispute are evidence and refutations. In the practice of prominent lawyers, the manner of presentation of the material (the predominance of logical or expressive ways of presentation), the choice of means of expression are largely determined by the speaker's personality and his inclination to a certain manner of speech construction.

Knowledge of the laws of language implies the observance of purity, precision and simplicity of the speech, since the main and final goal of any judicial speech is to be understood by those to whom it is addressed. The court speaker seems to lead the audience in his search for the truth, the only correct conclusion in the case. Undoubtedly, the need for proof and persuasion is the basis of judicial eloquence (Alekseev et al., 1989).

\subsubsection{Phonetic expressive means of judicial rhetoric}

The general tone of speech, its tempo, and the necessity of pauses in the semantic division of speech are also mandatory (Semikova, 1998: 123-127). There are techniques that are means of judicial speech expressiveness and enhance its emotional impact. These are: $a$ direct demand for attention; a pause that allows the speaker to highlight the main thing that follows it; voice techniques (the speaker raises or lowers his voice, changes the tempo); addressing the audience with a question related to the content of speech, which sharpens and attracts the audience's attention; pre-notification of what is to be said later; unexpected interruption of the idea; means of language expressiveness (Proverbs, sayings, humor); body language - gestures and movements (Alekseev et al., 1989).

The nature and scope of the case, the speaker's personality, and the court audience influence the content and form of judicial speech. Each of them also determines construction and presentation of the one. 
Knowledge of the most complex linguistic skills is required to convince judges and maximize the influence on the minds and feelings of citizens present in the courtroom. These skills would contribute to a clear semantic coherence of speech and express the logic of presentation. Special means of communication that indicate the sequence of thought development can be called important means of expressing logical connections between compositional parts and individual utterances (at first, in the beginning above all, first of all; primarily, chiefly, mainly, so, then, well, consequently, therefore, hence, now etc.), contradictory attitude (as has been said above; as it has been pointed out, therefore, and so, owing to the fact that, due to the fact that, in conformity (with), in accordance (with), etc.), result (thus, so; so then; well, then, now, in that way, so, in such a way; consequently, accordingly, hence; In conclusion it should be said that; In closing I want to say that; Summing up it should be underlined that; In the end / finally / in the long run / in the final analysis it should be pointed out that). Pronouns, adjectives, participles as well as logical questions can be used as communication tools. The role of interrogative constructions is determined both by the position in the text of judicial speech and by the communicative task. They pose problems and get new information in the form of a question. A problematic question used in the introduction of the court speech formulates the speaker's goal in a particular process, defines the task. Interrogative intonation allows the speaker to define the problem of the entire court session more expressively and helps to establish psychological contact between the communicator and the addressee.

\section{Conclusion}

So, oral public speech in court presupposes a situation of direct group communication. Informing, persuasion, and suggestion are the most significant means of speech influence on the audience. Therefore, we can say that any judicial speech should be aimed not only at transmitting objective information, but also at assessing events or phenomena. An inaccurate choice of words can lead to erroneous conclusions and wrong verdict.

An advocate's speech in court is addressed not only to the mind, but also to the feelings of the audience: participants of the trial and public in the courtroom. It uses persuasion and suggestion, which are closely interrelated and complement each other. The persuasion is addressed to the consciousness of each person, it is always supported by arguments, facts and evidence.

Logical reasons, arguments, and evidence are widely used in judicial speech. In order to convince the audience, it is necessary to make them agree with the defendant's opinions, views, and conclusions and make them accept the ones as their own. The speaker must compose his speech and arrange the evidence in such a way that the persuasiveness of the speech could grow as it is delivered. In defense speeches in court stylistic figures are widely used, in which imagery is achieved by the general composition of the utterance.

Defense speech is built not only on the basis of the interaction of rational and emotional layer, logical elements are developed taking into account the expressive capabilities of the language. The use of rhetorical figures in defense speech can be functionally justified if they are used by the speaker to achieve the goal, but not for the sake of embellishing the utterance.

\section{Acknowledgements}

This research did not receive any specific grant from funding agencies in the public commercial, or not-for-profit sectors.

The author declares no competing interests. 


\section{References}

Augustine (1995). De doctrina Christiana. Oxford early Christian texts. R. P. H. Green (Ed. and Trans.). Oxford: Clarendon Press.

Alekseev, N. S., Makarova, Z.V. (1989). Oratorical art in court. Leningrad: Leningrad University.

Aristotle (1978). Rhetoric - Ancient rhetoric. Moscow.

Cicero, Marcus Tullius (2002). De Inventione. Venezia: Baptista de Tortis.

Cicero, Marcus Tullius (2001). On the ideal orator. Translated by J. M. May and J. Wisse. Oxford University Press.

Gorsky, G. F., Kokorev, L. D., \& Kotov, D. P. (1973). Judicial ethics. Voronezh: Voronezh University.

Gubaeva, T. V. (1990). Practical course of the Russian language for lawyers. Kazan: Kazan University.

Kokhtev, N. N. (1992). Oratorical speech: Style and composition. Moscow: Lomonosov Moscow State University.

Lizzie Andrew (2020). Borden Virtual Museum and Library. URL: http://lizzieandrewborden.com (accessed 20 September 2020).

Minyar-Beloroucheva, A. P., Korobova, E. A., \& Bykova A. A. (2010) Principles of construction of the American judicial speech in the $19^{\text {th }}$ century. Bulletin of the South Ural State University. Series: Linguistics, SUSU Publishing House (Chelyabinsk), 1O(1) (177), 51-56.

Marchenko, M. N. (2017) Theory of state and law. Moscow: Lomonosov Moscow State University.

Nersesyants V. S. (2005). Philosophy of Law. Moscow: Norma.

Odintsovo, V. V. (2004). Stylistic analysis of public speech. Moscow: URSS.

Plato (1987). Gorgias. D. J. Zeyl translation. Indianapolis: Hackett.

Plato (1997). Phaedrus. Trans. by A. Nehamas and P. Woodruff. In J. M. Cooper (Ed.), Plato: Complete works.

Quintilian (2016). Quintilian on the teaching of speaking \& writing: Translations from Books One, Two \& Ten of the Institutio Oratoria, second edition. Translated by J. J. Murphy and C. Wiese. Carbondale: Southern Illinois University Press.

Roman, L. V. (1999) Metalanguage substantiality of the language of legal proceedings and speech aspects of its implementation. Abstract. PhD of Philology thesis. Krasnodar: Krasnodar University.

Semikova N. I. (1998). Pedagogical aspects of judicial rhetoric. In Topical issues of scientific research. Issue 2, part 1. Humanities. Saratov.

Shustova, M. L. (1990). Functions of interrogative constructions in judicial speech. In The status of stylistics in modern linguistics. Perm: Perm University.

Vlasenko, N.A., \& Magyarova, A. V. (2001). Technique of interpretation of normative legal acts in the legislation of the subjects of the Russian Federation. In V. M. Baranov (Ed.), Law-making techniques of modern Russia: State, problems, improvement: Collection of articles, in 2 Vols, Vol. 1. N. Novgorod. 


\title{
Feminization of Emigration
}

\author{
Petya Pachkova \\ South-West University "Neofit Rilski”, Blagoevgrad, BULGARIA \\ Faculty of Philosophy, Department of Philosophical and Political Sciences
}

Received: 11 October 2020 - Accepted: 27 November 2020 - Published Online: 25 December 2020

\section{Abstract}

The subject of study is the Bulgarian women, who for different, mainly economic, reasons emigrate to other countries and how this affects their social and psychological status. During the transition, immigration processes in Bulgaria accelerated. A special feature is the feminization of emigration. With this peculiarity, we get into the general flow of feminization of emigration around the world. Similar are some consequences of this feminization - breaking down families; keeping the children in the hands of spouses and parents who too often fail to cope with the challenge; bribery of children with dry money, which accustom them to laziness and to unacceptable and criminal activities; staying with the status of a non-married woman; loneliness etc.

Keywords: emigration, feminization, family, loneliness.

\section{Introduction}

One of the features of modern migration is its feminization. Due to the fact that the importance of this type of migration has increased over the last decades, its research is deepening.

According to widespread definition migration is a private solution to social problems (Castles \& Miller, 1998: 8). But it affects not only private individuals but also the whole society.

\section{Method}

The article was written based on the following research methods: or another in their lives;

- Conducted interviews with 15 Bulgarian women who were immigrants at one stage

- Literature research.

\section{Essence of feminization}

Until recently, women were mostly seen as accompanying their male immigrants. In addition, they too often work illegally, and this reduces the possibility of reliable statistical data

(C) Authors. Terms and conditions of Creative Commons Attribution 4.0 International (CC BY 4.0) apply. Correspondence: Assoc. Prof. Petya Pachkova (PhD), South-West University "Neofit Rilski”, Faculty of Philosophy, Department of Philosophical and Political Sciences, Blagoevgrad, BULGARIA. E-mail: pepun@abv.bg. 
for female migration. The focus on migration is slowly moving towards self-migrant women and illegal migrants as their role grows.

"The migration of large masses of people for reasons of religious, ethnic, political, military-political, etc. character has its origins since ancient times. However, international labor migration, which is mainly based on economic factors and motives, is a relatively new phenomenon that began in the early nineteenth century. Today, the international migration of labor resources can be interpreted as a global phenomenon, which in varying degrees and form affects a huge number of countries from all regions, encompasses significant social and professional qualifications groups" (Kaslz, 2001: 32).

"While the relative share of international migrants in the period 1965-1990 does not exceed 2.2-2.3\% of the world population, this share has increased significantly over the past 15 years and now stands at about 3.0\%" (see Marinov, 2007).

In order to resolve the emerging demographic problems and the need to provide labor resources highly developed countries such as the US and Canada, but mainly the EU countries are pursuing a consistent policy of systematically attracting economic migrants. This policy is reflected in the European Union's special multiannual "programs" from Tampere (1999), Hague (2004), Stockholm (2009). The "Open and Secure Europe: Making vision a reality program begins in 2014. In 2015, due to migratory events, the European Commission adopted a new "European Migration Program". It is significant that all "programs" point out as their main objective finding channels for "legal" migration needed to provide a minimum of 60 million migrants by 2050 " (Manov, 2015: 197-198).

"In modern conditions, immigration provides more than half of the demographic growth in developed countries (including around 90\% in Europe). By the year 2000, the share of immigrants in the total population of a number of developed countries reached high levels (Australia - 23.6\%, Switzerland - 19.3\%, Canada - 17.4\%, Sweden - 11.3\%, Austria - 10.4\% US $10.4 \%$, Netherlands - 10.1\%, France - 10.0\%, etc.). In the same year, the share of foreign workers in the economically active population of a number of host countries also reached impressive proportions (Australia - 24.5\%, Canada - 19.1\%, Switzerland - 18.3\%, the US - 12.4\%, Austria 9.8\%, Belgium - 9.8\%, GBG - 8.8\%, etc.)” (see Tsapenko, 2004).

There is a steady increase in the relative share of women in modern international migration. According to some estimates, as early in the mid-1990s women account for about $48 \%$ of the total number of international migrants, and in many host countries women even predominate in the total number of immigrants.

The issue of the term "feminization of emigration" is still debated. Overall, however, attention is concentrated on several aspects of the phenomenon (Vause \& Toma, 2015: 40-41):

- Gradual increase in the percentage of female migrants;

- Increase in absolute levels of female mobility;

- Increase in women's economic mobility in particular;

- Process of returning many women, even with a high degree of education, to the so-called "female roles";

- Women are playing an increasing part in all regions and in all types of migrations;

- More women are now migrating independently in search of jobs, rather than as family dependents travelling with their husbands or joining them abroad. 
It is becoming increasingly common to note that the degree of autonomy in the migration of women is increasing. This increase is competing as a criterion for feminization to increase the absolute amount of migrant women and their percentage vs. migrant men.

In different regions of the world, women's emigration is developing at its own speed, direction of migration flows and other peculiarities. But the socio-economic and psychological problems of migrant women are similar.

\section{Types of migrant women's behavior}

In terms of the reasons why women emigrate, their behavior as migrants, the problems they have to overcome, they are different types.

The article deals with those cases where women are the active factor rather than follow the man in his emigration.

Some women go on a journey to make a better career, to get to know the world without being forced by circumstances. For them, the term "voluntary migrants" is used.

And the others go to help survival of their families because of unemployment and poverty, such as escaping from a dangerous family or social environment, as a result of the psychological pressure of loved ones. For them, the term "forced women migrants" is used.

Let me suggest a hypothesis that I can't confirm with facts so far, but it seems to me to be too logical, probable and defensible. In the case of the first type of migrant women, there is probably more likely to be a planned permanent emigration, while the latter are probably more likely to be planned for temporary emigration.

More emancipated women who are psychologically motivated by a desire for realization seek less for their relatives in the country they go to, to become their "bridge" to travel, than less emancipated women who become migrants from a huge need.

In some cases, the woman leaves herself, another part is driven by her family. The degree of independence of the decision to emigrate largely depends on the degree of gender emancipation in the country concerned. The decision to emigrate into more modern societies is taken more independently, with less psychological pressure from the family. In the more "not emancipated" countries, the emigration of a woman is more of a collective solution. In the more "emancipated" countries, the percentage of women making their own decisions increases.

"Comparing five Latin American countries, Massey et al. (2006) show that the characteristics of female migration vary according to the patriarchal nature of the gender system. They find that in societies where women are more autonomous, independent, and less tied to men as partners, they are more likely to migrate as independent agents" (Vause \& Toma, 2015: 44).

"Similar findings are reported by Cerrutti and Gaudio (2010) in their comparison of Mexican and Paraguayan migration patterns: gender relations (among others) affect the volume of female migration, the characteristics of women who migrate and the channel of migration. According to Oishi (2005), the extent and the ways in which women cross borders depends on the "social legitimacy" of this behavior in a given society, and is deeply rooted in the prevailing social norms about gender equality and women's wage employment. Oishi convincingly shows how the low social legitimacy for female migration in Bangladesh, externalized in restrictive government policies and internalized by the women themselves, is a major factor explaining the low levels of female mobility from that country" (Vause \& Toma, 2015: 44-45). 


\section{Female emigration is both legal and illegal.}

There is a big difference between the economic, social and psychological problems of legal and illegal migrants. Legal migrants are less likely to be exploited, discriminated, to a greater extent with normal labor contracts, have a greater ability to solve their personal problems successfully. Towards illegal migrants are increasing exploitation rates, violence; increasing the unlawful requirements for personal behavior, the appearance of the migrant, the limitations of social life, problems in family status settlement, etc. The risk of psychological problems and the feeling of loneliness increases to them.

"In some cases care workers are compelled to co-reside in the houses of their rich employers to guarantee twenty-four-hour availability. This, however, isolates them from the outside world and renders socialization and integration into their new society nearly impossible.

Even more detrimental is the fact that cohabitation makes domestic workers nearly helpless in cases of discrimination, exploitation, and abuse - including incarceration, violence, sexual harassment, and/or rape. Removal of legal documents, under- or non-payment, as well as denial of resting times (even sick leave) or overtime pay, are more the rule than the exception. Due to the private nature of houses, locating women at risk of enslavement is nearly impossible. As many female migrant workers work without a residence or work permit, the fear of deportation aggravates their situation and makes it even harder to proceed against the culpable" (Gunduz, 2013: 36).

Sometimes migrants with undocumented status even are preferred, since this situation increases employers' control and power over them. All migrant host countries - to one degree or another, have a very deliberate policy of allowing migrants with illegitimate status for the sake of prosperity and the benefit of some of their citizens and/or the state as a whole. And they allow migrants to be subjected to violence of all kinds - economic, physical and psychological.

Much of the migrant, especially migrants with undocumented status, is in the sphere of what Bridget Anderson calls "three C's - cleaning, cooking, caring" (Anderson, 2007: 249).

In Asia "the largest proportion of these women, documented and undocumented, continues to work in job categories characteristically assigned to female migrants, such as live-in domestic workers, care givers, entertainers, sex workers and other service employees. A smaller but substantial proportion of women work in the garment sector and as agricultural and fish farm hands" (Piper, 2008: 1294).

The "care drain" migrant must also include emotion. The emotion that has moved away, alienated from her close people, she gives to strangers. This not only improves their quality of life through their work but also gives them an emotional surplus. There is an import of care and love from the poorer to the richer countries. And in the countries of migrants, the degradation of families and children is increasing. It comes to the paradox - female migrants to work as babysitters and at the same time to pay babysitters for their own children. There is talk of 'globalization of motherhood".

The other seemingly paradox, in fact a very regular phenomenon - when mother looks at children, is "motherhood" and is respected, and when it comes to the same but paid work of immigrants, it is disrespectful for unskilled labor. This is a condition for its lower pay and the result of the historically dominant male perspective in the management of social processes even today, even in the most developed countries. This point of view also proves to be psychological convenient for women who use the labor of migrants.

The patriarchal logic of the interpretation of public phenomena and attitudes towards people and their work influences the research of female migration. Interpretation of the fact that a migrant woman is a victim is probably another evidence of the millennia-rooted way of thinking 
that the woman is in a subordinate position, dependent on the decisions of the man, in need of these decisions, unable to play an active role in her own life. Such a way of thinking exists not only among male scientists but also among women scientists.

A woman is usually represented as a passive factor, as a victim, not as a co-operative factor in everything that happens to her in emigration. "Characteristically labelling women as "victims" objectifies them: their lives, feelings and humanness, are rendered invisible and transformed into stereotypical cardboard characters. More importantly, it denies them agency, as victims have no ability or power to change their circumstances" (Kihato, 2007: 91).

This interpretation is contradictory to the fact that migrants are usually from countries where there is a developed modernization or where it evolves, that is, there is some - a greater or lesser degree - of emancipation of the woman, socio-psychological readiness to be an active and decisive factor for her behavior. Migrant women are not from the most undeveloped and patriarchal countries in which women are a more passive factor in solving their fate. Migration from middle-developed countries to more developed countries is greatest. It is difficult for the women from poorest countries to emigrate, as it requires money, information and psychological characteristic of a more emancipated woman.

In fact, women take an initiative in the majority of cases of emigration. They also have different forms of response to the conditions in which they work and live in emigration. They change their jobs, negotiate, renegotiate their working conditions, fight. There are different categories of migrant women according to their psychological resilience and willingness to fight. Among migrants there are different categories of women. Those who are psychological ready to suffer, tolerate harsh discrimination and those who are psychological ready to fight for better working conditions and a fairer attitude towards them. Sometimes, when they seem to accept something that is not for acceptance, it is better than what they have escaped. It turns out they are not "sacrificing", but that they make the better choice for them.

A unique example of a migrant woman with psyche of a fighter is Kostadinka Kuneva. Bulgarian, with a high historical education, forced by her child's illness to emigrate to Greece. She works as a cleaner, becomes an active union member and actively struggles to improve the working conditions of Greek wipers. She assists in winning the right on a weekday for wipers on the subway. It gets too awkward and pours it with acid. She becomes a symbol of the struggle, and behind it stands a huge number of Greek workers to the point of electing her in the European Parliament elections in 2014 as a deputy for the "Syriza" party. She manages to survive psychologically and recover partially physically after 40 surgeries.

There is a big difference between migrant women according to their national background and their direction of migration movement - depending on the degree of modernization of their countries, their culture, religion, psychology and other factors.

In the Bulgarian case, it is about high unemployment, poverty and a pessimistic view of life during the transition. This tends to make the bulk of Bulgarian women in Greece - a neighboring country with a similar culture and job opportunities. "In terms of professions, females are in the service sectors, scientific and artistic professions while men are in agriculture and technical professions" (Lianos, 2001: 8). Much of the Bulgarians work in spheres traditionally related to the woman's historical roles - care of children and adults, cleaning. This activity is generally not particularly well paid. And when it comes to the common illegitimacy of their status, it is clear what the discrimination is. On the other hand, these migrants are somewhat interested in their illegal situation because they do not pay taxes. Therefore, many of them are ready to bear discrimination.

This is tolerated through the policy of the Greek state. "It should be noted that being an illegal migrant did not entail substantial risks of arrest and deportation, particularly in rural 
areas and in peak seasons when demand for labor is high, as long as one remained quiet and out of trouble" (Lianos, 2001: 4). More than 50\% of Bulgarian illegal immigrants in Greece are women.

Bulgarian migrants in other European countries are often doctors, nurses because of low pay for their work in Bulgaria and increased violence against them by patients. There are a lot of Bulgarian women practicing the prostitution craft and stealing in developed European countries, part of them being victims of trafficking. More varied is the profile of Bulgarians remaining in work in other countries after graduation.

Much of the female migration is related to the insertion of women into roles that are characteristic of the historic fate of women, associated with maternity and home, servicing the male (prostitution). This is because these women usually go to more developed countries, where women have more withdrawn from these roles and they have many vacancies. Women from underdeveloped countries with no special education use their knowledge and skills accumulated for thousands of years and passed on by family.

In other cases, like Bulgaria and Greece, Romania and Greece it's about countries with a similar degree of modernization but with a different economic situation. Therefore, in this case, women with a higher degree of education, they enjoyed in the time of "socialism" in a more appropriate way, often are going to the other states to perform unskilled work, not having something in common in their education. It is not a matter of self-development but of professional degradation. Greek women have a similar degree to Bulgarians but have better material opportunities and do not want to carry out the above-mentioned activities. Bulgarians fill the niche in the labor market, no matter what education they have.

This process of returning many women, even with a high degree of education, to the so-called "female roles" of the patriarchal times can also be denoted by the term "feminization" of emigration (Ho, 2006: 499). It is usually accompanied by great psychological drama, difficulty in accepting the new personal status and the attitude of others towards it.

One part of the Greek men, who behave towards their wives as emancipated women, are at the same time tempted to treat the Bulgarian women as women worthy of patriarchal roles only. The same applies to many American men who have emancipated women and treat them as such, and to the illegal domestic helpers refer from the position of the patriarchal man. In the book Global Woman by B. Erenrayh and A. R Hohshild, is mentioned a case of a man who works in an international human rights organization and at the same time treats a domestic worker as a slave.

\section{Married and unmarried family migrants}

The difference between unmarried and family migrants is quite substantial. Their motives, behaviors, problems and emotions vary to a great extent.

Some of the migrants are single. They have their own specific psychology. They often go on a journey from a career wish, for better professional realization, sometimes to follow in a higher education institution and then stay in the respective country. But another part is forced by the circumstances to emigrate.

One of the problems of unmarried migrants is finding a suitable professional realization. Finding jobs requiring lower qualifications is a loss to both them and the world economy. But surely this is a loss for the sending country.

Emigrants are usually subjected to less or very severe discrimination and exploitation in labor to the extent of talking about contemporary slavery (Erenrayh \& Hohshild, 2004). Being often illegal, they can't take advantage of the institutionalized rights of working people, harder 
may fight for their rights at all. They often have to use indirect, less painful ways for the employer to express their discontent - through language, songs and under similar tools (Tulud, 2006: 16).

Even when they have legal status and a high level of education, these women are much more difficult to prove themselves in the labor market they have to work more intensively and longer than the local population in order to gain a similar position in the profession. This often has a negative effect on their mental state.

Another problem directly related to the first is the difficulty of finding a partner, of forming a family, of reproducing. This is hampered by the difficulty of finding a job, the fear of losing a job that has already been found, greater discrimination against emigrants, the risk of being fired if they leave for maternity, etc. These are objective reasons that lead to a delay in solving the family problem, delaying, postponing births, to a feeling of loneliness. Perhaps such migrant women (as well as migrant men) are one of the streams in the great river of the so-called "lonely people" for whom the UK already has a ministry.

Of course, there are countries with a different policy. For example, countries where, due to modernization, birth rates are decreasing, and culture also causes the birth of more boys. At one point, the imbalance between men and women is becoming a problem. There are not enough women - for example, in South Korea. Some of the immigrants who want to stay in the host country at all costs sometimes try to solve their problem by marrying a local man. This phenomenon is becoming more and more massive in recent decades.

There is a developing of so-called "matchmaking industry" (Lee, 2012: 177). Adoption of women from other countries is a way to overcome the tendency to problems with the reproduction of the population, a way of providing cheap labor to low-income families (especially in the villages), a way of providing people to carry out social activities in the family - watching adults, patients, children, trying to keep family values. It is obviously relying on the fact that emigrant women are less emancipated than Korean women and are more likely to give birth and do farm work and domestic activities. The state respects its policy. "With the increase in crossborder marriages, the Korean government implemented a series of policies, including the Act to Support International Marriage for Rural Bachelors (2006-7), the Act on Regulation of Marriage Brokerage Agent (Act No. 8688) in 2007, and the Support for Multicultural Families Act (Act No. 8937) in 2008” (Lee, 2012: 178).

This is a way of slowing down the negative effects of woman's emancipation in the host country. And it is perhaps one of the most painless, sparing ways for an immigrant woman to adapt to her new place and obtain a decent, self-respecting social status. It is a way of moving away from the status of a lonely person.

The other emigrants are with family, sometimes with children. They have other problems. They usually go to work, most often to save their families from poverty and degradation. When they go to other countries, they usually go through a huge psychological drama.

In any case, the emigration of a woman and the provision of an important or even single income for her family sharply undermine the patriarchal model of role distribution between genders, accelerate changes in the psychological relationship between them, accelerate emancipation of both the woman and the man, regardless of his or her desire. It renegotiates the scheme of daily family commitments, generative and sexual relationships. It becomes necessary to change the perception of the other, the psychological expectations about his behavior.

The situation is similar with non-immigrant women but pursuing careers in their homeland. "A Swedish study recently found that women with a career are more at risk of divorce than men in leadership positions. The study found that within three years of reaching the CEO position, women divorces twice as often as men at the same level in the professional hierarchy. An analysis of data from the last 30 years for ladies who have held elected offices in Sweden as MPs 
or mayors shows that $25 \%$ of them were divorced at the eighth year of their political career. For those who are not so successful, the percentage is 15 , while for their male counterparts there is nothing like that. The changed social and economic situation of the wife usually does not meet the expectations of the husband" (Trifonova, 2020).

At the psychological level, it is still not considered normal for a woman to have a career, but for a man to act as her companion, a man who looks after home and children and does not pursue her own career. The vast majority of men who are for equality between men and women in the field of work have not yet matured to perceive such a reversal of historical roles in their own families. "The modern marriage market simply does not keep up with the labor market on gender equality" (see Trifonova, 2020). The pattern here is that changes in people's psychological attitudes are slower than changes in their socio-economic life.

A typical example of a career woman is the life of Soviet actress Lyudmila Gurchenko. She changes several spouses who are impressed and charmed at the beginning of their relationship by her vitality and talent. But over time, they are overtaken by creative envy, male intolerance of life in the shadow of the wife, and go to separation. Only her last husband, again in the field of artistic culture (musician), was able to take on the role of the service staff (in the good sense of the word), which has historically been played by a woman. Experiencing times of crisis he succeeds to the end to play the role of a loving husband, forgetting his creative abilities and ambitions.

But these types of men are still very difficult to find.

The situation is similar with emigrating women. They deprive their children and husbands of their basic needs. And as much as men and their children try to explain their mother's lack rationally and to accept it, to tolerate it on a psychological level, and for a long time, it is quite unbearable and many people do not manage to do it. And many men and children do not try to understand and bear it.

Changes in policies towards migrants and their families are needed, as well as in research into these issues. "There has been relatively little attention paid to the social protection of the migrant's family, migrants' social rights to family life, and the social protection of return migrants, but interest in all three is growing” (Locke, Seeley \& Rao, 2013: 1886).

“The term 'care drain' is generally used to indicate a reduction in the level of practical care and emotional and educational guidance available to the most vulnerable members of a family (particularly minors and the elderly) due to the emigration of the family members most engaged in the provision of care. Any man or woman who leaves their country deprives their natural family of care resources; the more involved the migrants were in family care before their departure, the more manifest this deprival will be" (Piperno, 2012: 192).

In general, the mother's absence at home affects the children worse than the lack of father. Even in more developed countries, where fathers' contribution to childcare is closest to that of mothers, the gap in willingness and skill to commit to children and home remains. And this is even more valid for less industrialized countries where gender equality is to a lesser extent and men's emancipation has developed to a lesser extent. Less is his psychological willingness to assume the functions of a woman. In other words, leaving children with the father is riskier for them. And this leads to an increase in psychological stress in the immigrant mother, as well as in other family members.

Migrants with families usually leave their children in the care of their husbands. In many cases they feel offended they think the situation is threatening their male dignity. The more unemancipated a man, the worse he feels and the worse he deals with the situation. On the one hand, he has a guilty conscience that he can't provide income, and because of that his wife has to emigrate to work. On the other hand, there is not enough skill and willingness to do these things a mother does with her children and looking at the house. Some of these men, to escape from their 
new problems, resort to alcohol and drugs, others become ill or find new partners (Hoang, Lam, Yeoh \& Graham, 2015). This, in turn, badly affects the children and the migrant woman.

More emancipated men have a better psyche to accept and deal with this situation. They learn new skills or deepen their old child and housekeeping skills. But even in countries like Romania and Bulgaria with a comparatively higher level of gender equality, most men find it difficult to take on the role of mothers in such a situation. In most cases, they look for other options - grandparents, professional caregivers, and so on. Or they happen to be listed above.

"With temporary migration involving highly feminized streams, this entails reversed gender roles by which a wife becomes the family's breadwinner while her husband is supposed to attend to the children and household. Studies have shown that marital conflict frequently results from this, at least in the initial stages, as such role reversal tends to challenge men's sense of masculinity, especially for those who experience long-term unemployment in a stagnant economy" (Piper, 2008: 1289-1290).

In romantic Western films, the plot of fathers abandoned by women or widows is often developed, making every effort to adapt to the situation and to care for their children and family. Of course, this is not the case with women who emigrated for economic reasons. But the problems of the fathers are identical.

They are even smaller men in the "non-emancipated" countries that decide to take on women's functions despite contempt, mockery and hardship on the part of most of society - their colleagues, friends, etc. Most are drenched, looking for lovers to prove their masculinity, play or drink their women's money.

Since men are less likely than women to live alone in such a situation, the lack of a woman at home is a condition for finding another partner. This further complicates the relationship with children and the psychological situation of the emigrant woman.

Usually, studies of the influence of missing parents on children's development focus on missing mothers and not on absent fathers. This may be indirect proof of creating a more problematic situation when the mother is an emigrant. Or, it is evidence that even in the most emancipated countries it is considered more natural to emigrate man not woman.

The other option for solving the problem of children with emigrated mothers is to remains their children to parents and relatives. This is a prerequisite for a number of problems of any nature. Parents are adults, of other generations, with quite different perceptions of life. At the value and psychological level, divergences are not easily overcome. In addition, the age, physical capabilities of the immigrant's parents sometimes prevent all engagements from being fulfilled in an appropriate manner. "Conflicts between migrants and their own parents or parents-in-law often arise when remittances are disrupted or there are disputes over differences in caring practices between generations" (Hoang, Lam, Yeoh \& Graham, 2015: 266).

The reduced degree of control or lesser quality control of children's development is present because there is no major control factor in the family - the mother. In any case, it is a fundamental change in family relationships and care system that often leads to substantial negative effects affecting all family members.

Some women manage to communicate with their children from a distance so that they develop properly. In the proper attitude of the mother and those who care for the child, the absence of the mother may not only act negatively but also motivate. Children can learn to participate more actively in family life, raising brothers and sisters. But in the majority of cases, the opposite results are obtained.

"Children's everyday responses may be classified in three ways: resilience, as expressed in the small shifts and turns that allow them to manage and adapt to life's changing 
circumstances; reworking, in the form of more deliberate, practical actions to alter inequalities and make daily lives more livable; and resistance, or acts invocating 'oppositional consciousness... to confront and redress' oppressive and exploitative conditions" (Katz, 2004: 251).

"Absenteeism and school dropout, combined with a growing decline in study motivation, were among the issues most frequently cited. Some also mentioned difficulties in reintegrating students into school on their return from visits abroad. Others again pointed to the fact that the lack of opportunities for parents and teachers to meet and discuss matters undermines the work of teachers and makes it more difficult to come up with an educational program tailored to individual students. Behavioral problems, such as conflict and lack of discipline, or simply the emotional distress experienced by students with parents abroad, make managing relationships with students even more complicated for teachers.

For these reasons also, many teachers raised the need for further training for themselves, and for greater involvement of school psychologists. From the report published by the Soros Foundation (Toth et al., 2007), it emerges that the care drain issue makes the need for improved triangular coordination with families and local social services, which are often lacking or inadequate, an even more pressing issue for school staff. Without these cooperation teachers end up directly performing a social work role that is outside their field of professional responsibility and for which they have not been trained" (Piperno, 2012: 199).

"A number of speakers emphasized that minors with parents abroad show a tendency to relate more to life on the street than to families or institutions and to adopt a value system that hinges more on earning money abroad than the importance of obtaining an education. The main effects of parental emigration on youths are negative, especially if it's the mother or both parents who leave... Absenteeism, deterioration in scholastic performance or school drop-out, social marginalization, behavioral problems and, sometimes, deviant behavior, are the main issues cited in the report. A second study by Alternative Social, carried out in collaboration UNICEF (UNICEF, 2008), confirmed such results. According to the authors of the study, the emigration of mothers has a particularly dramatic effect not only because it removes the principal source of family care, but also because the departure often takes place within the context of a failing relationship between parents, where there is a higher risk of child abuse by fathers" (Piperno, 2012: 199).

Women send tangible assets in an attempt to improve the lives of their children and their partner and to silence their guilty conscience. They try to keep in touch, but it is less or more hampered by objective circumstances. It is difficult for them to exercise the necessary control over the consumption of the material goods they send, the behavior of the people they have left their children and the development of their children's values and psyche. Reaction too often produces negative effects. The material benefits are:

- Not for learning but for demonstrating material goods in school;

- Not for learning and work, but for alcoholism or narcotics;

- Not for learning and work, but for indiscriminate sex, with all the major risks to youth in today's society.

suffer:

Some of these children neither study, nor work. So migrant women with families

- On the one hand, the separation with their families and the difficulties in regulating the family relations and the education of the children;

- On the other hand, from the problems in their foreign environment. 


\section{Socio-economic and psychological problems of migrant women}

problems.

It can be summed up that migrant women have different types of economic and status

One of the dangers for both unmarried and family women is the difficulty, often the inability to find a job in the specialty and the danger of de-qualifying, entering the ranks of the unskilled labor of a caregiver, a cleaner, etc., as is the mass case, because in countries, where they emigrate, people are usually looking for less-skilled work. There are formal and informal barriers to their work and professional development in the specialty - coercion to invest money for the recognition of diplomas, for taking part in courses. Some of these women fail, for financial or other reasons, to do this and are lagging behind in the more skilled labor market.

"Little mention is made of skilled migrant women's trajectories (those with tertiary education) like the large majority of health care professionals, who are persuaded to migrate to provide social care in advanced economies (Kofman \& Raghuram, 2006). Although they have a university/professional education in their countries of origin, they are expected to adapt their qualifications, access further and higher education, and attend English-language classes to advance their careers in a new country with many "paper walls" (Brinkmann 2006). These obstacles may prove to be too difficult to overcome; they can stay stuck in jobs significantly below their qualifications, such as being carers or cleaners (Cuban 2008). Without opportunities to advance, they can become deskilled. Pratt, in a study of Filipina nurses in Canada, explains: "deskilling happens through immigration, followed by ghettoisation within marginal occupations and low monetary returns on educational investments. It is a story that has been remarkably resistant to change, particularly for women (2004: 3)" (Cuban, 2010: 179).

Such de-qualifying policy is for example in the UK. "Recent 2008 UK immigration policies, for example, have instituted a points-based system, aimed at recruiting "skilled" migrants to work in low-paying jobs (like care work) but with little support for them to maintain a high quality of life" (Cuban, 2010: 180).

There is sexual segregation. Branches in which there are no men are much less than the non-female sectors. Feminized industries have lower pay rates.

"Women migrants tend to be located in the lower echelons of labor markets. This is the case for manufacturing employment as well as for employment in the service and care sectors" (Lourdes, Deere \& Kabeer, 2012: 6).

"Asymmetry in the terms on which different categories of labor are able to migrate has broadly gendered consequences. We have pointed out that, in general, it is largely male workers who fit the desired skill categories, while the kinds of skills that women acquire tend to fall outside these skill definitions - although there are some important exceptions, such as nurses" (Lourdes, Deere \& Kabeer, 2012: 21).

"Women do not escape the gender segmentation of labor markets by migrating from their home countries but simply experience it in a different, often intensified, form in the receiving countries. In fact, their labor market segregation in the latter is generally greater than that experienced by migrant men as well. The intersection of global and local inequalities has given rise to the irony that educated women are relatively more likely than educated men to migrate, presumably because of more limited opportunities at home, but they generally end up in jobs for which they are overqualified. A gender analysis of international migration also makes visible the increasing commodification of care work on a global scale" (Lourdes, Deere \& Kabeer, 2012: 7).

Slightly, these women are forced to settle for a little more money than they would receive in their home country at the expense of their professional disqualification. The psychological feeling of being undervalued and humiliated is growing. 
The extent of exploitation, discrimination, violence to the point of talking "contracted slaves", even in the most developed capitalist countries, is enormous. It is not about owning these people but about maximizing their control (Bales, 1999: 4). It is not about slave-owners, but about slave-holders.

It becomes words for fictitious labor contracts. "Immigrant women's employment opportunities tend to be in temporary and unstable jobs. Employment contracts tend to be temporary and unstable, both in high and low-income countries. Although this can be extended, this temporary nature often becomes a source of instability and concern in the lives of immigrants and their families" (Lourdes, Deere \& Kabeer, 2012: 6).

Contracts are absent, or not signed by a notary, or in a language that the worker does not understand, or does not describe the employer's obligations. In other words, to some extent, they are a fiction.

Asian and African female domestic workers in Lebanon are caught up not only in contract slavery but also, to some extent, in debt bondage. For example, the rights of freedom to withdraw their labor, to leave the country at will or to simply go out for a walk are routinely denied to live-in workers by their employers. The employer bears up-front costs of airfares, agency charges, visa, work permit and residency permit. These costs (up to US\$2,000 or more) are seen as an investment or debt that requires protection. Therefore, passports being routinely withheld and restriction of movement outside the household are deemed to be justified measures to safeguard against the employee absconding (Jureidini \& Moukarbel, 2004: 584).

In most cases, it's about an illegal or semi-legal status that prevents them from enjoying basic human rights. They face racial, religious, ethnic, gender discrimination. They are subjected except for economic but also to physical and psychological violence - unlimited working hours, restrictions on movement in space, on appearance, on external contacts, sexual and psychological abuse.

Employing women often act as the mother-in-law of the past. The house maid or caregiver is harassing, demonstrating jealousy in good relationship between the helper and the children. They often play the role of direct abuser.

The illegal status of many migrants undermines the democratic nature of the political regime. Migrant women can't enjoy the rights of the citizens' characteristic of this regime. These relations support racist values, xenophobic attitudes and practices. Citizens get used to link migrants to certain jobs. It is common to underestimate the real contribution of immigrants to their well-being.

Low-paid work in the field of care abroad corresponds to women's traditionally unpaid labor at home in their own countries.

The International Labor Organization, which is also an example of dominant male values and beliefs, does not distinguish as specific the problems of feminized and marginalized groups such as migrant home helpers. "Consequently, the dominant core labor standards (CLS) approaches to labor rights endorsed by the ILO have, by and large, failed to recognize the specific problems and issues faced by marginalized and feminized groups of workers such as migrant domestic workers" (Elias, 2010: 71).

The above problems are related to severe psychological problems.

Many immigrants, especially illegal, are subjected to less or greater disrespect, even contempt in the host country. Discrimination has not only economic but also psychological parameters. 
Migrants with lesser-skilled work are underestimated as potential family partners. Their cultural habits are often misunderstood or ridiculed. Illegal babysitters are often forced to bathe in a separate room, to be washed separately because they are declared unclean, especially when they are from another race or ethnic group, to emphasize the difference.

Apart from the psychological problems caused by the host country, the psychological problems associated with the sending country are great. The biggest psychological problems stem from the detachment from the family, relatives, friends as mentioned above.

However, in less modernized countries, with less gender emancipation and more "anti-woman" state policy, there is lesser legitimacy and acceptance of female migration.

In some Asian, African and Latin American countries where the process of emancipation of women is less developed, the disrespect for the effort and sacrifice of these women is great. Even the state is involved in criticizing them. Disrespectful, derogatory, even reprehensible opinions are spreading in the public space.

"Local gender ideology lags a few paces behind the economic reality that has created many women-headed households across the ocean... Even today, the leading ideology affirms that the woman's place is at home and the households of all migrant mothers point to the opposite. In response, government officials and journalists condemned migrant mothers by claiming that they had caused the Filipino family to decline, by abandoning their children, and that a long-term crisis in childcare was established in the Philippines" (Erenrayh \& Hohshild, 2004: 55). "The Philippine media support this view by continuously publishing and broadcasting sensational reports on the suffering of children from migrant families. The purpose of these reports is to condemn migrant mothers and emphasize that their children face much more serious problems than if the fathers are migrants; and despite the fact that most of these children are left with relatives, journalists are stubbornly calling them 'abandoned" (Erenrayh \& Hohshild, 2004: 55). The economic contribution of these women to the development of the Philippine economy is diminishing.

This moral deprivation of women affects mostly those most in need of protection. It pathologizes the situation of migrant children, while minimizing the emotional difficulties migrant mothers face (Erenrayh \& Hohshild, 2004: 72).

In the more patriarchal countries, the emigration of a woman is stigmatized, compared to prostitution, the woman risks being marginalized because it breaks social norms (Vause \& Toma, 2015: 47).

In more modernized countries like Bulgaria and other countries of the former "socialist" camp, female emigration is much more accepted as normal and possible, there is no such a degree of stigmatization. Public opinion in Bulgaria appears to be approached with greater understanding and respect for their decision. Even in the public sphere, the great importance of the money of the Bulgarian emigrants (including women) for the survival of many Bulgarian families is often mentioned. State actors and journalists are not allowed to criticize women on this line.

In countries like Bulgaria, where the emancipation of both women and men is to a greater extent, the difficulties, faced by children and men in the family of a migrant woman are, for that reason, with an idea smaller. But they are of the same nature.

Some states even market the image of female migrants by praising them as "economic heroes" who not only sacrifice themselves for their families but also for the nation.

Talking is allowed also about positive results from migration. But it is always necessary to distinguish for whom they are positive, for whom they are negative. There is usually a huge difference in this regard. 
We can talk about the productive and reproductive role of migrants.

In those women who migrate not so much or just for economic reasons but also because they want to escape unloved or abusive men, migration gives a breath of air, a sense of freedom, the possibility of another solution to the family question, a check on their possibilities. Some women find a more appropriate and desirable professional realization, psychologically calm down.

The feminization of international labor migration plays a positive role as it compensates for the relatively low economic activity of women in the countries from which they emigrate. There is some positive effect on the development of economies in their home countries.

The impact on consumption in the sending country, on the one hand, and on investment in the economy, on the other, must be distinguished. With their money transfers, they help to develop both.

Family situation, gender roles, the motivation for migration appear to be highly correlated with remittance behavior. Interestingly, women are more affectionate and responsible to their families and, to a greater extent, make these money transfers. "Governments view the feminization of migration flows positively because they assume women are motivated by a higher sense of commitment to family well-being and thus are more likely to remit" (Lourdes, Deere \& Kabeer, 2012: 14).

And in Asian women it is also because they have been chosen by their families to rescue them with their emigration and the corresponding money transfers. This can be interpreted as a patriarchal relationship in which daughters migrate to maintain the lifestyles of fathers or brothers. So here we are talking about lack of choice. This commitment to the family increases the tendency to send money transfers. families.

Money transfers help reduce poverty and social inequality, the survival of migrant

A distinction needs to be made between the impact of migrants on the economic development of their own countries and on the development of human capital in them. As can be seen from the above, the interpenetration between the two is too complex and sometimes contradictory in different countries and situations.

The balance between the damage caused and the benefits available must be analyzed. As far as the development of human potential is concerned, in many cases it seems as if the breaking of the families and the negative impact on the children, the spouses and the women themselves seem to prevail.

Women's emigration is usually a factor in the birth rate decrease in the sending country. This has positive dimensions for countries like China and India, for example, where the problem of overcrowding is high. At the same time, it has negative consequences for countries like Bulgaria with a huge demographic deficit. On the other hand, in the host countries migrants contribute to reducing their reproductive problems.

Female migration is a factor in questioning the traditional roles of man and woman in less modernized societies. Objectively, it helps to speed up their modernization.

\section{Conclusion}

As you can see, the feminization of emigration plays a very important role in the personal and social life of people in the modern world. In the vast majority of cases, it has serious negative psychological effects on the migrant women themselves and their loved ones. In other 
cases, psychological drama cannot be mentioned, but in all cases there is an increased risk of psychological problems. A common psychological condition is the feeling of loneliness. And it has a number of other negative social and physiological consequences.

In other words, globalization gives us great opportunities, but at the same time it gives us new challenges and problems.

My conclusion is that emigration usually complicates the lives of these women and very often has serious negative effects on the functioning of the family and social development of sending country. But it is necessary for each country to make a concrete analysis of the balance between positive and negative effects of female emigration.

\section{Acknowledgements}

This research did not receive any specific grant from funding agencies in the public commercial, or not-for-profit sectors.

The author declares no competing interests.

\section{References}

Anderson, B. (2007). A very private business: Exploring the demand for migrant domestic workers. European Journal of Women's Studies, 14(3), 247-264. https://doi.org/10.1177/1350506807079013

Bales, K. (1999). Disposable people: New slavery in the global economy. Berkeley and Los Angeles: University of California Press.

Castles, S., \& Miller, J. M. (1998). The age of migration: International population movements in the modern world, $3^{\text {rd }}$ edition. London: Guilford Press.

Cuban, S. (2010). Examining the feminization of migration concept for adult education, Gender and Education, 22(2), 177-191. https://www.tandfonline.com/doi/abs/10.1080/09540250903560455.

Elias, J. (2010). Gendered political economy and the politics of migrant worker rights: the view from SouthEast Asia. Australian Journal of International Affairs, 64(1), 70-85.

Erenrayh, B., \& Hohshild, A. R. (2004). The global woman. Publish House SIELA. Sofia. Bulgaria. [Еренрайх, Б. \& Хохшилд, А. Р. Глобалната жена. Издателство СИЕЛА].

Gunduz, Z. Y. (2013). The feminization of migration. Care and the new emotional imperialism, Monthly REVIEW, 32-43. https://monthlyreviewarchives.org/index.php/mr/article/view/MR-06507-2013-11 3 .

Ho, C. (2006). Migration as feminisation? Chinese women's experiences of work and family in Australia. Journal of Ethnic and Migration Studies, 32(3), 497-514. https://www.tandfonline.com/doi.

Hoang, L. A., Lam, T., Yeoh, S. A. B., \& Graham, E. (2015). Transnational migration, changing care arrangements and left-behind children's responses in South-east Asia. Children's Geographies, 13(3), 263-277. http://dx.doi.org/10.1080/14733285.2015.972653

INSTRAW (2007). Feminization of migration, gender, remittances and development. New York: United Nations, Working Paper No. 1. http://sd.pcm.gob.pe/contenido/803/Marta\%2520Carballo\%2520\%2520Feminization\%252 omig.pdf. 
Jureidini, R., \& Moukarbel, N. (2004). Female Sri Lankan domestic workers in Lebanon: A case of contract slavery. Journal of Ethnic and Migration Studies, 30(4), 581-607. https://www.tandfonline.com/doi/abs/10.1080/13691830410001699478.

Kaslz, S. (2001). International migration at the beginning of the XXI century: global trends and problem, International Journal of the Social Sciences, 32, 27-42. [Каслз С. Международная миграция в начале XXI века: глобальные тенденции и проблема, Международный журнал социальных наук, том 32, февраль. 2001, с. 27-42].

Katz, C. (2004). Growing up global: Economic restructuring and children's everyday lives. Minneapolis: University of Minnesota Press.

Kihato, W. C. (2007). Invisible lives, inaudible voices? The social conditions of migrant women in Johannesburg. African Identities, 5(1), 89-110. https://www.tandfonline.com/doi/abs/10.1080/14725840701253787.

Lee, H. (2012). Political economy of cross-border marriage: economic development and social reproduction in Korea. Feminist Economics, 18(2), 177-200. https://www.tandfonline.com/doi/abs/10.1080/13545701.2012.688139.

Lianos, T. P. (2001). Illegal migrants to Greece and their choice of destination. International Migration, 39(2), 3-27. https://onlinelibrary.wiley.com/doi/abs/10.1111/1468-2435.00147.

Locke, C., Seeley, J., \& Rao, N. (2013). Migration and social reproduction at critical junctures in family life course. Third World Quarterly, 34(10), 1881-1895. https://www.tandfonline.com/doi/abs/10.1080/01436597.2013.851948.

Lourdes, B., Deere, C. D., \& Kabeer, N. (2012). Gender and international migration: Globalization, development, and governance. Feminist Economics, 18(2), 1-33. https://www.researchgate.net/publication/254285201 Gender and International Migrati on Globalization Development and Governance.

Manov, B. (2015). Reading Spengler: has the modern West declined? - In Proceedings of the conference: "The Dialogue "East-West": Multi-direction of Readings" (pp. 189-198), compiled by Antoaneta Nikolova. University Press "Neofit Rilski”. Blagoevgrad, Bulgaria. [Манов, Б. Препрочитайки Шпенглер: залязва ли съвременният Запад? - В Сборник с доклади от конференцията: “Диалогът Изток-Запад: многопосочност на прочитите”, съставен от Антоанета Николова. Университетско издателство “Неофит Рилски”].

Marinov, V. (2007). International labor migration: economic aspects. Introduction. University Press UNWE. pp. 3-57. Sofia. Bulgaria. [Маринов, В. Международната трудова миграция: икономически аспекти. Увод. Университетско издателство УНСС. с. 3-57. София. България].

http://departments.unwe.bg/Uploads/ResearchPapers/Research\%20Papers vol2 2007 No 1 V\%20Marinov.pdf.

Piper, N. (2008). Feminization of migration and the social dimensions of development: the Asian case.

Third World Quarterly, 29(7), 1287-1303.

https://www.tandfonline.com/doi/abs/10.1080/01436590802386427.

Piperno, F. (2012). The impact of female emigration on families and the welfare state in countries of origin: The case of Romania. International Migration, $50(5)$.

https://onlinelibrary.wiley.com/doi/abs/10.1111/j.1468-2435.2010.00668.x.

Tsapenko, I. (2004). The role of emigration in the economy of the developed world. Journal "World Economy and International Relations”, № 5, 27-39. DEMOSCOPE weekly, № 207-208. http://www.demoscope.ru/weekly/2005/0207/analito1.php. [Цапенко, И. Роль иммиграции в экономике развитых стран. Журнал "Мировая экономика и международные отношения”, №5, 2004, с. 27-39 (г. ДЕМОСКОП weekly, № 207-208, 20 июня - 14 августа 2005)].

Tulud, C. (2006). Feminist theology, 15(1). SAGE Publications. Thousand Oaks CA and New Delhi. London. $\mathrm{UK}$. 
Vause, S., \& Toma, S. (2015). Is the feminization of international migration really on the rise? The case of flows from the Democratic Republic of Congo and Senegal. Population, 70(1), 39-63. https://www.cairn-int.info/article-E POPU 1501 0041--is-the-feminization-ofinternational.htm\#. 
P. Pachkova - Feminisation of Emigration

C O A $\mathrm{s}$ 


\title{
Behavioral Disorders in Children
}

\author{
Nikolaos Georgoulas \\ South-West University "Neofit Rilski”, Blagoevgrad, BULGARIA \\ Faculty of Philosophy, Department of Psychology
}

Received: 18 August 2020 - Accepted: 27 November 2020 - Published Online: 25 December 2020

\section{Abstract}

The child and adolescent psychopathology have been categorized into two broad classes, emotional (also called internalizing) and behavioral (externalizing) problems (disorders). In this paper, we describe the behavioral disorders in children. Behavioral problems are characterized by behaviors that are harmful and disruptive to others. Disruptive behavior disorders include attention deficit hyperactivity disorder (ADHD), conduct disorder and oppositional defiant disorder. These behavioral disorders, attention deficit hyperactivity disorder (ADHD), oppositional defiant disorder and conduct disorder in childhood and adolescence period will be discussed in more detail.

Keywords: behavioral disorders, attention deficit hyperactivity disorder (ADHD), conduct disorder, oppositional defiant disorder.

\section{Introduction}

Emotional and behavioral disorders and all other mental disorders, are described and classified in the following two diagnostic systems which are used by professionals around the world: the Diagnostic and Statistical Manual of Mental Disorders (DSM, currently version DSM5, American Psychiatric Association, 2013) and the International Classification of Diseases (ICD, currently version 10, World Health Organization, 1993).

These two systems - DSM-5 and ICD-10, offer the universally accepted standard criteria for the classification of mental and behavior disorders in childhood and adults (Ogundele, 2018).

The child and adolescent psychopathology have been categorized into two broad classes, emotional (also called internalizing) and behavioral (externalizing) problems (disorders). Whereas behavioral problems are characterized by behaviors that are harmful and disruptive to others, emotional disorders signify a core disturbance in intropunitive emotions and mood, namely, sorrow, guilt, fear and worry (Zahn-Waxler, Klimes-Dougan \& Slattery, 2000).

(C) Authors. Terms and conditions of Creative Commons Attribution 4.0 International (CC BY 4.0) apply. Correspondence: Nikolaos Georgoulas (PhD student), South-West University "Neofit Rilski", Faculty of Philosophy, Department of Psychology, Blagoevgrad, BULGARIA. E-mail: nikosgeorg@windowslive.com. 
2. Disruptive behavior disorders

Disruptive behavior disorders are considered to be the commonest externalizing behavioral disorders among children and adolescents (Ogundele, 2018). Disruptive behavior disorders include attention deficit hyperactivity disorder (ADHD), oppositional defiant disorder and conduct disorder.

\subsection{Attention deficit hyperactivity disorder (ADHD)}

ADHD is the commonest neurobehavioral disorder in children and adolescents (APA, 2013). According to the epidemiological studies' data the prevalence of ADHD ranges between $5 \%$ and 12\% (Ogundele 2018). The incidence of ADHD is reported to be 2.5 times higher in males than in females (9.2\% of males versus $2.9 \%$ of females cover the criteria for the diagnosis). Prevalence rates for ADHD vary by age. Studies indicate that school-age children are more likely to be diagnosed compared with preschool-age children and adolescents (Floet, Scheiner \& Grossman, 2010).

ADHD is considered a lifelong condition. There are reports that $-60 \%$ to $80 \%$ of adolescents who have been diagnosed with ADHD as children, continue to meet criteria for ADHD during their adolescence and adulthood (Floet, Scheiner \& Grossman, 2010).

The ICD-10 does not use the term "ADHD" but "hyperkinetic disorder", which is equivalent to severe $\mathrm{ADHD}$ (WHO, 1993).

ADHD is a behavioral disorder that is characterized by levels of hyperactivity, impulsivity and inattention that are disproportionately excessive for the child's age and development and cause functional impairment (Floet, Scheiner \& Grossman, 2010).

According to the DSM-5 classification ADHD includes three subtypes (APA, 2013):

(1) predominantly hyperactive/impulsive,

(2) predominantly inattentive, and

(3) combined types.

In order to diagnose attention deficit in childhood it is necessary at least 6 of the following symptoms to be presented for at least 6 months to a degree that is inconsistent with developmental level and that negatively influences directly social and academic activities of a child (APA, 2013: 59):

(a) Often fails to give close attention to details or makes careless mistakes in schoolwork, at work, or during other activities (e.g., overlooks or misses details, work is inaccurate).

(b) Often has difficulty sustaining attention in tasks or play activities (e.g., has difficulty remaining focused during lectures, conversations, or lengthy reading).

(c) Often does not seem to listen when spoken to directly (e.g., mind seems elsewhere, even in the absence of any obvious distraction).

(d)Often does not follow through on instructions and fails to finish schoolwork, chores, or duties in the workplace (e.g., starts tasks but quickly loses focus and is easily sidetracked).

(e) Often has difficulty organizing tasks and activities (e.g., difficulty managing sequential tasks; difficulty keeping materials and belongings in order; messy, disorganized work; has poor time management; fails to meet deadlines). 
(f) Often avoids, dislikes, or is reluctant to engage in tasks that require sustained mental effort (e.g., schoolwork or homework; for older adolescents and adults, preparing reports, completing forms, reviewing lengthy papers). (g) Often loses things necessary for tasks or activities (e.g., school materials, pencils, books, tools, wallets, keys, paperwork, eyeglasses, mobile telephones).

(h)Is often easily distracted by extraneous stimuli (for older adolescents and adults, may include unrelated thoughts).

(i) Is often forgetful in daily activities (e.g., doing chores, running errands; for older adolescents and adults, returning calls, paying bills, keeping appointments).

Similarly, the diagnosis of hyperactivity and impulsivity in children requires the presence of six or more of the following symptoms for at least 6 months to a degree that is inconsistent with developmental level and that negatively influence social and academic activities (DSM-5, APA, 2013: 60):

(a) Often fidgets with or taps hands or feet or squirms in seat.

(b) Often leaves seat in situations when remaining seated is expected (e.g., leaves his or her place in the classroom, in the office or other workplace, or in other situations that require remaining in place).

(c) Often runs about or climbs in situations where it is inappropriate.

(d)Often unable to play or engage in leisure activities quietly.

(e) Is often "on the go," acting as if "driven by a motor" (e.g., is unable to be or uncomfortable being still for extended time, as in restaurants, meetings; may be experienced by others as being restless or difficult to keep up with).

(f) Often talks excessively.

(g) Often blurts out an answer before a question has been completed (e.g., completes people's sentences; cannot wait for turn in conversation).

(h)Often has difficulty waiting his or her turn (e.g., while waiting in line).

(i) Often interrupts or intrudes on others (e.g., butts into conversations, games, or activities; may start using other people's things without asking or receiving permission; for adolescents and adults, may intrude into or take over what others are doing).

There is no evidence for a consistent association among ADHD incidence and race, ethnicity, or socioeconomic status of the individuals with this diagnosis although it is considered that environmental and biologic factors may increase the risk of ADHD (Floet, Scheiner \& Grossman, 2010). Environmental factors include early lead exposure and prenatal exposure to cigarette smoking and alcohol and biological factors include low birth weight, prematurity and intrauterine growth restriction (Floet, Scheiner \& Grossman, 2010).

Current research in the fields of neurobiology, genetics, and neuropsychology support a biologic origin for ADHD. Results of an impressive amount of studies demonstrate a relation between ADHD and brain systems that control attention and regulate inhibition (Floet, Scheiner \& Grossman, 2010).

Structural and functional differences in certain brain regions were found between individuals with and without $\mathrm{ADHD}$, respectively, especially in prefrontal cortex, striatum, and cerebellum (Qui et al., 2010; Norman et al., 2016, for meta-analysis).

A popular hypothesis of pathogenesis of ADHD suggests that ADHD is associated with deficits in executive functions. Many studies using neuropsychological assessment of executive function in children with ADHD have found worse performance of specific tasks such as set shifting, working memory, or processing speed, and other tasks in children with ADHD in 
comparison to their control peers, although some authors share the view thatexecutive function deficits may be a comorbid problem among children who have ADHD rather than a specific sign of ADHD (for a review see Floet, Scheiner \& Grossman, 2010).

In addition, genetic studies evidence that genes play an important role in etiology of ADHD, and its comorbidity with other disorders, with multiple genes contribute to the ADHD phenotype, including those related to dopaminergic, serotonergic, and noradrenergic neurotransmission (Faraone \& Larsson, 2019).

\subsection{Conduct disorder}

Conduct disorder refers to severe behavior problems including repetitive and persistent manifestations of serious aggressive or non-aggressive actions and behaviors in which the basic rights of others and major age-appropriate social norms or rules are violated (Pisano et al., 2017). This disorder seriously disturb a child's social and academic functioning (Campbell, Shaw \& Gilliom, 2000).

Children with conduct disorder often cannot understand the thoughts and feelings of others, and often look to others too restrained and non-emotional. They may misunderstand the intentions of others as malicious. Also, these children often suffer from immature language skills, immature or missing social skills to create and maintain friendships, which in turn become cause for increased feelings of sadness and frustration in these children (Ogundele, 2018).

According to the DSM-5, the diagnosis conduct disorder requires “...the presence of at least three of the following 15 criteria in the past 12 months from any of the categories below, with at least one criterion present in the past 6 months (APA, 2013: 469-470):

a. Aggression to people and animals: (1) Often bullies, threatens, or intimidates others; (2) Often initiates physical fights; (3) Has used a weapon that can cause serious physical harm to others (e.g., a bat, brick, broken bottle, knife, gun); (4) Has been physically cruel to people; (5) Has been physically cruel to animals; (6) Has stolen while confronting a victim (e.g., mugging, purse snatching, extortion, armed robbery); (7) Has forced someone into sexual activity.

b. Destruction of property: (8) Has deliberately engaged in fire setting with the intention of causing serious damage; (9) Has deliberately destroyed others' property (other than by fire setting).

c. Deceitfulness or theft: (10) Has broken into someone else's house, building, or car; (11) Often lies to obtain goods or favors or to avoid obligations (i.e., "cons" others); (12) Has stolen items of nontrivial value without confronting a victim (e.g., shoplifting, but without breaking and entering; forgery).

d. Serious violations of rules: (13) Often stays out at night despite parental prohibitions, beginning before age $13 \mathrm{yr}$; (14) Has run away from home overnight at least twice while living in the parental or parental surrogate home, or once without returning for a lengthy period; (15) Is often truant from school, beginning before age 13 years.

According to the epidemiological data, cited by Ogundele (2018), conduct disorder is the most common reason for psychological and psychiatric treatment in childhood and adolescence.

\subsection{Oppositional defiant disorder}

Oppositional defiant disorder is considered to be the mildest and commonest of the disruptive behavior disorders. According to the epidemiological studies' data its incidence is 
of $6 \%-9 \%$ for pre-schoolers with the disorder being 23 times more common in boys then in girls (Nock et al., 2007).

This disorder is diagnosed broadly on the basis of a pattern of frequent and persistent angry or irritable mood, argumentativenessor defiance, and vindictiveness, lasting at least 6 months (Ghosh, Ray, \& Basu, 2017).

According to the DSM-5 criteria, the diagnosis oppositional defiant disorder requires the presence of a specific pattern of a behavior which includes at least four out of 8 symptoms from any of the bellow listing categories that the child exhibits when interacting with at least one subject who is not a sibling (APA, 2013: 462):

(a)Angry/irritable mood: (1) Often loses temper; (2) Is often touchy or easily annoyed; (3) Is often angry and resentful.

(b)Argumentative/defiant behavior: (4) Often argues with authority figures or, for children and adolescents, with adults; (5) Often actively defies or refuses to comply with requests from authority figures or with rules; (6) Often deliberately annoys others; (7) Often blames others for his or her mistakes or misbehavior.

(c) Vindictiveness: (8) Has been spiteful or vindictive at least twice within the past 6 months.

Recent research has shown that the oppositional defiant disorder might have two separate symptom dimensions: affective and behavioral. Based on these two phenomenologicallydistinct signs of the disorder, two types of oppositional defiant disorder have been distinguished: the one subtype is characterized by affective symptoms of irritability, temper tantrums, and resentful attitude, and the other subtype is characterized with the features of defiance like vindictiveness and arguing (Mikolajewski, Taylor \& Iacono, 2017).

In a brief overview of the current studies' findings about the etiology of oppositional defiant disorder, Ghosh, Ray and Basu (2017) summarized that oppositional defiant disorder is highly heritable, with a definite genetic overlap with other externalizing disorders. The role of interactions between genes and environmental factors, both familial and extra familial, in the emergence of oppositional defiant disorder have been extensively explored in the past decade.

Also, neuroimaging findings suggested that various parts of the prefrontal cortex, amygdala, and insula may be related with pathogenetic mechanisms of oppositional defiant disorder.

\section{Conclusions}

Unfortunately, in the last 1-2 decades, a tendency of significant increases in the prevalence of childhood social, emotional, and behavioral problems have been observed (Layard \& Dunn, 2009). Emotional and behavioral disorders in childhood have significant negative impacts not only on the individual, but also on his/her family and the society as a whole. Their effect on the individual can be seen in the form of poor academic, occupational and psychosocial functioning. Their effect on the family can be seen in the form of trauma, disruption, psychological problems and all possible consequences and damages of deviant and delinquent behaviors of the affected family member. And finally, their effect on the society can be seen in the form of direct behavioral consequences related to the problems caused to the victims of crime or aggression in homes, schools and communities, as well as financial costs of services to treat the affected individuals (Ogundele, 2018). 


\section{Acknowledgements}

This research did not receive any specific grant from funding agencies in the public commercial, or not-for-profit sectors.

The author declares no competing interests.

\section{References}

APA (2013). Diagnostic and statistical manual of mental disorders (Fifth edition). Washington, DC: American Psychiatric Press.

Campbell, S. B., Shaw, D. S., \& Gilliom, M. 2000. (Early externalizing behavior problems: toddlers and preschoolers at risk for later maladjustment. Dev Psychopathol., 12, 467-488.

Faraone, S. V., \& Larsson, H. (2019). Genetics of attention deficit hyperactivity disorder. Molecular Psychiatry, 24, 562-575.

Floet, A-M. W., Scheiner, C., \& Grossman, L. (2010). Attention-Deficit/Hyperactivity Disorder. Pediatrics in Review, 31(2), 55-69.

Ghosh, A., Ray, A., \& Basu, A. (2017). Oppositional defiant disorder: current insight. Psychol Res Behav Manag, 10, 353-367.

Mikolajewski, A. J., Taylor, J., \& Iacono, W. G. (2017). Oppositional defiant disorder dimensions: genetic influences and risk for later psychopathology. $J$ Child Psychol Psychiatry, 58(6), 702-710.

Nock, M. K., Kazdin, A. E., Hiripi, E., \& Kessler, R. C. (2007). Lifetime prevalence, correlates, and persistence of oppositional defiant disorder: results from the National Comorbidity Survey Replication. J Child Psychol Psychiatry, 48, 703-713.

Norman, L. J., Carlisi, Ch., Lukito, S. et al. (2016). Structural and functional brain abnormalities in attention-deficit/hyperactivity disorder and obsessive-compulsive disorder: a comparative meta-analysis. JAMA Psychiatry, 73(8), 815-825.

Ogundele, M. O. (2018). Behavioural and emotional disorders in childhood: A brief overview for paediatricians. World $J$ Clin Pediatr., 7(1), 9-26.

Pisano, S., Muratori, P., Gorga, Ch., Levantini, V., \& Iuliano, R. (2017). Conduct disorders and psychopathy in children and adolescents: Aetiology, clinical presentation and treatment strategies of callous-unemotional traits. Ital $J$ Pediatr., 43, 84.

Qiu, M-G., Ye, Z., Li, Q-Y. et al. (2010). Changes of brain structure and function in ADHD children. Brain Topography, 24(3-4), 243-52.

WHO (1993). The ICD-1O classification of mental and behavioural disorders: diagnostic criteria for research. Geneva, Switzerland: World Health Organization.

Zahn-Waxler, C., Klimes-Dougan, B., \& Slattery, M. J. (2000). Internalizing problems of childhood and adolescence: Prospects, pitfalls, and progress in understanding the development of anxiety and depression. Development and Psychopathology, 12(3), 443-466. 


\title{
Kandinsky-Clérambault Syndrome: Narration and Psychosis
}

\author{
Petar Dimkov \\ South-West University "Neofit Rilski”, Blagoevgrad, BULGARIA \\ Faculty of Philosophy, Department of Philosophical and Political Sciences
}

Received: 23 September 2020 • Accepted: 10 December 2020 • Published Online: 25 December 2020

\section{Abstract}

Interpretation by means of retelling a story is an ordinary event in human life. However, under abnormal circumstances, e.g. delusions of the narrator, this process is altered and even distorted to various degrees in both qualitative and quantitative aspects. In such cases, the assumption of misrepresentation of the actual story emerges as most striking as it is in contradiction with the objective reality. In the current paper, I will focus on the discourse features in the narratives of patients with the Kandinsky-Clérambault syndrome since it provides some of the best cases that serve to support the main focus of my search, i.e. establishing to what degree we can believe the subjective interpretative narratives of mentally ill patients. This perspective, on its own, has given rise to some doubts in psychiatry as objective science. Our hypothesis is that there are clear-cut features of delusion, which can be outlined by linguistic analysis irrespective of the cultural belonging of the patient and described following the method of the omnipotence of language as a tool of semiotics. For our purpose, additional aspects of the problem will be developed in detail, such as the semantic levels in narration in general and outlined concepts of schizophrenia and delusion transparent in discourse carried out in any language.

Keywords: Victor Kandinsky, Kandinsky-Clérambault syndrome, narration, philosophy of psychiatry, philosophy of science.

\section{Introduction}

Human beings are one of the living species on Earth. They are very similar genetically to the other species, but evolutionarily they are quite different, i.e. they have some unique abilities and characteristics that make the enormous distinction between them and the rest living species. The main and the most important of those characteristics are: (1) language usage, and (2) logical thought - represented by the understanding (Verstand or the capacity for simple judging) and the reason (Vernunft or the capacity for generalization and conclusion).

In order to survive during the day, the human being has to adapt to the constantly changing environment. Except for all animal modes of behavior and adaptation, human beings also use language capacity and logical thought. The first, those that we share with other animals, are characteristics to the natural (psychosomatic) survivor, the latter - to the social (psychosocial) survival.

(C) Authors. Terms and conditions of Creative Commons Attribution 4.0 International (CC BY 4.0) apply. Correspondence: Petar Dimkov (PhD student), South-West University "Neofit Rilski", Faculty of Philosophy, Department of Philosophical and Political Sciences, Blagoevgrad, BULGARIA. E-mail: petardimkov@gmail.com. 
- In psychiatry, diagnosing still remains subjective to a large degree, which questions its objective status as a science.

- The Kandinsky-Clérambault syndrome (KCS) represents one of the most debilitating syndromes in psychiatry.

- Analyzing the discourse features in the narratives of patients manifesting this syndrome can, in general, shed an additional light on the degree of truth reliability of the psychiatric patients' subjective accounts.

- Dr. med. Victor Kandinsky is a unique figure that combined both the roles of a patient with a manifested KCS and a medical doctor - a psychiatrist.

- The analysis of the personal experience of Dr. med. Kandinsky reveals that KCS remains exclusively a subjective experience, which rises many methodological difficulties and doubts undermining the acceptance of psychiatry as an objective science.

However, it is necessary to mention that unique human abilities can sometimes err, especially under abnormal circumstances, e.g. during a mental illness period. One of the most famous and notorious errors that the Verstand and the Vernunft can make are the delusions (false beliefs based on false judgments) mostly founded on distortions in the representation-sensorial synthesis.

In the current paper, the main focuses will be on the concepts of delusional manifestations in schizophrenia, narration in psychiatric illnesses, the account of Dr. med. Victor Kandinsky and the concept of Kandinsky-Clérambault syndrome. We will also provide additional information on narration in general, on the conception of schizophrenia and also to what extent the narration has ecological validity in the mental illnesses.

Our main goal here is to develop in detail the narrative role of the self via the prism of the Kandinsky-Clérambault syndrome in the face of Kandinsky's personal accounts of his delusions as a reliable source of subjective information on the topic.

\section{Narration in general}

We will now concentrate on the human linguo-logical idiosyncratic characteristics and, more specifically, on the derivative linguistic faculty of narration and its role in mental illnesses as such.

The phenomenon of narration implies, in an apodictic fashion, the co-occurrence and co-availability of interpretative processes. That is to say, that narration without a (linguistic, but not perceptual) interpretation, and vice versa, is impossible. Narration is realizable only via the linguistic apparatus, but the latter's main function is, above all, an interpretative process; therefore, narration cannot be separated from it; it is some of the functions of language.

Narration consists of transformed (i.e. interpreted) internal and/or external perceptual material and hence it is observable and conceivable only in a particular form and shapes via the so-called linguistic interpreting process of the self and, subsequently, it could be shared and communicated to others. It is worth to mention that narration (as a part of the interpretative process) is playing the role of a limiting valve - it reduces (transforms, interprets) the real personal experience deriving from the so-called internal picture of the subjective experience to a formulated, fabricated and shaped generalized communicable entity, paying the price of some, in some cases even extreme, informational loss and also an addition of some noise. 


\section{Role of narration in psychiatry}

After this brief introduction to language, narration and interpretation, we could directly jump to their implications and applications in mental illness. Narration plays a key role in mental illnesses. It is interrelated to the whole range from the abstract scientific terminology, to the mere pragmatics - the conversation between the patent and the physician, on the one hand, the inner self-conversation of the patient himself, on the other. It also is included in the so-called being-in-the-world or phenomenology of everyday life as the narrative interpretation that constitutes the self of the human being; here, the interpretation is regarded as representing the internal and external linguistically formulated descriptions of oneself.

The topic of the self is more than contradictory, but we believe that the self is a formation based on the personal autobiographical experience (linguistic and perceptual interpretation), linguistic self-interpretation and external interpretations of the other human beings. However, some authors, e. g. the Bulgarian psychiatrist Timen Timev, are in a different position - there is no self at all; the self is a stolen concept from others - "in order to reflect himself the individual is forced to take the place of the instance of the other psyches that he ontogenetically bears in himself and the name, from which he addresses himself to call it Self, is their name" (Timev, 1992: 333; my translation). Timev argues for a multiple self and the omnipotence of the psyche and the brain so that everyone is virtually a multitude of selves.

Narration in mental illnesses could play multiple roles, such as a simple act of inner and creative energetic transformation from one perceptual or psychological ontological state to another, which could be further externalized into an eventual communication; a communicative message to oneself and to others; an utterance, a judgment, a ratiocination or other linguistically represented experience. If we consider human life as a constant and never-ending interpretative process, then narration accompanies us during our whole conscious life.

In respect to the mental illnesses, there are narrations from both sides - from the physician's point of view and from the patient's point of view. We could say that the first narrations are structured in complex abstract formations, whereas the second - they are more "down-toearth", i.e. described by simpler words and structures, but both are generalizations, hence reductions (everything put in words automatically and apodictically limits the uniqueness, i.e. denies some part of the initial perception or state - Omnis determinatio est negatio - "the grand dictum of Spinoza" (Macherey \& Ruddick, 2011: 7)). However, there are some unusual cases that involve a mixture between the two types - cases where the physician's and the patient's narrations are superimposed, integrated and interrelated one another, i. e. the narrator plays both roles of a patient and a physician. Our case here belongs to the last type - the mixed one, which we find and classify as the most intriguing one.

\section{Schizophrenia, psychosis and delusion}

Now we will give a brief outline of the nosological psychiatric concept of schizophrenia and more specifically of the concept of delusion as they are exposed by Piseva et al. (2005), Temkov and Kirov (1976) and Ivanov (1981). Schizophrenia is considered as an etalon of the psychotic phenomena; thus, not all schizophrenic psychoses are labeled as schizophrenia-form (or schizophrenia-like). It is necessary to mention that it is needed a distinction between the psychotic episode and the schizophrenia has to be made. Schizophrenia or schizotaxis (a pathological genetic predisposition) (Haralanov, Shkodrova \& Haralanova, 2005) can be defined as severe cerebral atrophy (initially the coined term for it was dementia praecox (premature dementia), usually accompanied by psychotic phenomena and manifestations. Thus, as in the case of its simple form, schizophrenia can exist without a psychotic state $/ \operatorname{mood}$ and it is not plausible to say that there is 
any strong kind of conceptual similarity between them; they are both terms that refer to completely different nosological psychiatric units.

As such, schizophrenia virtually affects all processes in the organism and leads to various pathophysiological and psychopathological states. Unfortunately, nothing is left completely unaffected. However, some authors (e.g. the Bulgarian psychiatrist Prof. Dr. med. Svetlozar Haralanovi ${ }^{1}$ also do consider the possibility of mutual non-antagonistic existence of a psychotic picture and fully preserved intellectual and cognitive capacities - our case can be even classified into this category. There can be observed alternations and disorders to various different degrees in the architecture and functionality of psychomotor, somatosensory, cognitive, perceptual, conscious, linguistic, volitional and reasoning apparatuses. When we consider that most of those phenomena are expressed in extreme qualities and quantities, we come to a profoundly disturbing and sad picture of the illness, very similar to that of global dementia; suicidal ideations and tendencies are frequent. De facto schizophrenia could also be described as psychotic dementia, except for the pure and simple form, in which the psychotic features are nondominant and often completely missing. The cerebral atrophy is more specific to it than the psychotic state, which is only an addition, but not an indispensable one.

However, there is another pole of the illness - the mind-blowing idiosyncratic psychotic (in some cases even eidetic) experience. Today, according to neuropsychiatry (the biomedical model in medicine; see D'Haenen, den Boer \& Willner, 2002), organic alternations in various brain areas (centers) represent the physical and physiological substrate, basis and cause of the psychotic phenomena, which on their own could furthermore additionally influence the impairment and atrophy of different cerebral loci. There are two main bio-psychiatric hypotheses about the neural correlates of psychosis, namely the dopamine-hypothesis and the glutamatehypothesis of schizophrenia, but various other important neurotransmitters (serotonin, norepinephrine, acetylcholine, GABA, endorphins) and their brain pathways are also suspected to be involved.

As finalization of the analysis of the concept of schizophrenia, we wish to refer to one more idiosyncratic and authentic conception of psychosis (in order to show that there are different points of view, hence different interpretations, about the psychotic experience among the clinicians themselves) offered by the Bulgarian psychiatrist Timen Timev, who considers the psychotic episode as compulsive self-cognition, compulsive gift and negative significance: "Psychosis as opposition against the power of the human and the power of knowledge over the soul and as a reduction of these two powers. Psychosis as the fear of reason from the unreason, the fear of logic from the illogical, the fear of human from the inhuman, the fear of the planetary from the cosmic, the fear of the social from the individual, the fear of the social from the natural, the fear of prose from poetry. Psychosis as an indispensable distance, which separates one from another the paradigms, as a compulsive abyss of the unknown, which accompanies the alternation of one paradigm with another, of one self with another, and of one world with another" (Timev, 1992: 331; my translation). Timev regards the psychotic experience not negatively as most of the clinicians do, but, on the contrary, positively. He focuses on the fact that this most unpleasant experience actually is for the good of the individual and is caused by some major alternations and transformations of the multiple psyche and the "self".

He further supports the idea that psychosis and creativity are somehow similar and that art as a whole could be used in the curing process of this mental disorder where narration as interpretation and self-expression takes one of leading roles - the individual should focus on something external to him in order to escape the dead circle of the psychotic chains. ${ }^{2}$

Delusion and delusional mood are some of the most interesting phenomena of mental illness as a whole. During our everyday perceptual and linguistic interpretation of the world, we understand the world, i.e. we make judgments about it. But as we mentioned already in the 
introductory part - we could make false judgments. They sometimes can constitute what is called delusions (delusional judgments and beliefs). Delusion represents "a morbid disorder of the thought process [...] in result of which emerges such a wrong logical reflection of reality that is in rough contradiction with it and is not subjected in any way to correction by a rational, nor a suggestive way" (Ivanov, 1981: 7; my translation).

It is far easier to notice that something is wrong during the observations of the patient than to find out the specific pathology and its causes. It is even harder to try to solve the puzzle by influencing these causal processes in a direction that aims at improving the current (and future) condition and complaints of the patient.

False beliefs leading to false judgments (and vice versa) are the main constituents of delusion. Delusion is defined as a particular state when someone has the firm hypothetical belief(s) that something exists or just is in a given way but not in another, but a way that is in conflict with the objective reality, i.e. the patient's interpretation of the reality is based on false premises; therefore, it is said that from an objective point of view the whole belief is false. It is widely accepted that the delusional beliefs cannot be influenced or changed by any logical means - the patient's conviction is so strong and so invulnerable and, additionally, it is often loaded with a large to extreme emotional charge. Although they are regarded as false (i.e. in severe contradiction with the objective reality), sometimes the false beliefs constituting delusion can be very picturesque and saturated with a richness of details, connections and relations (Ivanov, 1981).

There are many different types of delusions, such as grandomania (delusion of grandeur), delusions of influence and delusions of reference. Of importance for us are the delusions of influence that are part of the Schneider's first-rank symptoms of schizophrenia that are incorporated into and constitute the so-called syndrome of psychic (or mental) automatism or the Kandinsky-Clérambault syndrome.

Evaluating a given mental state requires the knowledge of the normal functioning of mind and, on this basis, the physician makes a multilevel judgment, a multi-modal interpretation, about the extent of normality or abnormality of the mental state of the individual. Thus, the medical doctor plays the role of a judge who determines what subjective experiences and objectively observable behavior of the person, as an eventual patient, will be considered as normal or as alternations from the norm, basing his assumptions on the psychiatric and neurological data.

Berrios and Markova address the problem of the role language in describing mental and brain states and their different epistemic value: "crudely, language of mind is not equivalent to the language of the brain, and this carries implications for the hermeneutics of data" (Berrios \& Markova, 2002: 6). They argue that the language of mind is used to describe psychological states and events (e.g. moods), the language of brain - cerebral ones (e.g. cerebral atrophy).

\section{Dr. med. Victor Kandinsky}

"Also as in our own time, psychiatrists then were vulnerable as they are today to mental disorders. Of the tragedies associated with mental illness, few are more ironic than the madness of a psychiatrist" (Agin, 2009) - a little bit harsh statement, but very close to the actual facts indeed.

Victor Khrisanfovich Kandinsky (1849-1889), an uncle of the famous artist Vassily Kandinsky, was born in Siberia into a family of successful businessmen, and later became one of the most famous and important figures in the Russian psychiatry by introducing the nosological entity of the syndrome of psychic automatism ${ }^{3}$ (Lerner, Margolin \& Witztum, 2012). Kandinsky's curriculum vitae is much more than just interesting, it is an unique example proving two hypotheses at the same time: (1) we do not know everything and even the best are not invulnerable 
to errors and misperceptions, and (2) the psychotic madness can exist simultaneously with fully intact intellect, i.e. logical reasoning capacity, together with disordered cognition and perception.

Kandinsky is famous for his detailed description of his own subjective personal experiences during his psychotic states and his illness as a whole that he used as construction blocks for working out the concept of psychic automatism or KCS. It is known that he had some relatives affected by paranoid schizophrenia. He was a calm, conscientious and hard-working young man. He graduated from Moscow University Medical School in 1872 and started to work as a general physician in one of the hospitals in Moscow.

Kandinsky was not only interested in practicing medicine, but also in the theoretical speculations and abstract research. He published many journal papers in different languages (German, French and Russian) on various medical subjects; he was a prolific author: "for example, from 1874 to 1876 he published 31 papers on different topics including original contributions and literature reviews (there were three papers in psychiatry)" (Lerner \& Witztum, 2003: 105). He elaborated a "system with 16 diagnostic categories of the mental illness in the domain of psychiatric classifications that was remarkably sophisticated for his time" (Lerner, Kaptsan \& Witztum, 2003; Rokhlin, 1975). It seemed at that time that the young Kandinsky had marvelous perspectives in his hands. As a general principle, Kandinsky was arguing against "a general and undifferentiated approach, suggesting that every case should be examined individually according to the specific diagnosis and the person's clinical state" (Lerner, Kaptsan \& Witztum, 2003).

However, fate had different plans for him - in May 1877, he became ill (psychotic) and was sent to a psychiatric hospital as a patient where he spent 11 months; there was a suicide attempt as well (Lerner \& Witztum, 2003: 106). During his stay at the hospital, he fell in love with one of the nurses and, after his recovery, they got married. Then, he started to work as a psychiatrist in St. Petersburg, at which position he remained for eight years until his suicide in 1889. To be noted and with reference to his lifetime mental condition, "Kandinsky also had depressive episodes without need for hospitalization [...] In transitional periods between illness and recovery, Kandinsky usually suffered from suicidal ideation" (Lerner \& Witztum, 2003: 106). He committed suicide by taking a lethal overdose of morphine or opium. He continued to write as the effects of the drug become dominant and wrote his last words describing his condition: "I am not able to write anymore because I cannot see. Light! Light! Light!" (Agin, 2009). His wife arranged the publication of his scientific papers and two books then she commits suicide too. "At the time of his premature tragic death in 1889 , he was still at the peak of his productivity" (Lerner \& Witztum, 2003: 108).

Kandinsky's physician diagnosed him as having melancholia, but his own diagnosis was Primäre Verrückheit or primary insanity, i.e. insanity not secondary to organic cause (Lerner, Kaptsan \& Witztum, 2003) plus "paranoid hallucinatory-descriptive labels without biological content" (Agin, 2009) or simply a schizophrenia-like state; some authors even consider his illness as schizoaffective psychotic disorder (Ibid.). He published in German in 1885 a book on pseudohallucinations. KCS or the syndrome of mental automatism is described in a monograph in Russian published posthumously in 1890 by his wife, which is based largely on his own selfobservations.

"To my sadness, during two years I suffered from insane hallucinations [...] I felt various abundant hallucinations in all my senses except taste. The most frequent and vivid were visual, tactile, and common sensibility hallucinations" (Ibid.; see Lerner \& Witztum, 2003: 106). However, he also reported that "in the first moths of my malady there were no hallucinations. This period was generally characterized by intense but chaotic intellectual activity [...] a lot of ideas that ran speeding but not in the right course, experienced as forced and false" (Ibid.; see Lerner \& Witztum, 2003: 106). 
The KCS is defined by Kandinsky himself with the following features (Ibid.; see Lavretsky, 1998: 545): imagined telepathy, reading and broadcasting of thoughts, enforced speaking, and enforced motor movements, disturbances in visual, auditory, olfactory and tactile perceptions, variations of mood from mania to depression, with depression predominant and often including thoughts of suicide. It also involves: alienation from or loss of one's own mental processes (cognitive, sensory and motor), which are attributed to somebody else, combined with delusions of physical or mental influences, such as stealing or insertion of thoughts.

Kandinsky describes the phenomenon also as "subjective perceptions which in vividness and character resemble real hallucinations except that they do not have objective reality [...] my hallucinations are not just images generated by my imagination or memory, but sensory full and involuntary, and in addition to their vividness and involuntariness, they are "forced" in character" (quoted in Berrios, 1996: 56).

Gaëtan Gatian de Clérambault himself gave a little bit more sophisticated systematic definition of what he called "mental automatism" (Lerner, Kaptsan, \& Witztum, 2001); he divided the automatisms in three subtypes that can occur separately in time or simultaneously as a "triple automatism":

(1) Associative type (ideatoric or ideoverbal) - disturbances in the form of thought, e.g. loosening of associations, derailment, blocking and flight of ideas, disturbances in the content of thought, e.g. delusions of influence on one's own mental processes (e.g. thought broadcasting).

(2) Sensory type (senestopathic) - unpleasant feelings in the internal organs thought to be caused by somebody else plus delusions of physical influence.

(3) Motor type (kinesthetic) - delusional belief that somebody else performs one's own movement and actions.

Clérambault introduced another syndrome known as Clérambault's syndrome or erotomania that has to be distinguished from the KCS. Unlike erotomania, KCS is largely unknown in English-speaking countries, although it shares many similarities with some of the first-rang symptoms of schizophrenia of Schneider (Temkov \& Kirov, 1976: 213). Some other conceptions have similarities with KCS such as the Gruhle's term paralysis of the ego - discontinuation in the psychic life caused by a cessation in the flow of a sense of consciousness - "loss of mastering over the interior environment leading to the loss of a sentiment of one's own activity and of the feeling of autonomy" and "thought or acts that happen spontaneously, independent of the will and which on occasions may even escape conscious registration" (Arboleda-Florez, 2002: 569).

Today we have a more detailed definition of the KCS. The appearance of the syndrome is accompanied usually by intense inquietude, feeling of inner tension, anxiety, fear, sometimes confusion and lack of clarity, also feelings of depersonalization and derealization could occur. Some authors argue that "there is no automatism without amnesia" (Ibid.: 572), but this is not consistent with our data, because the person preserves his subjective observational capacity while loses his feeling of agency. Some of the most frequent symptoms are: feeling of uncovering, feeling of abduction and reading of thoughts, experiences of broadcasting and "implanting" of foreign thoughts into the head of the patient, feelings of hypnotic suggestion, senestopathic images. Distinct motor mechanisms are rare; more usual are the feeling of being possessed, experiencing movements like an automat, a robot, et cetera. There are some more complex influences that can be encountered such as controlling of the sleep, implanting and depriving of power, taking away of the sexual potency, magical influence, influencing by the action of electromagnetic waves, electrical current, rays, apparatuses, et cetera (Ivanov, 1981).

In some cases, delusions of being possessed have somehow modernized contents (Ivanov, 1981): the assumption of being controlled by a complex system of apparatuses by an artificial satellite on the Earth, the assumption that the brain of the patient is an aperture card on 
which the others take in some information, the assumption that the verbal influence is being conducted via radio transmission and the receiver is installed in the gold replacement of one of the patient's teeth.

\section{Subjectivity in mental illness diagnosis assessment: The role of the narrative}

After having considered in details the concept of schizophrenia, and delusion in particular, the account of Victor Kandinsky and the Kandinsky-Clérambault syndrome, we can approach now the essence of our main goal - what are the advantages and the disadvantages of the mental illness narration, i.e. what is the importance of those narrations at all.

It is indispensable to mention that the very language of neurobiology is soaked in fundamental claims or, more precisely, theories, hypotheses and principles that, however, have been not all validated. Constructing a good and accurate diagnosis is a complex process.

We will consider both patient's (as viewed from clinician's perspective) and clinician's point of view. First, the subjective complaints (interpretations of some sort of perceived dysfunction or change in the physical and/or psychic functioning) of the patient have to be taken into consideration and analyzed.

Even at this first step, we encounter one serious problem - it is possible to assume that the "same" internal state will result in its equivalent interpretation and equivalent description by different individuals? Probably this is so not completely, but only to some extent. Then, how could we know that the internal state, as described by the individual, is de facto the particular experienced state that is matched by the description, i.e. does the description match the experience accurately (assumption of validity)? Having in mind that people differ much in their education, value systems, worldviews, personal experiences, also in the capacity to describe and discriminate between different states, i. e. the sensitivity to changes in the internal states, et cetera, we could conclude that the changes in the internal states are going to be interpreted in different ways by different individuals and that this interpretation will be affected by various factors: "there will be a marked degree of formatting going on (noise from various sources) which will change and distort the original signal to variable extends" (Berrios \& Markova, 2002: 10).

An important role also plays the language itself and the linguistic categories available to the individual for creating more or less adequate interpretation (description) of his complaints and his situation. It is interesting that we cannot say that interpretations themselves can be true or false, exact or apodictic; they can only be "fair, imaginative, beautiful, audacious, speculative or silly" (Ibid.: 20). For the complex symptom judgments the distortions will be greater, hence "the epistemological [epistemic - capacity to gain, construct, generate knowledge] justification for subjective data in terms of their validity and reliability remains poor" (Ibid.: 10).

The second step is the clinician's interpretation of the speech and the behavior manifested by the individual. The clinician is in a better position: he relies on the clinical knowledge (the agreement on specific diagnostic categories between the clinicians themselves; however, "current groupings are determined by more arbitrary factors with face validity based on consensus of opinions, but not information concerning the disease states themselves" (Ibid.: 11)) that is more or less closer to the objective state of affairs in the world; thus, the determination of the phenomena is better in quality and therefore the chance of distortion is slighter, but still present. At the moment, the features are chosen in terms of criteria that are easy to measure, of availability, saliency, et cetera, but not in terms of their conceptual representations. However, here we see that, in general, the epistemological validity is also weak. Also, little is known about the structure of the concepts of mental disorder, disease, illness, malady, sickness. 
Now we could conclude that, in principle, the psychiatric data (both from patient and clinician) is marked by weak epistemological support and, therefore, a poor epistemic validity. However, it seems that "there is little choice for the social collective but to accept and internalize as certain a worldview that has been choses for it" (Ibid.: 11), i.e. that patients' complaints, interpretations and descriptions are neglected, because they are based usually on false premises. On the other hand, the clinician's situation looks better, but here are still some controversies some of the premises are based on consensuses.

Our current case is concerned with the personal narration of the psychotic experiences by the patient and its epistemological validity. We have seen that patients' descriptions and interpretations are not a reliable source of information due to the above-mentioned big chance for distortion by different causes. However, our case is a little bit particular, because the roles of the patient and the clinician are played by one and the same individual, namely Dr. med. Victor Kandinsky: "a subjective description of such an internal experience by an expert psychiatrist may be particularly illuminating as to the nature of madness [...] much of his research in psychopathology was based upon his own experience, and his writings are significant sources in assessing his psychiatric condition [...] Kandinsky was an interesting patient, and he himself described his clinical picture with great detail, both in the acute phase and throughout his whole life" (Lerner \& Witztum, 2003: 104).

As we have mentioned already, there could exist strange cases where the intellect is almost intact in contrast to the manifestations of psychosis. The case of Kandinsky seems to be such. This is the major reason (together with the fact that he was a medical doctor) why the theoretical writings of Kandinsky are more detailed, with greater quality and greater epistemic validity in comparison with the interpretations and descriptions of the psychotic phenomena by the "ordinary" patients.

So, on the one hand, we have the internal states indicating some dysfunction or disorder in the physical or psychological domains. On the other, there are different individuals possessing different means of making different interpretations of the symptoms that, on their own, seem to be almost identical to all patients with small variations (clinician's perspective), i.e. after removing the interpretations of the different individuals and their different means for that it remains clear that for the purpose of the easiness of giving the appropriate diagnosis, the clinician reduces all individual subjective states and their descriptions to categories that are universal.

However, in the case of psychosis, there are some important points that affect the capacity of interpreting the internal experiences of oneself. It is widely accepted that there is a disruption in the sense of the self and alternations in self-experience in the psychotic patients, some authors even speak of a "collapse of the ability to maintain ongoing dialogue within the self" (Lysaker \& Lysaker, 2002: 207). There are observable disorders in the linguistic apparatus, i.e. the psychotics have troubles with following logical rules and meaning attribution and understanding. Thus, the patient preserves his capacities of an observer of his subjective phenomenal flow, but there is a marked confusion in determining and attributing the sense of agency to those phenomena, hence the possibility to consider some internal experience as alien to oneself, i.e. caused or imposed externally, thus involuntary and foreign. All this, according to J. Frosh (1983), is described as "the underlying danger the psychotic defends himself against is psychic and emotional death. It is this threat to survival that leads to their desperate means of creating an illogical reality" (quoted in Lysaker \& Lysaker, 2002: 208). 


\section{Conclusion}

It seems that the psychotic has severe disadvantages in conducting an adequate interpretation of the reality, which presupposes that his descriptions will be of little to no value due to his negative and positive psychotic symptoms. However, as we saw, there could be particular cases where the intellectual capacities are preserved, but the psychotic phenomena are full-blown. Then, for the individual, there is no other possible alternative than to just say that some of his experiences are alien to him. Intellectual capacities are essential for the interpretation itself, but it seems that what is more disturbing to the sound reason are the psychotic phenomena themselves and their paradoxes.

So, it seems that logic does not help much here - even if the patient knows that what he experiences is false and unreal, his personal beliefs and convictions seem to dominate. Even if we have the best and detailed interpretation of the psychotic phenomena, we must acknowledge that, after all, the real causes remain unknown and the descriptions and the interpretations remain nothing more than what they actually are - descriptions and interpretations. We should look for some more objective methods in finding the real causes, but not to disregard and neglect the mental illness narrations - they are indispensable and rich source of information.

Our conclusion, advanced in the previous two paragraphs, and augmented with the account of Dr. med. Victor Kandinsky and the symptoms of the syndrome he has developed, gives rise to many discussion points. On the one hand, it seems more than plausible a psychiatrist is in a better position to describe his psychotic states than the "normal" mentally ill patient with poor education and average intellectual skills. On the other hand, even taking into consideration this fact, the problem goes even further - it questions the whole psychiatry as an objective science because of the criteria used in the diagnosis assessment of mental illnesses.

The account of Kandinsky is a good example providing insight into the triad patientillness-interpretation. The important conclusion from our analysis is that the interpretation of the patient himself on his mental illness depends on many factors so that different people will give different accounts and descriptions to their psychic states. The latter, however, can be classified into categories such as symptoms and syndromes. However, the context should not be neglected, but on the contrary - it plays a more than an important role for the giving of a psychiatric diagnosis. In the end, as we already mentioned, psychiatry should seek more objective measurements and assessments of mental illnesses such as brain scans and blood tests measuring neurotransmitter levels that can be applied to all patients not only for the purposes of scientific research.

"We like to think we know so much, but we really do not know much at all. We remain children in the garden of knowledge. One hundred and twenty years after the death of Dr. med. Victor Kandinsky, mental illness still confounds us, a continuing and devastating plague. We are not alone in history" (Agin, 2009). "We believe that Kandinsky's life and work exemplifies a fine model of coping with a debilitating mental disorder. For this, alongside his clinical and scientific contributions, he deserves to be remembered in the history of psychiatry" (Lerner \& Witztum, 2003: 110).

\section{Endnotes}

${ }^{1}$ The statement is derived from private communication with the author (2014).

2 The statement is derived from private communication with the author (2012).

3 Known and used in Europe as Kandinsky-Clérambault Syndrome (KCS). 


\section{Acknowledgements}

This research did not receive any specific grant from funding agencies in the public commercial, or not-for-profit sectors.

The author declares no competing interests.

\section{References}

Agin, D. (2009). History revisited: Psychosis of a psychiatrist. Available at: https://www.huffpost.com/entry/history-revisited-psychos b 297300. Accessed on: 1 July 2020.

Arboleda-Florez, J. (2002). On automatism. Current Opinion in Psychiatry, 15(6), 569-576. https://doi.org/10.1097/00001504-200211000-00002

Berrios, G. E. (1996). The history of mental symptoms: Descriptive psychopathology since the nineteenth century. New York: Cambridge University Press. https://doi.org/10.1017/CBO9780511526725

Berrios, G. E., \& Markova, I. S. (2002). Conceptual issues. In D’Haenen, H., den Boer, H. \& Willner, P. (Eds.), Biological psychiatry (pp. 3-24). Chichester: Wiley \& Sons.

D'Haenen, H., den Boer, H., \& Willner, P. (2002). Biological psychiatry. Chichester: Wiley \& Sons.

Haralanov, S., Shkodrova, D., \& Haralanova, E. (2005). Schizotaxia as a cognitive-neurological phenotype of schizophrenia. Neurl. Psychiatry, 3, 22-23. [Хараланов, С., Шкодрова, Д., \& Хараланова, Е. (2005). Шизотаксията като когнитивно-неврологичен фенотип на шизофренията. Неврол. Психиатрия, 3, 22-23].

Ivanov, V. (1981). Delusion and schizophrenia. Sofia: Meditsina i fizkultura. [Иванов, В. (1990). Налудност и шизофрения. София: Медицина и физкултура].

Lavretsky, H. (1998). The Russian concept of schizophrenia: A review of the literature. Schizophrenia Bulletin, 24(4), 537-557. https://doi.org/10.1093/oxfordjournals.schbul.a033348

Lerner, V., Kaptsan, A., \& Witztum, E. (2001). The misidentification of Clérambault's and KandinskyClérambault's syndromes. The Canadian Journal of Psychiatry, 46(5), 441-443. https://doi.org/10.1177/070674370104600511

Lerner, V., \& Witztum, E. (2003). Victor Kandinsky, MD: Psychiatrist, researcher and patient. History of Psychiatry, 14, 103. https://doi.org/10.1177/0957154X03014001006

Lerner, V., Kaptsan, A., \& Witztum, E. (2003). Kandinsky-Clérambault's syndrome: Concept of use for Western psychiatry. Israel Journal of Psychiatry and Related Sciences, 4O(1), 40-46.

Lerner, V., \& Witztum, E. (2006). Victor Kandinsky, M.D., 1849-1889. American Journal of Psychiatry, 163(2), 209-209. https://doi.org/10.1176/APPI.AJP.163.2.209

Lerner, V., Margolin, J., \& Witztum, E. (2012). Victor Kandinsky (1849-89): A pioneer of modern Russian forensic psychiatry. History of Psychiatry, 23(2), 216-228. https://doi.org/10.1177/0957154X11416550

Lysaker, P. H., \& Lysaker, J. T. (2002). Narrative structure in psychosis: Schizophrenia and disruptions in the dialogical self. Theory \& Psychology, 12(2), 207-220. https://doi.org/10.1177/0959354302012002630

Macherey, P., \& Ruddick, S. M. (2011). Hegel reads Spinoza. Environment and Planning D: Society and Space, 29(2), 223-236. https://doi.org/10.1068/d2902tr

Piseva, D. et al. (2005). Psychiatry. Sofia: Arso. [Писева, Д., \& сътр. (2005). Психиатрия. София: Арсо]. 
P. Dimkov - Kandinsky-Clérambault Syndrome: Narration and Psychosis

Temkov, I., \& Kirov, К. (1976). Clinical psychopharmacology. Sofia: Medicina i fizkultura. [Темков, И., \& Киров, К. (1976). Клинична психофармакология. София: Медицина и физкултура].

Timev, T. (1992). The rebellion of idlers. Sofia: Omnisemantism. [Тимев, Т. (1992). Бунтът на бездарниците. София: Омнисемантизъм]. 


\title{
Psychotherapy of Psychosomatic Anxiety Responses
}

\author{
Lubomira Dimitrova \\ South-West University "Neofit Rilski”, Blagoevgrad, BULGARIA \\ Faculty of Philosophy, Department of Psychology
}

Received: 5 November 2020 • Accepted: 18 December 2020 • Published Online: 25 December 2020

\begin{abstract}
Psychotherapy of psychosomatic disorders in adolescents is one of the most responsible tasks that the therapist could undertake. The psychosomatic spectrum of disorders in children between the ages of 5 and 18 is wide. The similarity between the individual symptoms lies in the fact that they are masked satisfied desires, but not in an adequate, but in a neurotic way. In the process of psychotherapy should be approached individually and take into account the personal characteristics and character traits of adolescents. This article discusses some of the most common disorders, as well as the reasons that caused them. The focus is not on eliminating the symptom, but on the cause.
\end{abstract}

Keywords: psychotherapy, symptom, psychosomatic disorders, psychoanalysis, anxiety, aggression.

\section{Introduction}

Psychotherapy of psychosomatic disorders in adolescents is one of the most responsible tasks that the therapist could undertake. The psychosomatic spectrum of disorders in children between the ages of 5 and 18 is wide. The similarity between the individual symptoms lies in the fact that they are masked satisfying desires, but not in an adequate, but in a neurotic way. In the process of psychotherapy should be approached individually and take into account the personal characteristics and character traits of adolescents. This article discusses some of the most common disorders, as well as the reasons that caused them. The focus is not on eliminating the symptom, but on the cause.

\section{Method}

Psychotherapy of psychosomatic disorders is a responsible process and in most cases works with the painful awareness of the fact that a person is a bearer of self-degrading memories, intentions, traits and this is alarming. The desire to be saved from it acts as a motive for pushing out painful information. This repressed information, as well as the ongoing process of repression, has an unconscious nature, but for all of them, there is inherent evidence confirming their real existence. The leading part of this evidence is "uninvited, unsympathetic guests," which Freud called "symptoms." Methods of the most popular psychological theories are used for the aims of this report. The task of psychoanalysis and psychotherapy is to reveal specific manifestations of

(C) Authors. Terms and conditions of Creative Commons Attribution 4.0 International (CC BY 4.0) apply. Correspondence: Lubomira Dimitrova (PhD student), South-West University "Neofit Rilski", Faculty of Philosophy, Department of Psychology, Blagoevgrad, BULGARIA. E-mail: lubomira16@abv.bg. 
the relationship: repressed painful information - its specific conscious manifestations (symptoms).

In adolescents, unsatisfied desire causes frustration with an even stronger magnitude than in adults, and as a result, the child feels helpless and powerless. The natural emotional response to a blocked or thwarted desire is the appearance of anger as a pleasurable relief of the frustration process. Anger is the only tool by which a teenager can regain "power" over the situation (Wirsching, 1984).

In many cases, for one reason or another, it is difficult to express the spectrum of emotions experienced, because the nature of anger is of the "caliber" of the attacking emotions. When he is suppressed, along with the desire, he attaches himself to the Self and attacks it in parallel. The pronounced symptoms are the result of the attack on the Self (Peseschkian, 1977).

In the human psyche, no desire is denied: when it is impossible to fulfill and realize in the parameters desired by the Self, it is fulfilled in the form of psychosomatic symptoms. The paradox is that it is difficult to part with even some of the most painful symptoms because they are his satisfied needs. Due to the process of suppression of anger described above and since the symptom that appeared afterward is a satisfied desire, rules are formed regarding anger and symptoms, which indicate the following points:

- Where there is repressed anger, along with repressed desire, not only will there be symptoms, there must be symptoms;

- Where there is no repressed anger and repressed desire, not only will there be no symptom, but there can be no symptom;

- Where there is a symptom, not only will there be suppressed anger along with suppressed desire, but there should be suppressed anger with suppressed desire;

- Where there is no symptom, not only will there be no repressed anger and repressed desire, but there can be no repressed anger and repressed desire.

Despite the individual approach to each case of psychosomatic manifestation in adolescents, what they have in common is the reason for the appearance of anger, which lies behind the question "who?". In some cases, when the answer to "who?" In human equivalent is absent, then the target of this anger becomes the Self. This autoaggressive response gives rise to psychosomatics (Ringel, 1978).

When the target of anger is identified and this emotion is subsequently realized, then the anger disappears more easily in the process of psychotherapy. This process takes place by involving anger in "actively doing and doing something" related to the original desire. These actions accelerate the erasure of the symptom. The active participation of man puts him "in front of the line" - in a real place, outside the space "behind the line" - i.e. beyond the withdrawal in which the symptoms of the psychosomatic spectrum reside.

When the symptom is the result of implosion, due to anger directed at the Self, and given the high levels of magnitude, intensity, penetration, and chronicity of this anger, the maximum irradiation of the psyche involves overcoming the symptom by adding medication (Langen, 1968).

Anxiety caused by this whole process is a symptom in itself. The alarm is experienced in a specific way in adolescents. The above contingent between 5-18 years. deliberately avoids talking about painful and repressed topics, which are the roots of the angry and anxious reaction. In the psychotherapy office, the client performs a verbal account of the anxiety experienced. 
Verbalizing his emotion, a person is verbally "poor" in terms of experiences, even in terms of facts, due to the unconscious desire to suppress the rising anxiety (Jores, 1981).

My psychotherapeutic practice testifies to a directly proportional connection between personal anxiety and the manifestation of verbal and bodily aggression. The individual rebels against anxiety and this forces him to include aggressive behaviors in his behavioral repertoire. Therefore, the registration of such forms by the psychotherapist should be assessed as a sign of unconscious interest in blunting anxiety, which is based on repressed predecessors. All my hypotheses about the above were confirmed based on a study of 150 adolescents between 5 and 18 years of age to which the following methodologies were applied:

- Spielberger Self-Assessment Scale;

- Bus-dyurki aggression test.

\section{Results}

After an applied correlation analysis between the levels of personal anxiety and verbal aggression and personal anxiety and physical aggression, a proportional relationship was established in both directions. After analysis of the results of the applied statistical procedure, using the SPSS software, the presence of a significant, strong proportional relationship between personal anxiety and the manifestation of verbal aggression $(\mathrm{r}=0.585$; $\operatorname{sig}<0.001)$ and a proportional relationship with the presence of a strong and significant relationship between personality anxiety and the manifestation of physical aggression in the studied 150 adolescents undergoing psychotherapeutic process $(\mathrm{r}=0.586$; $\mathrm{sig}<0.001)$, where " $\mathrm{r}$ " is a correlation coefficient and "sig" determines the significance of the correlation. The obtained results are a contribution to the work of the psychotherapist, due to their statistical significance, relative to the whole population, and not only to the specific sample ( $\mathrm{Sig}<0.005)$.

The available psychosomatic symptoms, based on which the results discussed so far are derived, include a wide range of disorders, including those of an "implosive" nature, such as schizophrenia, personality disorder, affective and depressive disorders (Freud, 1956).

In psychotherapy with adolescents, the deep connection between traumatic childhood experiences and current behavioral manifestations in the form of clearly expressed symptoms has been established. The process included a family psychotherapeutic intervention, and with 10 of the families, the work continues to this day.

\section{Discussion}

Going through the emotional equivalents of the three interaction stages:

(1) Connection;

(2) Identification;

(3) Separation.

Above all, focusing on connection rather than separation reduces parental anxiety and allows the therapist to continue working on delegating independence to adolescents, which precedes the formation of responsibility as a key personality trait.

In many of the studied cases, after conducting a primary psychotherapeutic interview, the presence of autoaggressive manifestations was established, and the most common form of auto aggression is the depressive state (Dunbar, 1936). 


\section{Conclusion}

Regardless of the type of symptom and its magnitude, the relief of accumulated stress occurs by going through 4 basic steps to peace of mind, the key of which is to establish the origin of anger. The subsequent process is individual for each client, but the work of the therapist is more focused and aimed at eliminating NOT the symptom, but the cause of its appearance, which is the main task of the psychotherapeutic process.

\section{Acknowledgements}

This research did not receive any specific grant from funding agencies in the public commercial, or not-for-profit sectors.

The author declares no competing interests.

\section{References}

Dunbar, F., Wolfe, T., \& Rioch, J. (1936). Psychiatric aspects of medical problems: The psychic component of the disease process (incl. Convalescence) in cardiac, diabetic, and fracture patients. Am $J$ Psychiatry, 93, 649-679.

Freud, S. (1956). Abri $\beta$ der Psychoanalyse. S. Fischer, Frankfurt am Main.

Jores, A. (1981). Praktische Psychosomatik. Huber, Bern Stuttgart Wien.

Langen, D. (1968). Der Weg des autogenen Trainings. Steinkopf, Darmstadt.

Ringel, E. (1978). Das Leben wegwerfen. Herder, Wien.

Peseschkian, N. (1977). Positive psychotherapy. Springer: Berlin, Heidelberg, New York.

Wirsching, M. (1984). Familientherapeutische Aspekte bei Colitis ilcerosa und Morbus Crohn. Zschr Psychosom Med, 30, 238-246. 


\title{
Experimenting with Factors Enhancing Reading Comprehension of Media Texts in University Students Majoring in IR Studies
}

\author{
Elena Korotkova \\ Far Eastern Federal University, Vladivostok, RUSSIAN FEDERATION \\ Oriental Institute - School of Regional and International Studies
}

Received: 21 October 2020 • Accepted: 1 December 2020 • Published Online: 25 December 2020

\section{Abstract}

The goal of the current paper is to trace the way text-structure knowledge (TSK) and TSK related activities incorporated in students' experimental learning enhance reading comprehension (RC) strategies and contribute to higher comprehension indexes of contemporary media texts by $\mathrm{B} 2+$ level university students majoring in International Relations (IR) studies. The paper presents new notions of media text structure relating to text patterns, its general and specific information, topic sentence and main idea, text hierarchy levels etc. that hypothetically facilitates the perception of textual information and builds up a new cognitive mechanism in students. Research methods are thoroughly described in the article. Experimental data during the two-year period of 2018-2020 are submitted illustrating the most and the least developed RC strategies, those of drawing inferences and interpreting implicit information focusing on recognizing underlying assumptions being the least developed ones. Students' RC levels from frustration and instructional to an independent one have been systematized. Statistics confirm that the chosen relationship between media text structure knowledge and effective RC strategies boost the accuracy of comprehension levels in ESP students, thus, proving the efficiency of this method.

Keywords: text-structure knowledge (TSK), TSK related activities, reading comprehension strategies, media text, comprehension levels, experimental data, International Relations studies.

\section{Acknowledgements}

This research did not receive any specific grant from funding agencies in the public commercial, or not-for-profit sectors.

The author declares no competing interests.

(C) Authors. Terms and conditions of Creative Commons Attribution 4.0 International (CC BY 4.0) apply.

Correspondence: Elena Korotkova, Far Eastern Federal University, Oriental Institute - School of Regional and International Studies, Vladivostok, RUSSIAN FEDERATION. E-mail: korotkova.e2010@yandex.ru. 
E. Korotkova - Experimenting with Factors Enhancing Reading Comprehension of Media Texts in ...

C O A $\mathrm{s}$ 


\title{
Nietzsche and the Search of New Values
}

\author{
Valeri Valchev \\ South-West University "Neofit Rilski”, Blagoevgrad, BULGARIA \\ Faculty of Philosophy, Department of Philosophical and Political Sciences
}

Received: 1 December 2020 - Accepted: 24 December 2020 - Published Online: 25 December 2020

\section{Abstract}

The aim of the present study is to analyze and present Friedrich Nietzsche's ideas about the role of values in philosophy and their reassessment. Over a period of time Nietzsche's ideas regained popularity and brought back to the fore the topicality they had never lost. Speaking of F. Nietzsche and his ideas, we cannot fail to mention the concepts of revaluation, superman, Christianity and God. The other characteristic of F. Nietzsche is his aphoristic and metaphorical style, which is sometimes condemned and denied, sometimes supported and welcomed. Nietzsche's aspiration is to go beyond the masses, to search for the new and different in the projection of modern man - as a reappraisal of values and a search for new values. The other goal of the study is to show the similarities and differences of Nietzsche's thought with "dissenting" philosophers. There is a huge amount of literature on the subject, but for the present study, the works of F. Nietzsche will be used in the first place.

Keywords: Friedrich Nietzsche, search, new values.

\section{Introduction}

The aim of the present study is to analyze and present Friedrich Nietzsche's ideas about the role of values in philosophy and their reassessment. Over a period of time, Nietzsche's ideas regained popularity and brought back to the fore the topicality they had never lost. Speaking of Nietzsche and his ideas, we cannot fail to mention the concepts of revaluation, superman, Christianity and God. The other characteristic of Nietzsche is his aphoristic and metaphorical style, which is sometimes condemned and denied, sometimes supported and welcomed. Nietzsche's aspiration is to go beyond the masses, to search for the new and different in the projection of modern man - as a reappraisal of values and a search for new values. The other goal of the study is to show the similarities and differences of Nietzsche's thought with "dissenting" philosophers. There is a huge amount of literature on the subject, but for the present study, the works of Nietzsche will be used in the first place. The fragment is perhaps the new that replaces the old way of thinking.

(C) Authors. Terms and conditions of Creative Commons Attribution 4.0 International (CC BY 4.0) apply. Correspondence: Valeri Valchev (PhD student), South-West University "Neofit Rilski", Faculty of Philosophy, Department of Philosophical and Political Sciences, Blagoevgrad, BULGARIA. E-mail: vvalchev1234@abv.bg. 


\section{The revaluation of values}

Nietzsche focuses on this very problem, with the difficult task of thinking and making sense of the reassessment of values. Can God be dead? What causes nihilism? Why is a reassessment necessary?

These are the outstanding questions that we will look for answers to, and the goal is to find the need to re-evaluate values. The systematics is rejected as a technique by Nietzsche, we could even say that there is a certain "disorder" in his works. The person lives in delusion through the wrong ideas that have arisen over time, the main thing being to overcome them. Nihilism arises as a reaction against the current situation. The concept was taken by Arthur Schopenhauer: "will to live" was transformed by Nietzsche into "will to power".

Life has already become an aspiration, a "will" to rule over others. The meaning of life is what we give it. The "reassessment" is linked to the critique of Christianity and the death of God. Death, which marks the birth of the "new" and the "new values," is here the epicenter of the statement made by Zarathustra in the glorification of life. Zarathustra is the praiser of life (Nietzsche, 1990). The old beliefs have been interpreted as a regress, the aspirations for selfrealization of man have sunk into the old delusions. Regression is expressed in the loss of the meaning of life and the thirst for life, which is already absent from it, going beyond monotony is the way out of regression.

All eyes are on the person himself, after "God is dead", so that life itself can become more valuable. Nietzsche reassesses values, giving a new meaning to life, to its value. All criticism is focused on traditional values so far.

The most striking idea is perhaps that of the Übermensch (Superman or Superhuman), from which the other ideas will follow. If we place the idea of the Superman as a starting point to the idea of the revaluation of values and from it, as a kind of center from which all revaluations will start, we may be able to see the whole picture, the whole world, the world of Nietzsche, which he created and wanted to introduce us.

Nietzsche can be understood through Zarathustra: "I teach you the Superman. Man is something that should be overcome", to be replaced by the "Superman," "The superman is the meaning of the earth" (Nietzsche, 1990: 28).

This statement is a starting point. The Human has to change in all directions, to grow, to change one's religion or attitude. Here we can highlight the critique of Christianity. Nietzsche is an author who can be seen from many and different points of view, looking at many and different aspects of philosophy.

Christianity will be one of the topics of thought and strongly criticized by Nietzsche. For Nietzsche, the full development of Human is not achieved because Christian morality makes us all equal and reduces our capacity for "will":

"God is Dead" (Nietzsche, 1990: 27). Therefore, man is left alone, with himself, whence perhaps the "Superman" of Zarathustra will appear: "Man is something that should be overcome: and therefore you are obliged to love your virtues - because they will destroy you!" (Nietzsche 1990: 11). The emphasis is on opening the way of man to his self-realization and self-development, this new direction for man, as his overcoming, requires a harsh critique of established values.

Most of Nietzsche's work focuses on criticism and rethinking ethics and morality. Isaac Passy in his preface to Thus Spoke Zarathustra says: "It is not possible to live outside of morality - beyond good and evil" (Nietzsche, 1990: 13). Therefore, we must live within the bounds of morality. And the opposite: life is possible in immoral thinking, contrary to the imposed moral criteria. Criticism is directed at the non-traditional world, at the world and life "trance", "beyond" life. From the standpoint of life, of current morality, and from the point of view of morality, it is 
difficult to make the right decision: whether it is possible to live in morality - "beyond good and evil." Or there is an opportunity to live in normal thinking. The idea is to show the reappraisal of values, through the critique of the ethical and moral in Nietzsche's philosophy.

This is probably the time to recall the words of Isaac Passy, who made the connection between nineteenth-century antiquity and irrationalism in Nietzsche's philosophy: on the other hand, the more attractive is that written phrase in which they feel, present themselves, without being present themselves. And this makes Nietzsche a rare combination of homo scribes with homo rhetoric in the history of philosophy - and in this respect, he can only be compared to a select few, among whom are undoubtedly Plato, Augustine, Schopenhauer, Kierkegaard, that is, authors, who are as many philosophers as writers, and as many writers as philosophers" (Nietzsche, 1994: 6). Common positions are found between the authors, and the theme of God is common.

\section{The joyous science}

Here is what Nietzsche wrote about "the joy of science" and the relationship with God: "What does our joviality mean? The greatest recent event - that "God is dead", that faith in the Christian God is no longer trustworthy" (Nietzsche, 1994: 197). In terms of "jollity", it becomes intrinsic to science. This view, presented by Nietzsche, is quite interesting and leads us to further questions and subsequent answers. Here is the answer: Nietzsche has a unique and unconventional way of writing and expression present in his works. Nietzsche does not accept the system as a method and as "theoretically impossible", as "morally unacceptable", because the impossibility hides a moral component with a negative sign, so he does not use systems: "But whatever the advantages of the aphorism, no matter how "Joyous" science is, if it is still a science, it cannot but presuppose at least some - more or less definite - system, that is why one of the connoisseurs of Nietzsche's philosophy defines the Joyous Science as a system of aphorisms." (Nietzsche, 1994: 10). Regarding the issue of the system, I. Passy writes: "One system has not yet fully revealed its capabilities, and here it is, and often against it, another, offering greater opportunities" (Passy, 1991: 5). Each system leaves unfinished revealed secrets. Although Nietzsche initially rejected systematicity, Nietzsche still retained and used part of it, turning it into a "system of aphorisms," perhaps showing the superiority of his "system" over other systems.

Joy seems to be invariably present in Nietzsche's field of vision as if it gives strength, a premonition of the future, "they, the ideas, must have something to make them joyous." (Nietzsche, 1994: 10). The Jollity can be reproduced by freeing oneself from the influence of higher powers and former idols. Things that hinder the upliftment and improvement must be abandoned, "because only with this dear sacrifice can he achieve his forward movement and ascension" (Nietzsche, 1994: 11).

We can say that joy is a path to liberation to new horizons, albeit beyond the horizon, to remain God, the collapse of the old and the construction of the new, to some extent and the abandonment of something, but as an option, tragedy is not excluded. The individual should give up his current way of thinking in order to be able to accept the new that lies ahead in his life: "God is dead, He is killed, removed, so that man can come in His place (and let him be a Superman!)" (Nietzsche, 1994: 11).

With this comes a reassessment of values, forgetting the old and accepting the new. Joy comes as a result of God's death, and it is replaced by a man with the new morality or "superman" as a symbol of the new change, of completeness, of the reappraisal of old values and the perception of new ones. Nobility as a value is also present in most of Nietzsche's works, as the cause of nobility is passion. Joy seems to be this thin line of the transition that Nietzsche makes and at the same time binds joy, the religious, expressed through Christianity, even, "almost some 
madness," the moral, and the reappraisal of values. The reappraisal of values seems to be the end, the crown and the crown of Nietzsche's philosophy. Here we can recall Schopenhauer's words, which are semantically the same, the meaning in our case is that which is in question and sought: "But although these forms of knowledge are embedded in ourselves, they still have a single goal the emergence of consciousness about other things" (Schopenhauer, 1994: 51).

Nietzsche is obviously not satisfied with the state of man, he believes that man has the opportunity to realize, to move to a higher stage in his development, becoming a superman, overcoming his own self, dissatisfied with his current existence. Joy and the ensuing actions can also be found in laughter, which Nietzsche included as part of the process of reassessment and cheerfulness "Let a man laugh at himself, as he should laugh, to express with his laughter the whole truth - for such a manifestation even the best have not reached honesty, and the most gifted genius! Maybe laughter is a matter of the future! It will occur when the law "the genus gender is everything, the individual is always nobody" is fully accepted by humanity and everyone could at any time achieve this ultimate degree of liberation and irresponsibility. Perhaps then laughter will be united with wisdom, maybe then we will have only one "Joyous science" (Nietzsche, 1994: 40)

In the transcendence of man and his replacement by the Superman, the moral norms are replaced, the former man is to be overcome, the basis of overcoming is self-awareness. It is the main driving force behind the revaluation of values in my opinion. Nietzsche says: "Life must be loved", "Life must be loved because!", "Human must be useful to oneself and to one's neighbor because!", It is as if all these "musts" and "becauses" are called and will be called in the future! In order that what always happens by itself and without any purpose may from now on seem purposeful and be perceived by man as reason and supreme command, the teacher of ethics appears, as a teacher who reveals the purpose of being. To this end, he invents a second, different being, and with the help of the new mechanics shakes the old, ordinary being, detaches it from its old ordinary hinges" (Nietzsche, 1994: 40).

Everything is aimless to focus on a goal, but not any goal, but a new ethical goal, a goal of existence, beyond the "old" with a project to the future. Life is an opportunity to upgrade oneself, an opportunity to move to the next new step.

In life, human relations have become important, in support of the statement we add Jung's words, supporting the statement of self-esteem and self-knowledge, to the reassessment of values and the division of being in Nietzsche: "How else would it occur to man to divide the cosmos by analogy with day and night, summer and winter into a bright day world and a dark night world inhabited by incredible monsters, if he does not have the prototype of such a division within himself, the polarity between the conscious and the invisible and unknowable unconscious? The perception of objects by primitive man is determined only in part by the objective behavior of things themselves" (Jung, 1999: 109).

And Nietzsche writes: "The majority does not find it reprehensible for a person to believe in one thing or another and to live according to this belief, without first having ascertained the final, irrefutable arguments for and against this belief and without even making an effort to point out such arguments - the most gifted men and the noblest women - belong to this "majority." But what does well-being, finesse, and genius mean to me, if a person with such virtues allows himself to be indifferent in his feelings and judgments, if the desire to have confidence is not for him the deepest passion and deep necessity - something that distinguishes the higher personalities from the lower ones!" (Nietzsche, 1994: 42). No one can deny the distinction between day and night, or in other words the duality of the world, and sometimes the duality of the human choice that shapes our ideas, including, according to Nietzsche, faith, without evidence concerning his judgments and feelings. Confidence is also an important trait. It is not at all possible to understand how "experience," in the broadest sense of the word, or in this case anything psychic, 
can arise only from the outside world. The psyche is part of the innermost secret of life, and it has its own specific structure, shape and focus.

Whether this mental structure and its elements, archetypes, "originate" at all is a metaphysical question that cannot be answered" (Jung, 1999: 110). But can being be forgotten? A being emptied of content and meaning, but still existing. Nihilism is related to being itself, it is related to the "superman", to his inner and outer world, psyche and physics, to the other step "above" man, not related to the ordinary person. The human psyche, indeed, cannot be understood sometimes and where a person's decisions in certain situations come from: "This is how consciousness is tyrannized - and not least because a person is proud of it. According to him, it is the essence of man, the permanent, the eternal, the last, the original in him. Consciousness is considered a constant, given quantity. Deny her growth, her interruptions! Accept it as "unity of the organism!" (Nietzsche, 1994: 48-49). The organic has its last phase of development and that is consciousness. According to Nietzsche, consciousness is the most incomplete and the last stage of development, it is the cause of many wrong moves.

"Consciousness is considered a constant, given quantity" - Nietzsche wrote. Can the implication of old values be made with new ones, in this "death of God and the lowering of values of the highest degree"? According to Nietzsche, all values of the highest degree have disappeared, the most valuable - God's. But values have the opportunity to spread in their basic and natural form, in which to undergo a metamorphosis: "In place of morality and justice are placed the precepts of the law, of law. Moreover, morality and justice are seen not only as something relative and arbitrary, not only as something primitive and unprovable but also as something non-existent, as another illusion of human emotionality. There is no need for morality, after which there are a reasonable social contract and positive legislation.

Out of condescension, morality is allowed to exist only in the private sector of human life, along with all other arbitrary, unreasonable and primitive emotions, tastes and preferences. Morality is a matter of personal choice, it can be any, as long as it does not violate the social contract" (Kanev, 2008: 43). According to Kanev, the law of law has displaced morality and justice, they are also described as relative and arbitrary, primitive and unprovable, even illusory and nonexistent.

For Nietzsche, nihilism as a whole is the ultimate goal that must be achieved, all we must want. It has found its last expression in modern pessimism, as living and dramatic fulcrums: "man against the world", "man - denying the world as a principle", "man - a measure of things", "man - judge of the world" (Nietzsche, 1994: 202-203). Here again, Nietzsche's view of the divine is evident, as it is not moving in the world, not in human decisions, new values must be sought in the real world. The world is no longer one, it has split, it has even become multidimensional, and this is the modern human situation in a globalizing world that requires new values and new values.

\section{Conclusion}

I end with the thought of Isaac Passy, which I think shows the projections of the human spirit: "The universe is infinite, it knows no boundaries and points, and this is the human skill in the ability to discover and place them in them, only in them to realize what human can really do" (Passy, 2003: 682). Values, perhaps, are so important because they are the driving force of man.

Each of us must arrange our own values so that we are satisfied with their order and this order becomes the basis of his actions and development. If each of us does, we may live in a better world. 
Values are ideals or beliefs of good and bad, wrong and right. Probably the values are those laws that determine the relationship between us.

After analyzing Nietzsche's ideas, we found that his reassessment marked the beginning of the search for new values that would reveal the new value horizon to modern man.

The need arises to answer the question: How can one continue human development in the global world? And one of the possible answers: Ethics is the one that reveals the purpose of being.

\section{Acknowledgements}

This research did not receive any specific grant from funding agencies in the public commercial, or not-for-profit sectors.

The author declares no competing interests.

\section{References}

Kanev, P. (2008). The values of modernity and globalization. Philosophy, 3-4, 43. [Канев, П. Ценностите на модерността и глобализацията. - В: сп. Философия, 3-4/2008, с. 43].

Nietzsche, F (1994). The joyous science. St. Cl. Ohridski University Press. Sofia. Bulgaria. [Ницше, Ф. Веселата наука. УИ „Св. Кл. Охридски“. София. България].

Nietzsche, F. (1990). Thus spoke Zarathustra: A Book for All and None. Hristo Botev Publishing House.Sofia. Bulgaria. [Ницше, Ф. Тъй рече Заратустра. Издателство „Христо Ботев“. София. България].

Nietzsche, F. (1990). The antichrist. Eurasia Abagar Publishing House. Sofia. Bulgaria. [Ницше, Ф. Антихрист. Издателство Евразия Абагар. София. България].

Passy, I. (1991). German classical aesthetics. Science and Art Publishing House. Sofia. Bulgaria. [Паси, И. Немска класическа естетика. Издателство „Наука и изкуство“. София. България].

Passy, I. (2003). Selected works in six volumes. Volumes 6. Zahari Stoyanov Publishing House. Sofia. Bulgaria. [Паси, И. Избрани произведения в шест тома, Том шести. Издателство „Захари Стоянов”. София. България].

Schopenhauer, A. (1994). Ethics or philosophy of compassion. Eurasia Abagar Publishing House. Sofia. Bulgaria. [Шопенхауер, А. Етика или философия на състраданието. Издателство Евразия Абагар. София. България].

Jung, K. G. (1999). The archetypes and the collective unconscious. EA Publishing House. Pleven. Bulgaria. [Юнг, К. Г. Архетиповете и колективното несъзнавано. Издателство „ЕА”. Плевен. България]. 


\author{
E-Conference Discussion
}

1\#

Cecilia Alejandra Marambio Carrasco \& Carla Lobos (

2o December 2020, oo:05 (GMT+o1:0o) - Presentation: Situational map: A strategy to develop critical thinking in the teaching of scientific research

Presentation - PDF

2\#

Elizaveta Panova (14)

20 December 2020, oo:05 (GMT+01:00) - Presentation: Word-image interaction in the treatise "Voyage en Siberie"

Presentation - PDF

\#3

Lubomira Dimitrova (019)

2o December 2020, 18:32 (GMT+o1:0o) - Comment on oo1: L2 teaching to PR undergraduates through theatre techniques elements

Your report is very interesting for me as a researcher. I would like to ask you a question about what made you interested in this subject. Thank you.

\title{
\#4
}

Elizaveta Vishnyakova, Olga Vishnyakova, Alla Minyar-Beloroucheva \& Polina Sergienko (oo1)

2o December 2020, 19:57 (GMT+o1:0o) - Response to \#3 (comment on oo1): L2 teaching to PR undergraduates through theatre techniques elements

Dear Lubomira Dimitrova, thank you for your interest in our research. Your question is very important as it concerns everybody at the present time during the pandemic. It is essential for us to make our undergraduates happy. The only way to achieve it is to address the existing technology which is seldom used beyond the doors of theatrical colleges. As for the scope of your report Psychotherapy of psychosomatic anxiety responses (․ㅣㅇ), it concentrates on specific medical issues. Within this topic, theatre technologies can also be regarded as a certain psychotherapy.

\#5

Elizaveta Vishnyakova, Olga Vishnyakova, Alla Minyar-Beloroucheva \& Polina Sergienko (oo1)

20 December 2020, 20:15 (GMT+o1:0o) - Comment on o14: Word-image interaction in the treatise "Voyage en Siberie"

The report Word-image interaction in the treatise "Voyage en Siberie" is unique, because it deals with the works by French painter and etcher Jean-Baptiste Le Prince (1734-1781). The artist illustrated the book written by the French abbot and astronomer, member of the French Academy of Sciences Jean Chappe d'Auteroche (1722-1769), who travelled across Russian Siberia in the 18th century. The life of the people described in literature, was visualized in the cycle of works of art 
called "Russerie". The artistic value of the illustrations was highly appreciated both in France and in Russia. The work performed by Elizaveta Panova is important as it raises interest in the Russian culture and history. Thank you for the ppt-presentation provided for the conference.

\#6

Colleen Kennedy-Karpat (이)

20 December 2020, 20:40 (GMT+o1:00) - Comment on o14: Word-image interaction in the treatise "Voyage en Siberie"

Fascinating study, with valuable insight into the development of Russerie in France. Thanks particularly for the illustrations in the slides!

A question about the genesis of this text, which, if I understand the paper, was basically a travel narrative undertaken as a kind of side project during a research trip for astronomical observation. Generally speaking, how often would such methodologically produced travel documentation have been a secondary product of scientific research? Was this common particularly among French researchers during the Enlightenment, or can this be described as a more widespread phenomenon (either considering time frame or country of origin)?

\#7

Elizaveta Vishnyakova, Olga Vishnyakova, Alla Minyar-Beloroucheva \& Polina Sergienko (oo1)

20 December 2020, 21:01 (GMT+o1:00) - Comment on o20: Experimenting with factors enhancing reading comprehension of media texts in university students majoring in IR studies

The report called "Experimenting with factors enhancing reading comprehension of media texts in university students majoring in IR studies" is of certain interest as well. The abstract is very interesting, as it intrigues the readers by the depth of the research. Much has been written about international relations discourse and the methods of teaching L2 to PR undergraduates and IR students. This paper presents new notions of the structure of the media text, its patterns, general and specific information given in it, topic sentence and the main idea. The author is sure that such an approach can facilitate the perception of textual information and develop cognitive abilities.

\#8

Elizaveta Vishnyakova, Olga Vishnyakova, Alla Minyar-Beloroucheva \& Polina Sergienko (oo1)

20 December 2020, 21:08 (GMT+o1:0o) - Comment on o15: Particularities of defense in judicial rhetoric

The report "Particularities of defense in judicial rhetoric" is devoted to public defense speech in court. It presupposes the group communication dealing with information, persuasion and suggestion of the audience and the jury. These rhetoric devices of defense speech address the mind and feelings of the people. The analyzed speech patterns are useful not only for the students of law per se, but for L2 PR undergraduates as well as students of politics, international relations and history.

\#9

Elizaveta Vishnyakova, Olga Vishnyakova, Alla Minyar-Beloroucheva \& Polina Sergienko (ㅁo1)

20 December 2020, 21:22 (GMT+01:00) - Comment on o13: Application of problematic situational tasks method at Russian as a foreign language classes in technical high school 
The report "The studying of Russian phraseological units and paroemias in English speaking audience" by Anna Baskakova is highly important, as is compares the paroemias and phraseological units to find out similarities and differences of the conceptual fields of Russian and English peoples. The paroemias chosen for the research deal with family and work (labour), which are considered to be the universal concepts of humanity. The report is useful for all professionallyoriented L2 students of humanitarian scope. This knowledge enriches the worldview, enforces the understanding and promotes international communication.

\#10

Elizaveta Vishnyakova, Olga Vishnyakova, Alla Minyar-Beloroucheva \& Polina Sergienko (oo1)

20 December 2020, 21:36 (GMT+01:00) - Comment on o05: Application of problematic situational tasks method at Russian as a foreign language classes in technical high school

The report which is called "Application of problematic situational tasks method at Russian as a foreign language classes in technical high school” presented by Elena Shtekhman, Yulia Melnik and Anastasia Zhurova, deals with educational process demanding permanent improvement. In their article the authors discuss new forms and methods of teaching Russian as a foreign language which can be applied to teaching other languages as well. The objectives of the research are concentrated on training highly qualified graduates with perfectly developed competences.

\section{\#11}

Cecilia Alejandra Marambio Carrasco \& Carla Lobos Stevens (004)

20 December 2020, 22:26 (GMT+o1:0o) - Comment on oo4: Situational map: A strategy to develop critical thinking in the teaching of scientific research

The study focuses on developing a mental pattern model to teach university students to think critically, especially, lead them towards the evolution of a scientific mental structure, which allows them to develop both quantitative and qualitative investigations. The mental pattern developed is called the Situational Map and allows students to organize their ideas, so they can focus on the real problem of the context under study. The students have managed to carry out relevant and pertinent research, $100 \%$ of them have applied the Situational map and 81.5\% managed to develop critical reflection skills and problem solving.

\#12

Elizaveta Panova (․14)

20 December 2020, 22:46 (GMT+01:00) - Response to \#6 (comment on o14): Word-image interaction in the treatise "Voyage en Siberie"

Dear Colleen Kennedy-Karpat, thank you for your interest in my research. I have found it very interesting and useful to think over your question. As far as I know, the descriptions, secondary to scientific research, are very common during the Enlightenment, not only among French travelers but also among Europeans, in general. In my opinion, this is due to the instructions the travelers received from the scientific organizations had sent them. Unfortunately, I don't know any examples of instructions given to French travelers, but I know that the Russian Academy of Science at that time gave orders to travellers: firstly, to make sketches of everything that seemed curious to them, and secondly, to keep accurate diaries of everything that happens during the expedition. In fact, these diaries were included in the treatises that were published under the patronage of the Academy. I hope, I have managed to answer your question. 
\#13

Liudmila Osinovskaia \& Yuliya Shekhovskaya (ㅁ12)

20 December 2020, 22:59 (GMT+o1:0o) - Presentation: Russian and English metaphorics: Comparative analysis of biathlon discourse

Presentation - PDF

\#14

Liudmila Osinovskaia \& Yuliya Shekhovskaya (1ㅡ)

20 December 2020, 23:08 (GMT+o1:00) - Comment on o12: Russian and English metaphorics: Comparative analysis of biathlon discourse

In our report we would like to underline metaphor role and use in the biathlon mass media discourse framework. The research of biathlon discourse enriches metaphor definition. The concept "biathlon" serves the material for the analysis of metaphorical meaning transfer. We pay much attention to the question of metaphorical formation role and functions within biathlon mass media discourse. The article contains information on the classification of basic metaphorical models. The study defines groups of Russian and English metaphors in biathlon mass media discourse and reveals their linguistic and intercultural differences. To obtain data, we use comparative analysis method. We prove the importance of metaphors in biathlon mass media discourse quantitively. That lets us assume metaphor as a means of avoiding speech monotony therefore enhancing its emotional influence within biathlon mass media discourse.

\#15

Cecilia Alejandra Marambio Carrasco \& Carla Lobos Stevens (o4)

21 December 2020, o8:49 (GMT+o1:0o) - Comment on oo1: L2 teaching to PR undergraduates through theatre techniques elements

I found your research very interesting, since I have witnessed in my own classes that emotions are a key factor when learning. I teach undergraduate students from the English teacher training program, so they also need to understand that their future students must feel comfortable and safe, in order to successfully learn the L2. This year specially, emotions played a key role in our lessons, so it's definitely a subject to keep on learning about.

\#16

Cecilia Alejandra Marambio Carrasco \& Carla Lobos Stevens (o4)

21 December 2020, o8:57 (GMT+o1:0o) - Comment on oo4: Situational map: A strategy to develop critical thinking in the teaching of scientific research

This mental pattern called Situational map, becomes much needed in the Chilean or even in Latin American context, where in most schools, skills such as critical thinking are not trained. Undergraduate Students often struggle when developing their research projects, and this study shows how this mental pattern helped them to organize their ideas and supported them in their analytical processes when writing their thesis.

\#17

Petar Dimkov (ㅁ18)

21 December 2020, 14:45 (GMT+o1:00) - Comment on o19: Psychotherapy of psychosomatic anxiety responses 
The paper of L. Dimitrova raises and discuss the important question of the treatment of psychosomatic disorders, notably anxiety, with psychotherapy.

Depression often cooccurs with anxiety. Both CBT and antidepressants can be very useful for anxiety. There is evidence that CBT and antidepressants are equally effective for the treatment of depression (https://doi.org/10.1038/nrn2345; https://doi.org/10.1038/npp.2011.183). Cognitive enhancement (eg modafinil) by improving cognitive control can be beneficial as add-on (https://doi.org/10.1038/npp.2011.183).

Some cases wouldn't be resolved by psychotherapy alone. Thus, one has to consider combinations. Temkov \& Kirov (Clinical Psychopharmacology, 1976) show that combinations are more effective compared to monotherapy treatments. The combination of CBT + cognitive enhancement is encouraging. For worst cases, a triple combination of CBT + cognitive enhancement + antidepressant can be effective.

Thus, my question is the following one: What is your opinion about these combinations compared to psychotherapy monotherapy for the treatment of anxiety and mixed anxious-depressive disorder?

\#18

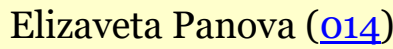

21 December 2020, 14:53 (GMT+o1:0o) - Comment on oo1: L2 teaching to PR undergraduates through theatre techniques elements

The article discusses a very important issue of today: how to distract PR graduates form depressive ideas at the time of on-line teaching/studying of L2 PR graduates in particular and university graduates in particular caused by the pandemic. It is evident, that in the class or on-line class both teachers and undergraduates perform their roles.

The idea of bringing theatre to a classroom is not new. 1 Plays and their parts have always been staged in class. It has always motivated students to learn foreign languages. The article is very interesting and useful for all ESP teachers.

\#19

Elena Shtekhman, Yulia Melnik \& Anastasia Zhurova (005)

21 December 2020, 18:11 (GMT+o1:0o) - Comment on o13: The studying of Russian phraseological units and paroemias in English speaking audience

The caption refers to the main problem of the article - how to explain Russian idioms to English speaking learners.

The article focuses not only on analysing the vocabulary, but also on offering the ways of teaching such vocabulary (using examples). The author outlines some idioms and paroemiological units in order to describe the connection between lexical and cultural sides which any language contains. In conclusion, the author notes that comparing idioms of two different languages (students' native language and Russian one) will also be very helpful for a successful intercultural communication.

\#20

Elena Shtekhman, Yulia Melnik \& Anastasia Zhurova (․0.5)

21 December 2020, 18:23 (GMT+o1:0o) - Comment on oo1: L2 teaching to PR undergraduates through theatre techniques elements 
The article deals with up-to-date issue in foreign language teaching. The authors examine useful and non-trivial technique for L2 teaching via theatrical performances. Such training combines educational, pedagogical, methodological and psychological components promoting students' motivation. The authors provide a solid theoretical base as well as ideas of practical application. The suggested approach seems to be highly effective and worth the attention of practicing teachers and instructors.

\#21

Elena Shtekhman, Yulia Melnik \& Anastasia Zhurova (0.5)

21 December 2020, 18:30 (GMT+o1:00) - Comment on o15: Particularities of defense in judicial rhetoric

The author emphasyses that in the course of history, judicial rhetoric has conserved its main rules. They are still in use by European advocates for defense purposes in courts nowadays. The article examines the linguistic particularities of defense in judicial rhetoric that have not considerably changed since antiquity.

\#22

Elizaveta Vishnyakova, Olga Vishnyakova, Alla Minyar-Beloroucheva \& Polina Sergienko (oo1)

21 December 2020, 20:12 (GMT+o1:00) - Comment on oo4: Situational map: A strategy to develop critical thinking in the teaching of scientific research

The work under entitled "Situational map: A strategy to develop critical thinking in the teaching of scientific research", presented by Cecilia Alejandra Marambio Carrasco and Carla Lobos Stevens is highly relevant for the process of developing cognitive thinking, known as one of the most relevant competences of the future. The authors work out a situational map model that correlates with the brain producing maps, thus informing itself. The provided graphs and illustrations clearly explain the need for the introduction of the new methods into the process of enhanced knowledge acquisition. We would like to pinpoint the creativity of the authors themselves to assist their students in strengthening critical thinking, which is highly essential for the development of research in all spheres.

\#23

Elizaveta Vishnyakova, Olga Vishnyakova, Alla Minyar-Beloroucheva \& Polina Sergienko (o1)

21 December 2020, 20:22 (GMT+o1:0o) - Comment on o12: Russian and English metaphorics: Comparative analysis of biathlon discourse

The report 012 called "Russian and English metaphorics: Comparative analysis of biathlon discourse" provided by Liudmila Osinovskaia and Yuliya Shekhovskaya is useful for the course of lectures on stylistics of the English and Russian languages. The particularity of this work lies in the material chosen for analysis, dealing with sports discourse. Such kind of a discourse seldom becomes the focus of linguistic analysis. The authors analyse Russian metaphors used in biathlon discourse and correlate them with English equivalents. The work can be seen as a contribution to metaphorical studies and professionally oriented L2 teaching.

\section{\#24}

Elena Korotkova (므)

21 December 2020, 21:17 (GMT+o1:0o) - Comment on oo1: L2 teaching to PR undergraduates through theatre techniques elements 
The report called "L2 teaching to PR undergraduates through theatre techniques elements" by Elizaveta Vishnyakova, Olga Vishnyakova, Alla Minyar-Beloroucheva \& Polina Sergienko raises the relevant issues of bringing the most effective elements of theatrical techniques based on Stanislavsky's "Method of Physical Action" into the ESP classroom with multiple purposes related to the creation of a favorable climate in the classroom for undergraduates, stimulation of learners' cognitive and creative abilities by developing their physical, intellectual and emotional aptitude. Such a competence-based approach can be called innovative as being used systematically it arouses positive emotions of enjoyment, pride and satisfaction in learners and neutralizes the negative ones students may experience outside the university classroom. The most precious part of this methodology, in my opinion, is the fact that it combines the emotional L2 learning and a high level of cognition by bringing closer the professionally oriented L2 material and students' life experience both in distance and classroom learning. I express my sincere gratitude to the authors for their original research.

\section{\#25}

Ekaterina Korobova (015)

21 December 2020, 22:04 (GMT+01:00) - Comment on o01: L2 teaching to PR undergraduates through theatre techniques elements

The article 001 entitled "L2 teaching to PR undergraduates through theatre techniques elements" has attracted my attention for its topicality. At the time of pandemic, the authors of the article do care about their undergraduates and want them to be happy. It can be good psychotherapy for PR undergraduates in addition to the tasks that are used for developing traditional tasks necessary for developing traditional and new competences, essential for future experts.

\#26

Ekaterina Korobova (․15)

21 December 2020, 22:04 (GMT+01:00) - Comment on oo4: Situational map: A strategy to develop critical thinking in the teaching of scientific research

The article 004 entitled "Situational map: A strategy to develop critical thinking in the teaching of scientific research" is evidently of great interest for those involved in process of teaching university students not only in the Chilean context but in any other country. More specifically the presentation shows the construction of the Situational map, its theoretical basis, the practical research and the results. Undoubtedly, at the beginning of any investigation students face research problems and they must be supported in the development of logical, rational process.

\#27

Jasminka Zloković, Zlatka Gregorović Belaić \& Nadja Čekolj (oㄱ)

21 December 2020, 22:13 (GMT+01:00) - Comment on o16: Feminization of emigration

The topic of your paper is very interesting. Can you give us an information about the method of respondents recruitment? Did you come up with data on how women solve the problems they face with? Do they have support from any source? Thank you for the answers.

\#28

Jasminka Zloković, Zlatka Gregorović Belaić \& Nadja Čekolj (으)

21 December 2020, 22:13 (GMT+01:00) - Comment on o17: Behavioral disorders in children 
In your work you deal with an ongoing topic. Although it is subject matter of a large number of experts, it seems that in practice there is a lack of sufficient emphasis on the prevention antisocial behaviors. Parents' role can be recognized through upbringing and establishing relationships with children. Later, school and society take a role in further prevention. Unfortunately, often there is a lack of primary prevention and the problem discovers too late.

\section{\#29}

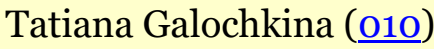

21 December 2020, 22:41 (GMT+01:00) - Comment on o20: Experimenting with factors enhancing reading comprehension of media texts in university students majoring in IR studies

Your report is very interesting for me as a lecturer. I'm looking for new methods and approaches to facilitate the perception of Latin texts. It would be very interesting to apply the strategies used for modern texts to texts in ancient languages.

\#30

Ekaterina Korobova (015)

21 December 2020, 22:56 (GMT+01:00) - Comment on o05: Application of problematic situational tasks method at Russian as a foreign language classes in technical high school

The article 005 entitled "Application of problematic situational tasks method at Russian as a foreign language classes in technical high school” presents new perspective on methods and techniques in teaching Russian as a foreign language. For instance, method of situational tasks which is extensively used mostly in teaching technical disciplines, aims at professionally oriented thinking, communication and creative skills development to form certain communication competences.

\#31

Lubomira Dimitrova (수)

22 December 2020, 16:22 (GMT+01:0o) - Comment on o19 (response to \#17): Psychotherapy of psychosomatic anxiety responses

In my practice there are only successfull result cases only by psychotherapy with no medicines at all.

\#32

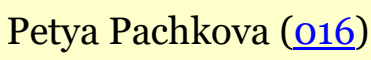

22 December 2020, 16:30 (GMT+o1:0o) - Comment on o16 (response to \#28): Feminization of emigration

The respondents are my acquaintances, close people. So the sample is not representative. That's why I didn't allow myself to offer percentages. In fact, the question of how these women solve their problems is not the subject of analysis. Maybe in the next material will be such a subject. I don't have enough information yet. I also do not have enough information on the question of who helps and who hinders them and I have not developed this question. In general, I can say that in some more patriarchal countries there are more negative attitudes towards their emigration - both on the part of the state and on the part of some strata of people. In countries like Bulgaria, it seems to me that there is a greater understanding of the reasons for their emigration. Especially when it comes to those women who are not looking for a career, but aim for the survival of their families. 
Thanks for the questions.

\section{\#33}

Anna Baskakova (․13)

\section{December 2020, 21:35 (GMT+o1:0o) - Comment on oo1: L2 teaching to PR undergraduates through theatre techniques elements}

The article "L2 teaching to PR undergraduates trough theatre techniques elements" opens a new way to the analysis of teaching methods while studying foreign languages. The subject of the article is quite interesting as a tool for a students' progress in a class and teachers' development in a methodological work. The authors give a brief description of literature sources which provide the information about the topic, observe the methods which consist of classical and modern ones and tell in detail about theatrical technologies which are very actual in a present situation in a pedagogical sphere. The idea of the plot motivates to search more information about using of this method at the lessons of any foreign language.

\section{\#34}

Anna Baskakova (013)

\section{December 2020, 21:35 (GMT+01:00) - Comment on o05: Application of problematic situational tasks method at Russian as a foreign language classes in technical high school}

The article "Application of problematic situational tasks method at Russian as a foreign language classes in technical high school" describes the methods of using situational tasks as the ways of improvement of the Russian language learning for foreigners. The demonstration and a brief characterization of different kinds of situational tasks shows a quite high level of the researches who have deeply studied the subject. This kind of a feed can be used as the direction for starting teachers who have a little experience in teaching Russian as foreign language in general and in training of communication skills of learners in particular, that, by itself, is quite difficult but the most important goal in teaching languages.

\section{\#35}

Anna Baskakova (․13)

\section{December 2020, 21:35 (GMT+01:00) - Comment on o15: Particularities of defense in judicial rhetoric}

The article "Particularities of defense in judicial rhetoric" gives a description of tools for constructing a material for defense counsel's speeches. It is quite an interesting text, consisting philosophical thoughts of antique philosophers speaking about the power of speech, which are used as the basement for later learning of rhetoric. The analysis of different types of court speech, rhetorical persuasion, linguistic, phonetic and stylistic features and characteristics gives a good opportunity for specialists in a juridical area to improve their skills in working with court documents and speaking at the process. The observation of that topic from a linguistic, philosophical and psychological side gives an opportunity to look at the topic as the idea for a discussion not only for specialists in a juridical sphere, but also for a wider group of researchers and scientists. 
\#36

Elena Korotkova (

22 December 2020, 22:35 (GMT+01:0o) - Comment on o10: Word formative structure of words with the root lěp- in Old Russian written records

The topic of the report which attracted me by its in-depth research, consistency and reasoning is "Word formative structure of words with the root lěp- in Old Russian written records" carried out by Tatiana Galochkina. The author studies the complex diachronic process of deriving compound words from Greek including words with the root *lěp- formed by analogy with Greek compounds, but using original morphemes inherent in Old Russian written records . Not only does the author research the word-formation process of words with the root *lěp-, but she also makes use of motivational and semantic classification to analyze the words with the root *lěp- in different registers of Old Russian. This study can arouse interest of those contributors who conduct research in the area of Old Slavonic and Old Church Slavonic studies and can inspire further detailed research in the same area.

\#37

Ekaterina Korobova (015)

23 December 2020, 18:21 (GMT+01:00) - Comment on 013: The studying of Russian phraseological units and paroemias in English speaking audience

The article 013 "The studying of Russian phraseological units and paroemias in English speaking audience" is of certain use and interest as it promotes international communication. Within the framework of intercultural dialogue, the author compares the main concepts and terms reflected in Russian and English phraseological units, aphorisms and proverbs. She comments on a great number of them, explains their meanings and shares her teaching methods and techniques while working with the material in class taking into consideration a specialization of learners.

\#38

Elena Korotkova (020)

23 December 2020, 20:21 (GMT+01:0o) - Comment on o20: Experimenting with factors enhancing reading comprehension of media texts in university students majoring in IR studies

I'd like to specify that the potential of text structure knowledge hasn't been applied to a large extent in teaching reading comprehension yet. Students proficient in RC take advantage of text patterns to understand key points of the text and their organization. However, less experienced readers, apparently, unaware of text structure concepts, have difficulty organizing and prioritizing text information. For this reason, variables of text structure concepts have a discernible impact on discourse processing and entail higher reading comprehension indexes in individuals, which was confirmed in the course of experimental learning. The methodology of text structure knowledge can be applied to any language, including the ancient one assuming that some instructions on text structure concepts are provided to learners in the course of teaching.

\section{\#39}

Elena Korotkova ( $\underline{020})$

23 December 2020, 20:21 (GMT+o1:0o) - Comment on o11: Cognitive approach to the theory of abbreviation 
The report headlined "Cognitive approach to the theory of abbreviation" by Tatyana Bychkova is particularly actual as it looks into the topic of acronyms in some areas of contemporary English. The author studies the language phenomena in terms of psychology and dialectical-materialistic approach which she applies to abbreviations and neologisms. The description of abbreviations and the structure of neologisms and their classification are the most impressive parts of the research, in my opinion. I would like to know whether you classify abbreviations into any groups: business, text messages, medicine, etc., and if it is so, what groups you classify them into. Thank you for your interesting report.

\section{\#40}

Cecilia Alejandra Marambio Carrasco \& Carla Lobos Stevens (004)

\section{December 2020, 09:12 (GMT+01:00) - Comment on o04: Situational map: A strategy to develop critical thinking in the teaching of scientific research}

The study called "Situation Map, a strategy for the development of critical thinking in the teaching of scientific research" is a contribution to the development of the research methodology in the process of approaching the study problem and analyzing the context where it is will conduct the investigation. Students learn to structure their thinking, to order their ideas, to project the results, in this way their mental processes are configured through mental patterns that allow them to advance in the investigation correctly.

\section{\#41}

Cecilia Alejandra Marambio Carrasco \& Carla Lobos Stevens (004)

\section{December 2020, 09:12 (GMT+01:00) - Comment on o16: Feminization of emigration}

The study called "Feminization of emigration" of Petya Pachkova (PhD) focuses on the social problem and exclusion suffered by immigrant women, revealing exploitation, conditions of human abuse, sexual harassment, where their human rights are trampled, the author explains from bibliographic sources that the immigration behavior of women. Women is conducive to seeking better living conditions in the case of more emancipated women, but the sociocultural context of an oppressive patriarchy does not allow women to develop on equal terms with men, they suffer the stigmatization of being mothers, wives who must be subjected and their human rights are not respected. The author makes us reflect on what states do to improve their human development conditions when they are the ones who train citizens.

\section{\#42}

Colleen Kennedy-Karpat (이)

\section{December 2020, o9:12 (GMT+01:00) - Comment on oo6: Hava Nagila}

Fascinating historical account of a widely known song. My question concerns its relationship to Turkey and Turkish musical traditions: the paper notes that the text was initially composed in celebration of a military victory over the Turks in 1917; however, it also notes that Idelsohn himself served in the Turkish army. It seems strange to celebrate the victory of your opponent! Can you clarify this?

A second question: I'm not a musicologist, but I have lived in Turkey many years, and the musical textures in Hava Nagila do bear at least a broad resemblance to certain kinds of Turkish folk music. Was this part of the inspiration or composition of the song?

Many thanks for your clarification and development of these points. 
\#43

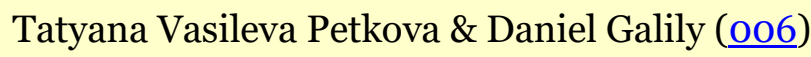

\section{December 2020, 16:20 (GMT+o1:00) - Response to \#42 (comment on oo6): Hava Nagila}

Thank you for your questions!

1. Idelsohn was drafted into the Turkish army, first as a hospital clerk and later as conductor of an orchestra in the Gaza trenches. He served in the Turkish army under duress, like many other people from the territories enslaved by Turkey. It was a great joy for all enslaved people to free themselves and get rid of the Turkish yoke and influence.

2. Turkish folklore is not authentic and original. In it, as in the folklore of the Balkan peoples and in Israel, there are many admixtures of different folklore traditions, so in general, the folklore melodies of the Mediterranean countries and the countries of the Middle East are similar.

\section{\#44}

Tatyana Bychkova (․11)

\section{December 2020, 16:21 (GMT+o1:00) - Comment on o11: Cognitive approach to the theory of abbreviation}

Dear organizers, congratulations on the most valuable impact of the e-conference in the field of humanitarian sciences. Thank you very much for excellent organization of the e-conference and bringing together researchers from many countries and institutions. Concerning our research, allow us to express hope that cognitive approach to the theory of abbreviation would throw more light on this highly productive way of creating new words. Thank you once again!

\section{\#45}

Elizaveta Vishnyakova, Olga Vishnyakova, Alla Minyar-Beloroucheva \& Polina Sergienko (oo1)

\section{December 2020, 16:31 (GMT+o1:oo) - Comment on organization of the e- conference}

Dear members of the Organizing committee! We express our sincere gratitude for your great work and effort to carry out such an important conference, entitled 6th International e-Conference on Studies in Humanities and Social Sciences (6IeCSHSS). It really brings researchers of the planet living in different continents closer together and gives the possibilities to exchange their ideas concerning various issues of human development in different scholarly and scientific fields. We are looking forward to participating in the 7 th e-conference, organized by your wonderful team.

\section{\#46}

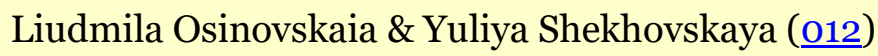

\section{December 2020, 16:40 (GMT+o1:00) - Comment on oo1: L2 teaching to PR undergraduates through theatre techniques elements}

It goes without saying, that theatrical techniques are effective means of teaching. But the novelty of the article is that justify it thoroughly both theoretically and on the basis of their experimental practice. Moreover, they broaden the implementation of theatrical techniques by using them in L2 classes of undergraduates. The authors give practical advice and hints how these techniques can be implemented into each class. That's really useful. We would like to thank the authors their special attention and detailed analyses of the emotional effect the described method has. 
\#47

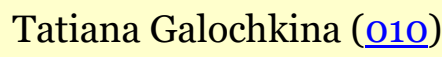

24 December 2020, 16:54 (GMT+o1:00) - Presentation: Word formative structure of words with the root lěp- in Old Russian written records

Presentation - PDF

\#48

Carla Lobos Stevens (004)

24 December 2020, 17:06 (GMT+o1:0o) - Comment on o20: Experimenting with factors enhancing reading comprehension of media texts in university students majoring in IR studies

I'd definitely like to read more about the study tittled "Experimenting with factors enhancing reading comprehension of media texts in university students majoring in IR studies". This contributes to Language Teaching at the university level, since students from different areas can benefit from the results.

Reading comprehension is a major issue at the university level today in Chile, since students enter university with a lack of training in this subject.

This research sheds some light on the issue since it can help improving this skills among undergraduate students from different areas in other countries as well.

\section{\#49}

Cecilia Alejandra Marambio Carrasco \& Carla Lobos Stevens (o4)

\section{December 2020, 19:58 (GMT+o1:00) - Final comment}

We'd like to thank the researchers for their comments \#22 and \#26, since they allow us to have an external opinion and thus, improve our work.

We'd also like to thank the organizing committee. Thanks to this conference we have learnt about different topics of study and had the possibility to share with high level researchers.

\#50

Elena Korotkova (므)

24 December 2020, 20:18 (GMT+o1:0o) - Response to \#48 (comment on 020): Experimenting with factors enhancing reading comprehension of media texts in university students majoring in IR studies

Dear Carla Lobos Stevens, I entirely agree with you that reading comprehension is one of the key factors undergraduates should be taught during their training at the university. There are different approaches to it, and the methodology of TSK application is one of them since it affects comprehension of conceptually demanding texts among EFL learners with varying reading comprehension proficiency. We could not boil down our training only to text structure knowledge which would be incomplete without reading comprehension strategies which we identify as sets of steps readers use to make sense of the text.

As for the full text, I am going to submit it to the COAS OJSL for publication next year, so everyone could have an access to it. Thank you for your interest in my research and valuable remarks. 
\#51

Elena Korotkova (므)

\section{December 2020, 21:32 (GMT+01:00) - Gratitude}

Dear Conference organizers, I'd like to join in with the comments on the Conference high quality organization and express my heartfelt gratitude for the innovative format of conferencing which made us all be involved in its events all these memorable days.

I'd also like to thank the Conference participants for their great inputs and scientific interaction which made 6th International e-Conference on Studies in Humanities and Social Sciences in Belgrade genuine success.

I extend my gratitude to researchers who made their comments \# 7, \#29 and \#48 on my submitted abstract and thank them for their interest in my research.

I hope that shared ideas will be instrumental in our future scientific and professional activities and we will retain high standards set by the Conference organizers to meet at the next conference in Belgrade.

\section{\#52}

COAS Editorial Council, Belgrade, SERBIA

\section{December 2020, 24:00 (GMT+01:00): The end of the Conference}

Dear participants, the COAS e-Conference is officially finished. We are so grateful to you for the activities of posting presentations and comments in these 5 days, and we think that it contributes to the Conference to be more successful.

In the next days we will send you copy edited versions of your manuscripts, for your final approval for publishing. The Conference Proceedings will be published online in the next 10-15 days, with official ISBN and DOI for each article.

We announce now that we will organize the $7^{\text {th }}$ International e-Conference on Studies in Humanities and Social Sciences (7IeCSHSS), on 28 June 2021, as our next online Conference.

We wish you Marry Christmas and a happy and fruitful New Year!

Best regards from Belgrade. 


\section{Upcoming e-Conference}

We are looking forward to the $7^{\text {th }}$ International $\boldsymbol{e}$-Conference on Studies in Humanities and Social Sciences (7IeCSHSS) that will be held on 28 June 2021, using the same online model. We hope that it will be an interesting and enjoying at least as the previous e-Conference.

https://www.centerprode.com/conferences/7IeCSHSS.html

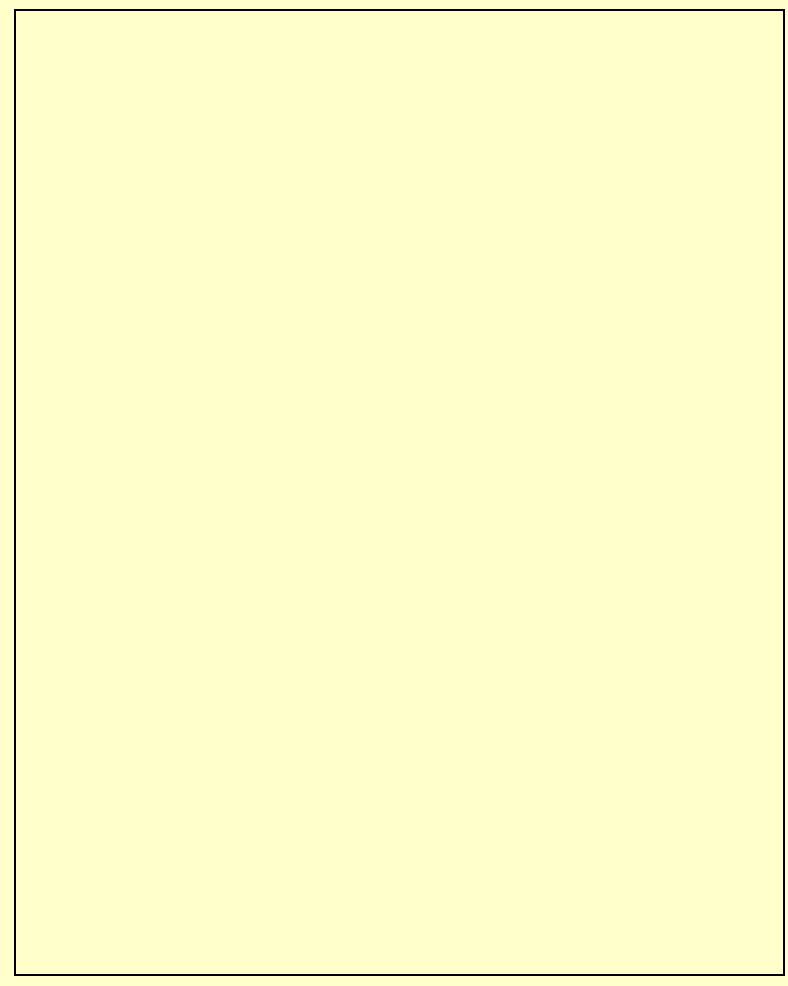




\section{OPEN ACCESS POLICY}

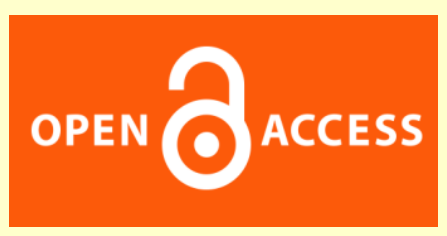

The COAS strictly follows open access rules which means that all contents of the e-Conference Proceedings are freely available without charge to the user or his/her institution. Users are allowed to read, download, copy, distribute, print, search, or link to the full texts of the articles, or use them for any other lawful purpose, without asking prior permission from the publisher or the author. This is in accordance with the BOAI definition of open access.

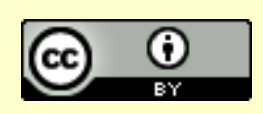

All articles published in the COAS Conference Proceedings are licensed under a $\underline{\text { Creative }}$ Commons Attribution 4.0 International License.

Authors hold the copyrights of their own articles by acknowledging that their articles are originally published in the COAS Conference Proceedings. 